Thiago Ruiz Zimmer

\title{
INFLUÊNCIA DA CARGA ORGÂNICA E DO TEMPO DE ENCHIMENTO SOBRE O DESEMPENHO DO REATOR ANAERÓBIO EM BATELADA SEQÜENCIAL COM BIOMASSA GRANULADA TRATANDO SORO DE QUEIJO
}

Dissertação apresentada à Escola de Engenharia de São Carlos da Universidade de São Paulo, como parte das exigências para a obtenção do Título de Mestre em Engenharia Hidráulica e Saneamento.

Orientador: Prof. Dr. José Alberto Domingues Rodrigues

São Carlos

2006 
A minha família, Antônio Carlos Zimmer, Agueda Maria Zimmer, Angélica Ruiz Zimmer Pontes, Virgínia Ruiz Zimmer, Agueda Maria Ruiz Zimmer, Neemias Ruiz Zimmer e Nathália Cristina Ruiz Zimmer,incluindo também Sérgio Pontes Silva, o cunhado.

Aos meus avós, Paulo Ruiz Villanova e Carmen Villanova Luna.

A minha noiva e futura esposa, Denise Silva Loubach.

"E agora, àquele que é poderoso para fazer infinitamente mais do que tudo quanto pedimos ou pensamos, conforme o seu poder que opera em nós, a ele seja a glória, na igreja e em Cristo Jesus, por todas as gerações, para todo o sempre. Amém!" Efésios 3:20 e 21 


\section{AGRADECIMENTOS}

Ao Prof. Dr. José Alberto Domingues Rodrigues pela amizade, orientação, pelo incentivo, dedicação e exemplo de profissionalismo.

À Profa. Dra. Suzana Maria Ratusznei pela amizade, co-orientação, atenção e aprendizado.

À Dra. Catarina Simone Andrade do Canto pela amizade, atenção, paciência e auxílio durante a etapa experimental.

Ao amigo Rogério Michelan pela amizade, apoio, sugestões e principalmente pelo companheirismo durante todos os anos em que estudamos e trabalhamos juntos, e também pela paciência no convívio e na divisão das despesas.

Aos colegas de laboratório Denise, Ricardo, Roberta e Roberto pela amizade e paciência durante a realização da etapa experimental.

Aos meus pais, Antônio Carlos Zimmer e Agueda Maria Zimmer, pelo amor, carinho, esforço e muita dedicação para que eu chegasse até aqui.

Aos meus irmãos, Angélica Zimmer, Virgínia Zimmer, “Aguidinha” Zimmer, Neemias Zimmer e Nathália Zimmer, pelo amor e carinho sem igual.

Aos meus avós, meus ídolos e inspiração, Paulo Villanova Ruiz e Carmen Villanova Luna, pelo apoio, incentivo e acolhimento.

À minha noiva, amiga e companheira, Denise Silva Loubach, pelo amor e carinho, pela paciência para suportar as dificuldades do relacionamento à distância, e principalmente pelo apoio e incentivo a perseverar.

Aos meus sogros, Neusa Maria Loubach e Cícero Loubach, pelo apoio e auxílio principalmente durante o último ano.

Aos professores, funcionários e colegas do Departamento de Hidráulica e Saneamento, pelo aprendizado e pelos serviços prestados.

À Escola de Engenharia Mauá, do Instituto Mauá de Tecnologia, na pessoa do Ilmo. Reitor Prof. Dr. Otávio de Mattos Silvares, pela utilização das instalações para a realização da etapa experimental.

À FAPESP pela concessão da bolsa de estudos (Processo No 02/06.154-5) e pelo financiamento do projeto (Processo No 2001/05.489-0).

A DEUS, pelo amor, pela vida e pelo privilégio de realizar este projeto. 


\section{RESUMO}

ZIMMER, T. R. (2006). Influência da carga orgânica e do tempo de enchimento sobre a estabilidade e eficiência do reator anaeróbio em batelada seqüencial com biomassa granulada tratando soro de queijo. 160p. Dissertação (Mestrado) - Escola de Engenharia de São Carlos, Universidade de São Paulo, São Carlos, 2006.

Avaliou-se a influência da carga orgânica volumétrica (COV) aplicada e do tempo de enchimento sobre a estabilidade e a eficiência do ASBR com biomassa granulada, operado em batelada e batelada alimentada seqüenciais, tratando soro de queijo diluído. Os ensaios foram realizados a $30^{\circ} \mathrm{C}$ com volume total de meio de 5,0 litros e tempo de ciclo de 8 horas. Na primeira etapa realizou-se a operação em batelada com tempo de enchimento $\left(\mathrm{T}_{\text {alim }}\right)$ de 10 min e freqüência de agitação de $150 \mathrm{rpm}$. A cada ciclo foram alimentados 2,0 litros de meio com concentração afluente $\left(\mathrm{C}_{\mathrm{AF}}\right)$ de 1000, 2000, $4000 \mathrm{e}$ $6000 \mathrm{mg} / \mathrm{l}$, em termos de DQO. A Suplementação de alcalinidade foi gradualmente otimizada partindo-se da proporção de 1 a 0,25 da razão $\mathrm{NaHCO}_{3} / \mathrm{DQO}$. Nestas condições foi possível operar o reator com estabilidade a COV aplicada de 4,8 g/l.d , com suplementação de alcalinidade de $25 \%$ e eficiência em remoção de matéria orgânica de 96,0\% e 98,4\% em termos de DQO filtrada e total, respectivamente. Na segunda etapa devido a problemas operacionais desenvolveram-se dispositivos para assegurar a retenção da biomassa a fim de viabilizar a operação em batelada alimentada. Os dispositivos testados foram ASBR Híbrido, sistema de agitação com 2 impelidores, hélice e pá-inclinada (a) e hélice e turbina inclinada (b). A solução utilizada foi hélice e turbina inclinada. Para essa configuração, diminuiu-se a freqüência de agitação para 75 rpm e reduziu-se o volume de biomassa para 1,0 1. Dessa forma foi possível avaliar a influência das estratégias de alimentação $\left(\mathrm{T}_{\text {alim }}\right)$ de 360, 180 e 10 minutos a COV aplicada constante de 2,4 g/l.d, para $\mathrm{C}_{\mathrm{AF}}$ de $4000 \mathrm{mg} / \mathrm{l}$ e $\mathrm{V}_{\text {alim }}$ de 1,01 e para $\mathrm{C}_{\mathrm{AF}}$ de $8000 \mathrm{mg} / \mathrm{l}$ e $\mathrm{V}_{\text {alim }}$ de 0,5 1. Para a $\mathrm{C}_{\mathrm{AF}}$ de $4000 \mathrm{mg} / \mathrm{l}$ o aumento de $\mathrm{T}_{\text {alim }}$ resultou em diminuição da eficiência, em termos de DQO filtrada, sendo de 97,8 , 96,7 e 94,5\% para os $\mathrm{T}_{\text {alim }}$ de 10, 180 e 360 minutos, respectivamente. Para a $\mathrm{C}_{\mathrm{AF}}$ de $8000 \mathrm{mg} / \mathrm{lo}$ aumento do $\mathrm{T}_{\text {alim }}$ resultou em menores valores de DQO total no efluente.

Palavras chaves: tratamento anaeróbio; soro de queijo; carga orgânica volumétrica, tempo de enchimento, batelada seqüencial; biomassa granulada. 


\begin{abstract}
ZIMMER, T. R. (2006). Effect of organic load and fill time on stability and efficiency of an ASBR containing granular biomass treating cheese whey. 160p. Master Thesis Escola de Engenharia de São Carlos, Universidade de São Paulo, São Carlos, 2006.

The effect of volumetric organic load (VOL) and fill time on the stability and efficiency of an ASBR was assessed. The ASBR containing granular biomass was operated in batch and fed-batch mode and treated diluted cheese whey. Assays were performed at $30^{\circ} \mathrm{C}$ with total medium volume of 5.0 liters and 8-h cycle lengths. In a first stage the reactor was operated batch-wise with fill time $\left(\mathrm{T}_{\text {feed }}\right)$ of $10 \mathrm{~min}$ and agitation frequency of $150 \mathrm{rpm}$. At each cycle 2.0 liters of medium were fed at influent concentration $\left(\mathrm{C}_{\mathrm{infl}}\right)$ of 1000, 2000, 4000 and $6000 \mathrm{mg} / \mathrm{L}$, in terms of COD. Alkalinity supplementation was gradually optimized from $100 \%$ to $25 \%$ of $\mathrm{NaHCO}_{3} / \mathrm{COD}$ ratio. At these conditions the reactor attained stability at applied VOL of $4.8 \mathrm{~g} / \mathrm{L} . \mathrm{d}$, alkalinity supplementation of $25 \%$ and organic matter removal efficiency of $96.0 \%$ and $98.4 \%$ in terms of soluble and total COD, respectively. In a second stage due to operational problems devices were developed to assure biomass retention and hence make fed-batch operation feasible. The tested devices included hybrid ASBR, agitation system with two impellers: helix and inclined blade impeller (a) and helix and inclined turbine impeller (b). The system chosen was the helix and inclined turbine. With this configuration agitation frequency and biomass volume were reduced to $75 \mathrm{rpm}$ and $1.0 \mathrm{~L}$, respectively. This way, it was possible to assess feed strategies $\left(\mathrm{T}_{\text {feed }}\right)$ of 360,180 and 10 minutes at constant applied VOL of $2.4 \mathrm{~g} / \mathrm{L} . \mathrm{d}$, for $\mathrm{C}_{\text {infl }}$ of $4000 \mathrm{mg} / \mathrm{L}$ at $\mathrm{V}_{\text {feed }}$ of $1.0 \mathrm{~L}$ and for $\mathrm{C}_{\text {infl }}$ of $8000 \mathrm{mg} / \mathrm{L}$ at $\mathrm{V}_{\text {feed }}$ of $0.5 \mathrm{~L}$. At $\mathrm{C}_{\text {infl }}$ of $4000 \mathrm{mg} / \mathrm{L}$ increase in $\mathrm{T}_{\text {feed }}$ resulted in decrease in efficiency in terms of soluble COD, which amounted to $97.8,96.7$ and $94.5 \%$ for $\mathrm{T}_{\text {feed }}$ of 10,180 and 360 minutes, respectively. At $\mathrm{C}_{\text {infl }}$ of $8000 \mathrm{mg} / \mathrm{L}$ the increase in $\mathrm{T}_{\text {feed }}$ resulted in lower values for COD effluent.
\end{abstract}

Key words: anaerobic treatment; cheese whey; volumetric organic load; fill time; sequencing batch; granular biomass. 



\section{LISTA DE FIGURAS}

Figura 4.1 - Esquema do reator anaeróbio com agitação mecânica operado em batelada seqüencial 24

Figura 4.2: Fotografia do aparato experimental. 25

Figura 4.3 - Tubo de PVC (o "draft tube") que foi inserido no reator e o impelidor tipo hélice.

Figura 4.4 - Esquema do reator híbrido testado nos ensaios BA-B, BA-C e BA-D...... 27

Figura 4.5 - Fotografia do reator híbrido testado nos ensaios BA-B, BA-C e BA-D.... 28

Figura 4.6 - Fotografia dos impelidores utilizados nos ensaios BA-F1 a BA-F7 e o impelidor tipo turbina inclinada em detalhe.

Figura 5.1 - Concentração da matéria orgânica, em termos de DQO, de amostras do efluente filtradas e não filtradas durante a operação do reator em batelada, nas condições $\mathrm{I}\left(\mathrm{NaHCO}_{3} / \mathrm{DQO}=1,0\right)$ e II $\left(\mathrm{NaHCO}_{3} / \mathrm{DQO}=0,5\right)$, para $\mathrm{COV}=1,2$ g/l.d .

Figura 5.2 - Eficiência de remoção da matéria orgânica, em termos de DQO, de amostras do efluente filtradas e não filtradas durante a operação do reator em batelada, nas condições I $\left(\mathrm{NaHCO}_{3} / \mathrm{DQO}=1,0\right)$ e II $\left(\mathrm{NaHCO}_{3} / \mathrm{DQO}=0,5\right)$, para $\mathrm{COV}=1,2 \mathrm{~g} / \mathrm{l} \cdot \mathrm{d}$

Figura 5.3 - Alcalinidade a Bicarbonato (AB) afluente e efluente durante a operação do reator em batelada nas condições $\mathrm{I}\left(\mathrm{NaHCO}_{3} / \mathrm{DQO}=1,0\right)$ e II $\left(\mathrm{NaHCO}_{3} / \mathrm{DQO}=\right.$ 0,5), para $\mathrm{COV}=1,2 \mathrm{~g} / \mathrm{l} . \mathrm{d}$.

Figura 5.4 - Ácidos Voláteis Totais (AVT) afluente e efluente durante a operação do reator em batelada nas condições I $\left(\mathrm{NaHCO}_{3} / \mathrm{DQO}=1,0\right)$ e II $\left(\mathrm{NaHCO}_{3} / \mathrm{DQO}=\right.$ 0,5), para $\mathrm{COV}=1,2 \mathrm{~g} / \mathrm{l} \cdot \mathrm{d}$.

Figura 5.5 - Perfil de concentração da matéria orgânica ao longo do ciclo, em termos de DQO, de amostras filtradas, durante a operação do reator em batelada, para COV = $1,2 \mathrm{~g} / \mathrm{l} . \mathrm{d}$

Figura 5.6 - Perfil de Ácidos Voláteis Totais (AVT) e Alcalinidade a Bicarbonato (AB) ao longo do ciclo, durante a operação do reator em batelada, para COV =1,2 g/l.d .

Figura 5.7 - Perfil de $\mathrm{pH}$ ao longo do ciclo durante a operação do reator em batelada, para $\mathrm{COV}=1,2 \mathrm{~g} / \mathrm{l} . \mathrm{d}$. 
Figura 5.8 - Perfil de Concentração e Composição do Biogás ao longo do ciclo durante a operação do reator em batelada, para COV $=1,2 \mathrm{~g} / \mathrm{l} . \mathrm{d}$ 44

Figura 5.9 - Concentração da matéria orgânica, em termos de DQO, de amostras do efluente filtradas e não filtradas durante a operação do reator em batelada nas condições I $\left(\mathrm{NaHCO}_{3} / \mathrm{DQO}=1,0\right)$, II $\left(\mathrm{NaHCO}_{3} / \mathrm{DQO}=0,5\right)$ e III $\left(\mathrm{NaHCO}_{3} / \mathrm{DQO}\right.$ $=0,25)$, para $\mathrm{COV}=2,4 \mathrm{~g} / \mathrm{l} \cdot \mathrm{d}$

Figura 5.10 - Eficiência de remoção da matéria orgânica, em termos de DQO, de amostras do efluente filtradas e não filtradas durante a operação do reator em batelada nas condições I $\left(\mathrm{NaHCO}_{3} / \mathrm{DQO}=1,0\right)$, II $\left(\mathrm{NaHCO}_{3} / \mathrm{DQO}=0,5\right)$ e III $\left(\mathrm{NaHCO}_{3} / \mathrm{DQO}=0,25\right)$, para COV $=2,4 \mathrm{~g} / \mathrm{l} . \mathrm{d}$

Figura 5.11 - Alcalinidade a Bicarbonato (AB) afluente e efluente durante a operação do reator em batelada nas condições $\mathrm{I}\left(\mathrm{NaHCO}_{3} / \mathrm{DQO}=1,0\right)$, II $\left(\mathrm{NaHCO}_{3} / \mathrm{DQO}=\right.$ $0,5)$ e III $\left(\mathrm{NaHCO}_{3} / \mathrm{DQO}=0,25\right)$, para $\mathrm{COV}=2,4 \mathrm{~g} / \mathrm{l} . \mathrm{d}$ 48

Figura 5.12 - Ácidos Voláteis Totais (AVT) afluente e efluente durante a operação do reator em batelada nas condições $\mathrm{I}\left(\mathrm{NaHCO}_{3} / \mathrm{DQO}=1,0\right)$, II $\left(\mathrm{NaHCO}_{3} / \mathrm{DQO}=\right.$ $0,5)$ e III $\left(\mathrm{NaHCO}_{3} / \mathrm{DQO}=0,25\right)$, para $\mathrm{COV}=2,4 \mathrm{~g} / \mathrm{l} . \mathrm{d}$ 48

Figura 5.13 - Perfil de concentração da matéria orgânica ao longo do ciclo, em termos de DQO, de amostras filtradas, durante a operação do reator em batelada, para $\mathrm{COV}=2,4 \mathrm{~g} / \mathrm{l} \cdot \mathrm{d}$

Figura 5.14 - Perfil de Ácidos Voláteis Totais (AVT) e Alcalinidade a Bicarbonato $(\mathrm{AB})$ ao longo do ciclo, durante a operação do reator em batelada, para $\mathrm{COV}=2,4$ g/l.d 50

Figura 5.15 - Perfil de $\mathrm{pH}$ ao longo do ciclo, durante a operação do reator em batelada, para $\mathrm{COV}=2,4 \mathrm{~g} / \mathrm{l} \cdot \mathrm{d}$ 50

Figura 5.16 - Perfil de Concentração e Composição do Biogás ao longo do ciclo, durante a operação do reator em batelada, para COV = 2,4 g/l.d 51

Figura 5.17 - Concentração da matéria orgânica, em termos de DQO, de amostras do efluente filtradas e não filtradas durante a operação do reator em batelada nas condições I $\left(\mathrm{NaHCO}_{3} / \mathrm{DQO}=1,0\right), \mathrm{II}\left(\mathrm{NaHCO}_{3} / \mathrm{DQO}=0,5\right)$ e III $\left(\mathrm{NaHCO}_{3} / \mathrm{DQO}\right.$ $=0,25)$, para $\mathrm{COV}=4,8 \mathrm{~g} / \mathrm{l} \cdot \mathrm{d}$ .55

Figura 5.18 - Eficiência de remoção da matéria orgânica, em termos de DQO, de amostras do efluente filtradas e não filtradas durante a operação do reator em batelada nas condições I $\left(\mathrm{NaHCO}_{3} / \mathrm{DQO}=1,0\right)$, II $\left(\mathrm{NaHCO}_{3} / \mathrm{DQO}=0,5\right)$ e III $\left(\mathrm{NaHCO}_{3} / \mathrm{DQO}=0,25\right)$, para $\mathrm{COV}=4,8 \mathrm{~g} / \mathrm{l} . \mathrm{d}$ 55 
Figura 5.19 - Alcalinidade a Bicarbonato (AB) afluente e efluente durante a operação do reator em batelada nas condições I $\left(\mathrm{NaHCO}_{3} / \mathrm{DQO}=1,0\right)$, II $\left(\mathrm{NaHCO}_{3} / \mathrm{DQO}=\right.$ $0,5)$ e III $\left(\mathrm{NaHCO}_{3} / \mathrm{DQO}=0,25\right)$, para $\mathrm{COV}=4,8 \mathrm{~g} / \mathrm{l} \cdot \mathrm{d}$

Figura 5.20 - Ácidos Voláteis Totais (AVT) afluente e efluente durante a operação do reator em batelada nas condições $\mathrm{I}\left(\mathrm{NaHCO}_{3} / \mathrm{DQO}=1,0\right)$, II $\left(\mathrm{NaHCO}_{3} / \mathrm{DQO}=\right.$ $0,5)$ e III $\left(\mathrm{NaHCO}_{3} / \mathrm{DQO}=0,25\right)$, para $\mathrm{COV}=4,8 \mathrm{~g} / \mathrm{l} . \mathrm{d}$ 56

Figura 5.21 - Perfil de concentração da matéria orgânica ao longo do ciclo, em termos de DQO, de amostras filtradas, durante a operação do reator em batelada, para $\mathrm{COV}=4,8 \mathrm{~g} / \mathrm{l} \cdot \mathrm{d}$ 57

Figura 5.22 - Perfil de Ácidos Voláteis Totais (AVT) e Alcalinidade a Bicarbonato $(\mathrm{AB})$ ao longo do ciclo, durante a operação do reator em batelada, para $\mathrm{COV}=4,8$ g/l.d 58

Figura 5.23 - Perfil de pH ao longo do ciclo, durante a operação do reator em batelada, para $\mathrm{COV}=4,8 \mathrm{~g} / \mathrm{l} . \mathrm{d}$. 58

Figura 5.24 - Perfil de Concentração e Composição do Biogás ao longo do ciclo, durante a operação do reator em batelada, para $\mathrm{COV}=4,8 \mathrm{~g} / \mathrm{l} . \mathrm{d}$.

Figura 5.25 - Concentração de matéria orgânica, de amostras filtradas e não filtradas do efluente, nas condições I $\left(\mathrm{C}_{\mathrm{AF}}=1000 \mathrm{mg} / \mathrm{l}\right)$, II $\left(\mathrm{C}_{\mathrm{AF}}=2000 \mathrm{mg} / \mathrm{l}\right)$ e III $\left(\mathrm{C}_{\mathrm{AF}}=4000\right.$ $\mathrm{mg} / \mathrm{l})$, durante o procedimento de partida para a operação em batelada alimentada.

Figura 5.26 - Eficiência de remoção de matéria orgânica de amostras filtradas e não filtradas do efluente, nas condições I $\left(\mathrm{C}_{\mathrm{AF}}=1000 \mathrm{mg} / \mathrm{l}\right)$, II $\left(\mathrm{C}_{\mathrm{AF}}=2000 \mathrm{mg} / \mathrm{l}\right)$ e III $\left(\mathrm{C}_{\mathrm{AF}}=4000 \mathrm{mg} / \mathrm{l}\right)$, durante o procedimento de partida para a operação em batelada alimentada.

Figura 5.27 - Concentração de Alcalinidade a Bicarbonato (AB), no afluente e no efluente nas condições I $\left(\mathrm{C}_{\mathrm{AF}}=1000 \mathrm{mg} / \mathrm{l}\right)$, II $\left(\mathrm{C}_{\mathrm{AF}}=2000 \mathrm{mg} / \mathrm{l}\right)$ e III $\left(\mathrm{C}_{\mathrm{AF}}=4000\right.$ $\mathrm{mg} / \mathrm{l})$, durante o procedimento de partida para a operação em batelada alimentada.

Figura 5.28 - Concentração de Ácidos Voláteis Totais (AVT) no afluente e no efluente nas condições I ( $\left.\mathrm{C}_{\mathrm{AF}}=1000 \mathrm{mg} / \mathrm{l}\right)$, II $\left(\mathrm{C}_{\mathrm{AF}}=2000 \mathrm{mg} / \mathrm{l}\right)$ e III $\left(\mathrm{C}_{\mathrm{AF}}=4000 \mathrm{mg} / \mathrm{l}\right)$, durante o procedimento de partida para a operação em batelada alimentada.

Figura 5.29 - Reator, com vista de cima em detalhe, ao final do ensaio BA-A (COV = $\left.4,8 \mathrm{~g} / \mathrm{l} . \mathrm{d} ; \mathrm{C}_{\mathrm{AF}}=16000 \mathrm{mg} / \mathrm{l}\right)$ 
Figura 5.30 - Concentração de matéria orgânica, de amostras filtradas e não filtradas do efluente, durante a operação em batelada alimentada a $\mathrm{C}_{\mathrm{AF}}=4000 \mathrm{mg} / \mathrm{l}, \mathrm{V}_{\mathrm{alim}}$. 1,0 1 nas condições I $\left(\mathrm{T}_{\text {alim. }}=360 \mathrm{~min}\right), \mathrm{II}\left(\mathrm{T}_{\text {alim. }}=180 \mathrm{~min}\right)$ e III $\left(\mathrm{T}_{\text {alim. }}=10 \mathrm{~min}\right)$.

Figura 5.31 - Eficiência de remoção da matéria orgânica, em termos de DQO, de amostras do efluente filtradas e não filtradas durante a operação em batelada alimentada a $\mathrm{C}_{\mathrm{AF}}=4000 \mathrm{mg} / \mathrm{l}, \mathrm{V}_{\text {alim. }}=1,01$ nas condições $\mathrm{I}\left(\mathrm{T}_{\text {alim. }}=360 \mathrm{~min}\right)$, $\mathrm{II}\left(\mathrm{T}_{\text {alim. }}=180 \mathrm{~min}\right)$ e III $\left(\mathrm{T}_{\text {alim. }}=10 \mathrm{~min}\right)$ 73

Figura 5.32 - Concentração de Alcalinidade a Bicarbonato $(\mathrm{AB})$ durante a operação em batelada alimentada a $\mathrm{C}_{\mathrm{AF}}=4000 \mathrm{mg} / \mathrm{l}, \mathrm{V}_{\text {alim. }}=1,0 \mathrm{l}$ nas condições $\mathrm{I}\left(\mathrm{T}_{\text {alim. }}=360\right.$ $\min ), \operatorname{II}\left(\mathrm{T}_{\text {alim. }}=180 \mathrm{~min}\right)$ e III $\left(\mathrm{T}_{\text {alim. }}=10 \mathrm{~min}\right)$.

Figura 5.33 - Concentração de Ácidos Voláteis Totais (AVT) durante a operação em batelada alimentada a $\mathrm{C}_{\mathrm{AF}}=4000 \mathrm{mg} / \mathrm{l}, \mathrm{V}_{\text {alim. }}=1,01$ nas condições $\mathrm{I}\left(\mathrm{T}_{\text {alim. }}=360\right.$ $\min ), \mathrm{II}\left(\mathrm{T}_{\text {alim. }}=180 \mathrm{~min}\right)$ e III $\left(\mathrm{T}_{\text {alim. }}=10 \mathrm{~min}\right)$. 74

Figura 5.34 - Perfil de concentração da matéria orgânica ao longo do ciclo, em termos de $\mathrm{DQO}$, de amostras filtradas, durante a operação em batelada alimentada a $\mathrm{C}_{\mathrm{AF}}=$ $4000 \mathrm{mg} / \mathrm{l}, \mathrm{V}_{\text {alim. }}=1,01$ nas condições I $\left(\mathrm{T}_{\text {alim. }}=360 \mathrm{~min}\right), \mathrm{II}\left(\mathrm{T}_{\text {alim. }}=180 \mathrm{~min}\right) \mathrm{e}$ III $\left(\mathrm{T}_{\text {alim. }}=10 \mathrm{~min}\right)$. .75

Figura 5.35 - Perfil de concentração de Ácidos Voláteis Totais (AVT) e de Alcalinidade a Bicarbonato $(\mathrm{AB})$ ao longo do ciclo, durante a operação em batelada alimentada a $\mathrm{C}_{\mathrm{AF}}=4000 \mathrm{mg} / \mathrm{l}, \mathrm{V}_{\mathrm{alim} .}=1,01$ nas condições $\mathrm{I}\left(\mathrm{T}_{\mathrm{alim} .}=360 \mathrm{~min}\right), \mathrm{II}\left(\mathrm{T}_{\mathrm{alim} .}=180\right.$ $\min )$ e III ( $\left.\mathrm{T}_{\text {alim. }}=10 \mathrm{~min}\right)$. 76

Figura 5.36 - Perfil de pH ao longo do ciclo, durante a operação em batelada alimentada $\mathrm{a} \mathrm{C}_{\mathrm{AF}}=4000 \mathrm{mg} / \mathrm{l}, \mathrm{V}_{\mathrm{alim} .}=1,01$ nas condições I $\left(\mathrm{T}_{\mathrm{alim} .}=360 \mathrm{~min}\right), \mathrm{II}\left(\mathrm{T}_{\mathrm{alim}}=180\right.$ $\min )$ e III $\left(\mathrm{T}_{\text {alim. }}=10 \mathrm{~min}\right)$. .76

Figura 5.37 - Concentração de matéria orgânica, em termos de DQO, de amostras filtradas e não filtradas no efluente durante a operação em batelada alimentada a $\mathrm{C}_{\mathrm{AF}}=8000 \mathrm{mg} / \mathrm{l}, \mathrm{V}_{\text {alim. }}=0,51$ nas condições I $\left(\mathrm{T}_{\text {alim. }}=360 \mathrm{~min}\right), \mathrm{II}\left(\mathrm{T}_{\text {alim. }}=180\right.$ $\min )$ e III ( $\left.\mathrm{T}_{\text {alim. }}=10 \mathrm{~min}\right)$. .81

Figura 5.38 - Eficiência de remoção da matéria orgânica, em termos de DQO, de amostras do efluente filtradas e não filtradas durante a operação em batelada alimentada a $\mathrm{C}_{\mathrm{AF}}=8000 \mathrm{mg} / \mathrm{l}, \mathrm{V}_{\text {alim. }}=0,51$ nas condições $\mathrm{I}\left(\mathrm{T}_{\text {alim. }}=360 \mathrm{~min}\right)$, $\mathrm{II}\left(\mathrm{T}_{\text {alim. }}=180 \mathrm{~min}\right)$ e III $\left(\mathrm{T}_{\text {alim. }}=10 \mathrm{~min}\right)$ 
Figura 5.39 - Concentração de Alcalinidade a Bicarbonato (AB) de amostras do afluente e do efluente durante a operação em batelada alimentada a $\mathrm{C}_{\mathrm{AF}}=8000$ $\mathrm{mg} / \mathrm{l}, \mathrm{V}_{\text {alim. }}=0,51$ nas condições $\mathrm{I}\left(\mathrm{T}_{\text {alim. }}=360 \mathrm{~min}\right), \mathrm{II}\left(\mathrm{T}_{\text {alim. }}=180 \mathrm{~min}\right)$ e III $\left(\mathrm{T}_{\text {alim. }}=10 \mathrm{~min}\right)$.

Figura 5.40 - Concentração de Ácidos Voláteis Totais (AVT) de amostras do afluente e do efluente durante a operação em batelada alimentada a $\mathrm{C}_{\mathrm{AF}}=8000 \mathrm{mg} / \mathrm{l}, \mathrm{V}_{\text {alim. }}=$ 0,5 1 nas condições I $\left(\mathrm{T}_{\text {alim. }}=360 \mathrm{~min}\right), \mathrm{II}\left(\mathrm{T}_{\text {alim. }}=180 \mathrm{~min}\right)$ e III $\left(\mathrm{T}_{\text {alim. }}=10 \mathrm{~min}\right)$.

Figura 5.41 - Perfil de concentração de matéria orgânica ao longo do ciclo, em termos de DQO, durante a operação em batelada alimentada a $\mathrm{C}_{\mathrm{AF}}=8000 \mathrm{mg} / \mathrm{l}, \mathrm{V}_{\text {alim. }}=$ 0,5 1 nas condições I $\left(\mathrm{T}_{\text {alim. }}=360 \mathrm{~min}\right), \mathrm{II}\left(\mathrm{T}_{\text {alim. }}=180 \mathrm{~min}\right)$ e III $\left(\mathrm{T}_{\text {alim. }}=10 \mathrm{~min}\right)$.

Figura 5.42 - Perfil de Concentração de Ácidos Voláteis Totais (AVT) e de Alcalinidade a Bicarbonato $(\mathrm{AB})$ ao longo do ciclo, durante a operação em batelada alimentada a $\mathrm{C}_{\mathrm{AF}}=8000 \mathrm{mg} / \mathrm{l}, \mathrm{V}_{\text {alim. }}=0,51$ nas condições $\mathrm{I}\left(\mathrm{T}_{\text {alim. }}=360\right.$ $\min ), \mathrm{II}\left(\mathrm{T}_{\mathrm{alim} .}=180 \mathrm{~min}\right)$ e III $\left(\mathrm{T}_{\mathrm{alim} .}=10 \mathrm{~min}\right)$.

Figura 5.43 - Perfil de pH ao longo do ciclo durante a operação em batelada alimentada a $_{\mathrm{AF}}=8000 \mathrm{mg} / \mathrm{l}, \mathrm{V}_{\text {alim. }}=0,5 \mathrm{l}$ nas condições $\mathrm{I}\left(\mathrm{T}_{\text {alim. }}=360 \mathrm{~min}\right), \mathrm{II}\left(\mathrm{T}_{\text {alim. }}=180\right.$ $\min )$ e III ( $\left.\mathrm{T}_{\text {alim. }}=10 \mathrm{~min}\right)$.

Figura 5.44 - Concentração de matéria orgânica, em termos de DQO, de amostras filtradas e não filtradas no efluente durante a operação em batelada a $\mathrm{C}_{\mathrm{AF}}=2000$ $\mathrm{mg} / \mathrm{l}, \mathrm{V}_{\text {alim. }}=2,01 \mathrm{e} \mathrm{T}_{\text {alim. }}=10$ minutos. 88

Figura 5.45 - Concentração de Alcalinidade a Bicarbonato (AB), de amostras do afluente e do efluente durante a operação em batelada a $\mathrm{C}_{\mathrm{AF}}=2000 \mathrm{mg} / \mathrm{l}, \mathrm{V}_{\text {alim. }}=$ $2,01 \mathrm{e} \mathrm{T}_{\text {alim. }}=10$ minutos. 88

Figura 5.46 - Concentração de Ácidos Voláteis Totais (AVT), de amostras filtradas e não filtradas no efluente durante a operação em batelada a $C_{A F}=2000 \mathrm{mg} / \mathrm{l}, \mathrm{V}_{\text {alimm }}$. $=2,0$ le $\mathrm{T}_{\text {alim. }}=10$ minutos

Figura 5.47 - Perfil de concentração da matéria orgânica ao longo do ciclo, em termos de DQO, durante a operação em batelada a $\mathrm{C}_{\mathrm{AF}}=2000 \mathrm{mg} / \mathrm{l}, \mathrm{V}_{\mathrm{alim} .}=2,01 \mathrm{e} \mathrm{T}_{\text {alim. }}=$ 10 minutos.

Figura 5.48 - Perfil de concentração de Ácidos Voláteis Totais (AVT) e de Alcalinidade a Bicarbonato $(\mathrm{AB})$ ao longo do ciclo durante a operação em batelada a $\mathrm{C}_{\mathrm{AF}}=2000$ $\mathrm{mg} / \mathrm{l}, \mathrm{V}_{\text {alim. }}=2,01 \mathrm{e} \mathrm{T}_{\text {alim. }}=10$ minutos. 90 
Figura 5.49 - Perfil de $\mathrm{pH}$ ao longo do ciclo durante a operação em batelada a $\mathrm{C}_{\mathrm{AF}}=$

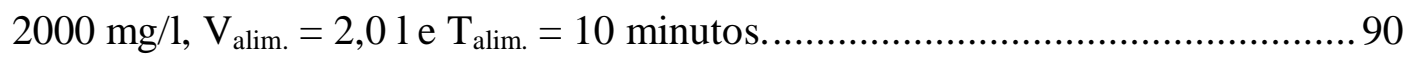

Figura 5.50 - Fotografia obtida por microscopia ótica comum, por contraste de fase e a imagem tratada para melhorar a visualização da estrutura de cocos aglomerados. 93 Figura 5.51 - Fotografia obtida por microscopia ótica comum, por contraste de fase e a imagem tratada para melhorar a visualização da estrutura de cocos em cadeia.....93 


\section{LISTA DE TABELAS}

Tabela 3.1 - Resumo dos resultados de alguns processos de tratamento anaeróbio de soro de queijo. 14

Tabela 4.1 - Composição do soro de queijo desidratado a ser utilizado nos experimentos 30

Tabela 4.2 - Composição da solução salina adicionada ao soro de queijo para suplementar nutrientes e metais traço nos ensaios BA-A, BA-B, BA-C e BA-D da operação em batelada alimentada.

Tabela 4.3 - Estratégias de alimentação implementadas durante a realização dos ensaios em batelada e em batelada alimentada.

Tabela 5.1 - Valores médios das variáveis monitoradas no afluente e no efluente durante os ensaios preliminares.

Tabela 5.2 - Valores médios das variáveis monitoradas no ensaio em batelada para $\mathrm{COV}=1,2 \mathrm{~g} / \mathrm{l} . \mathrm{d}$

Tabela 5.3 - Perfil de Ácidos Voláteis Intermediários (AVI) ao longo do ciclo, durante a operação do reator em batelada, para $\mathrm{COV}=1,2 \mathrm{~g} / \mathrm{l} . \mathrm{d}$.

Tabela 5.4 - Valores médios das variáveis monitoradas no ensaio em batelada para $\mathrm{COV}=2,4 \mathrm{~g} / \mathrm{l} . \mathrm{d}$ 46

Tabela 5.5 - Perfil de Ácidos Voláteis Intermediários (AVI) ao longo do ciclo, durante a operação do reator em batelada, para $\mathrm{COV}=2,4 \mathrm{~g} / \mathrm{l} . \mathrm{d}$.

Tabela 5.6 - Valores médios das variáveis monitoradas no ensaio em batelada para $\mathrm{COV}=4,8 \mathrm{~g} / \mathrm{l} \cdot \mathrm{d}$

Tabela 5.7 - Perfil de Ácidos Voláteis Intermediários (AVI) ao longo do ciclo, durante a operação do reator em batelada, para $\mathrm{COV}=4,8 \mathrm{~g} / \mathrm{l} . \mathrm{d}$. 59

Tabela 5.8 - Valores dos parâmetros cinéticos aparentes de primeira ordem $\mathrm{k}_{1}$, obtidos pelo ajuste cinético para o reator ASBR operado com e sem o DT em condições semelhantes.

Tabela 5.9 - Valores médios das variáveis monitoradas durante a operação em batelada alimentada a $\mathrm{C}_{\mathrm{AF}}=4000 \mathrm{mg} / \mathrm{l} \mathrm{e} \mathrm{V}_{\text {alim. }}=1,01$ para os $\mathrm{T}_{\text {alim. }}$ de 360,180 e $10 \mathrm{~min} .72$

Tabela 5.10 - Perfil de Ácidos Voláteis Intermediários (AVI) ao longo do ciclo, durante a operação do reator em batelada alimentada a $C_{\mathrm{AF}}=4000 \mathrm{mg} / \mathrm{l}$, Valim. $=1,01 \mathrm{e}$ Talim. $=360$ minutos. 77 
Tabela 5.11 - Perfil de concentração de Ácidos Voláteis Intermediários (AVI) ao longo do ciclo, durante a operação em batelada alimentada a $\mathrm{C}_{\mathrm{AF}}=4000 \mathrm{mg} / \mathrm{l}, \mathrm{V}_{\mathrm{alim}}=1,0$ $1 \mathrm{e} \mathrm{T}_{\text {alim. }}=180$ minutos. .77

Tabela 5.12 - Perfil de concentração de Ácidos Voláteis Intermediários (AVI) ao longo do ciclo, durante a operação em batelada a $\mathrm{C}_{\mathrm{AF}}=4000 \mathrm{mg} / \mathrm{l}, \mathrm{V}_{\text {alim. }}=1,01 \mathrm{e} \mathrm{T}_{\text {alim. }}=$ 10 minutos .78

Tabela 5.13 - Valores médios das variáveis monitoradas durante a operação em batelada alimentada a $\mathrm{C}_{\mathrm{AF}}=8000 \mathrm{mg} / \mathrm{l}, \mathrm{V}_{\text {alim. }}=0,51$ para os $\mathrm{T}_{\text {alim. }}$ de 360,180 e 10 $\min$ 80

Tabela 5.14 - Perfil de concentração de Ácidos Voláteis Intermediários (AVI) ao longo do ciclo durante a operação em batelada alimentada a $\mathrm{C}_{\mathrm{AF}}=8000 \mathrm{mg} / \mathrm{l}, \mathrm{V}_{\text {alim. }}=0,5$ $1 \mathrm{e} \mathrm{T}_{\text {alim. }}=360 \mathrm{~min}$

Tabela 5.15 - Perfil de concentração de Ácidos Voláteis Intermediários (AVI) ao longo do ciclo, durante a operação em batelada alimentada a $\mathrm{C}_{\mathrm{AF}}=8000 \mathrm{mg} / \mathrm{l}, \mathrm{V}_{\mathrm{alim}}=0,5$ $1 \mathrm{e} \mathrm{T}_{\text {alim. }}=180 \mathrm{~min}$ .85

Tabela 5.16 - Perfil de concentração de Ácidos Voláteis Intermediários (AVI) ao longo do ciclo durante a operação em batelada a $\mathrm{C}_{\mathrm{AF}}=8000 \mathrm{mg} / \mathrm{l}, \mathrm{V}_{\text {alim. }}=0,51 \mathrm{e} \mathrm{T}_{\text {alim. }}=$ 10 minutos. .85

Tabela 5.17 - Valores médios das variáveis monitoradas durante a operação em batelada $\mathrm{a} \mathrm{C}_{\mathrm{AF}}=2000 \mathrm{mg} / \mathrm{l}, \mathrm{V}_{\text {alim. }}=2,01 \mathrm{e} \mathrm{T}_{\text {alim. }}=10$ minutos .87

Tabela 5.18 - Perfil de concentração de Ácidos Voláteis Intermediários (AVI) ao longo do ciclo durante a operação em batelada a $\mathrm{C}_{\mathrm{AF}}=2000 \mathrm{mg} / \mathrm{l}, \mathrm{V}_{\text {alim. }}=2,0 \mathrm{le} \mathrm{T}_{\text {alim. }}=$ 10 minutos 


\section{LISTA DE ABREVIATURAS E SIGLAS}

$\mathrm{AB}$

Alcalinidade a bicarbonato $\left(\mathrm{gNAHCO}_{3} / \mathrm{l}\right)$.

ASBR Reator anaeróbio operado em bateladas seqüenciais (Anaerobic Sequencing Batch Reactor).

ASBBR Reator anaeróbio com biomassa imobilizada operado em bateladas seqüenciais (Anaerobic Sequencing Biofilm Batch Reactor).

AT Alcalinidade total $\left(\mathrm{gNAHCO}_{3} / \mathrm{l}\right)$.

AVT Ácidos voláteis totais (gHAc/l).

$\mathrm{AVT}_{\mathrm{C}} \quad$ Ácidos voláteis totais por cromatografia (g/l).

COV Carga orgânica volumétrica (g/l.d).

$\mathrm{COV}_{\mathrm{B}} \quad$ Carga orgânica volumétrica em reatores em batelada (g/l.d).

DQO Demanda química de oxigênio (g/l.d).

DT "draft tube", ou tubo interno.

rpm Rotações por minuto.

SST Sólidos suspensos totais (gSST/l).

SSV Sólidos suspensos voláteis $(\mathrm{gSSV} / \mathrm{l})$.

ST Sólidos totais (gST/l).

SVT Sólidos voláteis totais (gSVT/l).

UASB Reator anaeróbio de manta de lodo (Upflow Anaerobic Sludge Blanket). 


\section{LISTA DE SÍMBOLOS}

$\mathrm{N}_{\mathrm{C}}$

$\mathrm{Q}_{\text {MED }}$

T

$t_{C}$

$\mathrm{t}_{\mathrm{F}} / \mathrm{t}_{\mathrm{C}}$

$t_{\text {mist }}$

$\mathrm{t}_{\text {Tmist }}$

$\mathrm{T}_{\text {alim }}$

$\mathrm{V}_{\text {Alim }}$

$\mathrm{V}_{\mathrm{R}}$

Eficiência de conversão de matéria orgânica (\%).

Eficiência de conversão de matéria orgânica filtrada (\%).

Eficiência de conversão de matéria orgânica não filtrada (\%).

Tempo de detenção hidráulica (h).

Tempo de detenção hidráulica para reatores em batelada (h).

Concentração afluente (g/l, em termos de DQO).

Concentração de matéria orgânica, em termos de DQO, em amostras filtradas (g/l, em termos de DQO).

Concentração de matéria orgânica, em termos de DQO, em amostras não filtradas (g/l, em termos de DQO).

Razão substrato/microrganismos.

Número de ciclos ao dia.

Vazão média (1/h).

Temperatura $\left({ }^{\circ} \mathrm{C}\right)$.

Tempo de ciclo (horas).

Razão tempo de alimentação/tempo de ciclo.

Tempo de mistura (min).

Tempo total de mistura ( $\mathrm{min})$.

Tempo de enchimento do reator (min).

Volume alimentado por ciclo (1/ciclo).

Volume do reator (1). 


\section{SUMÁRIO}

1 INTRODUÇÃ

2 OBJETIVO

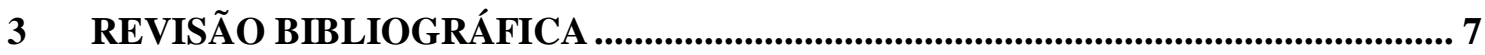

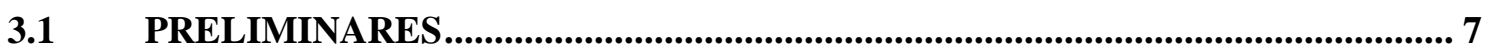

3.1.1 Tempo de Detenção Hidráulico $\left(\theta_{\mathrm{H}}\right)$................................................................. 7

3.1.2 Carga Orgânica Volumétrica Aplicada (COV) ........................................................ 8

3.1.3 Eficiência de Conversão de Matéria Orgânica $(\varepsilon)$.......................................................... 9

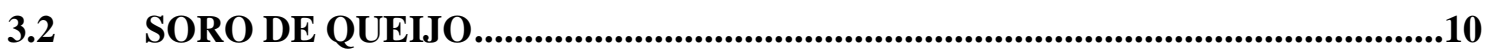

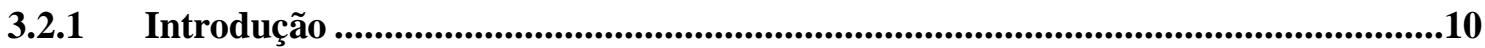

3.2.2 Reatores Anaeróbios Aplicados ao Tratamento do Soro de Queijo........................11

3.3 REATOR ANAERÓBIO OPERADO EM BATELADA SEQÜENCIAL (ASBR) ..

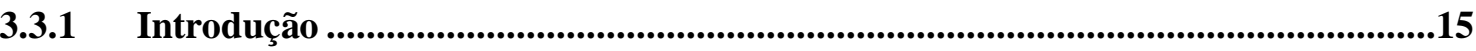

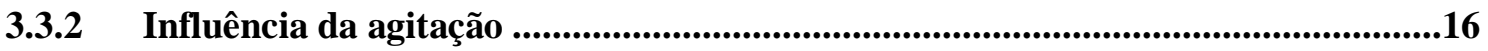

3.3.3 Influência da estratégia de alimentação...............................................................19

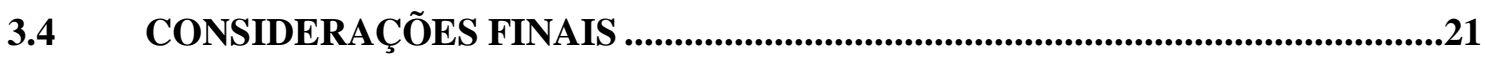

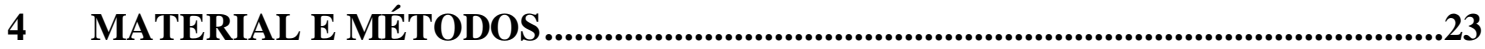

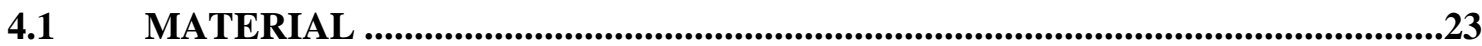

4.1.1 Configuração do Reator Anaeróbio Operado em Batelada Seqüiencial..................23

4.1.2 Desenvolvimento de dispositivos para assegurar a retenção da biomassa.............26

4.1.3 Inóculo .........................................................................................................................................30

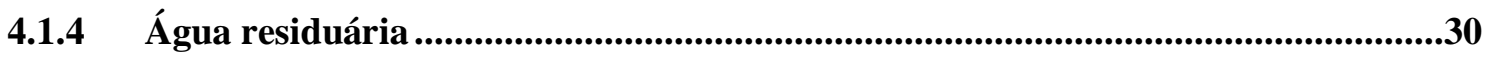

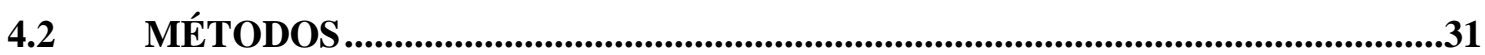

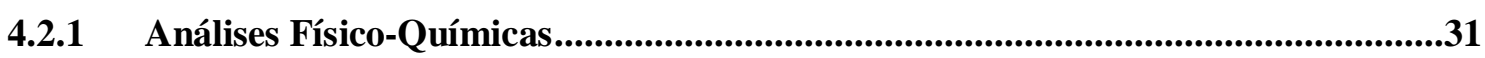

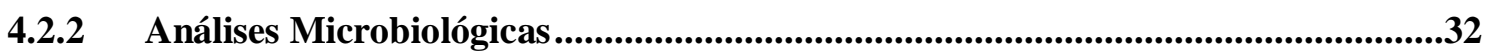

4.2.3 Composição e Produção do Biogás .......................................................................32

4.3 PROCEDIMENTO EXPERIMENTAL _..................................................................32

4.3.1 Operação do Reator em Batelada Seqüencial........................................................32

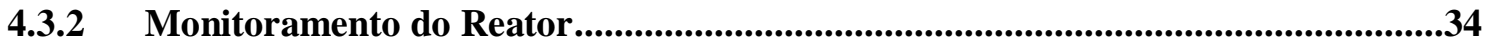

4.3.3 Perfil ao Longo do Ciclo de Operação ..............................................................................35

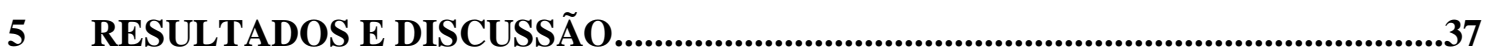

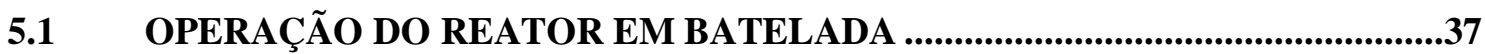

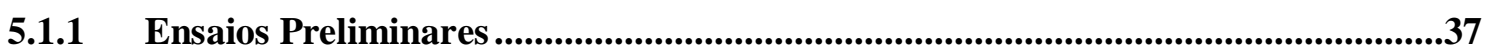

5.1.2 Operação em Batelada (COV = 1,2 g/l.d. ; $\left.\mathrm{C}_{\mathrm{AF}}=1000 \mathrm{mg} / \mathrm{l}\right)$.................................38 
5.1.3 Operação em Batelada $\left(\mathrm{COV}=2,4 \mathrm{~g} / \mathrm{l} . d\right.$. ; $\left.\mathrm{C}_{\mathrm{AF}}=2000 \mathrm{mg} / \mathrm{l}\right)$................................45

5.1.4 Operação em Batelada $\left(\mathrm{COV}=4,8 \mathrm{~g} / \mathrm{l.d}\right.$; $\left.\mathrm{C}_{\mathrm{AF}}=4000 \mathrm{mg} / \mathrm{l}\right)$................................53

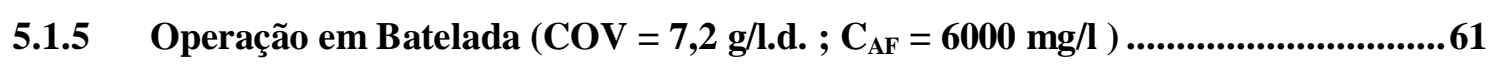

5.2 OPERAÇÃO DO REATOR EM BATELADA ALIMENTADA..........................62

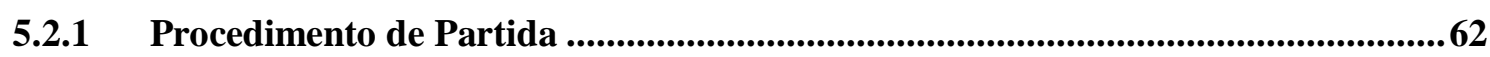

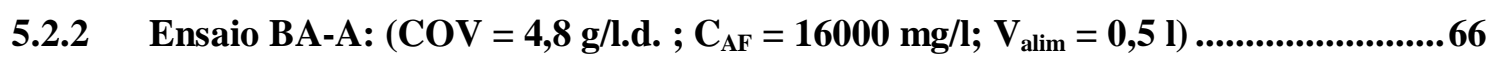

5.2.3 Operação em Batelada Alimentada utilizando a configuração de Reator ASBR Híbrido 67

5.2.4 Ensaio BA-E: (ASBR com agitação mecânica - utilização de 2 impelidores: hélice com pá inclinada)

69

5.2.5 Ensaio BA-F: (ASBR com agitação mecânica - utilização de 2 impelidores: hélice com turbina inclinada)..................................................................................................................................70

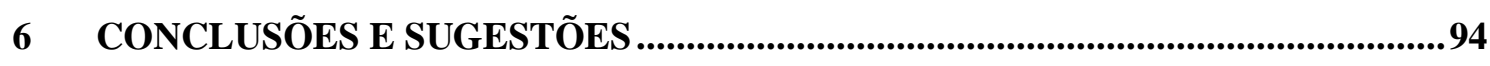

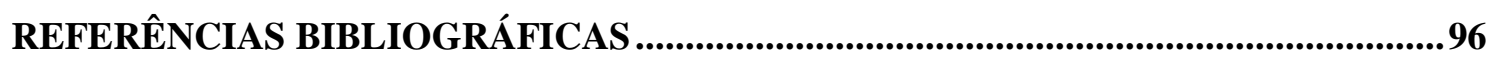

ANEXO A - ENSAIOS PRELIMINARES - VALORES EXPERIMENTAIS.................... 104

ANEXO B - $\left(\mathrm{COV}=1,2 \mathrm{~g} / \mathrm{l} . \mathrm{d} ; \mathrm{C}_{\mathrm{AF}}=1000 \mathrm{mg} / \mathrm{l}\right)-$ VALORES EXPERIMENTAIS

.106

ANEXO C $-\left(\mathrm{COV}=2,4\right.$ g./.d $\left.; \mathrm{C}_{\mathrm{AF}}=2000 \mathrm{mg} / \mathrm{l}\right)-$ VALORES EXPERIMENTAIS

109

ANEXO D - $\left(\mathrm{COV}=4,8 \mathrm{~g} / \mathrm{l} . \mathrm{d} ; \mathrm{C}_{\mathrm{AF}}=4000 \mathrm{mg} / \mathrm{l}\right)-$ VALORES EXPERIMENTAIS

112

ANEXO E $-\left(\mathrm{COV}=7,2 \mathrm{~g} / \mathrm{l} . \mathrm{d} ; \mathrm{C}_{\mathrm{AF}}=6000 \mathrm{mg} / \mathrm{l}\right)-$ VALORES EXPERIMENTAIS

115

ANEXO F - ENSAIO BA-A - VALORES EXPERIMENTAIS.................................... 117

ANEXO G - ENSAIO BA-E - VALORES EXPERIMENTAIS .......................................119

ANEXO H- ENSAIOS EM BATELADA ALIMENTADA - VALORES

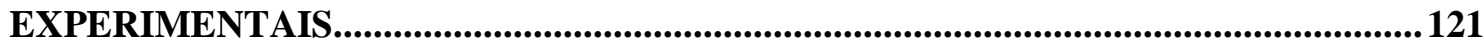

ANEXO H 1 - ENSAIO BA-F 1 - VALORES EXPERIMENTAIS.................................. 122

ANEXO H 2 - ENSAIO BA-F 2 - VALORES EXPERIMENTAIS.................................... 124

ANEXO H 3 - ENSAIO BA-F 3 - VALORES EXPERIMENTAIS.....................................126

ANEXO H 4 - ENSAIO BA-F 4 - VALORES EXPERIMENTAIS.................................... 128

ANEXO H 5 - ENSAIO BA-F 5 - VALORES EXPERIMENTAIS..................................... 130

ANEXO H 6 - ENSAIO BA-F 6 - VALORES EXPERIMENTAIS...................................... 132

ANEXO H 7 - ENSAIO BA-F 7 - VALORES EXPERIMENTAIS................................. 134 


\section{INTRODUÇÃO}

As indústrias de laticínios geram três resíduos na forma de efluentes líquidos: o soro resultante da produção de queijos, o leitelho resultante da produção de manteiga e o leite ácido. Desses, o soro é o de maior importância devido à quantidade produzida (cerca de 4 milhões de toneladas por ano, no Brasil - EMBRAPA 2002), ao amplo espectro de possibilidades de reutilização devido ao seu potencial nutritivo e, principalmente, pelo seu elevado poder poluente.

O soro é a fração líquida do leite obtida após a precipitação da caseína na fabricação de queijos, cuja produção é de cerca de 80-90\% do volume do leite. É um produto líquido, cujo teor em água varia entre 91 e 95\%. Seu extrato seco, da ordem de $7 \%$ da sua massa total, é dividido em frações glicídicas (77\%), protéicas (13\%), lipídicas $(1 \%)$ e ainda cinzas $(9 \%)$, representando a fração inorgânica do soro, tendo larga aplicação na indústria de alimentos (MARTINS et al. 2000).

Os tipos de soro são classificados de acordo com o tipo de queijo produzido. Dessa forma, o soro doce provém da separação da massa de queijo, precipitação da caseína, logo após o corte do coágulo sendo processado antes da acidificação por cultura Láctea. É geralmente obtido da produção de queijos como Cheddar, Colby, Mozarela e Suíço. O soro ácido é obtido como subproduto da fabricação de queijo tipo frescal, como o queijo Cottage, devido à fermentação parcial da lactose a ácido láctico.

As várias formas de disposição ou utilização do soro podem ser resumidas e agrupadas em três categorias gerais (MAWSON, 1994):

1. Uso Direto ou Disposição: Quando o soro é utilizado sem sofrer nenhum, ou quase nenhum tipo de processamento. Isso inclui os usos tradicionais como alimentação animal, o uso do soro deproteinado como ingredientes em alimentos, bebidas, irrigação e até a disposição nos corpos d’água ou em sistemas municipais de tratamento. 
2. Estabilização Direta: O soro sofre tratamento químico ou físico, sendo considerado mais estável para o tratamento microbiano. Essas técnicas incluem recuperação de proteína pela ultrafiltração ou denaturação térmica, concentração por osmose reversa ou evaporação, cristalização da lactose e secagem.

3. Processos de Conversão: A lactose é convertida a outro composto pela atividade de microrganismos (bioconversão) ou por reações químicas. Isso inclui a produção de latulose e lactitol.

Atualmente aplica-se, comercialmente, o soro no Brasil, na fabricação de alimentos enriquecidos, ricota fresca e na suinocultura como ração. Além disso, o mesmo é descartado direta ou indiretamente nos cursos dos rios sem qualquer tipo de tratamento.

A alternativa do descarte ocorre devido à produção de soro ser muito grande (para cada $10 \mathrm{~kg}$ de leite obtém-se $9 \mathrm{~kg}$ de soro e apenas $1 \mathrm{~kg}$ de queijo), além de dispersa, impossibilitando um aproveitamento mais apurado desse subproduto. Logo, o descarte em corpos hídricos torna-se uma solução menos onerosa para a produção deste soro, visto que atualmente no Brasil suas aplicações são bem limitadas, além de existirem inúmeras indústrias de laticínios de pequeno e médio porte que não possuem "knowhow" tecnológico para um efetivo aproveitamento deste soro.

O problema ambiental gerado por descarte indiscriminado deste soro em cursos de rios é demasiadamente sério para ser ignorado, devido ao seu poder poluente ser cerca de cem vezes maior que o do esgoto doméstico, fazendo-se necessário o desenvolvimento de um processo de tratamento para um descarte menos agressivo ao ambiente.

Portanto, muitos pesquisadores têm se esforçado no sentido de desenvolver tecnologia anaeróbia para o tratamento deste efluente, tendo em vista as vantagens econômicas do tratamento anaeróbio, principalmente no que se refere à questão energética e à produção de lodo biológico.

Com o desenvolvimento da tecnologia anaeróbia nos últimos anos, muitos novos tipos de reatores anaeróbios têm sido propostos. Entre essas novas configurações destaca-se o reator anaeróbio operado em batelada seqüencial (ASBR), desenvolvido inicialmente pelos grupos da Universidade do Estado de Iowa (Estados Unidos) e da Universidade de Ottawa (Canadá). No Brasil, este novo tipo de reator é pesquisado 
principalmente no Instituto de Pesquisas Hidráulicas da UFRGS, na Escola de Engenharia de São Carlos (EESC/USP) e no Instituto Mauá de Tecnologia (IMT).

Alguns dos trabalhos realizados no IMT visam viabilizar e otimizar o tratamento anaeróbio de soro de queijo em reatores ASBR (MOCKAITIS et al., 2006) e ASBBR (DAMASCENO et al., 2006).

A continuidade desses estudos é de fundamental importância para o desenvolvimento de tecnologias economicamente viáveis, com elevada aplicação e flexibilidade para o tratamento do soro de queijo. Dessa forma, o estudo da COV aplicada e das estratégias de alimentação visam reduzir os custos necessários à aplicação desta tecnologia ao tratamento do soro de queijo. 


\section{OBJETIVO}

O objetivo principal do projeto de pesquisa foi investigar a influência da carga orgânica volumétrica de diferentes estratégias de alimentação sobre o comportamento do reator operado em batelada seqüencial com agitação mecânica e "draft tube" (ou tubo interno), contendo biomassa granulada, aplicado ao tratamento de soro de queijo. Para isso foram estabelecidos os seguintes objetivos específicos:

I. Análise da influência da carga orgânica volumétrica aplicada e da suplementação de alcalinidade sobre a eficiência e estabilidade do reator biológico.

II. Estudo da viabilidade operacional do "draft tube" visando a redução das resistências à transferência de massa entre as fases líquida e sólida.

III. Desenvolvimento de dispositivos para assegurar a retenção da biomassa visando a otimização do sistema submetido a elevadas cargas orgânicas volumétricas aplicadas, durante a operação em batelada alimentada. 


\section{REVISÃO BIBLIOGRÁFICA}

\subsection{PRELIMINARES}

Como a grande maioria das unidades de tratamento de resíduos opera de maneira contínua, faz-se necessário o estabelecimento de ferramentas que permitam a comparação destes com sistemas operados em batelada. Assim, o objetivo deste item é apresentar, conceitualmente, os parâmetros que foram utilizados com esta finalidade.

\subsubsection{Tempo de Detenção Hidráulico $\left(\theta_{H}\right)$}

Por definição, o $\theta_{\mathrm{h}}$ representa o tempo médio que um elemento de volume permanece no interior do reator. Assim:

$$
\theta_{\mathrm{h}}=\frac{\mathrm{V}_{\mathrm{R}}}{\mathrm{Q}_{\mathrm{MED}}}
$$

Na qual:

$\mathrm{V}_{\mathrm{R}}=$ volume do reator $(\mathrm{l})$.

$\mathrm{Q}_{\mathrm{MED}}=$ vazão média $(1 / \mathrm{h})$.

Para sistemas em batelada, como não há vazão afluente, Camargo et al. (2000) propôs a determinação do tempo de detenção hidráulica em reatores em batelada $\left(\theta_{\mathrm{hb}}\right)$ a partir da seguinte equação: 
$\theta_{\mathrm{rb}}=\frac{\mathrm{t}_{\mathrm{c}} \times \mathrm{V}_{\mathrm{R}}}{\mathrm{V}_{\text {Alim }}}$

Na qual:

$\mathrm{t}_{\mathrm{c}}=$ tempo de ciclo $(\mathrm{h} /$ ciclo $)$.

$\mathrm{V}_{\mathrm{R}}=$ volume do reator (1).

$\mathrm{V}_{\text {Alim }}=$ volume alimentado por ciclo ( $1 /$ ciclo $)$.

\subsubsection{Carga Orgânica Volumétrica Aplicada (COV)}

A carga orgânica volumétrica representa a quantidade de matéria orgânica, em termos de DQO, aplicada durante um determinado tempo por unidade de volume do reator. É definida como:

$$
\mathrm{COV}=\frac{\mathrm{Q}_{\mathrm{MED}} \times \mathrm{C}_{\mathrm{AF}}}{\mathrm{V}_{\mathrm{R}}}
$$

Na qual:

$\mathrm{Q}_{\mathrm{MED}}=$ vazão média $(1 / \mathrm{d})$.

$\mathrm{C}_{\mathrm{AF}}=$ concentração de matéria orgânica afluente em termos de DQO (g/l).

$\mathrm{V}_{\mathrm{R}}=$ volume do reator.

O cálculo da carga orgânica volumétrica aplicada (ou inicial) em reatores operados em batelada pode ser realizado da seguinte forma:

$\operatorname{COV}_{\mathrm{B}}=\frac{\mathrm{C}_{\mathrm{AF}} \times \mathrm{V}_{\mathrm{Alim}} \times \mathrm{N}_{\mathrm{C}}}{\mathrm{V}_{\mathrm{R}}}$

Na qual:

$\mathrm{C}_{\mathrm{AF}}=$ concentração de matéria orgânica afluente em termos de DQO $(\mathrm{g} / \mathrm{l})$.

$\mathrm{V}_{\text {Alim }}=$ volume alimentado por ciclo (1/ciclo).

$\mathrm{N}_{\mathrm{C}}=$ número de ciclos ao dia (ciclos/d).

$\mathrm{Q}_{\text {MED }}=$ vazão média $(1 / d)$.

$\mathrm{V}_{\mathrm{R}}=$ volume do reator $(1)$. 
A aplicação destes parâmetros apresenta também uma falta de padronização no seu cálculo no que diz respeito ao volume de controle considerado. Em alguns artigos, o volume do reator $\left(V_{R}\right)$ diz respeito ao volume total do mesmo, enquanto que em outros leva-se em conta o volume efetivo (ou volume útil) no mesmo, composto somente do volume líquido do sistema.

Por considerar o cálculo com o volume útil no sistema uma representação mais realista das condições as quais o sistema foi submetido, este foi considerado como sendo o volume do reator $\left(\mathrm{V}_{\mathrm{R}}\right)$.

No decorrer do texto, para sistemas contínuos, o $\theta_{\mathrm{h}} \mathrm{e}$ a $\mathrm{COV}$ dizem respeito às definições apresentadas nas eq. (1) e (3), respectivamente. Em sistemas operados em batelada, o $\theta_{\mathrm{h}}$ e a COV referem-se às relações apresentadas na eq. (2) e (4), respectivamente.

Para a operação em batelada alimentada, a COV refere-se à relação apresentada pela eq (4). Utilizou-se esta equação realizando-se um jogo de variáveis, entre as variáveis $\mathrm{C}_{\mathrm{AF}}$ e $\mathrm{V}_{\mathrm{alim}}$, de forma que a $\mathrm{COV}$ foi mantida constante. Este jogo de variáveis permitiu observar a influência de diferentes formas de aplicação da mesma COV sobre a estabilidade e a eficiência do ASBR operado em batelada alimentada.

\subsubsection{Eficiência de Conversão de Matéria Orgânica $(\varepsilon)$}

A eficiência de conversão de matéria orgânica não filtrada $\left(\varepsilon_{\mathrm{T}}\right)$ em termos de DQO foi calculada a partir da seguinte relação:

$\varepsilon_{\mathrm{T}}=\left(\frac{\mathrm{C}_{\mathrm{AF}}-\mathrm{C}_{\mathrm{ST}}}{\mathrm{C}_{\mathrm{AF}}}\right) \times 100$

Na qual:

$\mathrm{C}_{\mathrm{AF}}=$ concentração de matéria orgânica afluente em termos de DQO (g/l).

$\mathrm{C}_{\mathrm{ST}}=$ concentração de matéria orgânica efluente em amostras não filtradas em termos de DQO $(\mathrm{g} / \mathrm{l})$.

Para amostras filtradas, a conversão $\left(\varepsilon_{\mathrm{F}}\right)$ foi calculada da seguinte forma: 
$\varepsilon_{\mathrm{F}}=\left(\frac{\mathrm{C}_{\mathrm{AF}}-\mathrm{C}_{\mathrm{SF}}}{\mathrm{C}_{\mathrm{AF}}}\right) \times 100$

Na qual:

$\mathrm{C}_{\mathrm{AF}}=\mathrm{DQO}$ afluente $(\mathrm{g} / \mathrm{l})$.

$\mathrm{C}_{\mathrm{SF}}=\mathrm{DQO}$ efluente em amostras filtradas $(\mathrm{g} / \mathrm{l})$.

Essas relações foram utilizadas para se permitir a comparação do desempenho do sistema em diferentes tempos de enchimento.

\subsection{SORO DE QUEIJO}

\subsubsection{Introdução}

Devido ao seu elevado valor nutritivo o soro de queijo deveria ser altamente reaproveitado com elevada aplicação comercial. Contudo, devido à produção dispersa e aos elevados custos para a aplicação das tecnologias de reutilização, o descarte tem sido a alternativa mais viável para a maioria das indústrias de laticínios.

O soro de queijo possui carga orgânica bastante elevada, com valores de concentração em termos de DQO, atingindo aproximadamente 60.000 a 80.000 mg/l. Sua aplicação em sistema de tratamento anaeróbio requer cuidado, pois embora possua biodegradabilidade muito alta (cerca de 99\%), o soro in natura é um material que apresenta baixa alcalinidade a bicarbonato, apresentando uma tendência de acidificar o meio muito rapidamente, sendo necessário uma adição suplementar de alcalinidade na forma de bicarbonato, carbonato ou algum hidróxido (WILDENAUER e WINTER, 1985; LO e LIAO, 1986). 
Apresenta ainda alguns problemas operacionais como a dificuldade de granulação da biomassa no tratamento biológico e a tendência a produzir material polimérico viscoso, de provável origem microbiológica, que reduz severamente a sedimentabilidade do lodo, podendo causar o arraste da biomassa (YAN et al., 1988; MALASPINA et al., 1996).

Observa-se, portanto, que a estabilidade do processo normalmente depende da existência do controle do $\mathrm{pH}$ e/ou da adição de micronutrientes, pois a rápida conversão da lactose em ácidos voláteis de cadeia curta durante a digestão anaeróbia faz com que a alcalinidade presente no sistema seja rapidamente consumida, havendo a necessidade de monitoramento constante da mesma e do pH (BACKUS et al., 1988).

Assim, os problemas encontrados são normalmente associados à inadequada capacidade tampão e à deficiência de micronutrientes (YAN et al., 1988).

\subsubsection{Reatores Anaeróbios Aplicados ao Tratamento do Soro de Queijo}

Nos últimos anos foram realizadas várias pesquisas aplicando diversos tipos de reatores anaeróbios ao soro de queijo. Destacam-se os reatores tipo UASB (reator de manta de lodo e fluxo ascendente), reatores em duas fases (fase acidogênica e fase metanogênica) e reatores ASBR (reator operado em bateladas seqüenciais) e ASBBR (reator com biomassa imobilizada operado em batelada seqüenciais).

\subsubsection{UASB}

Kalyuzhnyi et al. (1997), utilizando reator UASB, concluíram que após uma partida adequada é possível operar o reator com soro pré-acidificado mesmo com valores elevados de carga orgânica, eliminando a necessidade de suplementação de alcalinidade no decorrer do ensaio, desde que o sistema permaneça bem agitado e com alta eficiência. 
O problema da baixa alcalinidade também pode ser minimizado pela utilização de uma concentração de soro menor que aquela in natura conforme os resultados de Yan et al. (1988) em reatores tipo UASB, os quais sugerem concentrações de afluente entre 20 e $41 \mathrm{~g} / \mathrm{l}$ para tempos de residência hidráulicos entre 5 e 10 dias. Kato et al. (1994) também estudaram esta variável, mas para sistemas com concentrações menores que $1.000 \mathrm{mg} / \mathrm{l}$. Outra alternativa é a utilização de recirculação da fase líquida para aumentar a alcalinidade e a diluição do afluente (MALASPINA et al., 1996).

\subsubsection{Reatores em duas fases (acidogênica e metanogênica)}

A separação da fase acidogênica da metanogênica, como forma de minimizar as principais limitações operacionais dos reatores que utilizam apenas uma fase, quanto à instabilidade e necessidade de suplementação de alcalinidade, também tem sido investigada (GARCIA et al., 1991; GERMILI et al., 1993; YILMAZER e YENIGÜN, 1999; MARTINS et al., 2000). Garcia et al. (1991) obtiveram remoção em termos de DQO maior que $99 \%$ para operação com carga orgânica de $30 \mathrm{~kg} / \mathrm{m}^{3}$.d no reator de acidificação e $15 \mathrm{~kg} / \mathrm{m}^{3}$.d no reator metanogênico, fazendo a recirculação do efluente do reator metanogênico no intuito de produzir uma diluição do afluente, conferindo boa estabilidade ao sistema sem a necessidade de correção de alcalinidade. Germirli et al. (1993) recomendam tratamento em dois estágios para águas residuárias com concentração de matéria orgânica acima de 2.000-3.000 mg/l. Yilmazer e Yenigün (1999) utilizaram um reator com agitação mecânica para a etapa acidogênica e um filtro ascendente para a etapa metanogênica. Após a determinação do tempo de residência hidráulico para a maior acidificação (de 24 horas com conversão de 50\%, distribuídos em 14\% como ácido propiônico, $27 \%$ como ácido butírico e $7 \%$ como ácido isovalérico), foi investigada a operação ótima do reator ascendente (com tempo de residência entre 3-6 dias) obtendo uma eficiência de remoção de 90\% com uma produção de biogás de $0,55 \mathrm{~m}^{3} / \mathrm{kg}$ para o tempo de residência hidráulico de 4 dias. 


\subsubsection{ASBR e ASBBR}

Ergüder (2001), utilizando reator ASBR e UASB em 1 e 2 estágios, comparou reatores alimentados com soro de queijo e meio basal (solução salina) e reatores alimentados apenas com o soro de queijo obtendo maior eficiência em termos de remoção de DQO e maior produção de biogás nos reatores alimentados com soro de queijo e meio basal.

Rautsznei et al. (2003), operando um reator ASBBR com agitação mecânica, diminuíram gradualmente a quantidade de bicarbonato de sódio adicionada ao processo até atingir $10 \%$ da relação mássica $\mathrm{NaHCO}_{3} / \mathrm{DQO}$ e obtiveram remoção em termos de DQO de $96 \%$ para carga orgânica de $5,7 \mathrm{~kg} / \mathrm{m}^{3} . \mathrm{d}$.

Operando um ASBR com biomassa granular, Mockaitis et al. (2006) avaliaram o efeito da COV aplicada e da suplementação de Alcalinidade a Bicarbonato sobre a estabilidade e o desempenho do ASBR. O reator foi operado em ciclos de 8 horas com $\mathrm{C}_{\mathrm{AF}}$ de 500, 1000, 2000 e 4000mg/l correspondendo a COV aplicada de 0,6 a 4,8 g/l.d , em termos de DQO. Os autores obtiveram eficiência em remoção de DQO sempre superior a $90 \%$ para $50 \%$ da razão mássica $\mathrm{NaHCO}_{3} / \mathrm{DQO}$.

Damasceno et al. (2006) tratando soro de queijo em ASBBR avaliou a influência da COV aplicada e da estratégia de alimentação sobre a estabilidade e o desempenho do reator. As COV aplicadas foram de 2, 4, 8 e 12 g/l.d para as estratégias de alimentação de 10, 120 e 240 minutos, mantendo-se a suplementação de Alcalinidade a Bicarbonato em $50 \%$ da razão mássica $\mathrm{NaHCO}_{3} / \mathrm{DQO}$. Obtiveram melhores resultado para as COV aplicadas de 2 a 4 g/l.d com a estratégia de alimentação de 120 minutos, e para as COV de 8 e 12 g/l.d a estratégia de alimentação de 240 minutos apresentou melhores resultados.

A Tabela 3.1 resume os resultados obtidos em escalas de bancada e piloto para os vários tipos de reatores, operados em uma ou duas fases, conforme a etapa acidogênica esteja ou não separada da metanogênica, com ou sem recirculação da fase líquida, utilizados no tratamento anaeróbio de soro de queijo, in natura ou diluído, variando-se a carga orgânica volumétrica, o tempo de residência hidráulico, a temperatura e a concentração do afluente. 
Tabela 3.1 - Resumo dos resultados de alguns processos de tratamento anaeróbio de soro de queijo.

\begin{tabular}{|c|c|c|c|c|c|c|c|}
\hline Ref. & $\begin{array}{l}\text { Tipo de Reator } \\
\text { (volume) }\end{array}$ & $\begin{array}{l}\text { Tipo de } \\
\text { Afluente }\end{array}$ & $\begin{array}{c}\mathrm{COV} \\
\text { (gDQO/L.d) }\end{array}$ & $\begin{array}{c}\mathrm{T} \\
\left({ }^{\circ} \mathrm{C}\right)\end{array}$ & $\begin{array}{c}\varepsilon \\
(\%)\end{array}$ & $\begin{array}{l}\text { TRH } \\
\text { (d) }\end{array}$ & $\begin{array}{c}\mathrm{C}_{\mathrm{AF}} \\
(\mathrm{gDQO} / \mathrm{L})\end{array}$ \\
\hline [1] & DSFFR $(3,5 \mathrm{~L})$ & $\mathrm{SQ}_{\mathrm{dn}}$ & $3,1-3,8$ & 35 & $85-87$ & $4,3-3,5$ & 13,43 \\
\hline [2] & UFFLR (3,9 L) & $\mathrm{SQ}_{\mathrm{b}}$ & 14 & 35 & 95 & 5 & 79 \\
\hline \multirow{2}{*}{ [3] } & \multirow{2}{*}{ UASB $(17,5 \mathrm{~L})$} & \multirow{2}{*}{$\mathrm{SQ}_{\mathrm{b}}$} & $0,91-8,14$ & 33 & $97-99$ & 5 & $4,56-41,1$ \\
\hline & & & 8,21 & 33 & 81 & 5 & 41,1 \\
\hline \multirow{2}{*}{ [4] } & $\operatorname{UASB}^{\mathrm{a}}(1 \mathrm{~L})$ & \multirow{2}{*}{$\mathrm{SQ}_{\mathrm{d}}$} & 30 & 35 & 99 & 0,45 & - \\
\hline & $\mathrm{UASB}^{\mathrm{m}}(1 \mathrm{~L})$ & & 15 & 35 & 99 & 0,75 & - \\
\hline \multirow[t]{2}{*}{ [5] } & HUASBR (8 L) & $\mathrm{SQ}_{\mathrm{d}}$ & $5,53-17$ & 35 & $87-75$ & $\begin{array}{l}1,02- \\
0,47\end{array}$ & $6-8$ \\
\hline & $\operatorname{UASB}^{\mathrm{b}}(3,0 \mathrm{~L})$ & \multirow{3}{*}{$\mathrm{SQ}_{\mathrm{b}}$} & $1-28,5$ & 35 & $95-99$ & $2,3-11,6$ & $5-77$ \\
\hline \multirow[t]{2}{*}{ [6] } & $\mathrm{UASB}^{\mathrm{b}}(3,0 \mathrm{~L})$ & & $7-9,5$ & $22-30$ & $90-94$ & $5,4-6,8$ & $42-55$ \\
\hline & $\operatorname{UASB}^{\mathrm{p}}(10.740 \mathrm{~L})$ & & $1-6,7$ & $20-29$ & 90-95 & $3,3-12,8$ & $16-50$ \\
\hline \multirow{2}{*}{ [7] } & $\operatorname{CSTR}^{\mathrm{a}}(1,5 / 4,5 \mathrm{~L})$ & \multirow{2}{*}{$\mathrm{SQ}_{\mathrm{b}}$} & \multirow{2}{*}{$5-20$} & 35 & 50 & 1 & 20 \\
\hline & $\operatorname{UFAF}^{\mathrm{m}}(5 \mathrm{~L})$ & & & 35 & 95 & 4 & 11 \\
\hline \multirow{3}{*}{ [8] } & $\operatorname{BSTR}^{\mathrm{a}}(8 \mathrm{~L})$ & \multirow{3}{*}{$\mathrm{SQ}_{\mathrm{b}}$} & \multirow{3}{*}{$5-9$} & 35 & 30 & 1 & \multirow{3}{*}{70} \\
\hline & $\operatorname{UASB}^{\mathrm{m}}(22 \mathrm{~L})$ & & & 35 & 35 & 7 & \\
\hline & $\operatorname{UASB}^{\mathrm{m}}(7,25 \mathrm{~L})$ & & & 35 & 80 & 7 & \\
\hline
\end{tabular}

\section{Nomenclatura:}

Símbolos: COV - carga orgânica volumétrica; $\mathrm{T}$ - temperatura; $\varepsilon$ - eficiência; TRH - tempo de residência hidráulico; $\mathrm{C}_{\mathrm{AF}}$ - concentração do afluente.

Reator: DSFFR - reator de fluxo descendente e leito fixo; UFFLR - reator de leito fixo, fluxo ascendente e recirculação; UASB - reator de fluxo ascendente e manta de lodo; HUASBR reator híbrido de fluxo ascendente e manta de lodo; CSTR - reator contínuo de mistura perfeita; UFAF - filtro anaeróbio de fluxo ascendente; BSTR - reator em batelada de mistura perfeita.

Fases: ${ }^{\mathrm{a}}$ - fase acidogênica; ${ }^{\mathrm{m}}$ - fase metanogênica.

Escala: ${ }^{\mathrm{b}}$ - escala de bancada; ${ }^{\mathrm{p}}$ - escala piloto.

Afluente: $\mathrm{SQ}_{\mathrm{dn}}$ - Soro de queijo diluído e neutralizado; $\mathrm{SQ}_{\mathrm{b}}-$ Soro de queijo in natura; $\mathrm{SQ}_{\mathrm{d}}-$ Soro de queijo diluído.

Referência: [1] De Haast et al. 1983; [2] Wildenauer \& Winter (1985); [3] Yan et al. (1988); [4] Garcia et al. (1991); [5] Öztürk et al. (1993); [6] Kalyuzhnyi et al. (1997); [7] Yilmazer \& Yenigün (1999); [8] Martins et al. (2000). 


\subsection{REATOR ANAERÓBIO OPERADO EM BATELADA SEQÜENCIAL (ASBR)}

\subsubsection{Introdução}

O reator anaeróbio operado em batelada seqüencial (ASBR) é um reator operado de modo intermitente em ciclos que se repetem sucessivamente.

Um ciclo típico de um reator ASBR é composto por quatro etapas: alimentação, reação, sedimentação e descarga (DAGUE, 1992). A primeira etapa, alimentação do reator, define a operação do reator como batelada ou batelada alimentada, de acordo com a duração da alimentação em relação ao tempo do ciclo (RATUSZNEI et al., 2001). As reações têm início durante a etapa de alimentação e continuam durante a etapa de reação consumindo a matéria orgânica e reduzindo a elevada razão inicial F/M com altas taxas de produção de biogás. Ao final da etapa de reação, as condições de sedimentação são excelentes devido à escassez de substrato aos organismos, ou seja, à razão F/M baixa. Em seguida ocorre a fase de sedimentação, na qual há a separação física entre a biomassa e o efluente tratado, que é descarregado do reator completando o ciclo (DAGUE et. al., 1992; ANGENENT \& DAGUE, 1995; NDON \& DAGUE, 1997; ZAIAT et al., 2001).

O tratamento de efluentes em ASBR é particularmente indicado para os casos de indústrias que geram efluentes de maneira intermitente ou somente em algumas épocas do ano; indústrias que trabalham com padrões de lançamento muito restritivo ou com águas residuárias de difícil degradação nos quais o tempo de ciclo é o parâmetro a ser ajustado para se garantir a degradação do composto presente ou para se atingir a remoção necessária para a disposição; para sistemas que tenham como finalidade o reuso da água residuária tratada, por permitir um maior controle operacional e em estudos que visam o entendimento de fenômenos relacionados com a digestão anaeróbia por permitirem maior instrumentação e controle (ZAIAT et al., 2001). 


\subsubsection{Influência da agitação}

Dois aspectos muito importantes em digestores agitados são a intensidade e a duração da agitação. Grande parte da literatura sobre agitação enfatiza a importância de se obter agitação adequada para promover a distribuição do substrato, enzima e microrganismos através do reator (PARKING \& OWEN, 1986; CHAPMAN, 1989; LEMA et al.,1991). Entretanto, as informações disponíveis sobre os efeitos da intensidade e da duração da agitação no comportamento dos reatores anaeróbios são contraditórias.

Geralmente a agitação em ASBR é implementada pela recirculação do biogás proveniente do processo de digestão, mas também pode ser proporcionada por agitação mecânica, que pode ser aplicada de forma intermitente ou contínua, ou pela recirculação de líquido (ANGENENT \& DAGUE, 1995; NDON \& DAGUE, 1997; ZAIAT et al., 2001). A intensidade de agitação é um importante fator a ser observado, porque a mesma pode causar danos ou até mesmo destruir os grânulos presentes na biomassa.

Embora seja a mais aplicada, a recirculação de biogás é insuficiente para promover a turbulência necessária para minimizar a ocorrência de possíveis zonas de estagnação e resistências à transferência de massa, sendo necessário um sistema de agitação para distribuir uniformemente o substrato durante a fase de reação. Entretanto, se a agitação for muito intensa, pode causar a ruptura de grânulos, resultando em diminuição da eficiência do processo e redução da sedimentabilidade do lodo com conseqüente perda de biomassa (ANGENENT \& DAGUE, 1995; BRITO et al., 1997).

Angenent et al. (2001) avaliaram os efeitos da intensidade de agitação sobre o desempenho do ASBR e a estrutura da comunidade microbiana, tratando efluente de suinocultura. Para isso compararam a agitação intermitente, realizada durante $1 \mathrm{~min} / \mathrm{h}$ pela recirculação de biogás à vazão de 26 1/h, com a agitação contínua, realizada durante $55 \mathrm{~min} / \mathrm{h}$. Posteriormente a intensidade de agitação também foi aumentada pela recirculação da fase líquida à vazão de 12,6 1/h. Destes ensaios concluíram que a agitação suave e intermitente foi mais vantajosa que a agitação suave e contínua pois proporcionou maior eficiência em remoção de DQO total $(49,4 \%$ e $30,4 \%$, respectivamente).Essa vantagem ocorreu devido à perda de biomassa nos ensaios de agitação contínua. Da mesma forma o aumento da intensidade de agitação diminuiu a eficiência do processo devido à maior perda de biomassa. 
Ao avaliar a influência da intensidade de agitação em reator ASBBR tratando esgoto sintético, Ratusznei et al. (2001) observaram que a velocidade de agitação afeta o tempo necessário para o sistema atingir a eficiência máxima em um ciclo de agitação. Concluíram que o tempo de ciclo poderia ser reduzido de 8 para 3 horas mantendo-se a eficiência máxima do processo, em remoção de DQO, aumentando o número de ciclos diários e com isto, otimizaria-se o processo.

Camargo et al. (2000) avaliaram um ASBBR com recirculação externa da fase aquosa no tratamento de água residuária sintética à base de glicose na concentração de $500 \mathrm{mg} / \mathrm{l}$, em termos de DQO. O reator foi operado com e sem recirculação. As velocidades superficiais testadas de recirculação foram de 0,030 a $0,18 \mathrm{~cm} / \mathrm{s}$. A utilização da recirculação ocasionou em um incremento no desempenho do reator, aumentando a eficiência de conversão de DQO total de 83\%, para a condição sem recirculação, para 95\%, para a condição com recirculação. Os autores relacionaram este incremento a um maior contato entre o substrato e a biomassa devido à diminuição dos efeitos de transferência de massa.

Rodrigues et al. (2003) pesquisando a influência da velocidade de rotação em um ASBR operado com impelidor tipo turbina com seis pás planas verticais nas freqüências de rotação de $0,25,50$ e $75 \mathrm{rpm}$ tratando 21 de esgoto sintético com concentração de aproximadamente $500 \mathrm{mg} / \mathrm{l}$. Para a rotação de $50 \mathrm{rpm}$ o sistema obteve eficiência de remoção de $80 \%$ e $88 \%$ para amostras não filtradas e filtradas, respectivamente. Nesta condição o sistema também apresentou boa retenção de sólidos evitando a ruptura dos grânulos.

Pinho et al. (2002) analisaram a influência da velocidade de agitação, utilizando diferentes freqüências de rotação $(500,700,900$ e $1100 \mathrm{rpm})$, no tratamento de efluentes parcialmente solúveis em um reator ASBBR. O substrato utilizado foi leite de soja com $\mathrm{C}_{\mathrm{AF}}$ de aproximadamente $1000 \mathrm{mg} / \mathrm{l}$, em termos de DQO, com tempo de ciclo de 8 horas. Os autores observaram que a concentração de substrato residual diminuiu com o aumento da rotação, melhorando as condições do efluente tratado. Além disso, a velocidade de conversão aumentou com o aumenta da frequiência de rotação de 500 para $900 \mathrm{rpm}$. 
Rodrigues et al. (2004) durante a operação deb um reator ASBR com agitação contínua e impelidor tipo turbina com seis pás planas verticais avaliaram duas estratégias de agitação. Na primeira a agitação foi mantida constante e igual a $50 \mathrm{rpm}$, e na segunda a agitação foi variável permanecendo uma hora a $75 \mathrm{rpm}$, duas horas a 50 rpm e meia hora a $25 \mathrm{rpm}$, em um ciclo de quatro horas. Nestes ensaios os autores obtiveram eficiência de remoção de DQO solúvel de $87 \%$ e $88 \%$ nas condições de agitação constante e variável, respectivamente. Contudo, diferenças mais significativas foram observadas para a avaliação da cinética de degradação da matéria orgânica sendo a condição de velocidade variável mais vantajosa.

Este projeto implementou uma inovação no sistema de agitação mecânica acrescentando o "draft tube" (DT) ao sistema de agitação. A agitação contendo "draft tube" visava direcionar o fluxo da mistura líquida no interior do reator implementando um comportamento hidrodinâmico semelhante ao comportamento de fluxo axial. Shaw (1982) recomendou que o diâmetro do DT tivesse entre 20 e $40 \%$ do diâmetro do tanque . O autor também aponta para dois critérios que devem ser levados em conta no projeto do DT. A velocidade mínima dentro do "draft tube" capaz de arrastar as partículas sólidas para a região anela, externa ao DT, e a velocidade mínima de suspensão dos sólidos na região anelar.

Jiricková \& Rieger (1995) estudando a suspensão de sólidos em vasos altos agitados contendo tubo interno, concluíram que o consumo de potência em reatores contendo tubo interno foi mais baixo que o consumo de potência em tanques padrão (diâmetro = altura). Os autores atribuíram essa vantagem energética ao fato de que somente uma parte do volume do vaso é utilizada para que o impelidor promova suspensão, enquanto que a outra parte, funciona como uma região de sedimentação pela gravidade. 


\subsubsection{Influência da estratégia de alimentação}

A estratégia de alimentação é um dos fatores que afetam o desempenho do reator ASBR assim como a agitação, a razão inicial das concentrações de substrato e biomassa (F/M) e a configuração geométrica do reator (ZAIAT et al., 2001). Em reatores operados em batelada ou batelada alimentada a estratégia de alimentação exerce forte influência, já que está relacionada com a razão $\mathrm{F} / \mathrm{M}$ aplicada e com a retenção de sólidos.

Um reator tem o regime de escoamento classificado como batelada quando o tempo de enchimento do mesmo é desprezível em relação ao tempo total de ciclo. A operação em batelada alimentada é caracterizada por um tempo de enchimento considerável em relação ao tempo total de ciclo. Este tipo de estratégia de alimentação pode ser utilizado para minimizar os efeitos do controle do metabolismo celular, prevenir a inibição por substrato ou precursores, minimizar a formação de produtos de metabolismos tóxicos, superar problemas de estabilidade em processos contínuos, adequar o processo às condições operacionais e estudar a cinética do processo.

Assim, quando se quer manter uma baixa concentração de um determinado substrato dentro do reator, opera-se o mesmo em batelada alimentada. A vazão de alimentação pode ser constante ou variar com o tempo, de acordo com o interesse do processo.

Segundo Angenent \& Dague (1995) o aumento do tempo de alimentação causaria uma diminuição da quantidade de ácidos voláteis totais, aumentando o desempenho do processo. Com o fornecimento do substrato em um tempo maior, haveria uma menor disponibilidade do mesmo para os microrganismos ocasionando um menor acúmulo de ácidos no interior do reator. Bagley \& Brodkorb (1999) sugeriram que maiores tempos de alimentação seriam benéficos para reatores ASBR, especialmente para substratos que acidificam rapidamente.

Rodrigues et al. (2003) ao operar um ASBR com biomassa granulada e agitação mecânica tratando esgoto sintético na concentração de $0,5 \mathrm{~g} / \mathrm{l}$, concluíram que a utilização de tempos de alimentação longos não influenciou o sistema. 
Ratusznei et al. (2003a) operando um ASBR com biomassa imobilizada em espuma de poliuretano, notaram a queda da eficiência em longos períodos de alimentação pois, parte da biomassa imobilizada ficava exposta ao ar até que o volume total do afluente alimentado fosse atingido.

Orra et al. (2004) avaliaram o efeito da estratégia de alimentação no desempenho de um ASBBR com recirculação da fase líquida no tratamento de esgoto doméstico sintético com concentração de $500 \mathrm{mg} / \mathrm{l}$, em termos de DQO. As estratégias de alimentação implementados foram de 6 min (operação em batelada), 60, 120, 240 e 360 min (operação em batelada alimentada). Foi detectada queda sensível da eficiência da conversão de DQO para amostras filtradas de 85 para $81 \%$ na transição da operação em batelada para batelada alimentada de 6 horas.

Borges et al. (2004) submeteram um ASBBR com agitação mecânica a diferentes tempos de alimentação no tratamento de esgoto doméstico sintético. O volume tratado por ciclo foi de 2,5 litros com tempo de ciclo de 8 horas e freqüência de agitação de $500 \mathrm{rpm}$. As estratégias de alimentação investigadas foram de $10 \mathrm{~min}, 120$, 240, 260 e 480 min Concluiu-se que para relações $t_{\mathrm{F}} / \mathrm{t}_{\mathrm{C}}$ menores que 0,5 o sistema atingiu eficiências de conversão de matéria orgânica para amostras filtradas e não filtradas superiores a 70 e $75 \%$, respectivamente. Em relações $t_{\mathrm{F}} / t_{\mathrm{C}}$ maiores que 0,5 observou-se queda na eficiência e formação de polímeros extracelulares.

Damasceno et al. (2006) investigaram a influência das estratégias de alimentação de 10,120 e 240 min sobre o desempenho de um ASBBR tratando soro de queijo. As COV aplicadas foram de 2, 4, 8 e 12 g/l.d, em termos de DQO, suplementando alcalinidade na razão de $50 \% \mathrm{NaHCO}_{3} / \mathrm{DQO}$. Os autores concluíram que a estratégia de alimentação de 120 min obteve melhores resultados em remoção de matéria orgânica filtrada para as COV aplicadas de 2 e 4 g/l.d, enquanto a estratégia de alimentação de 240 min obteve melhores resultados para as COV aplicadas de 8 e 12 g/l.d . Observaram também que as concentrações máximas de AVT e mínima de AB não são alteradas com a variação das estratégias de alimentação, porém são deslocadas ao longo do ciclo atingindo o máximo (para AVT) e o mínimo(para $\mathrm{AB}$ ) ao final do período de alimentação. 


\subsection{CONSIDERAÇÕES FINAIS}

Por se tratar de um efluente produzido de maneira intermitente, o tratamento em bateladas se mostra uma alternativa interessante devido à flexibilidade operacional do sistema.

Devido à distância entre os estudos realizados em escala de bancada e a aplicação do ASBR em escala real, muitos estudos ainda são necessários para esclarecer os fenômenos envolvidos nesse processo de digestão.

Assim, o estudo da influência da carga orgânica e do tempo de enchimento sobre o desempenho do reator anaeróbio em batelada seqüencial com agitação mecânica, contendo "draft tube", e biomassa granulada tratando soro de queijo, torna-se um ponto importante para o desenvolvimento do ASBR sob diferentes condições de operação. 


\section{MATERIAL E MÉTODOS}

\subsection{MATERIAL}

\subsubsection{Configuração do Reator Anaeróbio Operado em Batelada Seqüiencial}

\section{Etapa 1 - Operação em Batelada}

A Figura 4.1e a Figura 4.2 mostram o esquema do reator com agitação mecânica e operado em batelada seqüencial contendo lodo granulado e a fotografia do sistema, respectivamente. $\mathrm{O}$ reator foi constituído por um frasco cilíndrico de acrílico de $20 \mathrm{~cm}$ de diâmetro e $20 \mathrm{~cm}$ de altura, com capacidade total de 6 litros. A agitação foi implementada por um impelidor tipo hélice de $6 \mathrm{~cm}$, inserido em um tubo de PVC, o "draft tube" (DT), de 7,5 cm de diâmetro e 10,5 cm de altura. A Figura 4.3 apresenta o tubo interno e o impelidor utilizado em detalhe.

A alimentação e descarga foram realizadas por bombas tipo diafragma, marca Prominente, modelos $\beta$ e Concept, respectivamente. Um sistema de automação, composto por temporizadores, foi o responsável pelo acionamento/parada das bombas e do agitador, de modo a implementar as etapas da operação em batelada seqüencial: alimentação, reação, sedimentação e descarga.

Para manter a temperatura, o reator foi colocado numa câmara climatizada na qual a manutenção da temperatura foi realizada por um sistema composto de sensor, controlador, ventilador e resistência elétrica. 


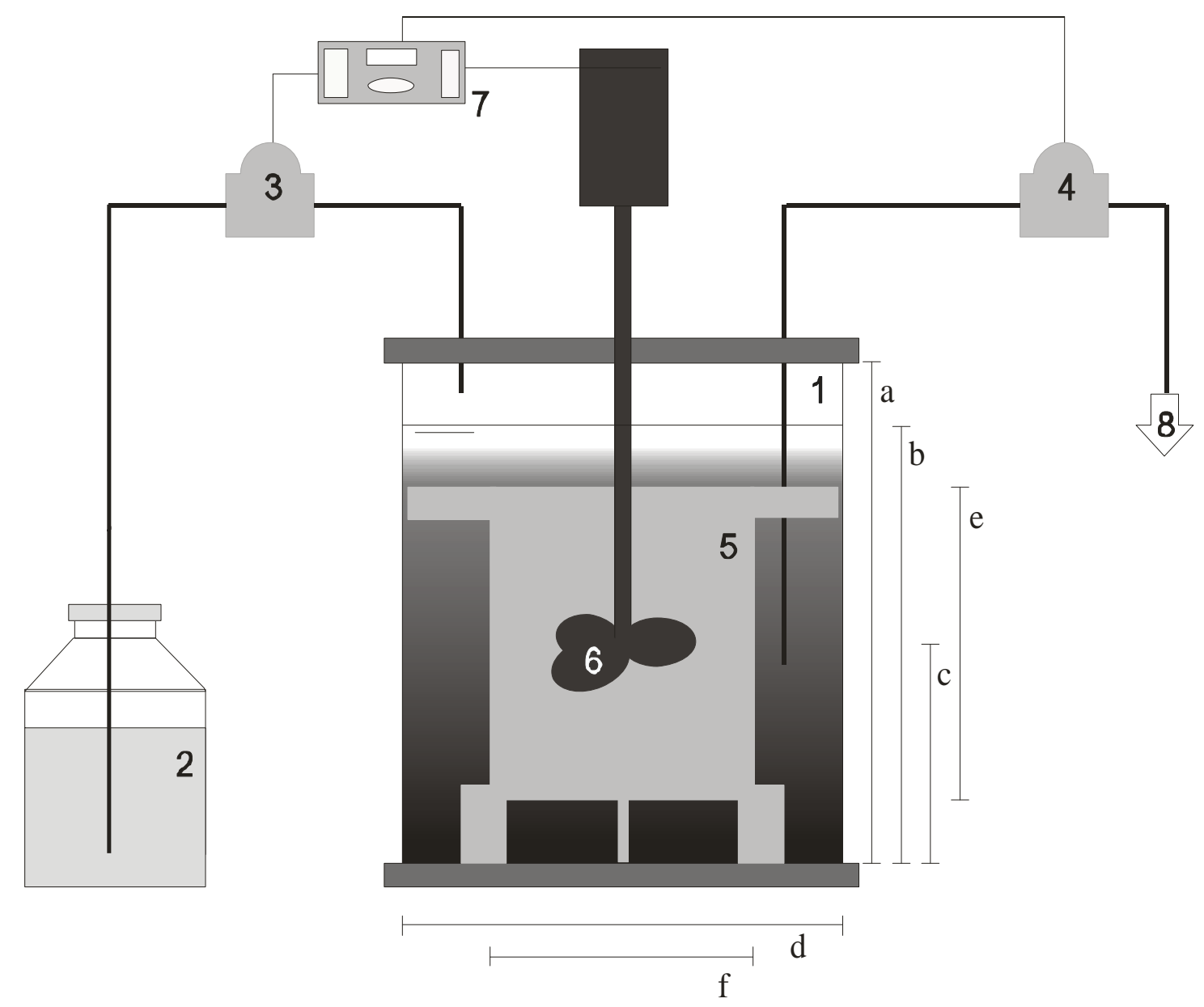

Figura 4.1 - Esquema do reator anaeróbio com agitação mecânica operado em batelada seqüencial

[1-Biorreator com capacidade de $6 L(a=20 \mathrm{~cm} ; b=16 \mathrm{~cm} ; c=8 \mathrm{~cm} ; d=20 \mathrm{~cm}) ; 2$ - Afluente; 3 - Bomba de alimentação; 4 - Bomba de descarga; 5 - "Draft Ttube” (e = 10,5 cm; $f=7,5 \mathrm{~cm}) ; 6$ - Sistema de agitação com impelidor tipo hélice; 7 Sistema de automação; 8 - Efluente]. 

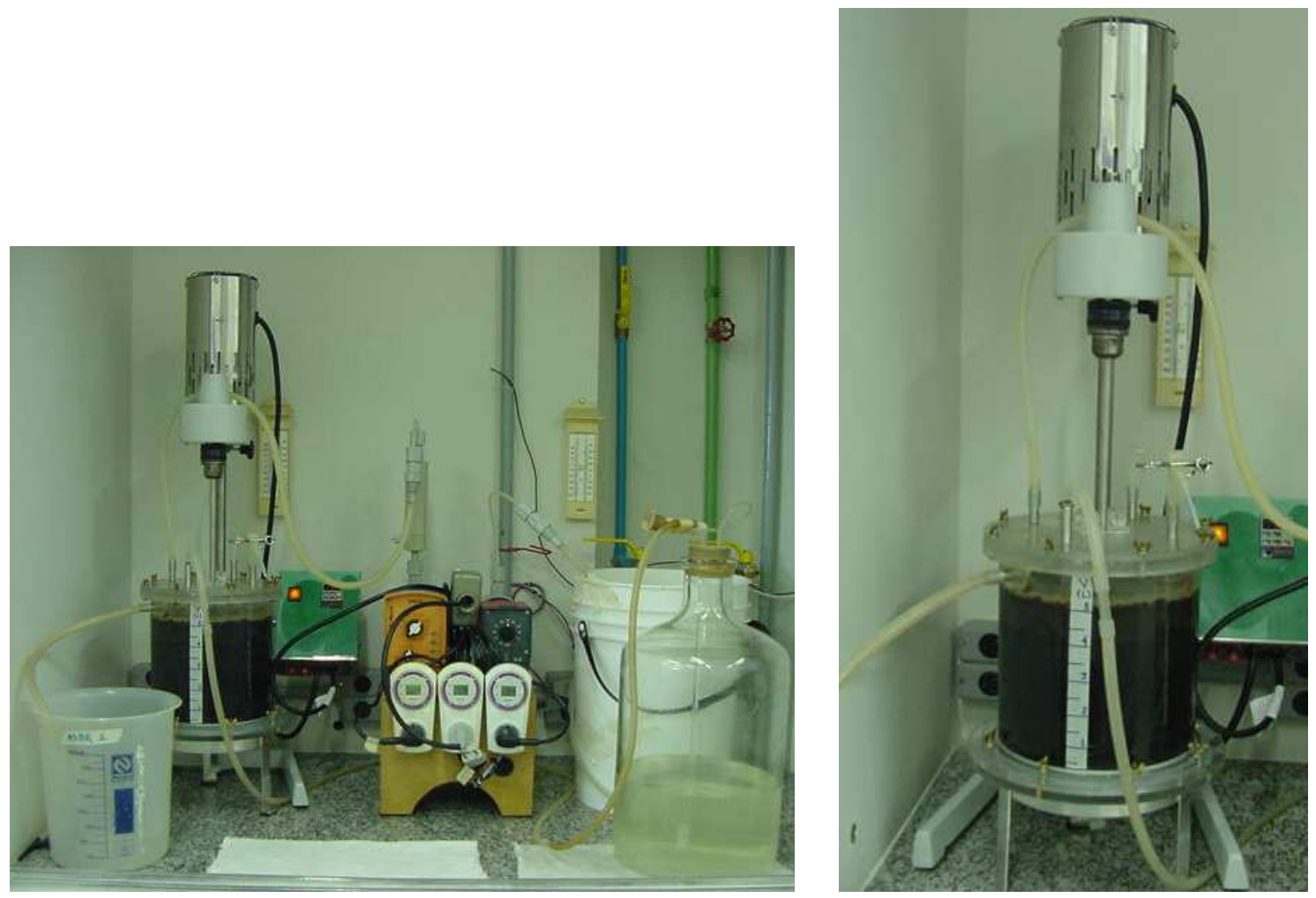

Figura 4.2: Fotografia do aparato experimental.
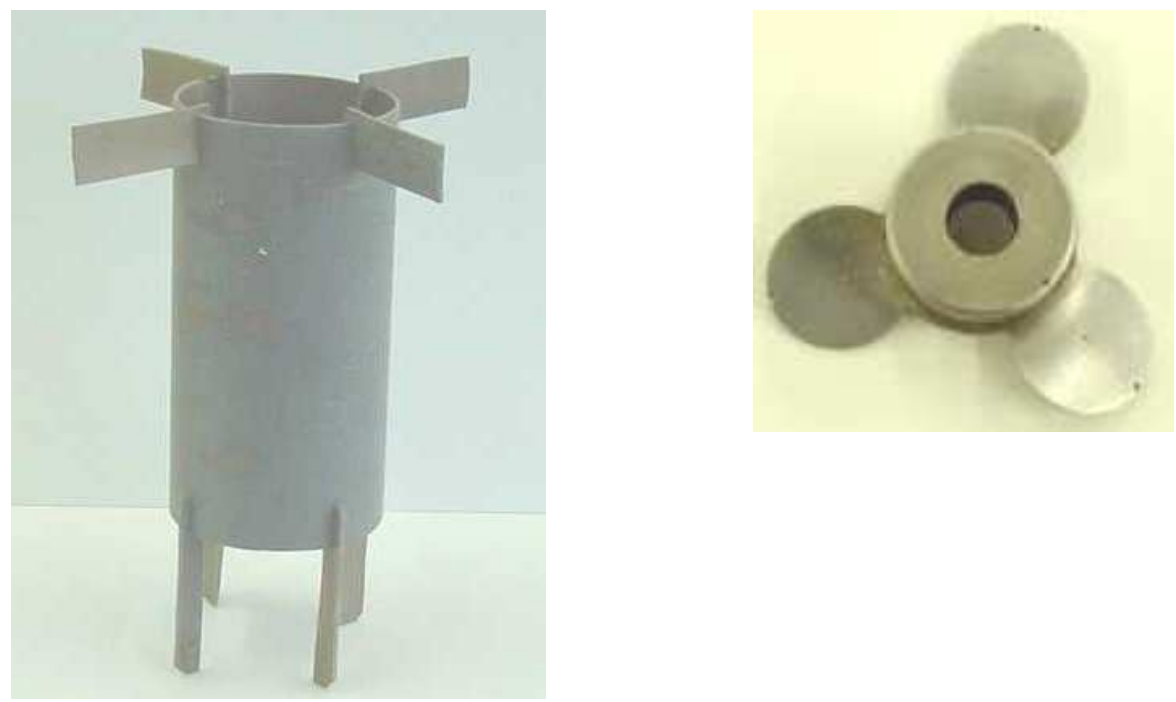

Figura 4.3 - Tubo de PVC (o "draft tube") que foi inserido no reator e o impelidor tipo hélice. 


\section{Etapa 2 - Operação em Batelada Alimentada}

Durante o ensaio BA-A $\left(\mathrm{C}_{\mathrm{AF}}\right.$ de $16000 \mathrm{mg} / \mathrm{l}$ e $\mathrm{V}_{\text {alim }}$ de 0,5 l) da operação em batelada alimentada grande parte da biomassa granular flotou, formando uma camada estagnada sobre o "draft tube". Essa camada além de dificultar a passagem do biogás para a fase gasosa, prejudicava o sistema de agitação, resultando em perda de biomassa e danos aos grânulos.

Para evitar o arraste de biomassa e viabilizar os ensaios em batelada alimentada mantendo a agitação do reator sem causar danos aos grânulos foi necessário desenvolver dispositivos que assegurassem a retenção da biomassa e a mistura entre as fases líquida e sólida.

\subsubsection{Desenvolvimento de dispositivos para assegurar a retenção da biomassa}

\subsubsection{ASBR Híbrido}

O primeiro dispositivo utilizado foi uma camada de biomassa imobilizada em espuma de poliuretano caracterizando configuração de reator híbrido. A camada de biomassa imobilizada foi inserida ao reator com a finalidade formar uma barreira física que impedisse a biomassa granular flotada de atingir a superfície líquida evitando assim prejudicar a agitação do reator. Nos ensaios BA-B $\left(\mathrm{C}_{\mathrm{AF}}\right.$ de $16000 \mathrm{mg} / \mathrm{l}$ e $\mathrm{V}_{\text {alim }}$ de 0,5 l) e BA-C $\left(\mathrm{C}_{\mathrm{AF}}\right.$ de $16000 \mathrm{mg} / \mathrm{l}$ e $\mathrm{V}_{\text {alim }}$ de 0,5 1) a espessura da camada de biomassa imobilizada foi de 4,0 cm, contudo no ensaio BA-C além da camada de biomassa imobilizada utilizou-se também uma camada protetora ao fundo do "draft tube". No ensaio BA-D ( $\mathrm{C}_{\mathrm{AF}}$ de $16000 \mathrm{mg} / \mathrm{l}$ e $\mathrm{V}_{\text {alim }}$ de 1,0 l) a espessura da camada de biomassa imobilizada foi reduzida para 1,0 cm devido aos problemas operacionais originados pela perda de carga no espaço anelar (externo ao "draft tube") do reator.

A Figura 4.4 apresenta o reator híbrido utilizado nos ensaios BA-B, BA-C e BAD. Destaca-se nessa figura a biomassa granular no fundo do reator e a camada de biomassa imobilizada sobre o "draft tube". 


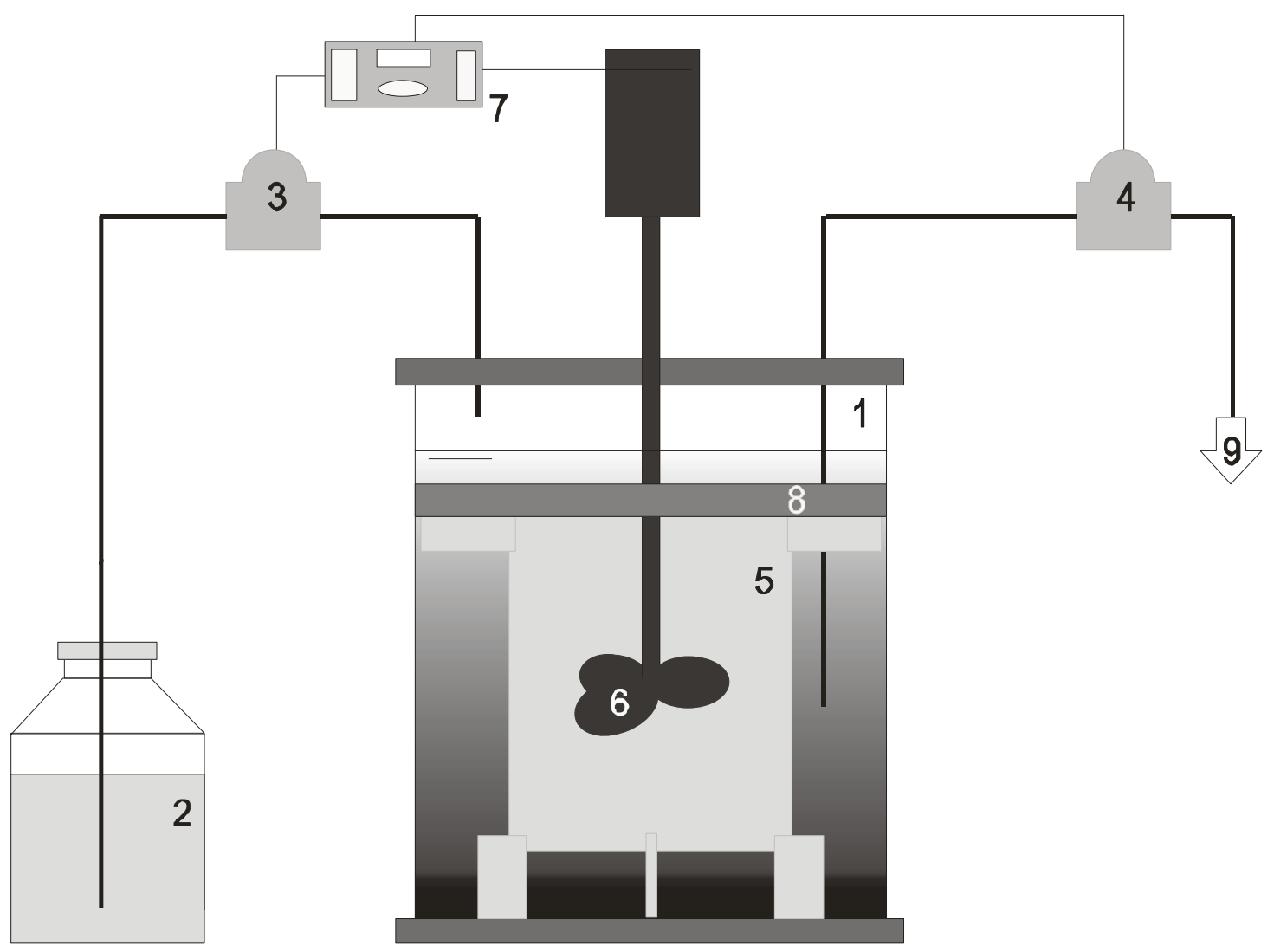

Figura 4.4 - Esquema do reator híbrido testado nos ensaios BA-B, BA-C e BA-D.

[1 - Biorreator com capacidade de 6; 2 - Afluente; 3 - Bomba de alimentação; 4 Bomba de descarga; 5 - "Draft Tube”; 6 - Sistema de agitação com impelidor tipo hélice; 7 Sistema de automação; 8-Camada de biomassa imobilizada; 9 - Efluente]. 


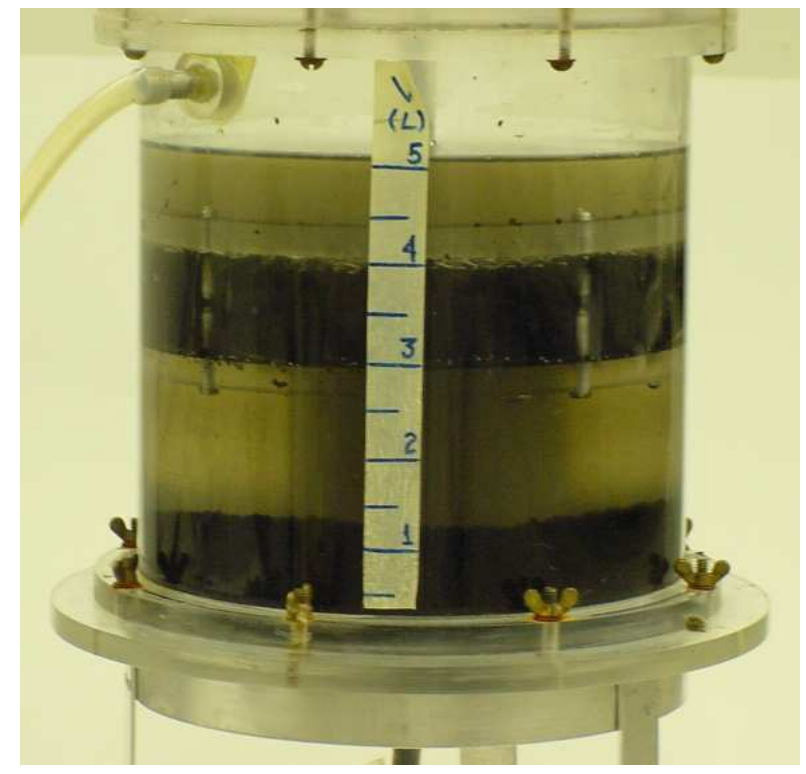

Figura 4.5 - Fotografia do reator híbrido testado nos ensaios BA-B, BA-C e BA-D.

A Figura 4.5 apresenta a fotografia do ASBR híbrido, na qual pode-se observar o "draft tube" ao centro do reator, a biomassa granulada ao fundo do reator e a camada de biomassa imobilizada próxima à superfície líquida.

\subsubsection{Dois Impelidores}

Após os testes com a configuração ASBR Híbrido, testou-se uma configuração mais simples, que consistiu apenas em acrescentar mais um impelidor ao sistema de agitação. Para se escolher o impelidor utilizado, realizaram-se testes qualitativos (visuais), de modo a se escolher o impelidor que além de manter a agitação obtida nos ensaios em batelada, nos quais a biomassa era suspensa, também pudesse agitar a porção de biomassa flotada, que ficava sobre o DT, impedindo a formação de uma camada estagnada que atrapalhasse o direcionamento do fluxo imposto pelo "draft tube".

Dessa forma escolheu-se acrescentar o impelidor pá-inclinada ao sistema de agitação a freqüência de 120 rpm. Essa configuração foi utilizada no ensaio BA-E. 
Devido à destruição dos grânulos, ocasionada pela elevada força de cisalhamento da pá-inclinada sobre os grânulos, decidiu-se substituir a pá-inclinada pela turbina inclinada.

Finalmente, com esta configuração foi possível operar o ASBR em batelada alimentada nas seguinte condições: $\mathrm{C}_{\mathrm{AF}}$ de $4000 \mathrm{mg} / \mathrm{l}$ e $\mathrm{V}_{\text {alim }}$ de 1,0 l para os tempos de enchimento de 360, 180 e 10 minutos (BA-F1 a BA-F3), $\mathrm{C}_{\mathrm{AF}}$ de $8000 \mathrm{mg} / \mathrm{l}$ e $\mathrm{V}_{\text {alim }}$ de 0,5 1 para os tempos de enchimento de 360, 180 e 10 minutos (BA-F4 a BA-F6). Para fins de comparação também foi realizado o ensaio BA-F7 $\left(\mathrm{C}_{\mathrm{AF}}\right.$ de $2000 \mathrm{mg} / \mathrm{l}, \mathrm{V}_{\text {alim }}$ de 2,0 1 e $\mathrm{T}_{\text {alim }}$ de $10 \mathrm{~min}$ ).

A Figura 4.6 apresenta os impelidores hélice e turbina inclinada utilizados nos ensaios BA-F1 a BA-F7 e a turbina inclinada em detalhe.

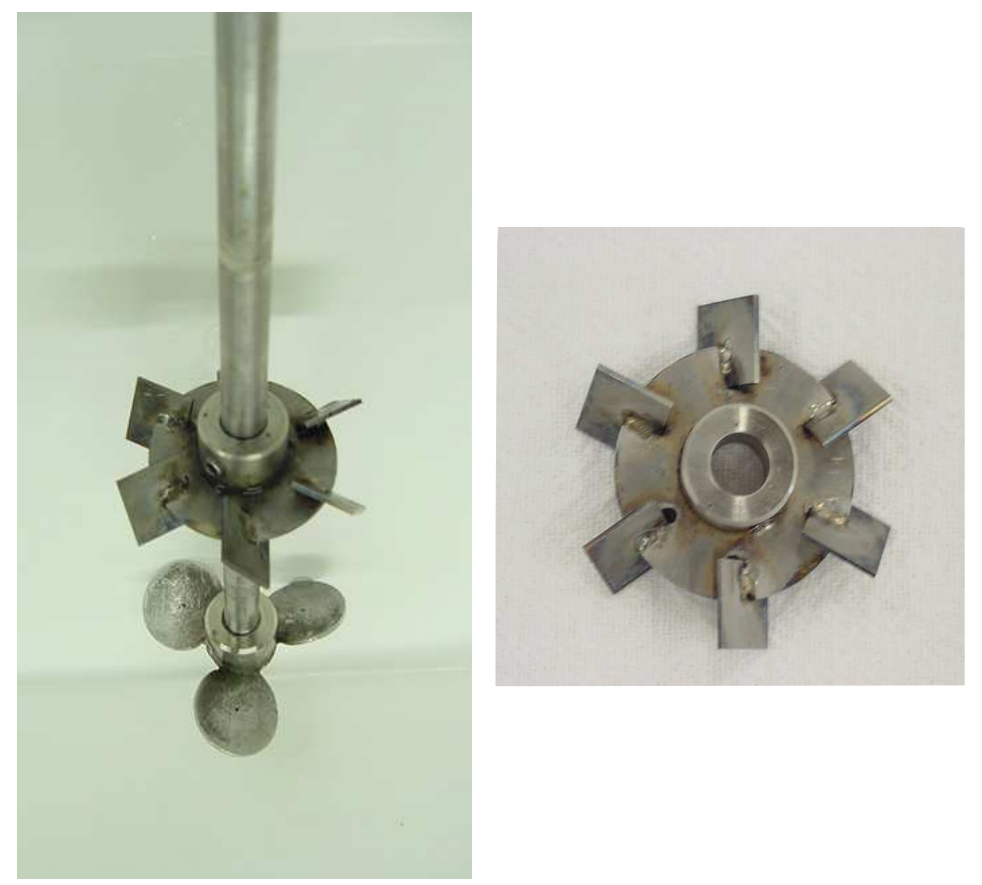

Figura 4.6 - Fotografia dos impelidores utilizados nos ensaios BA-F1 a BA-F7 e o impelidor tipo turbina inclinada em detalhe. 


\subsubsection{Inóculo}

O inóculo utilizado em todos os experimentos foi proveniente de reator anaeróbio de manta de lodo e escoamento ascendente (UASB), tratando água residuária de abatedouro de aves (Avícola Dacar), sediada em Tietê, SP.

\subsection{4 Água residuária}

\section{Etapa 1 - Operação em Batelada}

Durante a operação em batelada foi utilizado soro de queijo reconstituído a partir de soro desidratado (umidade de 3\%), cuja composição é apresentada na Tabela 4.1.

Tabela 4.1 - Composição do soro de queijo desidratado a ser utilizado nos experimentos

\begin{tabular}{cc}
\hline Composto & Composição (\%) \\
\hline Proteínas & 11 \\
Glicídios & 76 \\
Lipideos & 1 \\
\hline
\end{tabular}

\section{Etapa 2 - Operação em Batelada Alimentada}

Durante a operação em batelada alimentada visando suplementar metais traço, micro e macro nutrientes, foi utilizado o soro de queijo cuja composição está apresentada na Tabela 4.1 suplementado com uma solução salina cuja composição está apresentada na Tabela 4.2. Esta suplementação ao afluente foi realizada nos ensaios BA-A, BA-B, BA-C e BA-D durante a operação em batelada alimentada.

Para os ensaios BA-E e BA-F a suplementação de nutrientes e metais traços foi feita pela mistura do soro de queijo com o esgoto sintético a concentração de $400 \mathrm{mg} / \mathrm{l}$. 
Tabela 4.2 - Composição da solução salina adicionada ao soro de queijo para suplementar nutrientes e metais traço nos ensaios BA-A, BA-B, BA-C e BA-D da operação em batelada alimentada.

\begin{tabular}{cc}
\hline Composto & Concentração (mg/l) \\
\hline Uréia & 62,5 \\
$\mathrm{NiSO}_{4}$ & 0,5 \\
$\mathrm{FeSO}_{4}$ & 2,5 \\
$\mathrm{FeSO}_{3}$ & 0,25 \\
$\mathrm{CaCl}_{2}$ & 23,5 \\
$\mathrm{CoCl}_{2}$ & 0,04 \\
$\mathrm{SeO}_{2}$ & 0,035 \\
$\mathrm{KH}_{2} \mathrm{PO}_{4}$ & 42,5 \\
$\mathrm{KHPO}_{4}$ & 10,85 \\
$\mathrm{Na}_{2} \mathrm{HPO}_{4}$ & 16,7 \\
\hline
\end{tabular}

Fonte: Del Nery (1987)

\subsection{MÉTODOS}

\subsubsection{Análises Físico-Químicas}

As medidas de concentrações de matéria orgânica, nas formas não filtrada e filtrada, de sólidos (totais e em suspensão, não voláteis e voláteis), de ácidos voláteis totais, de alcalinidade (total, parcial, intermediária e a bicarbonato) foram realizadas segundo o Standard Methods for the Examination of Water and Wastewater (1995), considerando também o método proposto por Ripley et al. (1986) na determinação da alcalinidade. Os ácidos voláteis intermediários foram analisados por cromatografia em fase gasosa, utilizando Cromatógrafo HP 6890 com detector de ionização de chama. 


\subsubsection{Exames Microbiológicos}

O exame microbiológico do lodo anaeróbio foi realizada por microscopia óptica comum, por contraste de fases e por fluorescência, utilizando microscópio Olympus modelo $\mathrm{BH} 2$.

\subsubsection{Composição e Produção do Biogás}

A composição do biogás gerado pela degradação anaeróbia foi monitorada cromatografia em fase gasosa utilizando um Cromatógrafo HP 6890 com detector de condutividade térmica.

\subsection{PROCEDIMENTO EXPERIMENTAL}

\subsubsection{Operação do Reator em Batelada Seqüencial}

A operação do reator em batelada seqüencial foi realizada a temperatura constante de $30 \pm 1^{\circ} \mathrm{C}$, utilizando-se um ciclo de operação de 8 horas (ou $480 \mathrm{~min}$ ), ou seja, três ciclos por dia. O reator utilizado possuía um volume total de 6 litros e um volume de trabalho de 5 litros, constituído de lodo e água residuária.

Para a operação em batelada foram tratados 2 litros de água residuária por ciclo. A concentração inicial do afluente foi de $1.000 \mathrm{mg} / \mathrm{l}$ e foram realizados ensaios com concentrações de afluente de 2.000, 4.000 e 6.000 mg/l. Assim, a carga orgânica volumétrica aplicada foi de 1,2 a 7,2 g/l.d. O tempo de duração de cada ensaio foi de, aproximadamente, 25 dias.

Durante a operação em batelada alimentada manteve-se a COV aplicada constante, COV igual a 2,4 g/l.d, variando-se o volume de água residuária e a concentração do afluente. As concentrações dos afluentes foram de $4000 \mathrm{mg} / \mathrm{l}$ e 8000 $\mathrm{mg} / \mathrm{l}$ para volumes de 1 e 0,5 litro, respectivamente, tratados por ciclo. 
As estratégias de alimentação que foram implementadas estão contidas na Tabela 4.3, na qual se pode verificar a transição entre a operação em batelada e batelada alimentada seguida de batelada no intuito de minimizar o impacto causado pela carga do afluente, procurando, desta forma, uma operação mais eficiente e segura do ponto de vista operacional.

Tabela 4.3 - Estratégias de alimentação implementadas durante a realização dos ensaios em batelada e em batelada alimentada.

\begin{tabular}{cccc}
\hline Estratégia & $\begin{array}{c}\text { Período de } \\
\text { alimentação } \\
(\min )\end{array}$ & $\begin{array}{c}\text { Período de } \\
\text { reação } \\
(\text { min })\end{array}$ & $\begin{array}{c}\text { Período de } \\
\text { descarga } \\
(\mathrm{min})\end{array}$ \\
\hline $\begin{array}{c}\text { (1) Batelada } \\
\text { (2) Batelada Alimentada / }\end{array}$ & $0-10$ & $11-470$ & $471-480$ \\
Batelada & $0-180$ & $181-470$ & $471-480$ \\
(3) Batelada Alimentada / & & $361-470$ & $471-480$ \\
Batelada & $0-360$ & & \\
\hline
\end{tabular}

A concentração inicial do afluente foi de $1.000 \mathrm{mg} / \mathrm{l}$, sendo realizados os ensaios conforme descrito na Tabela 4.3. O tempo de duração de cada ensaio foi de, aproximadamente, 25 dias, ou seja, no total um período de 100 dias. Foram realizados ensaios com concentrações de afluente de 2.000, 4.000 e 6.000 mg/l para a operação em batelada. Assim, a carga orgânica volumétrica aplicada, nesta etapa, foi de 1,2 a 7,2 g/l.d. Os ensaios em batelada alimentada foram implementados com carga orgânica volumétrica aplicada constante de 2,4 g/l.d para concentrações de afluentes de 4000 e $8000 \mathrm{mg} / \mathrm{l}$ correspondendo a volumes, de efluente tratado por ciclo, de 1 litro e 0,5 litro, respectivamente. 
A suplementação de alcalinidade ao afluente na forma de bicarbonato de sódio $\left(\mathrm{NaHCO}_{3}\right)$ foi realizada considerando-se a relação entre $\mathrm{mgNaHCO}$ adicionado por $\mathrm{mg}$ de matéria orgânica em termos de DQO do afluente. Dessa forma, para cada concentração de soro de queijo estudada seguiu-se o procedimento adotado por Ratusznei et al. (2003), no qual a operação iniciou-se com a relação mássica $\mathrm{NaHCO}_{3} / \mathrm{DQO}$ no afluente igual a 1,0 sendo diminuída gradualmente para 0,25 conforme o sistema apresentava estabilidade no intuito de minimizar a quantidade de alcalinizante necessária conferindo um certo grau de segurança para não prejudicar o escopo principal do projeto que é a relação carga orgânica e tempo de enchimento.

Vale mencionar que a relação entre a concentração de soro de queijo em termos de mg/l e a concentração de matéria orgânica em termos de DQO foi experimentalmente determinado como 1:1.

\subsubsection{Monitoramento do Reator}

O monitoramento do reator foi feito por amostras do afluente e do efluente, medindo-se as concentrações de matéria orgânica (medida como demanda química de oxigênio - DQO), de alcalinidade parcial (AP), de alcalinidade intermediária (AI), de alcalinidade total (AT), de alcalinidade a bicarbonato (AB), de ácidos voláteis (AV), de sólidos totais (ST), de sólidos voláteis totais (SVT), de sólidos suspensos totais (SST) e de sólidos suspensos voláteis (SSV), além da medida de $\mathrm{pH}$ e do volume descarregado. A análise da composição do biogás gerado foi realizada 15 minutos antes do início da descarga retirando-se a amostra do "head-space" do reator, cuja saída de gás foi previamente conectada a um selo hídrico para garantir apenas a saída da corrente gasosa do reator. Estes parâmetros foram monitorados com uma frequiência de, pelo menos, duas ou três vezes por semana. 


\subsubsection{Perfil ao Longo do Ciclo de Operação}

Uma vez atingida a estabilidade nas diferentes condições experimentais foi medido o perfil ao longo do ciclo de operação de algumas das variáveis monitoradas. Estes perfis foram obtidos pela retirada de amostras ao longo das 8 horas de operação de um ciclo. As variáveis de interesse foram: concentrações de matéria orgânica na forma filtrada, de metano, de alcalinidade a bicarbonato e de ácidos voláteis totais e intermediários, além do pH. Desta forma, foi possível obter uma melhor compreensão das rotas de degradação ao longo de um ciclo, além da estimativa dos parâmetros cinéticos de degradação da matéria orgânica.

As amostras retiradas para obtenção do perfil anteriormente citado foram colhidas em intervalos de tempo ao longo do ciclo de 15 a $60 \mathrm{~min}$, conforme o tipo de variável a ser medida. $\mathrm{O}$ volume total retirado nas amostragens foi, no máximo, de $500 \mathrm{ml}$, ou seja, $10 \%$ do volume de meio contido no reator. Após cada operação, amostras do lodo foram retiradas do reator para análise de sólidos da biomassa presente no reator. 


\section{RESULTADOS E DISCUSSÃO}

\subsection{OPERAÇÃO DO REATOR EM BATELADA}

\subsubsection{Ensaios Preliminares}

Os ensaios realizados no período em que o reator foi alimentado com um afluente com concentração de $500 \mathrm{mg} / \mathrm{l}$ foram considerados ensaios preliminares. Esse período teve duração de 20 dias (60 ciclos) e consistiu de um período de adaptação e aprendizado para a realização das análises Físico-Químicas dos ensaios posteriores. Também serviu como período de adaptação para a biomassa. Os valores médios dos dados obtidos durante esses ensaios estão apresentados na Tabela 5.1 na qual $\mathrm{C}_{\mathrm{ST}}$ é a concentração da matéria orgânica para amostras não filtradas, $\mathrm{C}_{S S}$ é a concentração da matéria orgânica para amostras filtradas, $\varepsilon_{\mathrm{T}}$ é a eficiência de remoção para as amostras não filtradas, $\varepsilon_{S}$ é a eficiência de remoção para amostras filtradas. Os valores experimentais obtidos durante o monitoramento dos ensaios preliminares estão apresentados no anexo A. 
Tabela 5.1 - Valores médios das variáveis monitoradas no afluente e no efluente durante os ensaios preliminares.

\begin{tabular}{ccc}
\hline Parâmetro & Afluente & Efluente \\
\hline $\mathrm{C}_{\mathrm{ST}}(\mathrm{mg} / \mathrm{l})$ & $513,8 \pm 16,8^{(10)}$ & $90,4 \pm 60,2^{(11)}$ \\
$\varepsilon_{\mathrm{T}}(\%)$ & - & $82,4 \pm 11,7^{(11)}$ \\
$\mathrm{C}_{\mathrm{SS}}(\mathrm{mg} / \mathrm{l})$ & - & $26,9 \pm 25,7^{(11)}$ \\
$\varepsilon_{\mathrm{S}}(\%)$ & - & $94,8 \pm 2,9^{(11)}$ \\
$\mathrm{AVT}(\mathrm{mgHAc} / \mathrm{l})$ & $49,5 \pm 21,05^{(4)}$ & $28,0 \pm 11,4^{(11)}$ \\
$\mathrm{AB}(\mathrm{mgCaCO} / \mathrm{l})$ & $149,0 \pm 110,40^{(4)}$ & $335,4 \pm 61,9^{(11)}$ \\
$\mathrm{AI} / \mathrm{AP}$ & $0,4 \pm 0,05^{(4)}$ & $0,3 \pm 0,06^{(11)}$ \\
$\mathrm{pH}$ & $8,2 \pm 0,45^{(4)}$ & $7,27 \pm 0,23^{(11)}$ \\
$\mathrm{Volume}(\mathrm{l})$ & $2,08 \pm 0,02^{(10)}$ & $2,08 \pm 0,02^{(10)}$ \\
$\mathrm{ST}(\mathrm{mg} / \mathrm{l})$ & 1070 e $1150^{(\mathrm{obs})}$ & 526 e $568^{(\mathrm{obs})}$ \\
$\mathrm{SVT}(\mathrm{mg} / \mathrm{l})$ & 872 e $972^{(\mathrm{obs})}$ & 254 e $278^{(\mathrm{obs})}$ \\
$\mathrm{SST}(\mathrm{mg} / \mathrm{l})$ & 14 e $22^{(\mathrm{obs})}$ & 0 e $32^{(\text {obs })}$ \\
$\mathrm{SSV}(\mathrm{mg} / \mathrm{l})$ & 4 e $22^{(\mathrm{obs})}$ & 0 e $32^{(\text {obs })}$ \\
\hline
\end{tabular}

*Entre parênteses o número de amostras consideradas no cálculo da média.

Obs: Valores mínimo e máximo das variáveis monitoradas.

\subsubsection{Operação em Batelada $\left(\mathrm{COV}=1,2\right.$ g/l.d. $\left.; \mathrm{C}_{\mathrm{AF}}=1000 \mathrm{mg} / \mathrm{l}\right)$}

Após os ensaios preliminares foi iniciado o ensaio 1 (operação em batelada com concentração afluente $\mathrm{C}_{\mathrm{AF}}=1000 \mathrm{mg} / \mathrm{l}$ ) e foi inserido um tubo interno, o "draft tube", com o objetivo de otimizar a agitação - operando o reator em batelada com o leito de lodo expandido - e proteger a biomassa evitando o contato entre a biomassa e o impelidor. A freqüência do agitador foi aumentada para $160 \mathrm{rpm}$. Iniciou-se este ensaio operando-se o reator na condição I (100\% de suplementação de alcalinidade). Esta condição foi mantida durante cinco dias após os quais o reator passou a ser operado na condição II (50\% de suplementação de alcalinidade). Os valores experimentais obtidos durante o monitoramento do ensaio 1 estão apresentados no anexo B. 


\section{Monitoramento do reator}

Os valores médios das variáveis monitoradas no afluente e no efluente durante este ensaio estão apresentados na Tabela 5.2. e nas Figuras 5.1 a 5.4 nas quais $\mathrm{C}_{\mathrm{ST}}$ é a concentração da matéria orgânica para amostras não filtradas, $\mathrm{C}_{\mathrm{SS}}$ é a concentração da matéria orgânica para amostras filtradas, $\varepsilon_{\mathrm{T}}$ é a eficiência de remoção para as amostras não filtradas, $\varepsilon_{S}$ é a eficiência de remoção para amostras filtradas. Este ensaio foi realizado durante 25 dias (75 ciclos), a condição I foi mantida durante 5 dias (15 ciclos) e a condição II foi mantida durante 20 dias (60 ciclos).

Tabela 5.2 - Valores médios das variáveis monitoradas no ensaio em batelada para $\mathrm{COV}=1,2$ g/l.d.

\begin{tabular}{ccc}
\hline Parâmetro & Afluente & Efluente \\
\hline $\mathrm{C}_{\mathrm{ST}}(\mathrm{mg} / \mathrm{l})$ & $1000,8 \pm 17,5^{(14)}$ & $98,3 \pm 85,5^{(17)}$ \\
$\varepsilon_{\mathrm{T}}(\%)$ & - & $90,2 \pm 8,5^{(17)}$ \\
$\mathrm{C}_{\mathrm{SS}}(\mathrm{mg} / \mathrm{l})$ & - & $41,5 \pm 24,4^{(17)}$ \\
$\varepsilon_{\mathrm{S}}(\%)$ & - & $95,9 \pm 2,4^{(17)}$ \\
$\mathrm{AVT}(\mathrm{mgHAc} / \mathrm{l})$ & $52,0 \pm 15,93^{(13)}$ & $24,0 \pm 10,2^{(12)}$ \\
$\mathrm{AB}(\mathrm{mgCaCO} 3 / \mathrm{l})$ & $204,1 \pm 107,18^{(13)}$ & $347,9 \pm 136,9^{(12)}$ \\
$\mathrm{AI} / \mathrm{AP}$ & $0,30 \pm 0,14^{(13)}$ & $0,46 \pm 0,31^{(12)}$ \\
$\mathrm{pH}$ & $8,0 \pm 0,50^{(13)}$ & $6,80 \pm 0,24^{(12)}$ \\
$\mathrm{Volume}(\mathrm{l})$ & $1,99 \pm 0,04^{(15)}$ & $1,99 \pm 0,04^{(15)}$ \\
$\mathrm{ST}(\mathrm{mg} / \mathrm{l})$ & $1528 \pm 195^{(5)}$ & $675 \pm 104^{(5)}$ \\
$\mathrm{SVT}(\mathrm{mg} / \mathrm{l})$ & $1106 \pm 108^{(5)}$ & $267 \pm 49^{(5)}$ \\
$\mathrm{SST}(\mathrm{mg} / \mathrm{l})$ & $21 \pm 8^{(4)}$ & $18 \pm 18^{(5)}$ \\
$\mathrm{SSV}(\mathrm{mg} / \mathrm{l})$ & $18 \pm 7^{(4)}$ & $16 \pm 14^{(5)}$ \\
\hline
\end{tabular}

*Entre parênteses o número de amostras considerado no cálculo da média 
Como se pode observar na Tabela 5.2 e nas Figuras 5.1 a 5.4 o reator apresentou elevada eficiência em remoção da matéria orgânica, em termos de DQO filtrada $(95,9 \pm$ $2,4 \%)$. A baixa concentração de $\operatorname{AVT}(24,0 \pm 10,2 \mathrm{mgHAc} / \mathrm{l})$, de $\mathrm{AB}(347,9 \pm$ $\left.136,9 \mathrm{mgCaCO}_{3} / \mathrm{l}\right)$ e o $\mathrm{pH}(6,8 \pm 0,24)$ no efluente mostram que a operação foi mantida estável durante todo o ensaio.

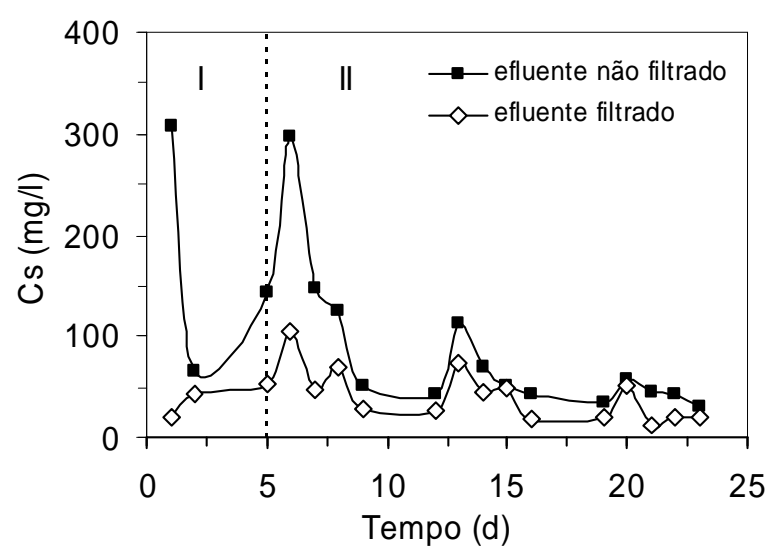

Figura 5.1 - Concentração da matéria orgânica, em termos de DQO, de amostras do efluente filtradas e não filtradas durante a operação do reator em batelada, nas condições I $\left(\mathrm{NaHCO}_{3} / \mathrm{DQO}=1,0\right)$ e II $\left(\mathrm{NaHCO}_{3} / \mathrm{DQO}=0,5\right)$, para COV $=1,2 \mathrm{~g} / \mathrm{l} . \mathrm{d}$.

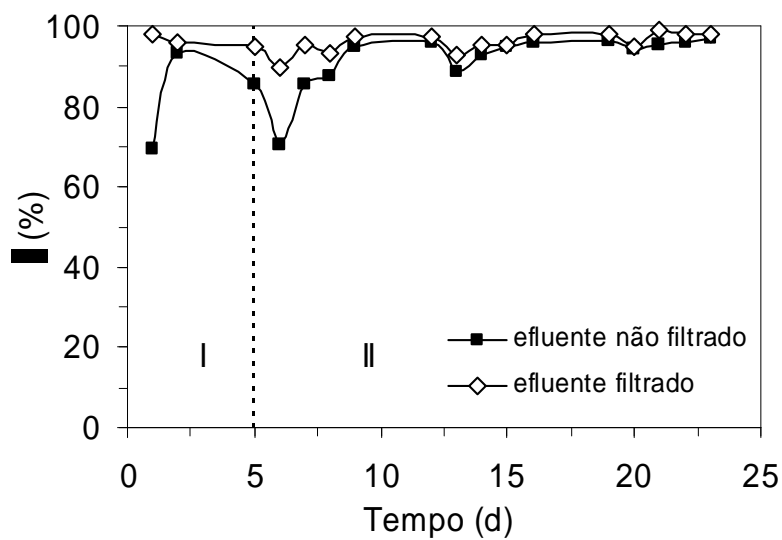

Figura 5.2 - Eficiência de remoção da matéria orgânica, em termos de DQO, de amostras do efluente filtradas e não filtradas durante a operação do reator em batelada, nas condições I $\left(\mathrm{NaHCO}_{3} / \mathrm{DQO}=1,0\right)$ e II $\left(\mathrm{NaHCO}_{3} / \mathrm{DQO}=0,5\right)$, para $\mathrm{COV}=1,2 \mathrm{~g} / \mathrm{l} . \mathrm{d}$. 


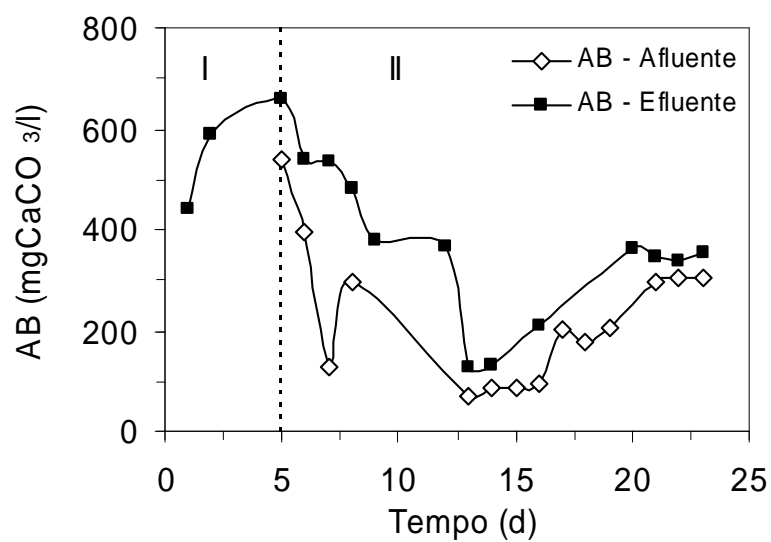

Figura 5.3 - Alcalinidade a Bicarbonato (AB) afluente e efluente durante a operação do reator em batelada nas condições I $\left(\mathrm{NaHCO}_{3} / \mathrm{DQO}=1,0\right)$ e II $\left(\mathrm{NaHCO}_{3} / \mathrm{DQO}=0,5\right)$, para $\mathrm{COV}=1,2$ g/l.d.

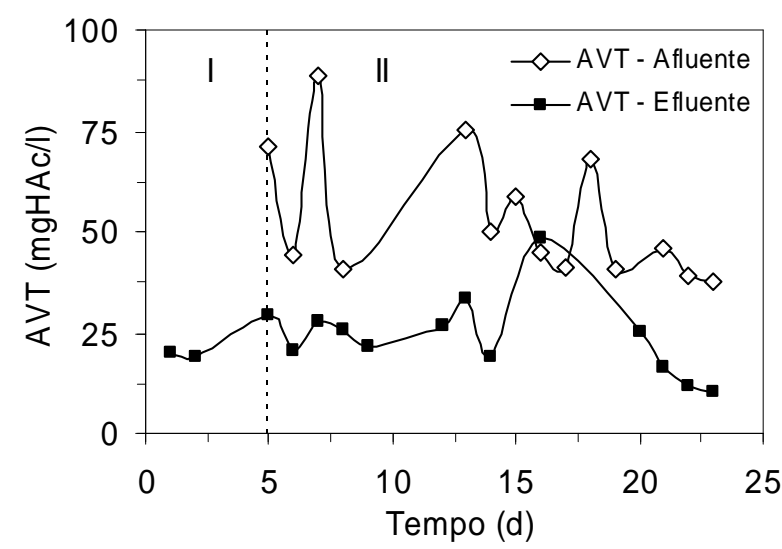

Figura 5.4 - Ácidos Voláteis Totais (AVT) afluente e efluente durante a operação do reator em batelada nas condições $\mathrm{I}\left(\mathrm{NaHCO}_{3} / \mathrm{DQO}=1,0\right)$ e II $\left(\mathrm{NaHCO}_{3} / \mathrm{DQO}=0,5\right)$, para $\mathrm{COV}=1,2$ g/l.d.

Observou-se neste ensaio a flotação de uma pequena porção da biomassa provavelmente devido à adsorção do biogás ao grânulo. Observou-se também o surgimento de material particulado suspenso de provável origem microbiológica. 


\section{Perfil de Conversão ao longo do ciclo}

Os perfis de conversão ao longo do ciclo foram realizados na condição II, $\mathrm{C}_{\mathrm{AF}}=$ $1000 \mathrm{mg} / \mathrm{l}$ e 0,5 da relação AB/DQO. Os perfis de conversão de matéria orgânica solúvel $\mathrm{C}_{\mathrm{ss}}(\mathrm{mg} / \mathrm{l}), \mathrm{AB}\left(\mathrm{mgCaCO}_{3} / \mathrm{l}\right), \mathrm{AVT}(\mathrm{mgHAc} / \mathrm{l})$ e $\mathrm{AVI}$ foram realizados nos ciclos 37 e 40, enquanto os perfis de concentração e composição do biogás foram realizados nos ciclos 70 e 73 .

A Figura 5.5 mostra que a conversão da matéria orgânica solúvel, em termos de DQO, neste ensaio foi muito rápida atingindo eficiência próxima a $100 \%$ e estabilidade após 2 horas de ciclo.

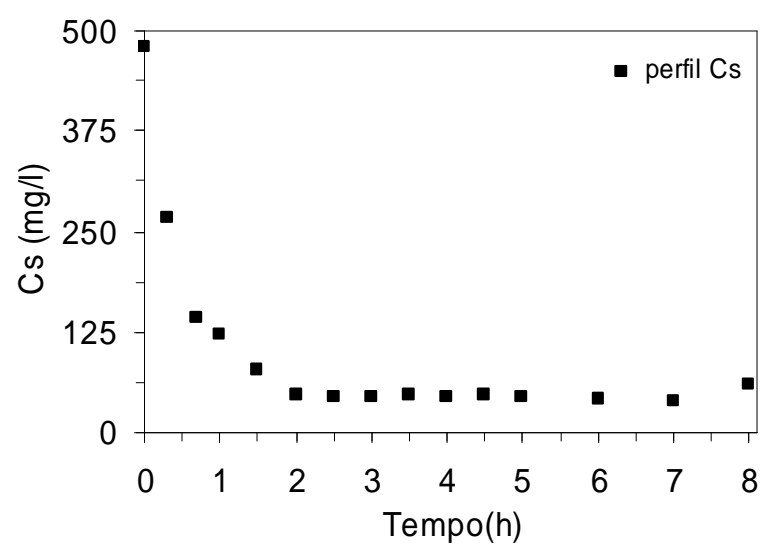

Figura 5.5 - Perfil de concentração da matéria orgânica ao longo do ciclo, em termos de DQO, de amostras filtradas, durante a operação do reator em batelada, para COV =1,2 g/l.d . 

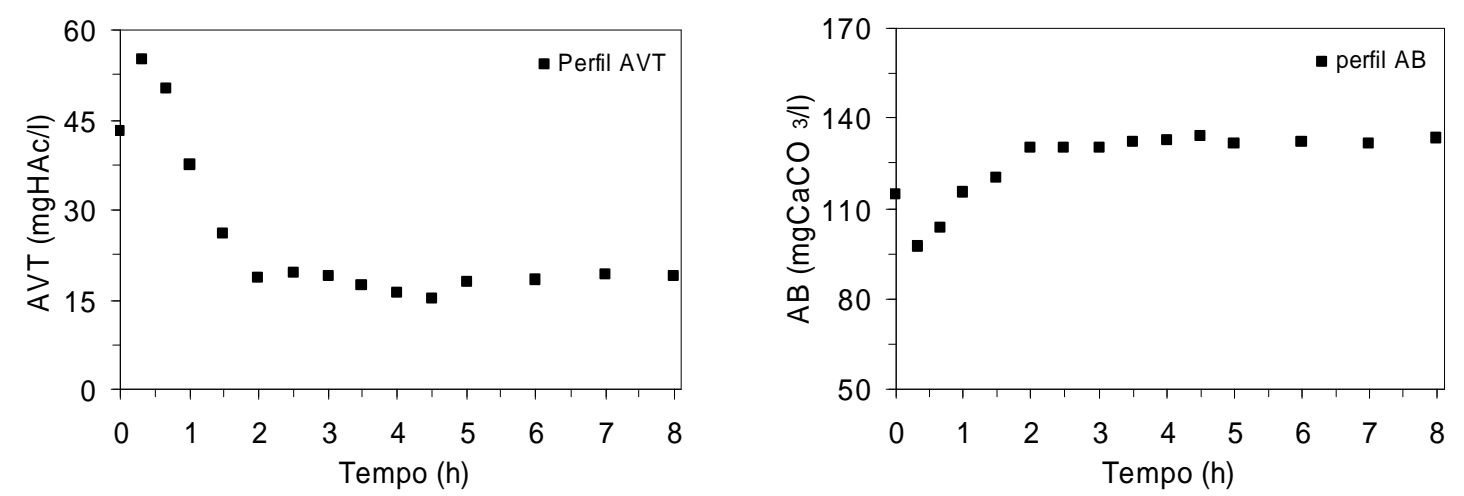

Figura 5.6 - Perfil de Ácidos Voláteis Totais (AVT) e Alcalinidade a Bicarbonato (AB) ao longo do ciclo, durante a operação do reator em batelada, para COV =1,2 g/l.d .

Observa-se na Figura 5.6 que os picos de AVT e AB foram pouco acentuados e que a recuperação do reator em relação a estes picos também foi rápida, alcançando estabilidade após 2 horas de ciclo, o que significou pouca alteração do $\mathrm{pH}$ durante o ciclo conforme se observa na Figura 5.7.

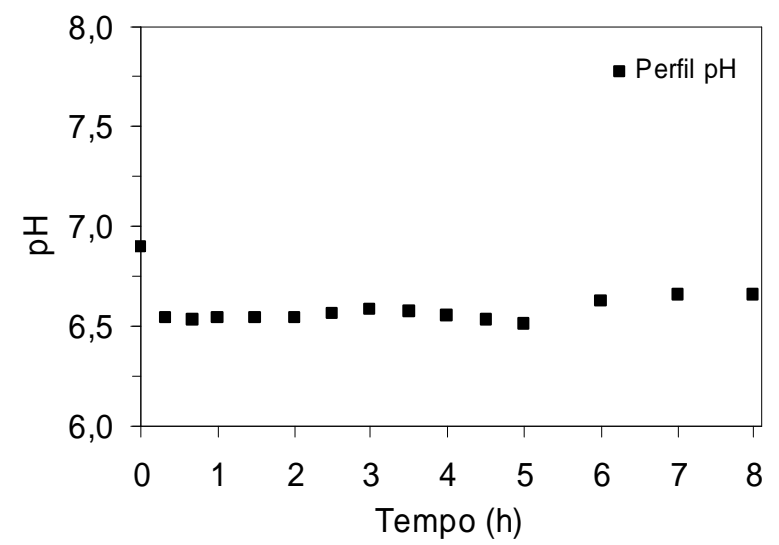

Figura 5.7 - Perfil de $\mathrm{pH}$ ao longo do ciclo durante a operação do reator em batelada, para COV

$$
=1,2 \mathrm{~g} / \mathrm{l} \cdot \mathrm{d} \text {. }
$$



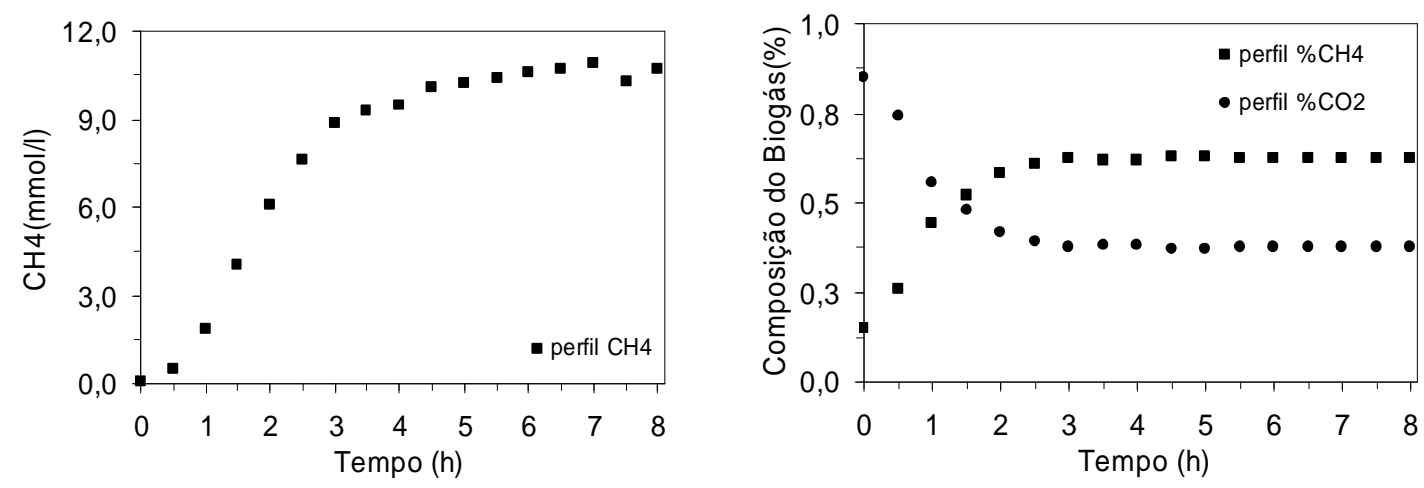

Figura 5.8 - Perfil de Concentração e Composição do Biogás ao longo do ciclo durante a operação do reator em batelada, para $\mathrm{COV}=1,2 \mathrm{~g} / \mathrm{l} . \mathrm{d}$.

Observa-se na Figura 5.8 que a concentração de metano no "head space" do reator foi elevada e atingiu aproximadamente $10 \mathrm{mmol} / \mathrm{l}$. A composição do biogás permaneceu constante após 2 horas de ciclo com 60\% de metano $\left(\mathrm{CH}_{4}\right)$ e $40 \%$ de dióxido de carbono $\left(\mathrm{CO}_{2}\right)$.

A Tabela 5.3 mostra que os ácidos detectados em maiores concentrações nas análises de AVI foram os ácidos propiônico e butírico. Dessa forma, em termos de concentração os ácidos voláteis intermediários mais relevantes para o processo foram os ácidos propiônico e butírico. A observação dessa tabela pode sugerir que nessa condição praticamente todo o ácido acético produzido era consumido antes de se poder detectar qualquer acúmulo.

Tabela 5.3 - Perfil de Ácidos Voláteis Intermediários (AVI) ao longo do ciclo, durante a operação do reator em batelada, para $\mathrm{COV}=1,2 \mathrm{~g} / \mathrm{l} . \mathrm{d}$.

\begin{tabular}{cccccc}
\hline \multicolumn{6}{c}{ AVI (mmol/l) } \\
\hline tempo (h) & Acético & Propiônico & Iso-Butírico & Butírico & Iso-Valérico \\
\hline 0 & 0,0 & 1,7 & 0,0 & 0,0 & 0,0 \\
0,33 & 7,9 & 9,2 & 3,8 & 11,0 & 1,0 \\
0,67 & 0,0 & 13,5 & 4,5 & 16,0 & 2,6 \\
1 & 0,0 & 11,5 & 5,4 & 11,0 & 3,1 \\
1,5 & 0,0 & 6,4 & 5,2 & 5,2 & 2,5 \\
2 & 0,0 & 1,3 & 1,5 & 0,9 & 0,7 \\
2,5 & 0,0 & 0,0 & 0,0 & 0,0 & 0,0 \\
3 & 0,0 & 0,0 & 0,0 & 0,0 & 0,0 \\
\hline
\end{tabular}




\section{Análise de Sólidos do Lodo}

Após a realização dos perfis de concentração ao longo do ciclo, para a Operação em Batelada com $\mathrm{COV}=1,2 \mathrm{~g} / \mathrm{l} . \mathrm{d}$, retirou-se uma amostra para a análise do lodo presente no reator durante os ensaios. Dessa análise foi possível obter a relação mássica SVT/ST que serve de indicação da quantidade de microrganismos presentes na biomassa. Dessa forma obteve-se que fração mássica (SVT/ST) foi de 85,8\% para este ensaio.

\subsubsection{Operação em Batelada $\left(\mathrm{COV}=2,4 \mathrm{~g} / \mathrm{l.d} . ; \mathrm{C}_{\mathrm{AF}}=2000 \mathrm{mg} / \mathrm{l}\right)$}

Encerrado o ensaio 1 iniciou-se o ensaio 2 (operação em batelada com concentração afluente $\mathrm{C}_{\mathrm{AF}}=2000 \mathrm{mg} / \mathrm{l}$ ) operando-se o reator na condição I (relação $\mathrm{AB} / \mathrm{DQO}=1$ ). Esta condição foi mantida durante cinco dias após os quais passou-se a operar o reator na condição II (relação $\mathrm{AB} / \mathrm{DQO}=0,5$ ) a qual também foi mantida por cinco dias, quando enfim deu-se início à operação do reator na condição III (relação $\mathrm{AB} / \mathrm{DQO}=0,25)$. Os valores experimentais obtidos durante o monitoramento do ensaio 2 estão apresentados no anexo $\mathrm{C}$.

\section{Monitoramento do reator}

Os valores médios das variáveis monitoradas no afluente e no efluente durante esta etapa, na condição III, estão apresentados na Tabela 5.4e nas Figuras 5.9 a 5.12, nas quais $\mathrm{C}_{\mathrm{ST}}$ é a concentração da matéria orgânica para amostras não filtradas, $\mathrm{C}_{S S}$ é a concentração da matéria orgânica para amostras filtradas, $\varepsilon_{\mathrm{T}}$ é a eficiência de remoção para as amostras não filtradas, $\varepsilon_{S}$ é a eficiência de remoção para amostras filtradas. Este ensaio durou 25 dias (75 ciclos), a condição I foi mantida durante 5 dias (15 ciclos), a condição II também durante 5 dias (15 ciclos) e a condição III foi mantida durante 15 dias (45 ciclos). 
Tabela 5.4 - Valores médios das variáveis monitoradas no ensaio em batelada para COV=2,4 g/l.d.

\begin{tabular}{ccc}
\hline Parâmetro & Afluente & Efluente \\
\hline $\mathrm{C}_{\mathrm{ST}}(\mathrm{mg} / \mathrm{l})$ & $2009,5 \pm 61,7^{(16)}$ & $89,7 \pm 42,9^{(16)}$ \\
$\varepsilon_{\mathrm{T}}(\%)$ & - & $95,7 \pm 2,2^{(16)}$ \\
$\mathrm{C}_{\mathrm{SS}}(\mathrm{mg} / \mathrm{l})$ & - & $22,5 \pm 8,5^{(16)}$ \\
$\varepsilon_{\mathrm{S}}(\%)$ & - & $98,9 \pm 0,4^{(16)}$ \\
$\mathrm{AVT}(\mathrm{mgHAc} / \mathrm{l})$ & $62,4 \pm 4,88^{(8)}$ & $18,1 \pm 2,8^{(8)}$ \\
$\mathrm{AB}(\mathrm{mgCaCO})^{(1)}$ & $312,7 \pm 13,52^{(8)}$ & $403,7 \pm 78,4^{(8)}$ \\
$\mathrm{AI} / \mathrm{AP}$ & $0,33 \pm 0,02^{(8)}$ & $0,52 \pm 0,05^{(8)}$ \\
$\mathrm{pH}$ & $8,3 \pm 0,13^{(8)}$ & $6,45 \pm 0,09^{(8)}$ \\
$\mathrm{Volume}(\mathrm{l})$ & $2,03 \pm 0,01^{(13)}$ & $2,03 \pm 0,01^{(13)}$ \\
$\mathrm{ST}(\mathrm{mg} / \mathrm{l})$ & $2295 \pm 909^{(6)}$ & $1175 \pm 611^{(7)}$ \\
$\mathrm{SVT}(\mathrm{mg} / \mathrm{l})$ & $1703 \pm 750^{(6)}$ & $638 \pm 591^{(7)}$ \\
$\mathrm{SST}(\mathrm{mg} / \mathrm{l})$ & $35 \pm 17^{(6)}$ & $55 \pm 19^{(7)}$ \\
$\mathrm{SSV}(\mathrm{mg} / \mathrm{l})$ & $30 \pm 11^{(6)}$ & $45 \pm 19^{(7)}$ \\
\hline
\end{tabular}

*Entre parênteses o número de amostras consideradas no cálculo da média

Como se pode observar na Tabela 5.4e nas Figuras 5.9 a 5.12, o reator apresentou elevada eficiência em remoção de DQO filtrada $(98,9 \pm 0,4 \%)$. A baixa concentração de AVT (18,1 \pm 2,8 mgHAc/l), a concentração de AB (403,7 \pm $78,4 \mathrm{mgCaCO} 3 / \mathrm{l})$ e o $\mathrm{pH}(6,45 \pm 0,09)$ no efluente mostram que a operação foi mantida estável durante todo o ensaio.

De maneira semelhante ao ensaio anterior observou-se neste ensaio a flotação de uma pequena porção da biomassa provavelmente devido à adsorção do biogás ao grânulo. Observou-se também o aumento da quantidade de material particulado suspenso, de provável origem microbiológica e a mudança da coloração dos grânulos que ficaram com aspecto acinzentado. 


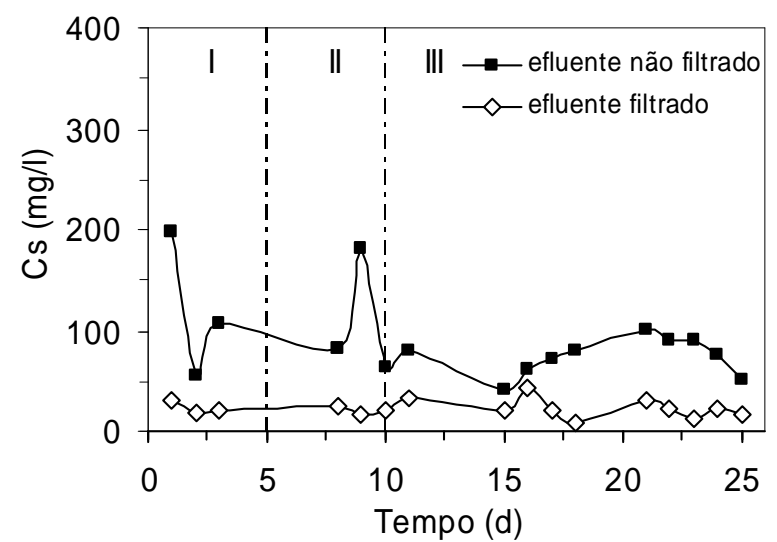

Figura 5.9 - Concentração da matéria orgânica, em termos de DQO, de amostras do efluente filtradas e não filtradas durante a operação do reator em batelada nas condições I $\left(\mathrm{NaHCO}_{3} / \mathrm{DQO}=1,0\right), \mathrm{II}\left(\mathrm{NaHCO}_{3} / \mathrm{DQO}=0,5\right)$ e III $\left(\mathrm{NaHCO}_{3} / \mathrm{DQO}=0,25\right)$, para COV = 2,4 g/l.d.

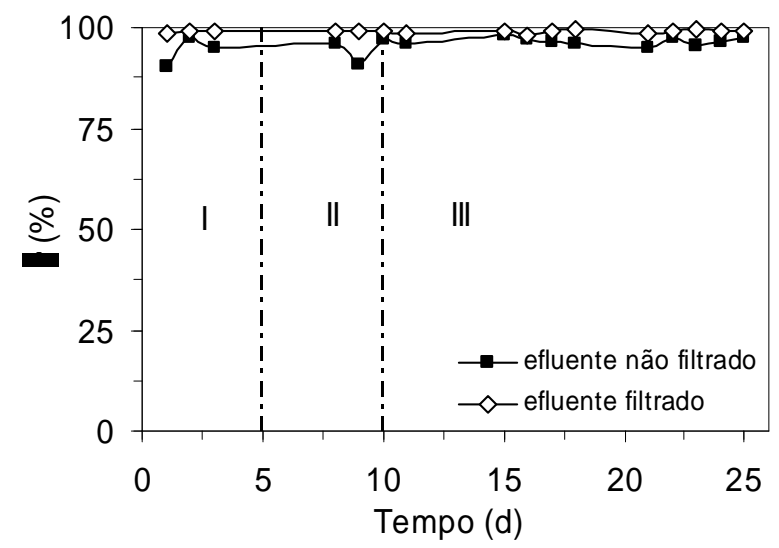

Figura 5.10 - Eficiência de remoção da matéria orgânica, em termos de DQO, de amostras do efluente filtradas e não filtradas durante a operação do reator em batelada nas condições I $\left(\mathrm{NaHCO}_{3} / \mathrm{DQO}=1,0\right)$, II $\left(\mathrm{NaHCO}_{3} / \mathrm{DQO}=0,5\right)$ e III $\left(\mathrm{NaHCO}_{3} / \mathrm{DQO}=0,25\right)$, para COV $=2,4$ g/l.d . 


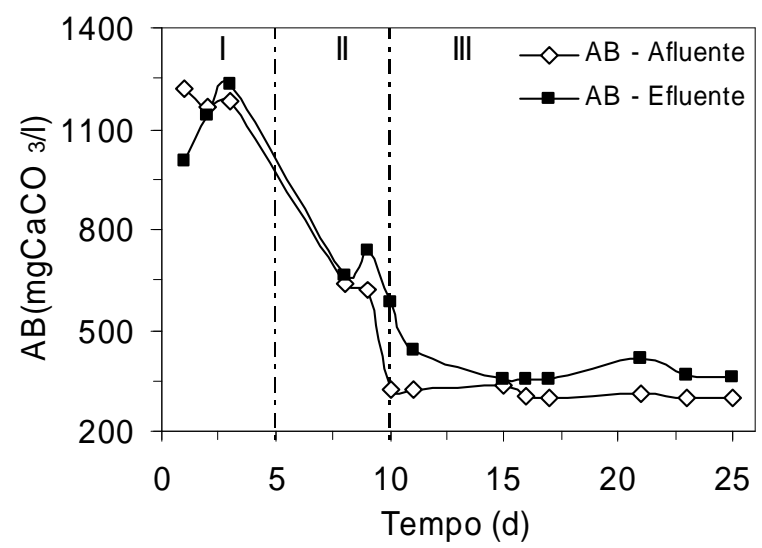

Figura 5.11 - Alcalinidade a Bicarbonato $(\mathrm{AB})$ afluente e efluente durante a operação do reator em batelada nas condições I $\left(\mathrm{NaHCO}_{3} / \mathrm{DQO}=1,0\right)$, II $\left(\mathrm{NaHCO}_{3} / \mathrm{DQO}=0,5\right)$ e III $\left(\mathrm{NaHCO}_{3} / \mathrm{DQO}=0,25\right)$, para COV $=2,4 \mathrm{~g} / \mathrm{l} . \mathrm{d}$.

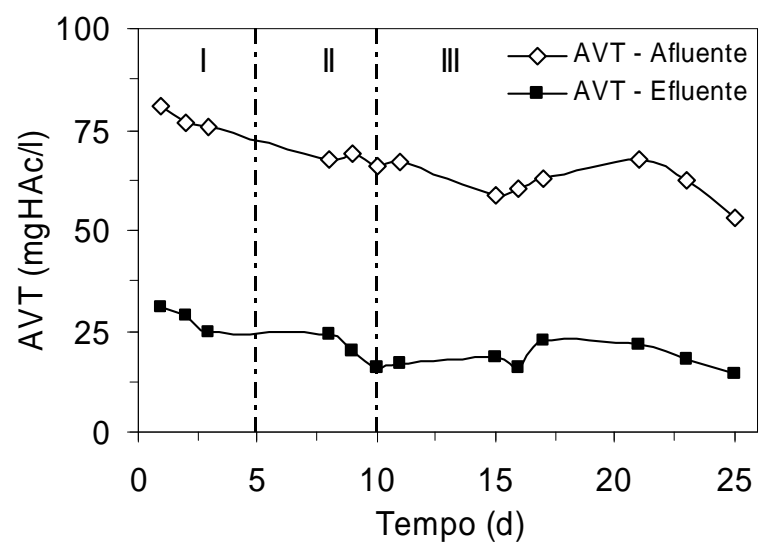

Figura 5.12 - Ácidos Voláteis Totais (AVT) afluente e efluente durante a operação do reator em batelada nas condições I $\left(\mathrm{NaHCO}_{3} / \mathrm{DQO}=1,0\right)$, II $\left(\mathrm{NaHCO}_{3} / \mathrm{DQO}=0,5\right)$ e III $\left(\mathrm{NaHCO}_{3} / \mathrm{DQO}\right.$ $=0,25)$, para $\mathrm{COV}=2,4 \mathrm{~g} / \mathrm{l} \cdot \mathrm{d}$. 


\section{Perfil de Conversão ao longo do ciclo}

Os perfis de conversão ao longo do ciclo foram realizados na condição III, $\mathrm{C}_{\mathrm{AF}}=$ $2000 \mathrm{mg} / \mathrm{l}$ e 0,25 da relação AB/DQO. Os perfis de conversão de matéria orgânica solúvel $\mathrm{C}_{\mathrm{s}}(\mathrm{mg} / \mathrm{l}), \mathrm{AB}\left(\mathrm{mgCaCO}_{3} / \mathrm{l}\right), \mathrm{AVT}(\mathrm{mgHAc} / \mathrm{l})$ e $\mathrm{AVI}$ foram realizados nos ciclos 67 e 73, enquanto os perfis de concentração e composição do biogás foram realizados nos ciclos 55 e 70 .

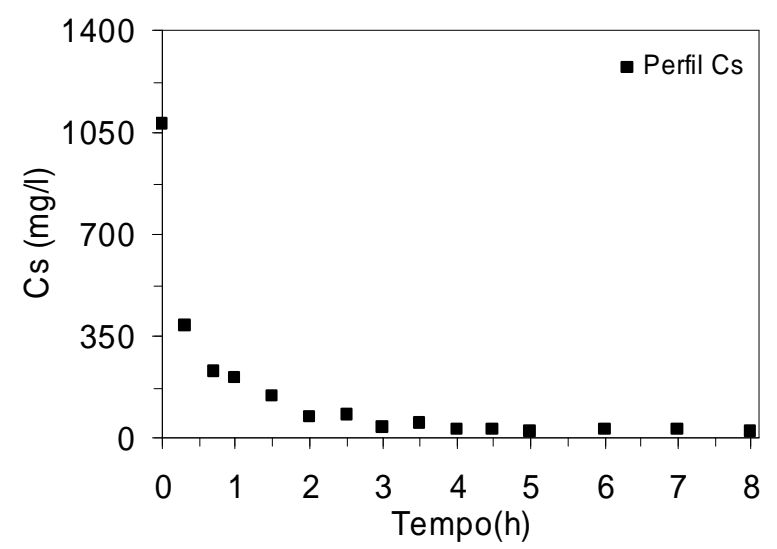

Figura 5.13 - Perfil de concentração da matéria orgânica ao longo do ciclo, em termos de DQO, de amostras filtradas, durante a operação do reator em batelada, para COV =2,4 g/l.d .

A rápida degradação do soro de queijo apresentada na Figura 5.13, com eficiência de remoção de DQO solúvel próxima de 100\%, confirma os resultados do monitoramento $\left(\varepsilon_{\mathrm{ss}}=98,9 \pm 0,4 \%\right)$. 

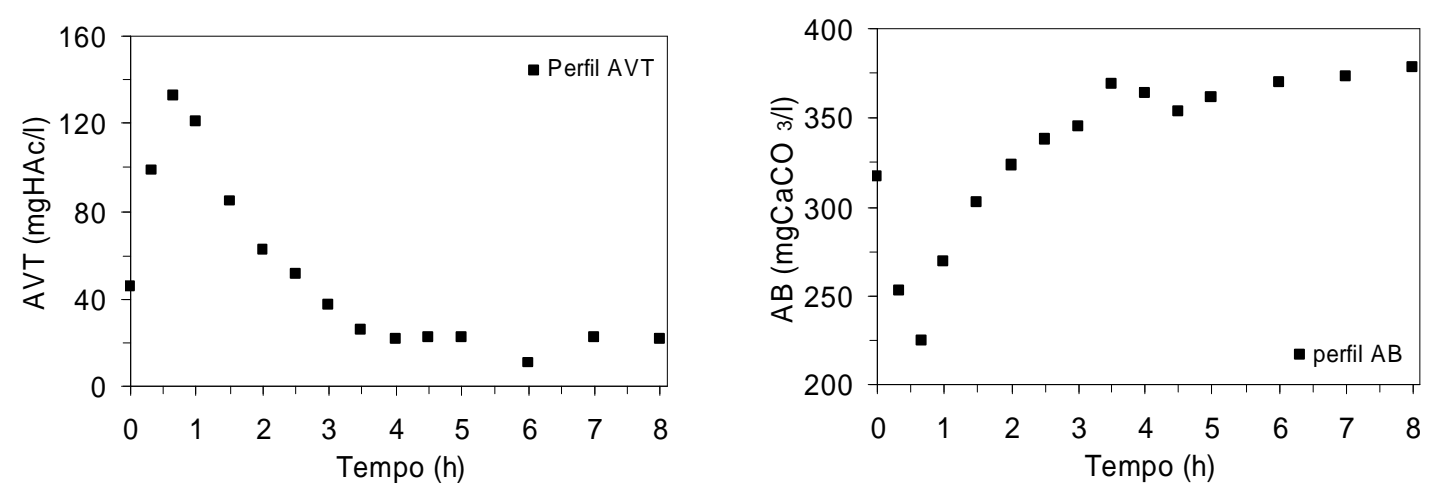

Figura 5.14 - Perfil de Ácidos Voláteis Totais (AVT) e Alcalinidade a Bicarbonato (AB) ao longo do ciclo, durante a operação do reator em batelada, para COV $=2,4 \mathrm{~g} / \mathrm{l}$.d .

A Figura 5.14 mostra que apesar do acentuado pico de AVT, após 4 horas de ciclo os valores de AVT já estavam estáveis, confirmando a rápida degradação da matéria orgânica presente no reator. Também se observa nesta figura a rápida recuperação do reator em termos de $\mathrm{AB}$. Dessa forma o $\mathrm{pH}$ manteve-se praticamente constante conforme se observa na Figura 5.15.

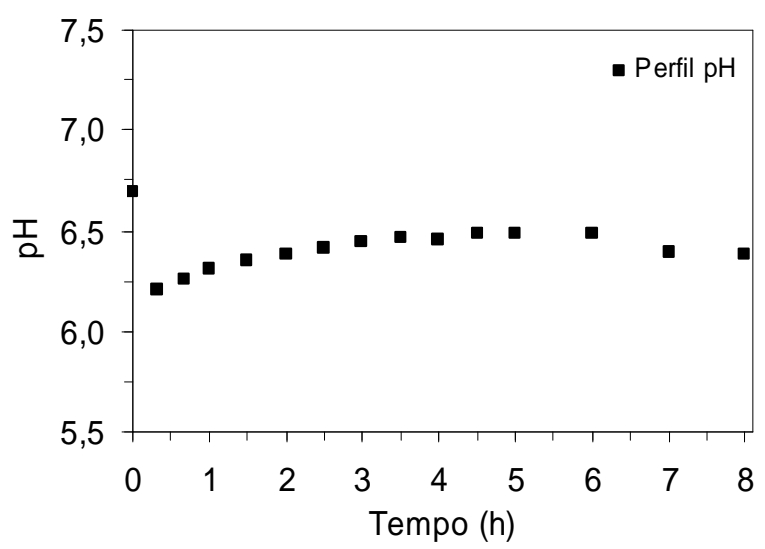

Figura 5.15 - Perfil de pH ao longo do ciclo, durante a operação do reator em batelada, para

$$
\mathrm{COV}=2,4 \mathrm{~g} / \mathrm{l} \cdot \mathrm{d} \text {. }
$$



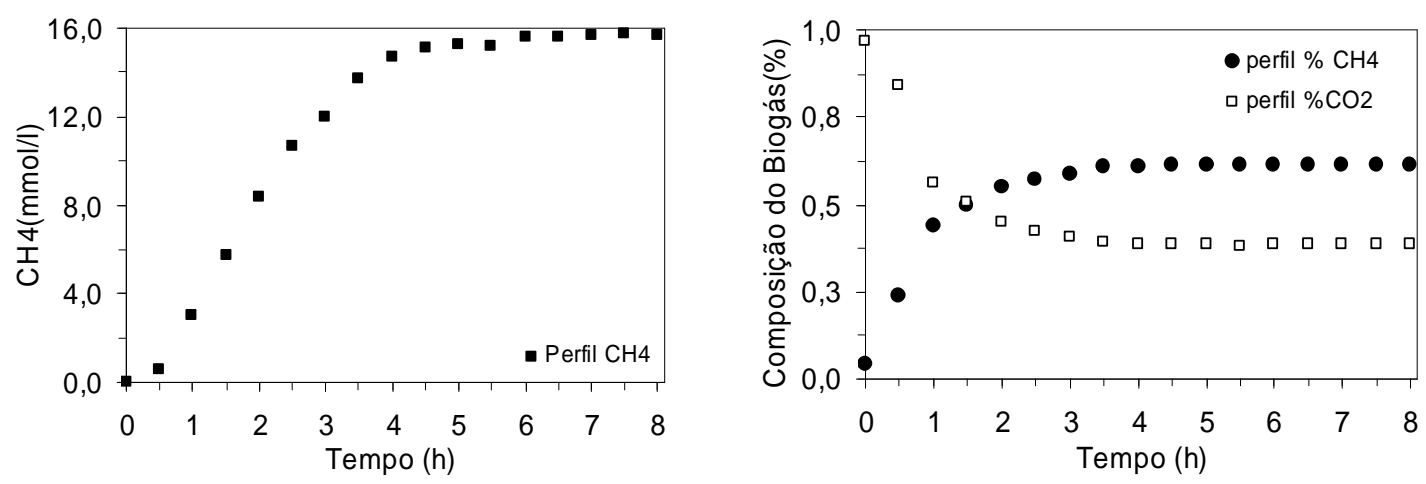

Figura 5.16 - Perfil de Concentração e Composição do Biogás ao longo do ciclo, durante a operação do reator em batelada, para $\mathrm{COV}=2,4 \mathrm{~g} / \mathrm{l} . \mathrm{d}$.

Observa-se na Figura 5.16 que devido ao aumento da COV aplicada, a elevada concentração do biogás no "head space" do reator aumentou (16 mmol/l), contudo a composição do biogás ( $60 \%$ de metano e $40 \%$ de $\mathrm{CO}_{2}$ ) foi semelhante ao ensaio anterior. Também se observa nesta figura que tanto a composição quanto a concentração de metano no "head space" mantiveram-se constantes após 4 horas de ciclo.

A Tabela 5.5 mostra que em termos de concentração os AVI mais relevantes para o processo durante este ensaio foram o ácido acético e o ácido propiônico. Também se pode observar nesta figura a rápida degradação dos AVI, os quais não foram detectados após 4 horas de ciclo. 
Tabela 5.5 - Perfil de Ácidos Voláteis Intermediários (AVI) ao longo do ciclo, durante a operação do reator em batelada, para $\mathrm{COV}=2,4 \mathrm{~g} / \mathrm{l} . \mathrm{d}$.

\begin{tabular}{cccccc}
\hline \multicolumn{7}{c}{ AVI (mmol/l) } \\
\hline tempo $(\mathrm{h})$ & Acético & Propiônico & Iso-Butírico & Butírico & Iso-Valérico \\
\hline 0 & 15,2 & 15,5 & 0,0 & 0,0 & 0,0 \\
0,33 & 31,5 & 82,5 & 0,0 & 3,0 & 1,2 \\
0,67 & 51,7 & 99,6 & 1,2 & 2,9 & 2,8 \\
1 & 36,2 & 97,4 & 2,0 & 2,4 & 5,1 \\
1,5 & 8,5 & 83,9 & 1,3 & 0,8 & 6,2 \\
2 & 0,0 & 60,1 & 2,3 & 0,0 & 5,2 \\
2,5 & 0,0 & 38,4 & 1,9 & 0,0 & 3,5 \\
3 & 0,0 & 9,1 & 0,0 & 0,0 & 1,3 \\
3,5 & 0,0 & 4,5 & 0,0 & 0,0 & 0,0 \\
4 & 0,0 & 0,0 & 0,0 & 0,0 & 0,0 \\
4,5 & 0,0 & 0,0 & 0,0 & 0,0 & 0,0 \\
\hline
\end{tabular}

\section{Análise de Sólidos do Lodo}

Após a realização dos perfis de concentração ao longo do ciclo, para a Operação em Batelada com $\mathrm{COV}=2,4 \mathrm{~g} / \mathrm{l} . \mathrm{d}$, retirou-se uma amostra para a análise do lodo presente no reator durante os ensaios. Dessa análise foi possível obter a relação mássica SVT/ST que serve de indicação da quantidade de microrganismos presentes na biomassa. Dessa forma obteve-se que fração mássica (SVT/ST) foi de 88,6\% para este ensaio. 


\subsubsection{Operação em Batelada $\left(\mathrm{COV}=4,8\right.$ g/l.d. ; $\left.\mathrm{C}_{\mathrm{AF}}=4000 \mathrm{mg} / \mathrm{l}\right)$}

Encerrado o ensaio 2 (operação em batelada com concentração afluente $\mathrm{C}_{\mathrm{AF}}=$ 2000 mg/l) iniciou-se o ensaio 3 (operação em batelada com concentração afluente $\mathrm{C}_{\mathrm{AF}}=4000 \mathrm{mg} / \mathrm{l}$ ) operando o reator na condição $\mathrm{I}$ (relação $\mathrm{AB} / \mathrm{DQO}=$ 1). Esta condição foi mantida durante cinco dias após os quais passou-se a operar o reator na condição II (relação $\mathrm{AB} / \mathrm{DQO}=0,5$ ) a qual também foi mantida por cinco dias quando se iniciou a operação do reator na condição III (relação $\mathrm{AB} / \mathrm{DQO}=0,25)$. Os valores experimentais obtidos durante $\mathrm{o}$ monitoramento do ensaio 3 estão apresentados no anexo D.

\section{Monitoramento do reator}

Os valores médios das variáveis monitoradas no afluente e no efluente durante esta etapa, na condição III, estão apresentados na Tabela 5.6 e nas Figuras 5.17 a 5.20, nas quais $\mathrm{C}_{\mathrm{ST}}$ é a concentração da matéria orgânica para amostras não filtradas, $\mathrm{C}_{S S}$ é a concentração da matéria orgânica para amostras filtradas, $\varepsilon_{\mathrm{T}}$ é a eficiência de remoção para as amostras não filtradas, $\varepsilon_{S}$ é a eficiência de remoção para amostras filtradas. Este ensaio durou 25 dias (75 ciclos), a condição I foi mantida durante 3 dias (9 ciclos), a condição II também durante 7 dias (21 ciclos) e a condição III foi mantida durante 15 dias (45 ciclos). 
Tabela 5.6 - Valores médios das variáveis monitoradas no ensaio em batelada para COV=4,8 g/l.d.

\begin{tabular}{ccc}
\hline Parâmetro & Afluente & Efluente \\
\hline $\mathrm{C}_{\mathrm{ST}}(\mathrm{mg} / \mathrm{l})$ & $3986,4 \pm 62,1^{(14)}$ & $158,9 \pm 54,7^{(15)}$ \\
$\varepsilon_{\mathrm{T}}(\%)$ & - & $96,0 \pm 1,4^{(15)}$ \\
$\mathrm{C}_{\mathrm{SS}}(\mathrm{mg} / \mathrm{l})$ & - & $63,4 \pm 27,6^{(15)}$ \\
$\varepsilon_{\mathrm{S}}(\%)$ & - & $98,4 \pm 0,7^{(15)}$ \\
$\mathrm{AVT}(\mathrm{mgHAc} / \mathrm{l})$ & $123,3 \pm 6,26^{(14)}$ & $40,1 \pm 5,6^{(14)}$ \\
$\mathrm{AB}(\mathrm{mgCaCO})^{(1)}$ & $665,2 \pm 195,88^{(14)}$ & $823,0 \pm 202,0^{(14)}$ \\
$\mathrm{AI} / \mathrm{AP}$ & $0,28 \pm 0,04^{(14)}$ & $0,38 \pm 0,07^{(14)}$ \\
$\mathrm{pH}$ & $8,2 \pm 0,10^{(14)}$ & $6,71 \pm 0,08^{(14)}$ \\
$\mathrm{Volume}(\mathrm{l})$ & $2,02 \pm 0,01^{(12)}$ & $2,02 \pm 0,01^{(12)}$ \\
$\mathrm{ST}(\mathrm{mg} / \mathrm{l})$ & $4797 \pm 805^{(7)}$ & $1639 \pm 502^{(7)}$ \\
$\mathrm{SVT}(\mathrm{mg} / \mathrm{l})$ & $3581 \pm 135^{(7)}$ & $531 \pm 112^{(7)}$ \\
$\mathrm{SST}(\mathrm{mg} / \mathrm{l})$ & $86 \pm 28^{(7)}$ & $122 \pm 36^{(7)}$ \\
$\mathrm{SSV}(\mathrm{mg} / \mathrm{l})$ & $73 \pm 24^{(7)}$ & $95 \pm 36^{(7)}$ \\
\hline
\end{tabular}

*Entre parênteses o número de amostras consideradas no cálculo da média

Como se pode observar na Tabela 5.6 e nas Figuras, o reator apresentou elevada eficiência em remoção de DQO filtrada $(98,4 \pm 0,7 \%)$. A baixa concentração de AVT $(40,1 \pm 5,6 \mathrm{mgHAc} / \mathrm{l})$, o $\mathrm{pH}(6,71 \pm 0,08)$ e a concentração de $\mathrm{AB}(823,0 \pm 202,0$ $\left.\mathrm{mgCaCO}_{3} / \mathrm{l}\right)$ no efluente mostram que a operação foi mantida estável durante todo o ensaio.

Observou-se neste ensaio a flotação de uma porção da biomassa maior que nos ensaios anteriores, provavelmente devido à adsorção do biogás ao grânulo. Observou-se também o aumento da quantidade de material particulado suspenso, de provável origem microbiológica e a acentuação do aspecto acinzentado dos grânulos. 


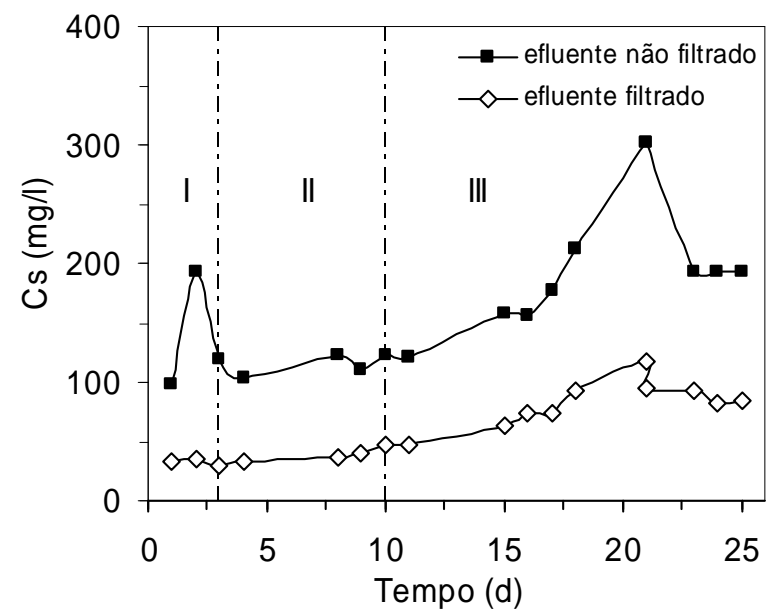

Figura 5.17 - Concentração da matéria orgânica, em termos de DQO, de amostras do efluente filtradas e não filtradas durante a operação do reator em batelada nas condições I $\left(\mathrm{NaHCO}_{3} / \mathrm{DQO}=1,0\right), \mathrm{II}\left(\mathrm{NaHCO}_{3} / \mathrm{DQO}=0,5\right)$ e III $\left(\mathrm{NaHCO}_{3} / \mathrm{DQO}=0,25\right)$, para COV $=4,8$ g/l.d.

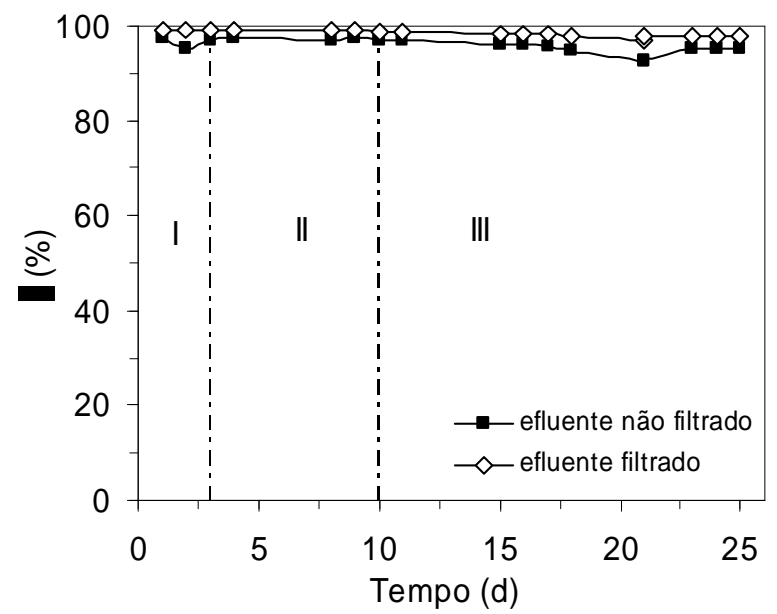

Figura 5.18 - Eficiência de remoção da matéria orgânica, em termos de DQO, de amostras do efluente filtradas e não filtradas durante a operação do reator em batelada nas condições I $\left(\mathrm{NaHCO}_{3} / \mathrm{DQO}=1,0\right), \mathrm{II}\left(\mathrm{NaHCO}_{3} / \mathrm{DQO}=0,5\right)$ e III $\left(\mathrm{NaHCO}_{3} / \mathrm{DQO}=0,25\right)$, para COV $=4,8$ g/l.d . 


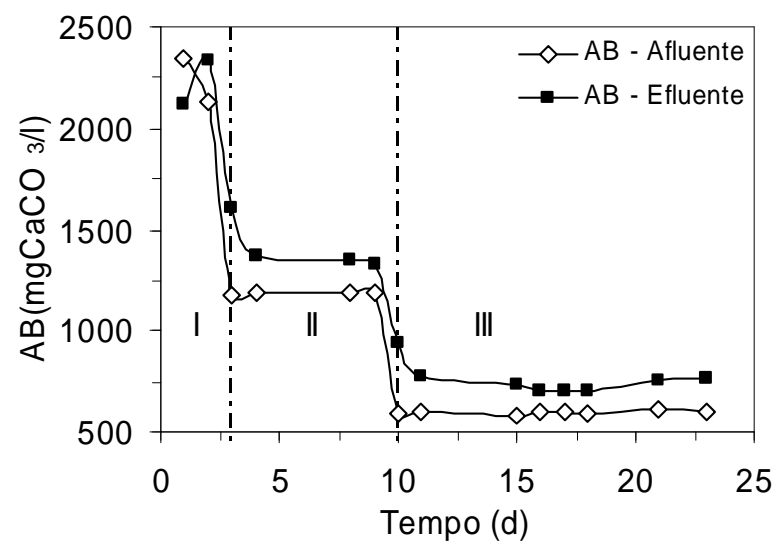

Figura 5.19 - Alcalinidade a Bicarbonato $(\mathrm{AB})$ afluente e efluente durante a operação do reator em batelada nas condições I $\left(\mathrm{NaHCO}_{3} / \mathrm{DQO}=1,0\right)$, II $\left(\mathrm{NaHCO}_{3} / \mathrm{DQO}=0,5\right)$ e III $\left(\mathrm{NaHCO}_{3} / \mathrm{DQO}=0,25\right)$, para COV $=4,8 \mathrm{~g} / \mathrm{l} . \mathrm{d}$.

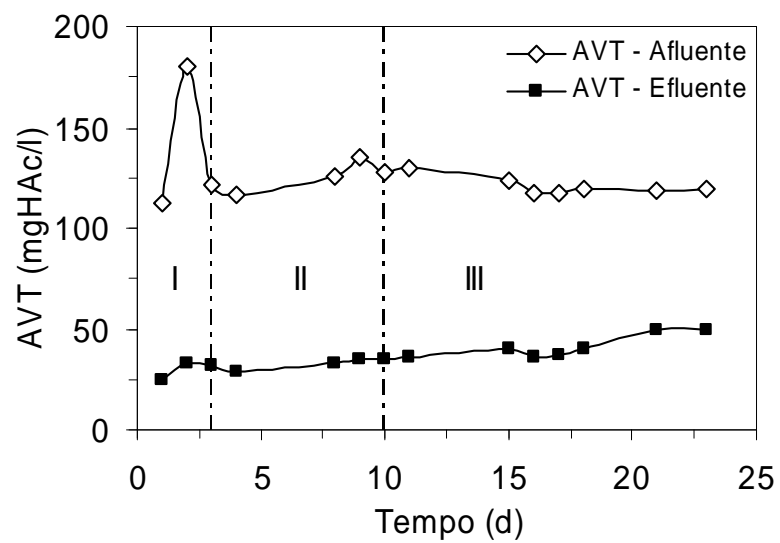

Figura 5.20 - Ácidos Voláteis Totais (AVT) afluente e efluente durante a operação do reator em batelada nas condições I $\left(\mathrm{NaHCO}_{3} / \mathrm{DQO}=1,0\right)$, II $\left(\mathrm{NaHCO}_{3} / \mathrm{DQO}=0,5\right)$ e III $\left(\mathrm{NaHCO}_{3} / \mathrm{DQO}\right.$ $=0,25)$, para COV $=4,8 \mathrm{~g} / \mathrm{l} \cdot \mathrm{d}$. 


\section{Perfil de Conversão ao longo do ciclo}

Os perfis de conversão ao longo do ciclo foram realizados na condição III, $\mathrm{C}_{\mathrm{AF}}=$ $4000 \mathrm{mg} / \mathrm{l}$ e $25 \%$ de suplementação de alcalinidade. Os perfis de conversão de matéria orgânica solúvel $\mathrm{C}_{\mathrm{s}}(\mathrm{mg} / \mathrm{l}), \mathrm{AB}\left(\mathrm{mgCaCO}_{3} / \mathrm{l}\right)$, AVT $(\mathrm{mgHAc} / \mathrm{l})$ e AVI foram realizados nos ciclos 64 e 70, enquanto os perfis de concentração e composição do biogás foram realizados nos ciclos 61 e 67.

A Figura 5.21 mostra a rápida degradação do soro de queijo, com eficiência de remoção de DQO filtrada próxima de 100\%, confirmando os resultados do monitoramento $\left(\varepsilon_{\mathrm{ss}}=98,4 \pm 0,7 \%\right)$. Também se observa nesta figura dois comportamentos cinéticos distintos, um de rápida degradação da matéria orgânica até a terceira hora de ciclo e outro de degradação lenta, após a terceira hora de ciclo. Essa diferença de comportamento indica a ocorrência de inibição, provavelmente devido ao acúmulo de ácidos voláteis.

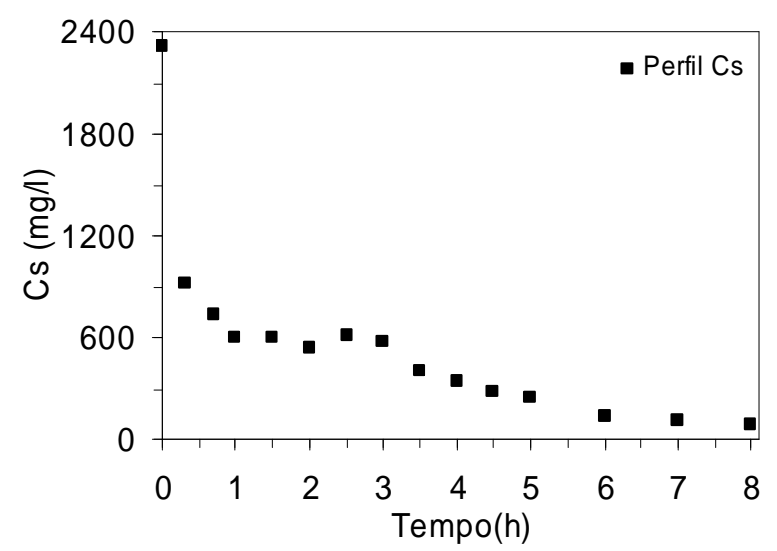

Figura 5.21 - Perfil de concentração da matéria orgânica ao longo do ciclo, em termos de DQO, de amostras filtradas, durante a operação do reator em batelada, para COV = 4,8 g/l.d . 

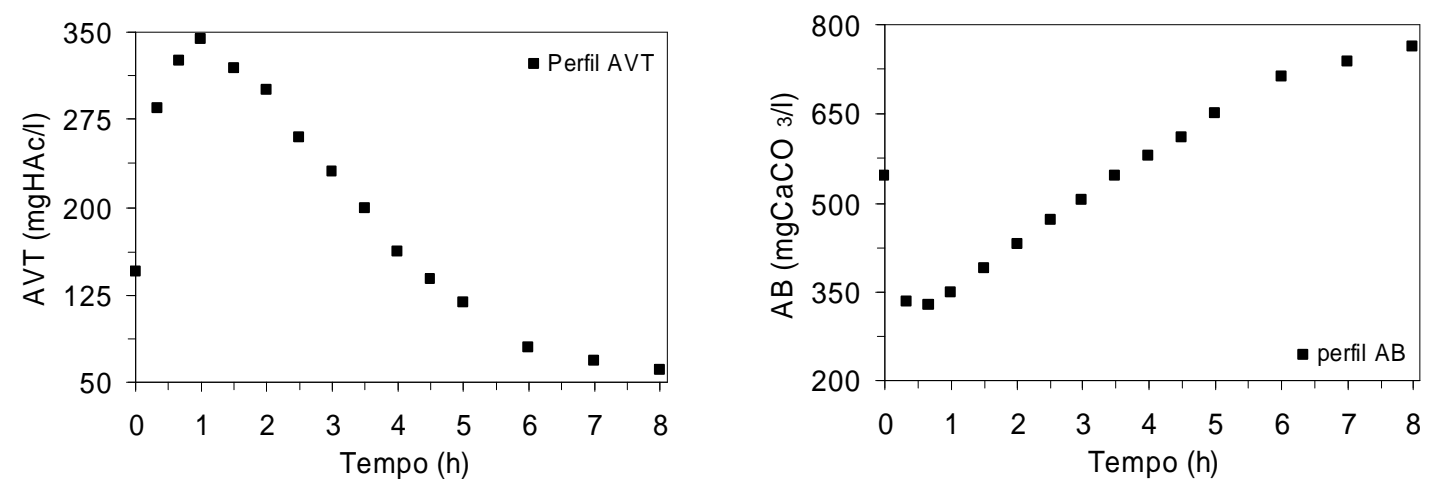

Figura 5.22 - Perfil de Ácidos Voláteis Totais (AVT) e Alcalinidade a Bicarbonato (AB) ao longo do ciclo, durante a operação do reator em batelada, para COV $=4,8 \mathrm{~g} / \mathrm{l}$.d .

A Figura 5.22 mostra que os picos de AVT e AB além de acentuados são largos atingindo valores estáveis ao final do ciclo. Isso indica que o reator apresentou dificuldades em degradar rapidamente os AVT, provavelmente devido ao acúmulo de ácidos voláteis totais no reator. Contudo, o reator operou com estabilidade e atingiu elevada eficiência em remoção de DQO no fim do ciclo. Este fato pode ser uma indicação de que a biomassa já encontrava dificuldades em degradar o afluente com concentração de 4000 mg/l. Da maneira semelhante a recuperação dos valores de pH foi mais lenta estabilizando após 5 horas de ciclo, conforme se observa na Figura 5.23.

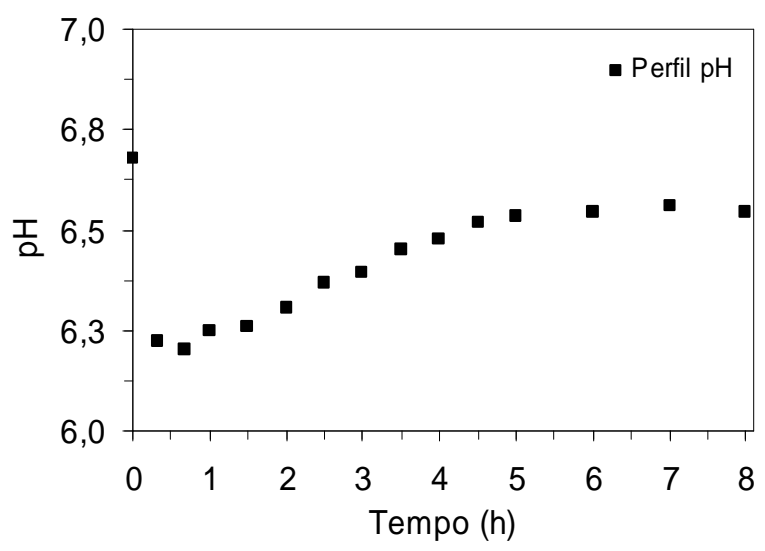

Figura 5.23 - Perfil de pH ao longo do ciclo, durante a operação do reator em batelada, para

$$
\mathrm{COV}=4,8 \mathrm{~g} / \mathrm{l} . \mathrm{d} \text {. }
$$


A Tabela 5.7 mostra que os ácidos acético e propiônico foram os que exerceram maior influência, em termos de concentração, no processo de degradação da matéria orgânica. Observa-se que o pico de ácido propiônico além de acentuado está bem espalhado indicando que houve acúmulo deste ácido. Esses resultados indicam que a velocidade de formação de ácido propiônico, pelas bactérias acidogênicas foi muito superior à velocidade de degradação do ácido propiônico pelas bactérioas acetogênicas, gerando o acúmulo do ácido propiônico e conseqüentemente a elevada concentração de pico do mesmo. Este acúmulo pode ter causado algum efeito de inibição dificultando a rápida degradação da matéria orgânica.

Tabela 5.7 - Perfil de Ácidos Voláteis Intermediários (AVI) ao longo do ciclo, durante a operação do reator em batelada, para $\mathrm{COV}=4,8 \mathrm{~g} / \mathrm{l} . \mathrm{d}$.

\begin{tabular}{ccccccc}
\hline \multicolumn{6}{c}{ AVI (mmol/l) } \\
\hline tempo $(\mathrm{h})$ & Acético & Propiônico & Iso-Butírico & Butírico & Iso-Valérico & Valérico \\
\hline 0 & 29,6 & 28,8 & 0,0 & 4,1 & 0,0 & 0,0 \\
0,33 & 116,4 & 106,5 & 1,4 & 21,0 & 2,3 & 0,0 \\
0,67 & 163,2 & 172,0 & 2,5 & 23,9 & 5,0 & 1,4 \\
1 & 171,4 & 209,2 & 4,0 & 22,5 & 9,0 & 2,1 \\
1,5 & 147,2 & 208,4 & 5,8 & 20,2 & 14,6 & 3,4 \\
2 & 131,9 & 205,4 & 6,9 & 17,0 & 17,7 & 4,4 \\
2,5 & 121,6 & 201,2 & 8,3 & 14,7 & 20,8 & 5,3 \\
3 & 81,7 & 167,5 & 7,9 & 10,1 & 20,2 & 5,7 \\
3,5 & 60,9 & 150,3 & 8,7 & 7,5 & 21,5 & 6,1 \\
4 & 44,4 & 122,7 & 8,3 & 4,0 & 18,2 & 4,9 \\
4,5 & 31,1 & 91,9 & 8,6 & 4,1 & 18,9 & 5,1 \\
5 & 23,9 & 71,7 & 6,8 & 2,2 & 14,7 & 3,6 \\
6 & 19,6 & 31,4 & 6,8 & 0,0 & 6,2 & 1,4 \\
7 & 9,5 & 21,5 & 3,9 & 0,0 & 4,2 & 0,7 \\
8 & 8,9 & 14,3 & 2,9 & 0,0 & 2,4 & 0,0 \\
\hline
\end{tabular}

A Figura 5.24 mostra que o aumento da COV aplicada resulta em maior concentração de metano (24 mmol/l) no "head space" do reator o que não aconteceu com a composição do biogás que se manteve semelhante aos ensaios anteriores (60\% de metano e $40 \%$ de $\mathrm{CO}_{2}$ ). Também se observa nesta figura que a estabilidade foi atingida apenas nas últimas horas de ciclo. Isso indica que de fato a degradação da matéria orgânica neste ensaio foi mais lenta que nos ensaios anteriores. 

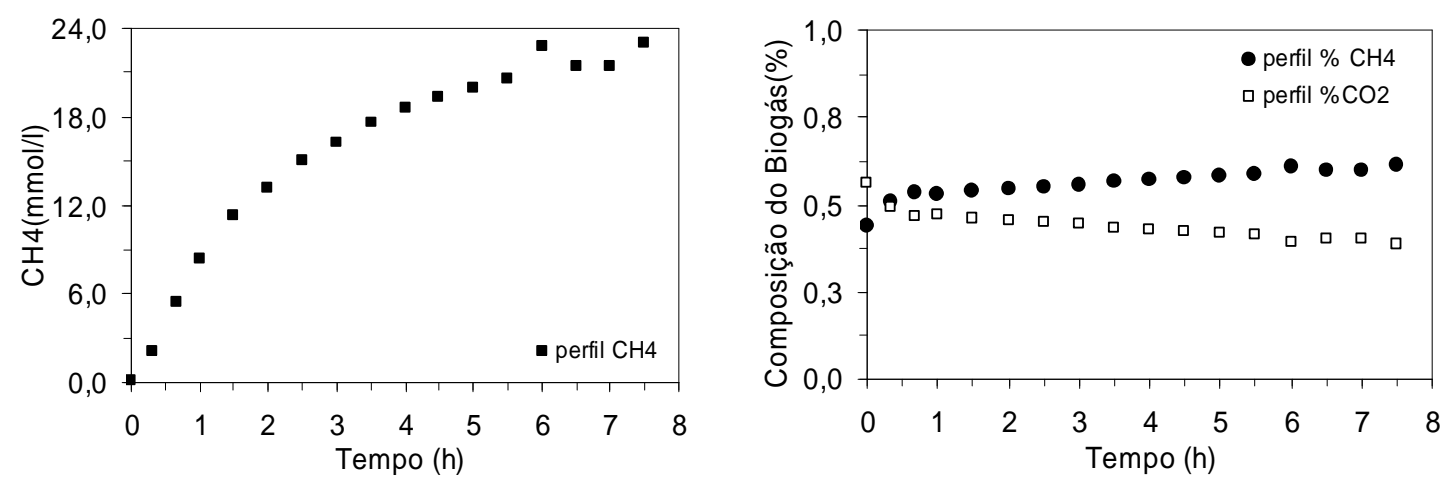

Figura 5.24 - Perfil de Concentração e Composição do Biogás ao longo do ciclo, durante a operação do reator em batelada, para $\mathrm{COV}=4,8 \mathrm{~g} / \mathrm{l} . \mathrm{d}$.

\section{Análise de Sólidos do Lodo}

Após a realização dos perfis de concentração ao longo do ciclo, para a operação em batelada com $\mathrm{COV}=4,8 \mathrm{~g} / \mathrm{l} . \mathrm{d}$, retirou-se uma amostra para a análise do lodo presente no reator durante os ensaios. Dessa análise foi possível obter a relação mássica SVT/ST que serve de indicação da quantidade de microrganismos presentes na biomassa. Dessa forma obteve-se que fração mássica(SVT/ST) foi de 90,4\% para este ensaio. 


\subsubsection{Operação em Batelada $\left(\mathrm{COV}=7,2\right.$ g/l.d. ; $\left.\mathrm{C}_{\mathrm{AF}}=6000 \mathrm{mg} / \mathrm{l}\right)$}

Encerrado o ensaio 3 (operação em batelada com concentração afluente $\mathrm{C}_{\mathrm{AF}}=$ $4000 \mathrm{mg} / \mathrm{l}$ ) iniciou-se o ensaio 4 (operação em batelada com concentração afluente $\mathrm{C}_{\mathrm{AF}}$ $=6000 \mathrm{mg} / \mathrm{l}$ ). O reator, entretanto, mostrou-se instável e aparentemente o sistema não suportou a COV aplicada. Os valores de DQO eram sempre crescentes, os valores de AVT muito elevados e o efluente bastante turvo. A operação do reator na condição I ( $100 \%$ de suplementação de alcalinidade) foi mantida por 2 dias e a operação do reator na condição II (50\% de suplementação de alcalinidade) foi mantida por 7 dias. Os valores experimentais obtidos durante o monitoramento do ensaio 4 estão apresentados no anexo E.

\section{Ajustes Cinéticos}

Após a realização dos ensaios em batelada realizaram-se os ajustes dos parâmetros cinéticos. A partir da equação do balanço de massa para um biorreator isotérmico operado em batelada, ajustou-se um modelo de primeira ordem, no qual $\mathrm{k}_{1}$ é o parâmetro cinético aparente de primeira ordem $\left(\mathrm{h}^{-1}\right)$. A equação do balanço de massa foi ajustada no modo integral, apresentado na equação 7 , onde $C_{S}$ é a concentração de substrato para amostra filtrada (mg/l, em termos de DQO), $\mathrm{C}_{\mathrm{S} 0}$ é a concentração afluente (mg/l, em termos de DQO), $\mathrm{C}_{\mathrm{SR}}$ é a concentração residual de substrato para amostra filtrada (mg/l, em termos de DQO), t é o tempo (h) e $\mathrm{k}_{1}$ é o parâmetro cinético aparente de primeira ordem $\left(\mathrm{h}^{-1}\right)$.

$$
\mathrm{C}_{\mathrm{S}}=\mathrm{C}_{\mathrm{SR}}+\left(\mathrm{C}_{\mathrm{So}}-\mathrm{C}_{\mathrm{SR}}\right) \cdot \mathrm{e}^{-\mathrm{k}_{1} \mathrm{t}}
$$

Para a realização dos ajustes foi utilizado o método de Levemberg-Marquadt que é o método utilizado pelo software Origin. Foi utilizado o software Origin 6.0 . A Tabela 5.8 apresenta os valores de $\mathrm{k}_{1}$ obtidos e os valores de $\mathrm{k} 1$ obtidos por Mockaitis et al. (2006), para o ASBR operado em condições semelhantes sem o "draft tube". 
Tabela 5.8 - Valores dos parâmetros cinéticos aparentes de primeira ordem $\mathrm{k}_{1}$, obtidos pelo ajuste cinético para o reator ASBR operado com e sem o DT em condições semelhantes.

\begin{tabular}{c|ccc|ccc}
\hline \multirow{2}{*}{$\mathrm{C}_{\mathrm{AF}}\left(\operatorname{mgDQO} .1^{-1}\right)$} & \multicolumn{3}{c}{ sem "draft tube" } & \multicolumn{3}{c}{ com "draft tube" } \\
\cline { 2 - 7 } & $\mathrm{k}_{1 \mathrm{~S}}\left(\mathrm{~h}^{-1}\right)$ & $\mathrm{C}_{\mathrm{SR}}$ & $\mathrm{R}^{2}$ & $\mathrm{k}_{1 \mathrm{~S}}\left(\mathrm{~h}^{-1}\right)$ & $\mathrm{C}_{\mathrm{SR}}$ & $\mathrm{R}^{2}$ \\
\hline 1000 & 0,765 & 16 & 0,983 & 2,030 & 46 & 0,994 \\
2000 & 0,473 & 49 & 0,958 & 2,590 & 30 & 0,964 \\
4000 & 0,287 & 132 & 0,904 & 5,366 & 600 & 1,000 \\
4000 & - & & - & 0,568 & 61,4 & 1,000 \\
\hline
\end{tabular}

*Valores de $\mathrm{k}_{1}$ para o reator operado sem DT - Mockaitis et al. (2006).

Observou-se na Tabela 5.8 que os valores de $\mathrm{k}_{1}$ do ajuste cinético para o reator ASBR com "draft tube" foram muito maiores que os valores de k1 ajustados para o reator ASBR sem "draft tube". Essa diferença comprova que o direcionamento de fluxo que o DT impõe no interior do reator melhora a mistura dentro do reator e conseqüentemente a eficiência da transferência de massa entre as fases líquida e sólida.

Para a $\mathrm{C}_{\mathrm{AF}}$ de $4000 \mathrm{mg} / \mathrm{l}$ foram feitos dois ajustes. Um para as primeiras 2,5 horas de ciclo e outro para o restante do ciclo, visto que o perfil de $\mathrm{C}_{\mathrm{S}}$ apresentou comportamentos distintos antes e depois de 2,5 horas de ciclo. Essa diferença de comportamento pode ser observada pela diferença dos valores de $\mathrm{k}_{1}$ obtidos.

\subsection{OPERAÇÃO DO REATOR EM BATELADA ALIMENTADA}

\subsubsection{Procedimento de Partida}

Com o encerramento da operação em batelada iniciou-se uma nova etapa deste projeto, a operação em batelada alimentada. Contudo, antes de iniciar a operação em batelada alimentada foi dada nova partida no reator, em operação em batelada, com $\mathrm{C}_{\mathrm{AF}}$ de $1000 \mathrm{mg} / 1$ (condição I) visando a adaptação da biomassa. Após 14 dias a $\mathrm{C}_{\mathrm{AF}}$ foi aumentada para 2000 mg/l (condição II) e após 8 dias aumentada novamente para 4000 $\mathrm{mg} / \mathrm{l}$ (condição III) mantendo-se esta condição por 8 dias. 
À água residuária utilizada nesta etapa foi adicionada uma solução salina, conforme apresentado na Tabela 4.2 (Del Nery, 1987), para que houvesse a suplementação de metais traço, micro e macro nutrientes. Essa suplementação visou suprir a falta de nutrientes do soro de queijo balanceando a relação $\mathrm{C}: \mathrm{N}: \mathrm{P}$ devido às elevadas concentrações do afluente.

O procedimento de partida do reator foi realizado em um período de 30 dias (90 ciclos) e após este período iniciou-se a operação em batelada alimentada.

\section{Monitoramento do reator}

As Figuras 5.25 a 5.28 apresentam os valores das variáveis monitoradas nas condições I, II e III durante o período de 30 dias em que se realizou o procedimento de partida do reator.

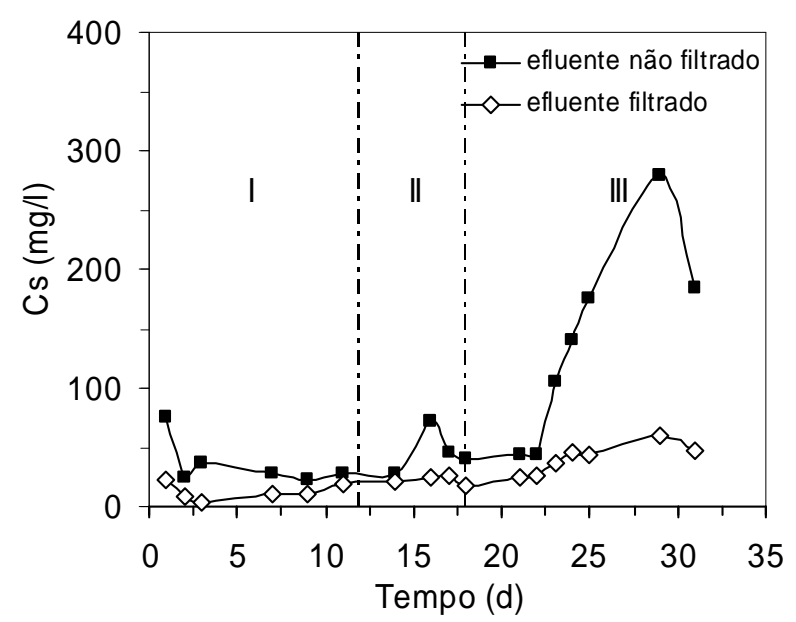

Figura 5.25 - Concentração de matéria orgânica, de amostras filtradas e não filtradas do efluente, nas condições I $\left(\mathrm{C}_{\mathrm{AF}}=1000 \mathrm{mg} / \mathrm{l}\right)$, II $\left(\mathrm{C}_{\mathrm{AF}}=2000 \mathrm{mg} / \mathrm{l}\right)$ e III $\left(\mathrm{C}_{\mathrm{AF}}=4000 \mathrm{mg} / \mathrm{l}\right)$, durante o procedimento de partida para a operação em batelada alimentada. 
Os dados apresentados nas Figuras 5.28 a 5.28 mostram que o sistema mantevese estável durante o procedimento de partida, apesar do aumento da concentração de matéria orgânica não filtrada no efluente, e conseqüente redução na eficiência em remoção de matéria orgânica, durante a condição III, $\mathrm{C}_{\mathrm{AF}}=4000 \mathrm{mg} / \mathrm{l}$. Esse aumento ocorreu devido ao fato de parte da biomassa, principalmente biomassa flotada, ser lavada durante a descarga do reator. Contudo, a operação foi considerada estável, uma vez que a concentração de ácidos voláteis totais (AVT) permaneceu abaixo de 50 mgHAc/l e a concentração de alcalinidade a bicarbonato $(\mathrm{AB})$ estabilizou próxima de $1800 \mathrm{mgCaCO}_{3} / \mathrm{l}$.

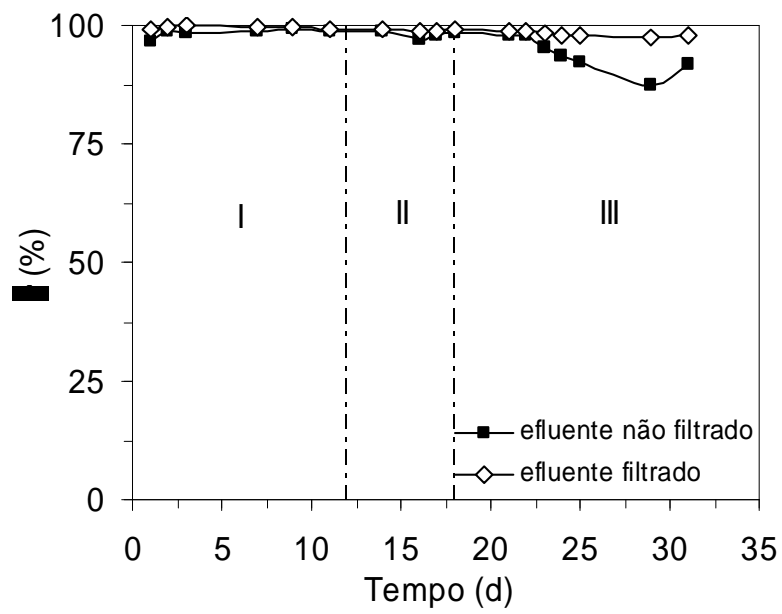

Figura 5.26 - Eficiência de remoção de matéria orgânica de amostras filtradas e não filtradas do efluente, nas condições I $\left(\mathrm{C}_{\mathrm{AF}}=1000 \mathrm{mg} / \mathrm{l}\right)$, II $\left(\mathrm{C}_{\mathrm{AF}}=2000 \mathrm{mg} / \mathrm{l}\right)$ e III $\left(\mathrm{C}_{\mathrm{AF}}=4000 \mathrm{mg} / \mathrm{l}\right)$, durante o procedimento de partida para a operação em batelada alimentada. 


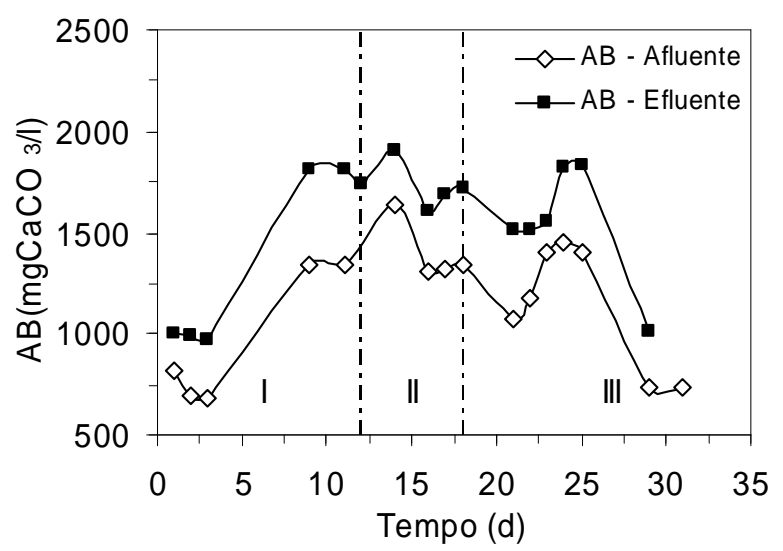

Figura 5.27 - Concentração de Alcalinidade a Bicarbonato (AB), no afluente e no efluente nas condições I $\left(\mathrm{C}_{\mathrm{AF}}=1000 \mathrm{mg} / \mathrm{l}\right), \mathrm{II}\left(\mathrm{C}_{\mathrm{AF}}=2000 \mathrm{mg} / \mathrm{l}\right)$ e III $\left(\mathrm{C}_{\mathrm{AF}}=4000 \mathrm{mg} / \mathrm{l}\right)$, durante o procedimento de partida para a operação em batelada alimentada.

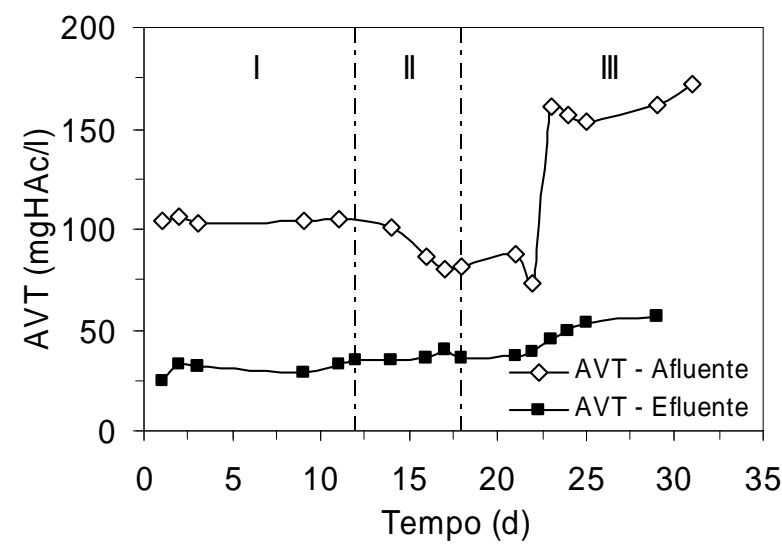

Figura 5.28 - Concentração de Ácidos Voláteis Totais (AVT) no afluente e no efluente nas condições I $\left(\mathrm{C}_{\mathrm{AF}}=1000 \mathrm{mg} / \mathrm{l}\right), \mathrm{II}\left(\mathrm{C}_{\mathrm{AF}}=2000 \mathrm{mg} / \mathrm{l}\right)$ e III $\left(\mathrm{C}_{\mathrm{AF}}=4000 \mathrm{mg} / \mathrm{l}\right)$, durante o procedimento de partida para a operação em batelada alimentada.

Ao final do período de partida do reator a biomassa mostrou-se bastante adaptada ao tratamento do soro de queijo, uma vez que a operação manteve-se estável em cada uma das condições I, II e III. 


\subsubsection{Ensaio BA-A: $\left(\mathrm{COV}=4,8 \mathrm{~g} / \mathrm{l} . \mathrm{d}\right.$. $\left.; \mathrm{C}_{\mathrm{AF}}=16000 \mathrm{mg} / \mathrm{l} ; \mathrm{V}_{\mathrm{alim}}=0,5 \mathrm{l}\right)$}

O volume de afluente alimentado nos ensaios de operação em batelada alimentada foi inferior ao volume de afluente alimentado nos ensaios de operação em batelada, pois a agitação fornecida pelo impelidor inserido ao"draft tube", com conseqüente suspensão da biomassa, só é garantida se o "draft tube" estiver totalmente submerso. Dessa forma, o volume máximo de efluente tratado por ciclo, nesta condição, foi 0,51 .

Durante a realização deste ensaio a $\mathrm{C}_{\mathrm{AF}}$ foi escolhida de maneira que a $\mathrm{COV}$ fosse correspondente a COV aplicada na última condição da operação em batelada, na qual o reator mostrou-se estável, a fim de se ter um parâmetro de comparação. Como a operação em batelada foi estável para $\mathrm{COV}=4,8 \mathrm{~g} / \mathrm{l} . \mathrm{d}\left(\mathrm{C}_{\mathrm{AF}} \mathrm{de} 4000 \mathrm{mg} / \mathrm{l}\right)$, a batelada alimentada foi realizada a $\mathrm{C}_{\mathrm{AF}}$ de $16000 \mathrm{mg} / \mathrm{l}$ para alimentação de 0,5 litro de afluente por ciclo.O $\mathrm{T}_{\text {alim }}$ adotado foi de 480 minutos.

Esta operação foi monitorada durante 8 dias (24 ciclos). Os valores experimentais obtidos durante o monitoramento do ensaio BA-A estão apresentados no anexo F.

\section{Monitoramento do reator}

Durante o monitoramento observou-se a formação de grande quantidade de biogás no meio líquido e conseqüentemente a flotação de grande parte da biomassa. A biomassa flotada formou uma camada estagnada sob a superfície líquida que além de dificultar a passagem do biogás, prejudicou a agitação promovida pelo sistema de agitação constituído pelo impelidor inserido ao "draft tube". Devido a esses problemas operacionais essa condição foi considerada instável.

A Figura 5.29 mostra o reator e a biomassa, respectivamente, ao final deste ensaio. Observa-se nesta figura a grande quantidade de espuma, biomassa flotada e material polimérico viscoso de provável origem microbiológica sobre a superfície líquida. 

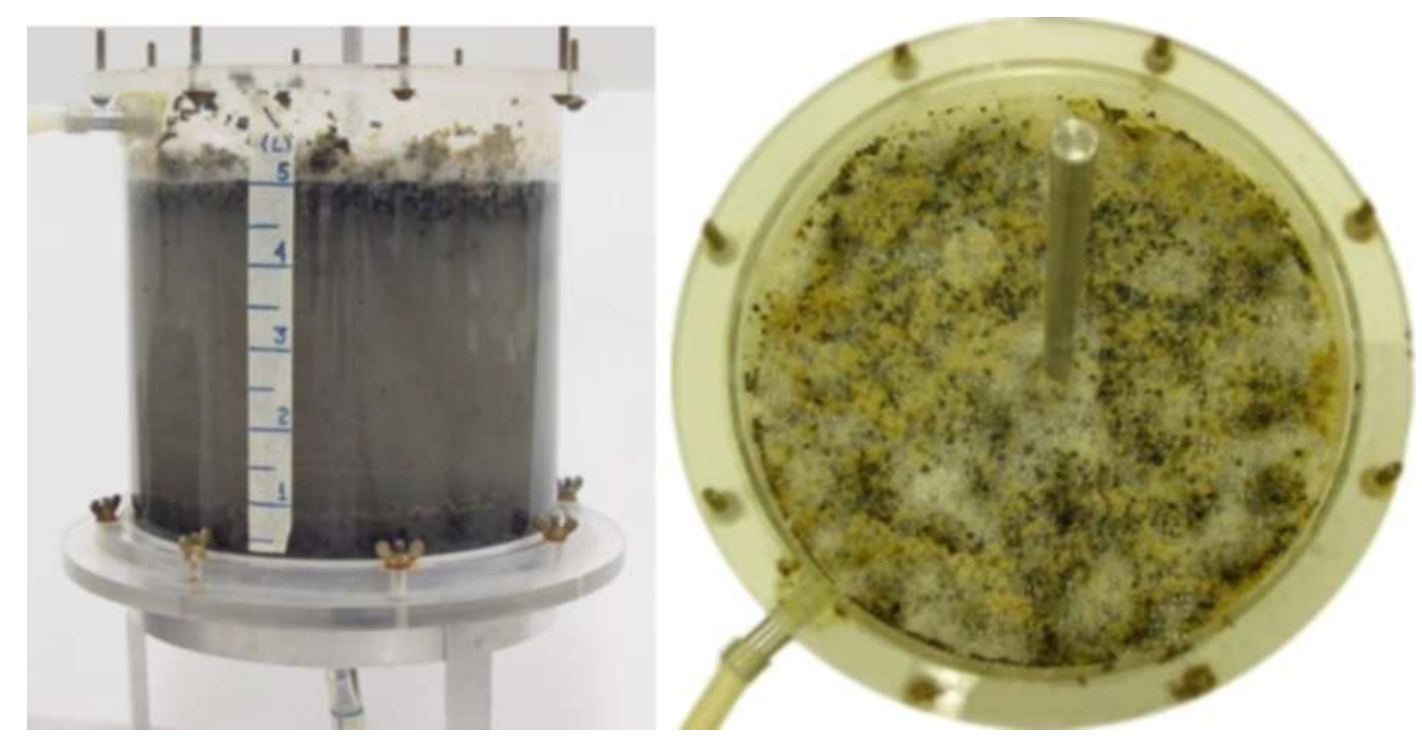

Figura 5.29 - Reator, com vista de cima em detalhe, ao final do ensaio BA-A (COV = 4,8 g/l.d ;

$$
\left.\mathrm{C}_{\mathrm{AF}}=16000 \mathrm{mg} / \mathrm{l}\right)
$$

\subsubsection{Operação em Batelada Alimentada utilizando a configuração de Reator ASBR Híbrido}

Devido aos problemas operacionais ocorridos durante a realização do ensaio $\mathrm{BA}-\mathrm{A}\left(\mathrm{COV}=4,8 \mathrm{~g} / \mathrm{l} . \mathrm{d} ; \mathrm{C}_{\mathrm{AF}}=16000 \mathrm{mg} / \mathrm{l} ; \mathrm{V}_{\mathrm{alim} .}=0,5 \mathrm{l}\right)$ iniciou-se uma etapa denominada de desenvolvimento de dispositivo para assegurar a retenção da biomassa flotada no reator.

Durante este período testou-se a configuração ASBR Híbrido , com duas alturas de camada de biomassa imobilizada, $\lambda=4,0 \mathrm{~cm}$ e $\lambda=1,0 \mathrm{~cm}$. 


\subsubsection{Ensaio BA-B: Reator Híbrido (COV=4,8 g/l.d. ; $C_{A F}=16000 \mathrm{mg} / \mathrm{l}$; Valim. =} $0,5 \mathrm{l} ; \lambda=4,0 \mathrm{~cm})$

Uma hipótese para solucionar os problemas operacionais causados pela biomassa flotada seria a utilização de uma camada de biomassa imobilizada que serviria de filtro impedindo a biomassa flotada de chegar à superfície líquida, além de servir de suporte para uma parcela da biomassa contida no reator (biomassa imobilizada). Dessa forma seriam evitados o arraste da biomassa, a destruição dos grânulos e a formação da camada estagnada sobre o DT.

Entretanto a presença dessa camada prejudicou a agitação do reator, pois na região anelar (externa ao "draft tube") parte da biomassa teve o sentido de movimento invertido sendo "puxada" para o interior do "draft tube" e, conseqüentemente, para a seção superior à biomassa imobilizada. Ao passar pelo interior do "draft tube" os grânulos entraram em contato com o impelidor em alta rotação e foram muito danificados.

\subsubsection{Ensaio BA-C: Reator Híbrido (COV=4,8 g/l.d. ; $C_{A F}=16000 \mathrm{mg} / \mathrm{l}$; Valim. =} $0,5 \mathrm{l} ; \lambda=4,0 \mathrm{~cm}$ com camada protetora)

A fim de evitar a passagem da biomassa pelo interior do "draft tube" inseriu-se uma camada de espuma de poliuretano no fundo do DT para que os grânulos ficassem impedidos de entrar em contato com o impelidor.

Contudo, essa proteção ao mesmo tempo em que formou uma barreira impedindo o contato da biomassa com o impelidor, aumentou a perda de carga dentro do reator prejudicando a agitação. Após alguns dias de operação a baixa eficiência em transferência de massa ficou evidente devido à falta de mistura dentro do reator. 


\subsubsection{Ensaio BA-D: Reator Híbrido $\left(\mathrm{COV}=4,8 \mathrm{~g} / \mathrm{l} . d\right.$. ; $C_{A F}=16000 \mathrm{mg} / \mathrm{l}$; Valim. $=$ $1,0 \mathrm{l} ; \lambda=1,0 \mathrm{~cm})$}

Visando obter melhor agitação e evitar os problemas operacionais causados pela camada de poliuretano diminuiu-se a espessura dessa camada com o objetivo de manter a proteção aos grânulos e ao mesmo tempo garantir a agitação suficiente para promover uma boa mistura do meio líquido, dentro do reator.

Para isso o "draft tube" foi modificado diminuindo-se a distância deste em relação à base do reator e o volume alimentado foi aumentado para 1,01 , visto que a distância do DT em relação à superfície líquida foi aumentada. Assim, seria possível tratar um volume maior de efluente e ainda manter o DT submerso.

Contudo, observou-se que parte da biomassa continuava a ser "puxada" para o interior do "draft tube" sendo assim destruída. Essa biomassa destruída aderiu à camada de espuma de poliuretano formando uma espécie de "torta de filtração" que impedia a mistura do líquido, formando uma camada estagnada na seção superior do reator.

Dessa forma a agitação proporcionada pelo impelidor mecânico utilizando "draft tube" mostrou-se muito sensível a perdas de carga, o que inviabilizou a operação do ASBR Híbrido com as configurações apresentadas.

\subsubsection{Ensaio BA-E: (ASBR com agitação mecânica - utilização de 2 impelidores: hélice com pá inclinada)}

Após os testes realizados com a configuração ASBR Híbrido, testou-se a modificação apenas do sistema de agitação através do acréscimo de mais uma impelidor.

Esse impelidor foi alinhado ao nível superior do "draft tube" visando manter a agitação na superfície líquida impedindo a formação de uma camada estagnada, bem como manter a agitação do fluido em todo o reator e a conseqüente suspensão da biomassa. Após a realização de um teste qualitativo (visual) foi escolhida a pá inclinada a frequiência de $120 \mathrm{rpm}$ para obtenção de uma agitação mais efetiva em todo o reator mesmo com a camada de biomassa flotada que se formou. 
O ensaio BA-E foi realizado com $\mathrm{C}_{\mathrm{AF}}$ de $8000 \mathrm{mg} / \mathrm{l}, \mathrm{V}_{\text {alim. }}$ de 1,0 litro e $\mathrm{T}_{\text {alim }}$ de 360 min, mantendo-se a COV aplicada correspondente a $48 \mathrm{~g} / \mathrm{l} . \mathrm{d}$.

Apesar de se ter obtido melhor agitação do reator com os dois impelidores, após 15 dias de ensaio observou-se que praticamente toda a biomassa estava danificada. Os valores experimentais obtidos durante o monitoramento do ensaio BA-E estão apresentados no anexo G.

\subsubsection{Ensaio BA-F: (ASBR com agitação mecânica - utilização de 2 impelidores: hélice com turbina inclinada)}

Mantendo-se o mesmo objetivo de manter agitação efetiva no reator, mesmo com a biomassa flotada, e ao mesmo tempo minimizar os efeitos do contato entre o impelidor e os grânulos trocou-se a pá inclinada por turbina inclinada e diminuiu-se a freqüência de agitação de 120 para 75 rpm. Reduziu-se, também, o volume de biomassa granulada no reator à metade da quantidade utilizada nos ensaios anteriores. Assim, o reator passou a conter 1,0 litro de biomassa.

Nesta nova configuração manteve-se a COV aplicada correspondente a 2,4 g/l.d

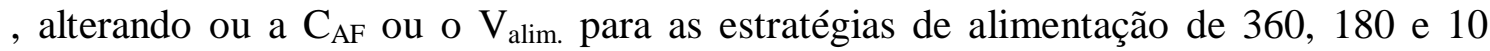
minutos. Assim, os ensaios BA-F1, BA-F2 e BA-F3 foram realizado com $\mathrm{C}_{\mathrm{AF}}$ de $4000 \mathrm{mg} / \mathrm{l}, \mathrm{V}_{\text {alim }}$ de 1,0 litro para as estratégias de alimentação de 360, 180 e 10 minutos respectivamente. Os ensaios $\mathrm{BA}-\mathrm{F} 4, \mathrm{BA}-\mathrm{F} 5$ e $\mathrm{BA}-\mathrm{F} 6$ foram realizados com $\mathrm{C}_{\mathrm{AF}}$ de $8000 \mathrm{mg} / \mathrm{l}, \mathrm{V}_{\text {alim. }}$ de 0,5 litro para as estratégias de alimentação $\left(\mathrm{T}_{\text {alim }}\right)$ de 360,180 e 10 minutos respectivamente.

A suplementação de nutrientes e metais traços nesses ensaios foi implementada pela diluição do soro de queijo em esgoto sintético com concentração (esgoto sintético) de $400 \mathrm{mg} / \mathrm{l}$ e a suplementação de alcalinidade a bicarbonato na forma de bicarbonato de sódio foi mantida em $50 \%$ da relação mássica $\mathrm{NaHCO}_{3} / \mathrm{DQO}$. 
5.2.5.1 $\left(C_{A F}=4000 \mathrm{mg} / \mathrm{l} ; V_{\text {alim. }}=1,0 \mathrm{l}\right)$

Os ensaios BA-F1, BA-F2 e BA-F3 foram realizados a $\mathrm{C}_{\mathrm{AF}}=4000 \mathrm{mg} / \mathrm{l}$ e $\mathrm{V}_{\text {alim }}$ = 1,0 1 para as estratégias de alimentação de 360, 180 e 10 minutos, respectivamente. Dessa forma, manteve-se a COV aplicada correspondente a 2,4 g/l.d .

Os anexos H1, H2 e H3 apresentam os valores experimentais obtidos nos ensaios BA-F1, BA-F2 e BA-F3, respectivamente.

\section{Monitoramento do reator}

Os valores médios das variáveis monitoradas no afluente e no efluente durante os ensaios BA-F1 a BA-F3 estão apresentados na Tabela 5.9, na qual $\mathrm{C}_{\mathrm{ST}}$ é a concentração da matéria orgânica para amostras não filtradas, $\mathrm{C}_{S S}$ é a concentração da matéria orgânica para amostras filtradas, $\varepsilon_{\mathrm{T}}$ é a eficiência de remoção para as amostras não filtradas, $\varepsilon_{S}$ é a eficiência de remoção para amostras filtradas. 
Tabela 5.9 - Valores médios das variáveis monitoradas durante a operação em batelada alimentada a $\mathrm{C}_{\mathrm{AF}}=4000 \mathrm{mg} / \mathrm{l} \mathrm{e} \mathrm{V}_{\text {alim. }}=1,01$ para os $\mathrm{T}_{\text {alim. }}$ de 360,180 e $10 \mathrm{~min}$.

\begin{tabular}{|c|c|c|c|c|}
\hline \multirow{2}{*}{ Parâmetro } & \multirow{2}{*}{ Afluente } & \multicolumn{3}{|c|}{ Efluente } \\
\hline & & $\mathrm{T}_{\mathrm{alim}}=360 \mathrm{~min}$ & $\mathrm{~T}_{\mathrm{alim}}=180 \mathrm{~min}$ & $\mathrm{~T}_{\mathrm{alim}}=10 \mathrm{~min}$ \\
\hline $\mathrm{C}_{\mathrm{ST}}(\mathrm{mg} / \mathrm{l})$ & $4577,8 \pm 211,6^{(12)}$ & $686,8 \pm 107,7^{(4)}$ & $514,2 \pm 122,3^{(4)}$ & $274,3 \pm 24,4^{(4)}$ \\
\hline$\varepsilon_{\mathrm{T}}(\%)$ & - & $85,5 \pm 2,3^{(4)}$ & $88,5 \pm 2,7^{(4)}$ & $93,9 \pm 0,5^{(4)}$ \\
\hline $\mathrm{C}_{\mathrm{SS}}(\mathrm{mg} / \mathrm{l})$ & - & $259,5 \pm 55,1^{(4)}$ & $148,7 \pm 21,2^{(4)}$ & $97,3 \pm 13,3^{(4)}$ \\
\hline$\varepsilon_{\mathrm{S}}(\%)$ & - & $94,5 \pm 1,2^{(4)}$ & $96,7 \pm 0,5^{(4)}$ & $97,8 \pm 0,3^{(4)}$ \\
\hline AVT (mgHAc/l) & $159,8 \pm 35,50^{(9)}$ & $67,1 \pm 13,6^{(4)}$ & $38,6 \pm 13,5^{(4)}$ & $26,9 \pm 2,6^{(4)}$ \\
\hline $\mathrm{AB}\left(\mathrm{mgCaCO}_{3} / \mathrm{l}\right)$ & $1358,9 \pm 194,11^{(9)}$ & $1790,7 \pm 246,7^{(4)}$ & $1049,1 \pm 287,7^{(4)}$ & $1353,3 \pm 230,2^{(4)}$ \\
\hline $\mathrm{AI} / \mathrm{AP}$ & $0,42 \pm 0,07^{(9)}$ & $0,36 \pm 0,05^{(4)}$ & $0,39 \pm 0,05^{(4)}$ & $0,40 \pm 0,01$ \\
\hline $\mathrm{pH}$ & $8,0 \pm 0,23^{(9)}$ & $7,2 \pm 0,16^{(4)}$ & $6,83 \pm 0,06^{(4)}$ & $6,87 \pm 0,06^{(4)}$ \\
\hline $\mathrm{ST}(\mathrm{mg} / \mathrm{l})$ & $5535 \pm 116,2^{(9)}$ & 2782 e $3328^{(o b s)}$ & $2002 \pm 456^{(4)}$ & $1567 \pm 247^{(4)}$ \\
\hline $\mathrm{SVT}(\mathrm{mg} / \mathrm{l})$ & $3791,0 \pm 85,5^{(9)}$ & 854 e $1218^{\text {(obs) }}$ & $732 \pm 148^{(4)}$ & $533 \pm 6^{(4)}$ \\
\hline $\mathrm{SST}(\mathrm{mg} / \mathrm{l})$ & $143,0 \pm 33,5^{(9)}$ & 388 e $472^{(\text {obs })}$ & $347 \pm 106^{(4)}$ & $151 \pm 58^{(4)}$ \\
\hline $\mathrm{SSV}(\mathrm{mg} / \mathrm{l})$ & $120,0 \pm 23,2^{(9)}$ & 340 e $372^{\text {(obs) }}$ & $293 \pm 86^{(4)}$ & $134 \pm 48^{(4)}$ \\
\hline
\end{tabular}

*Entre parênteses o número de amostras consideradas no cálculo da média obs: Valores mínimo e máximo das variáveis monitoradas

Como se pode observar na Tabela 5.9 e nas Figuras 5.30 a 5.33, o reator apresentou elevada eficiência em remoção da matéria orgânica em cada uma das três condições. Observa-se também que a eficiência em remoção de DQO, principalmente DQO total, aumentou com a diminuição do $\mathrm{T}_{\text {alim. }}$ Os valores de $\mathrm{AVT}$ e de $\mathrm{AB}$ mostram que a operação manteve-se estável durante os ensaios, o que se comprovou com os valores de $\mathrm{pH}$ no efluente, mantido próximo do neutro.

A diferença mais significativa observada foi o aumento da remoção de sólidos com a diminuição do $\mathrm{T}_{\text {alim}}$. 


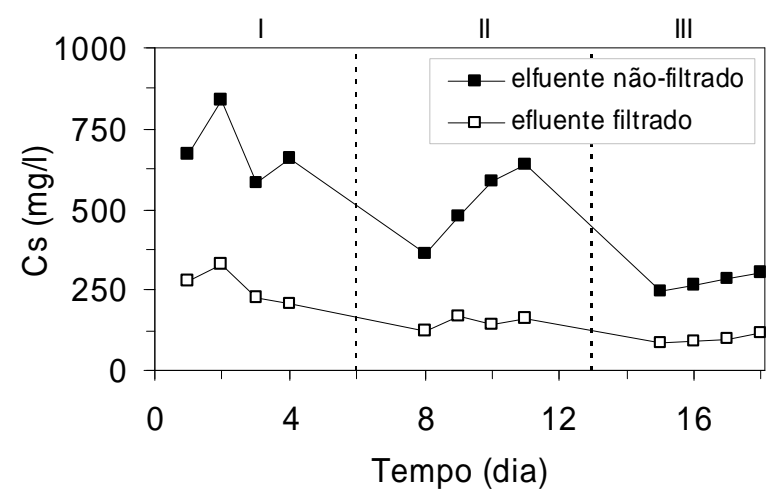

Figura 5.30 - Concentração de matéria orgânica, de amostras filtradas e não filtradas do efluente, durante a operação em batelada alimentada a $C_{\mathrm{AF}}=4000 \mathrm{mg} / \mathrm{l}, \mathrm{V}_{\text {alim. }}=1,01 \mathrm{nas}$ condições I $\left(\mathrm{T}_{\text {alim. }}=360 \mathrm{~min}\right), \mathrm{II}\left(\mathrm{T}_{\text {alim. }}=180 \mathrm{~min}\right)$ e III $\left(\mathrm{T}_{\text {alim. }}=10 \mathrm{~min}\right)$.

As Figuras 5.30 e 5.31 mostram que a eficiência em remoção de matéria

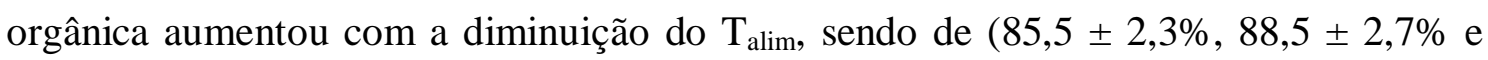
$93,9 \pm 0,5 \%)$, em DQO total, e $(94,5 \pm 1,2 \%, 96,7 \pm 0,5 \%$ e $97,8 \pm 0,3 \%)$,em DQO solúvel, para respectivos $\mathrm{T}_{\text {alim }}$ de 360,180 e $10 \mathrm{~min}$.

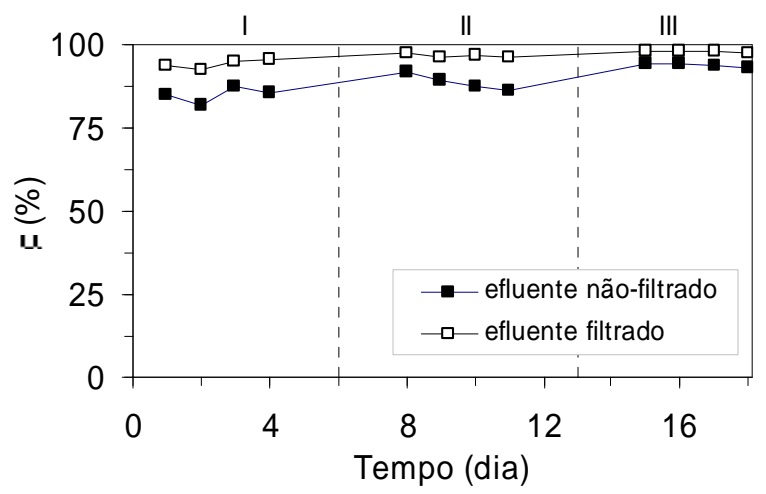

Figura 5.31 - Eficiência de remoção da matéria orgânica, em termos de DQO, de amostras do efluente filtradas e não filtradas durante a operação em batelada alimentada a $\mathrm{C}_{\mathrm{AF}}=4000 \mathrm{mg} / \mathrm{l}$, $\mathrm{V}_{\text {alim. }}=1,01$ nas condições $\mathrm{I}\left(\mathrm{T}_{\text {alim. }}=360 \mathrm{~min}\right)$, II $\left(\mathrm{T}_{\text {alim. }}=180 \mathrm{~min}\right)$ e III $\left(\mathrm{T}_{\text {alim. }}=10 \mathrm{~min}\right)$.

Dessa forma observou-se que o aumento do tempo de enchimento, apesar de manter menores concentrações de substrato no reator evitando o acúmulo, prejudicou consideravelmente a eficiência do processo, principalmente em termos de DQO total. 


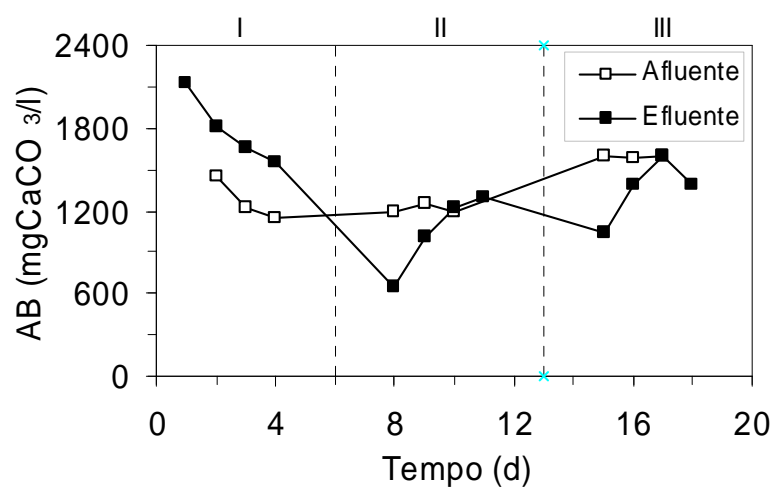

Figura 5.32 - Concentração de Alcalinidade a Bicarbonato (AB) durante a operação em batelada alimentada a $\mathrm{C}_{\mathrm{AF}}=4000 \mathrm{mg} / \mathrm{l}, \mathrm{V}_{\text {alim. }}=1,01$ nas condições $\mathrm{I}\left(\mathrm{T}_{\text {alim. }}=360 \mathrm{~min}\right), \mathrm{II}\left(\mathrm{T}_{\text {alim. }}=180\right.$ $\min )$ e III ( $\left.\mathrm{T}_{\text {alim. }}=10 \mathrm{~min}\right)$.

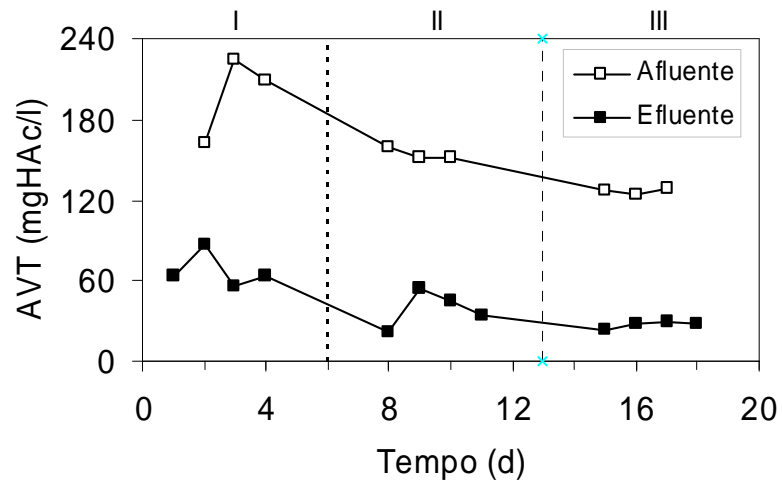

Figura 5.33 - Concentração de Ácidos Voláteis Totais (AVT) durante a operação em batelada alimentada a $\mathrm{C}_{\mathrm{AF}}=4000 \mathrm{mg} / \mathrm{l}, \mathrm{V}_{\text {alim. }}=1,01$ nas condições $\mathrm{I}\left(\mathrm{T}_{\text {alim. }}=360 \mathrm{~min}\right), \mathrm{II}\left(\mathrm{T}_{\text {alim. }}=180\right.$ $\min )$ e III ( $\left.\mathrm{T}_{\text {alim. }}=10 \mathrm{~min}\right)$.

Embora as concentrações de $\mathrm{AB}$, conforme se observou na Figura 5.32, tenham sido maiores durante a condição I, o que indicaria uma operação mais estável, o aumento do tempo de enchimento reduziu a eficiência do processo. Além disso, as diferenças dos valores de AVT, Figura 5.33, não foram muito conclusivas. 


\section{Perfil de Conversão ao longo do ciclo}

Os perfis de conversão ao longo do ciclo de $\mathrm{C}_{\mathrm{s}}(\mathrm{mg} / \mathrm{l}), \mathrm{AB}\left(\mathrm{mgCaCO}_{3} / \mathrm{l}\right)$, AVT (mgHAc/l) e AVI ( $\mathrm{mmol} / \mathrm{l})$ foram realizados no oitavo ciclo de cada condição.

A Figura 5.34 mostra que as operações em batelada alimentada (condições I e II), apesar de não permitirem a formação de elevados picos de concentração de matéria orgânica durante o ciclo, apresentaram menor remoção de DQO filtrada.

Dessa forma o processo parece ser mais eficiente com a variação da relação F/M, muito elevada no início de ciclo e baixa ao final do ciclo, conferindo com Dague et al. (1992).

Além disso, os resultados apresentados nas Figuras 5.34 e 5.35 contrariam os resultados obtidos por Bagley e Brodkorb (1995), pois mostram que o aumento do tempo de enchimento não resultou apenas no deslocamento dos picos de concentração ao longo do ciclo como também possibilitou manter baixas concentrações ao longo do ciclo, ou seja, diferentes valores de pico de concentração de matéria orgânica, AVT e $\mathrm{AB}$ para diferentes estratégias de alimentação.

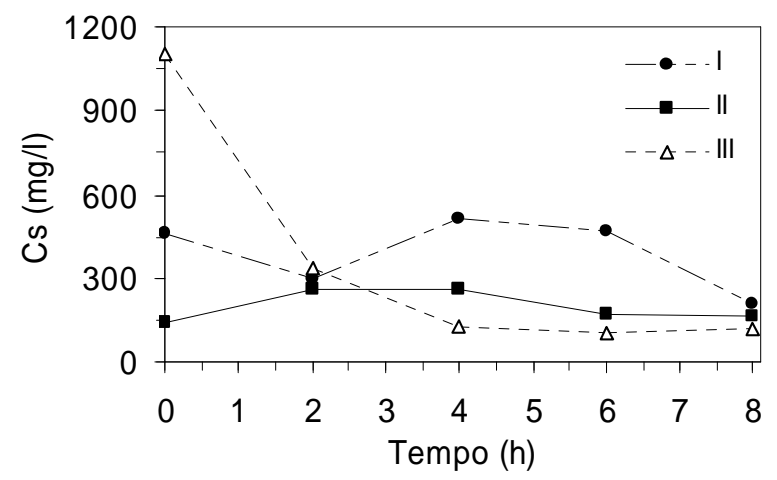

Figura 5.34 - Perfil de concentração da matéria orgânica ao longo do ciclo, em termos de DQO, de amostras filtradas, durante a operação em batelada alimentada a $C_{\mathrm{AF}}=4000 \mathrm{mg} / \mathrm{l}, \mathrm{V}_{\text {alim. }}=1,0$ 1 nas condições I ( $\left.\mathrm{T}_{\text {alim. }}=360 \mathrm{~min}\right)$, II $\left(\mathrm{T}_{\text {alim. }}=180 \mathrm{~min}\right)$ e III $\left(\mathrm{T}_{\text {alim. }}=10 \mathrm{~min}\right)$. 

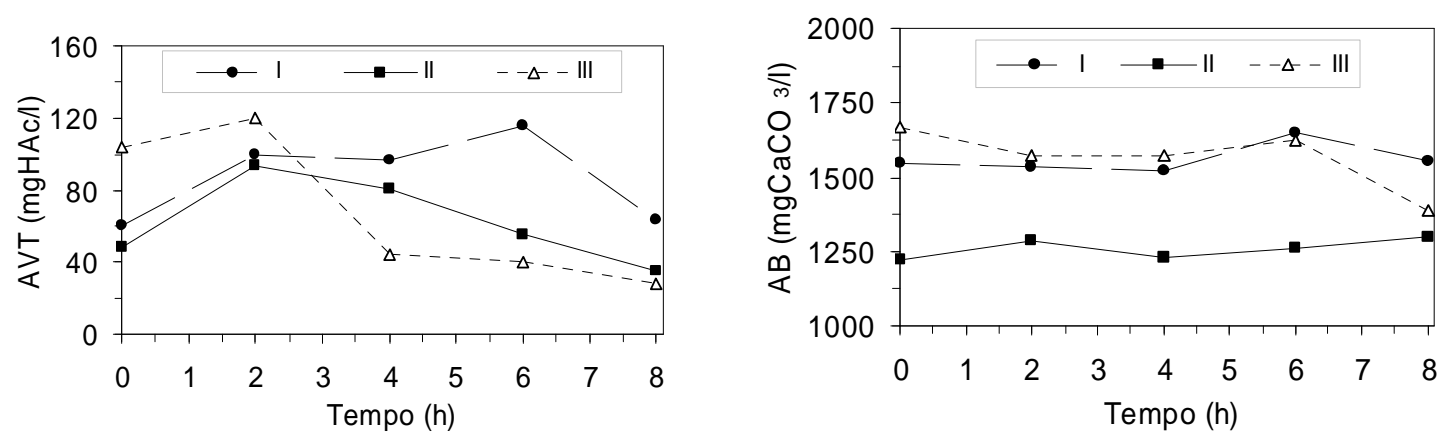

Figura 5.35 - Perfil de concentração de Ácidos Voláteis Totais (AVT) e de Alcalinidade a Bicarbonato $(\mathrm{AB})$ ao longo do ciclo, durante a operação em batelada alimentada a $\mathrm{C}_{\mathrm{AF}}=4000$ $\mathrm{mg} / \mathrm{l}, \mathrm{V}_{\text {alim. }}=1,01$ nas condições $\mathrm{I}\left(\mathrm{T}_{\text {alim. }}=360 \mathrm{~min}\right), \mathrm{II}\left(\mathrm{T}_{\text {alim. }}=180 \mathrm{~min}\right)$ e III $\left(\mathrm{T}_{\text {alim. }}=10 \mathrm{~min}\right)$.

Observou-se na Figura 5.35 que a concentração de ácidos voláteis totais teve maior redução após o término do tempo de alimentação nos ensaios em batelada alimentada. Para o ensaio em batelada, os maiores valores dos picos de AVT e de AB podem não ter sido detectados devido ao grande espaço de tempo entre as amostras, principalmente durante a primeira hora de ciclo.

Contudo, as poucas alterações detectadas nas concentrações de AVT e de AB condizem com o perfil de $\mathrm{pH}$ que permaneceu praticamente constante, conforme se observa na Figura 5.36. Maiores variações do $\mathrm{pH}$ podem não ter sido detectadas, principalmente durante a operação em batelada (condição III).

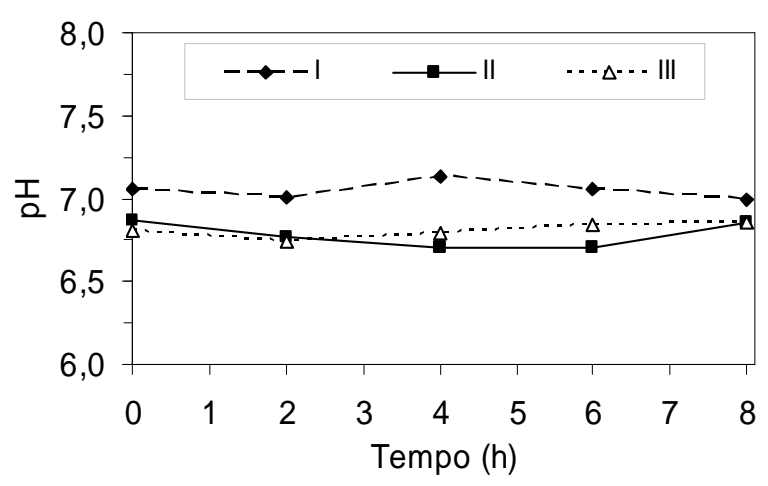

Figura 5.36 - Perfil de $\mathrm{pH}$ ao longo do ciclo, durante a operação em batelada alimentada a $\mathrm{C}_{\mathrm{AF}}=$ $4000 \mathrm{mg} / \mathrm{l}, \mathrm{V}_{\text {alim. }}=1,01$ nas condições I $\left(\mathrm{T}_{\text {alim. }}=360 \mathrm{~min}\right)$, II $\left(\mathrm{T}_{\text {alim. }}=180 \mathrm{~min}\right)$ e III $\left(\mathrm{T}_{\text {alim. }}=10\right.$ $\min )$. 
As Tabelas 5.9, 5.10 e 5.11 apresentam os perfis de ácidos voláteis intermediários dos ensaios a $\mathrm{C}_{\mathrm{AF}}$ de $4000 \mathrm{mg} / \mathrm{l}$ e $\mathrm{V}_{\text {alim }}$ de 1,0 l para os $\mathrm{T}_{\text {alim }}$ de 360, 180 e $10 \mathrm{~min}$, respectivamente. Os perfis foram colocados separadamente, cada um em uma tabela, para facilitar a visualização dos perfis de AVI.

Segundo a Tabela 5.10, durante a condição I ( $\mathrm{T}_{\text {alim }}$ de $\left.360 \mathrm{~min}\right)$ os ácidos voláteis intermediários que tiveram maior influência no processo, em termos de concentração, foram os ácidos acético e propiônico.

Tabela 5.10 - Perfil de Ácidos Voláteis Intermediários (AVI) ao longo do ciclo, durante a operação do reator em batelada alimentada a $\mathrm{C}_{\mathrm{AF}}=4000 \mathrm{mg} / \mathrm{l}$, Valim. $=1,01 \mathrm{e}$ Talim. $=360$ minutos.

\begin{tabular}{cccccc}
\hline \multicolumn{5}{c}{ AVI (mmol/l) } \\
\hline tempo (h) & Acético & Propiônico & Iso-Butírico & Butírico & Iso-Valérico \\
\hline 0 & 0,00 & 17,74 & 1,47 & 0,00 & 1,33 \\
2 & 32,16 & 19,23 & 3,39 & 10,51 & 1,83 \\
4 & 31,40 & 33,41 & 2,01 & 4,67 & 2,17 \\
6 & 38,47 & 42,01 & 2,77 & 5,85 & 2,85 \\
8 & 0,00 & 0,00 & 0,00 & 0,00 & 0,00 \\
\hline
\end{tabular}

Tabela 5.11 - Perfil de concentração de Ácidos Voláteis Intermediários (AVI) ao longo do ciclo, durante a operação em batelada alimentada a $\mathrm{C}_{\mathrm{AF}}=4000 \mathrm{mg} / \mathrm{l}, \mathrm{V}_{\text {alim. }}=1,01 \mathrm{e} \mathrm{T}_{\text {alim. }}=180$ minutos.

\begin{tabular}{cccccc}
\hline \multicolumn{6}{c}{ AVI (mmol/l) } \\
\hline tempo (h) & Acético & Propiônico & Iso-Butírico & Butírico & Iso-Valérico \\
\hline 0 & 0,00 & 2,57 & 1,56 & 1,43 & 2,92 \\
2 & 20,59 & 12,62 & 11,16 & 35,47 & 4,63 \\
4 & 0,00 & 13,59 & 18,13 & 38,67 & 1,28 \\
6 & 0,00 & 0,00 & 9,33 & 5,60 & 0,00 \\
8 & 0,00 & 0,00 & 0,00 & 0,00 & 0,00 \\
\hline \hline
\end{tabular}


Tabela 5.12 - Perfil de concentração de Ácidos Voláteis Intermediários (AVI) ao longo do ciclo, durante a operação em batelada a $\mathrm{C}_{\mathrm{AF}}=4000 \mathrm{mg} / \mathrm{l}, \mathrm{V}_{\text {alim. }}=1,01$ e $\mathrm{T}_{\text {alim. }}=10$ minutos.

\begin{tabular}{ccccccc}
\hline tempo $(\mathrm{h})$ & Acético & Propiônico & Iso-Butírico & Butírico & Iso-Valérico & Valérico \\
\hline 0 & 28,71 & 4,76 & 0,00 & 7,26 & 0,00 & 0,00 \\
2 & 23,05 & 69,34 & 9,76 & 17,67 & 9,55 & 1,69 \\
4 & 0,00 & 7,93 & 1,47 & 0,00 & 1,06 & 0,00 \\
6 & 0,00 & 0,00 & 0,00 & 0,00 & 0,00 & 0,00 \\
8 & 0,00 & 0,00 & 0,00 & 0,00 & 0,00 & 0,00 \\
\hline
\end{tabular}

Os ácidos voláteis intermediários que tiveram maior influência no processo, em termos de concentração durante a condição II ( $\mathrm{T}_{\text {alim }}$ de $\left.180 \mathrm{~min}\right)$, foram os ácidos butírico, acético, iso-butírico e propiônico em ordem decrescente de concentração, conforme a Tabela 5.11. Destaca-se nesta tabela o aumento das concentrações dos ácidos butírico e iso-butírico, o que não aconteceu nos ensaios em batelada.

Durante a condição III ( $\mathrm{T}_{\text {alim }}$ de $10 \mathrm{~min}$ ) os ácidos voláteis intermediários que tiveram maior influência no processo, em termos de concentração, foram os ácidos acético e propiônico, conforme se observa na Tabela 5.12.

Comparando-se as três Tabelas, 5.10, 5.11 e 5.12, não foi possível detectar nenhuma tendência de comportamento, provavelmente devido ao limite de detecção do equipamento utilizado. Se essa hipótese for verdadeira, talvez não tenha sido possível detectar nenhum AVI em concentração maior que o limite do equipamento e assim, nenhuma conclusão poderia ser obtida pelos resultados apresentados nas Tabelas 5.10, 5.11 e 5.12 .

\section{Análise de Sólidos do Lodo}

Após a realização dos perfis de concentração ao longo do ciclo, em cada um dos ensaios retirou-se uma amostra para a análise do lodo presente no reator. Dessa análise foi possível obter a relação mássica SVT/ST que serve de indicação da quantidade de microrganismos presentes na biomassa. Dessa forma obteve-se que fração mássica(SVT/ST) foi de 87,6\% para a condição I ( $\mathrm{T}_{\text {alim }}$ de $\left.360 \mathrm{~min}\right), 87,7 \%$ para a condição II ( $\mathrm{T}_{\text {alim }}$ de $\left.180 \mathrm{~min}\right)$ e $86,1 \%$ para a condição III ( $\mathrm{T}_{\text {alim }}$ de $\left.10 \mathrm{~min}\right)$. 


\subsubsection{2 $\left(C_{A F}=8000 \mathrm{mg} / \mathrm{l} ; V_{\text {alim }}=0,5 \mathrm{l}\right)$}

Após o término dos ensaios a $\mathrm{C}_{\mathrm{AF}}$ de $4000 \mathrm{mg} / \mathrm{l}$ e $\mathrm{V}_{\text {alim }}$ de 1,0 l, iniciaram-se os ensaios a $\mathrm{C}_{\mathrm{AF}}$ de $8000 \mathrm{mg} / \mathrm{l}$ e $\mathrm{V}_{\text {alim }}$ de 0,5 1. Os ensaios BA-F4, BA-F5 e BA-F6 foram realizados a $\mathrm{C}_{\mathrm{AF}}=4000 \mathrm{mg} / \mathrm{l}$ e $\mathrm{V}_{\text {alim }}=1,01$ para as estratégias de alimentação de 360 , 180 e 10 minutos, respectivamente. Dessa forma, manteve-se a COV aplicada correspondente a $2,4 \mathrm{~g} / \mathrm{l} . \mathrm{d}$.

Os anexos H4, H5 e H6 apresentam os valores experimentais obtidos nos ensaios BA-F4, BA-F5 e BA-F6, respectivamente.

\section{Monitoramento do reator}

Os valores médios das variáveis monitoradas no afluente e no efluente durante os ensaios BA-F4 a BA-F6 estão apresentados na Tabela 5.13, onde $\mathrm{C}_{\mathrm{ST}}$ é a concentração da matéria orgânica para amostras não filtradas, $\mathrm{C}_{\mathrm{SS}}$ é a concentração da matéria orgânica para amostras filtradas, $\varepsilon_{\mathrm{T}}$ é a eficiência de remoção para as amostras não filtradas, $\varepsilon_{S}$ é a eficiência de remoção para amostras filtradas. 
Tabela 5.13 - Valores médios das variáveis monitoradas durante a operação em batelada alimentada a $\mathrm{C}_{\mathrm{AF}}=8000 \mathrm{mg} / \mathrm{l}, \mathrm{V}_{\text {alim. }}=0,51$ para os $\mathrm{T}_{\text {alim. }}$ de 360,180 e $10 \mathrm{~min}$.

\begin{tabular}{|c|c|c|c|c|}
\hline \multirow{2}{*}{ Parâmetro } & \multirow{2}{*}{ Afluente } & \multicolumn{3}{|c|}{ Efluente } \\
\hline & & Talim $=360 \mathrm{~min}$ & Talim $=180 \mathrm{~min}$ & Talim $=10 \mathrm{~min}$ \\
\hline $\mathrm{C}_{\mathrm{ST}}(\mathrm{mg} / \mathrm{l})$ & $8848,5 \pm 563,0^{(12)}$ & $531,9 \pm 193,8^{(4)}$ & $784,3 \pm 117,3^{(4)}$ & $747,7 \pm 44,1^{(4)}$ \\
\hline$\varepsilon_{\mathrm{T}}(\%)$ & - & $91,8 \pm 3,0^{(4)}$ & $90,9 \pm 1,4^{(4)}$ & $91,9 \pm 0,5^{(4)}$ \\
\hline $\mathrm{C}_{\mathrm{SS}}(\mathrm{mg} / \mathrm{l})$ & - & $122,7 \pm 49,0^{(4)}$ & $176,4 \pm 31,5^{(4)}$ & $172,0 \pm 21,7^{(4)}$ \\
\hline$\varepsilon_{\mathrm{S}}(\%)$ & - & $98,1 \pm 0,8^{(4)}$ & $98,0 \pm 0,5^{(4)}$ & $98,1 \pm 0,2^{(4)}$ \\
\hline AVT (mgHAc/l) & $262,2 \pm 26,1^{(9)}$ & $127,7 \pm 1,1^{(3)}$ & $73,5 \pm 3,4^{(4)}$ & $70,1 \pm 2,6^{(4)}$ \\
\hline $\mathrm{AB}\left(\mathrm{mgCaCO}_{3} / \mathrm{l}\right)$ & $2508,6 \pm 488,1^{(9)}$ & $3043,6 \pm 33,8^{(3)}$ & $2281,0 \pm 240,8^{(4)}$ & $2184,0 \pm 84,7^{(4)}$ \\
\hline $\mathrm{AI} / \mathrm{AP}$ & $0,37 \pm 0,09^{(9)}$ & $0,34 \pm 0,04^{(3)}$ & $0,41 \pm 0,02^{(4)}$ & $0,37 \pm 0,04^{(4)}$ \\
\hline $\mathrm{pH}$ & $7,9 \pm 0,4^{(9)}$ & $7,30 \pm 0,11^{(3)}$ & $7,18 \pm 0,08^{(4)}$ & $7,21 \pm 0,05^{(4)}$ \\
\hline $\mathrm{ST}(\mathrm{mgll})$ & $9802,3 \pm 946,2^{(7)}$ & 3572 e $3896^{(\text {obs })}$ & 3746 e $3810^{\text {(obs) }}$ & $3687 \pm 180^{(3)}$ \\
\hline $\mathrm{SVT}(\mathrm{mg} / \mathrm{l})$ & $6825,7 \pm 585,3^{(7)}$ & 1022 e $3000^{\text {(obs) }}$ & 1138 e $1230^{(o b s)}$ & $1027 \pm 87^{(3)}$ \\
\hline $\mathrm{SST}(\mathrm{mg} / \mathrm{l})$ & $251,1 \pm 41,8^{(7)}$ & 370 e $423^{\text {(obs) }}$ & 467 e $510^{\text {(obs) }}$ & $381 \pm 115^{(3)}$ \\
\hline $\mathrm{SSV}(\mathrm{mg} / \mathrm{l})$ & $194,9 \pm 35,0^{(7)}$ & 277 e $323^{\text {(obs) }}$ & 277 e $383^{\text {(obs) }}$ & $324 \pm 74^{(3)}$ \\
\hline
\end{tabular}

*Entre parênteses o número de amostras consideradas no cálculo da média obs: Valores mínimo e máximo das variáveis monitoradas

Como se pode observar na Tabela 5.13 e nas Figuras 5.37 a 5.40, o reator ter apresentado elevada eficiência em remoção de matéria orgânica, tanto para DQO total quanto para DQO filtrada. Observou-se, contudo que apesar das condições não apresentarem diferenças muito significativas em termos de eficiência, as diferenças dos valores de DQO no efluente, principalmente DQO total, são grandes o suficiente para concluir que nessas condições, $\mathrm{C}_{\mathrm{AF}}$ de $8000 \mathrm{mg} / \mathrm{l}$ e $\mathrm{V}_{\text {alim }}$ de $0,5 \mathrm{l}$, o aumento do $\mathrm{T}_{\text {alim }}$ resultou em maior eficiência do processo, embora o valor de $\mathrm{C}_{\mathrm{ST}}$ tenha sido muito alto $(531,9 \pm 193,8 \mathrm{mg} / \mathrm{l})$.

Para a condição I ( $\mathrm{T}_{\text {alim }}$ de $360 \mathrm{~min}$ ) a concentração média de AVT no efluente (127,7 $\pm 1,1 \mathrm{mgHAc} / \mathrm{l})$ ficou acima de $100 \mathrm{mgHAc} / \mathrm{l}$ e a concentração média de AB (3043,6 \pm 33,8 $\left.\mathrm{mgCaCO}_{3} / \mathrm{l}\right)$ próxima a $3000 \mathrm{mgCaCO}_{3} / 1$, enquanto nas condições II e III as concentrações médias de AVT $(73,5 \pm 3,4$ e 70,1 $\pm 2,6 \mathrm{mgHAc} / 1$, respectivamente) permaneceram abaixo de $100 \mathrm{mgHAc} / \mathrm{l}$ e as concentrações médias de $\mathrm{AB}(2281,0 \pm$ 240,8 e 2184,0 $\pm 84,7 \mathrm{mgCaCO}_{3} / 1$, respectivamente) ficaram abaixo de 3000 $\mathrm{mgCaCO}_{3} / 1$. Esses resultados mostram que, em termos de estabilidade, as operações mantiveram-se semelhantes. 


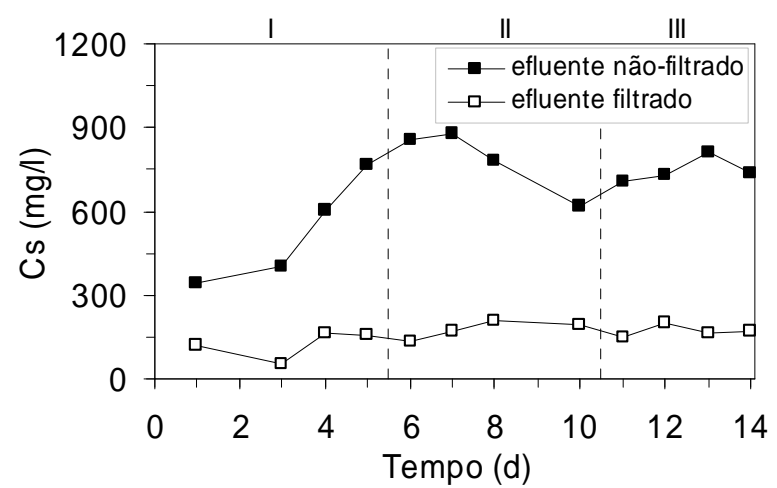

Figura 5.37 - Concentração de matéria orgânica, em termos de DQO, de amostras filtradas e não filtradas no efluente durante a operação em batelada alimentada a $\mathrm{C}_{\mathrm{AF}}=8000 \mathrm{mg} / \mathrm{l}, \mathrm{V}_{\text {alim. }}=$ 0,5 1 nas condições I $\left(\mathrm{T}_{\text {alim. }}=360 \mathrm{~min}\right), \mathrm{II}\left(\mathrm{T}_{\text {alim. }}=180 \mathrm{~min}\right)$ e III $\left(\mathrm{T}_{\text {alim. }}=10 \mathrm{~min}\right)$.

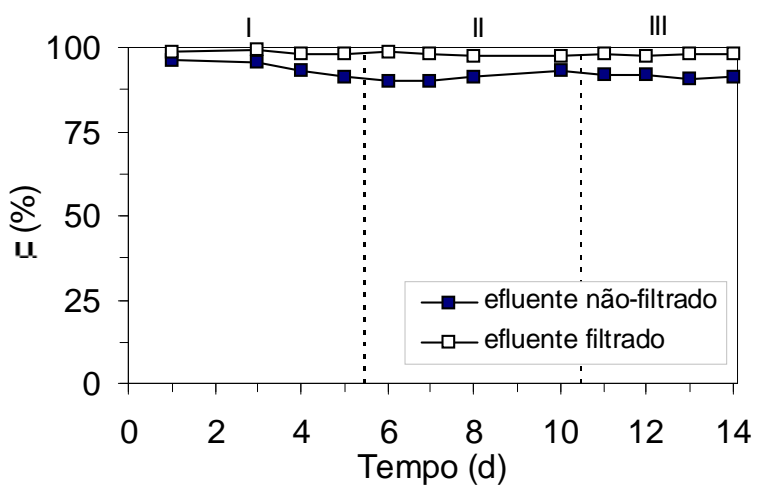

Figura 5.38 - Eficiência de remoção da matéria orgânica, em termos de DQO, de amostras do efluente filtradas e não filtradas durante a operação em batelada alimentada a $\mathrm{C}_{\mathrm{AF}}=8000 \mathrm{mg} / \mathrm{l}$, $\mathrm{V}_{\text {alim. }}=0,51$ nas condições I $\left(\mathrm{T}_{\text {alim. }}=360 \mathrm{~min}\right), \mathrm{II}\left(\mathrm{T}_{\text {alim. }}=180 \mathrm{~min}\right)$ e III $\left(\mathrm{T}_{\text {alim. }}=10 \mathrm{~min}\right)$. 


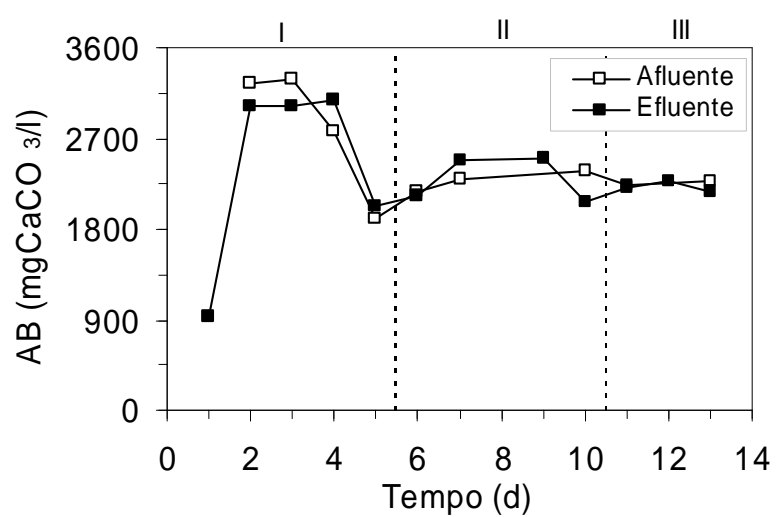

Figura 5.39 - Concentração de Alcalinidade a Bicarbonato (AB) de amostras do afluente e do efluente durante a operação em batelada alimentada a $C_{\mathrm{AF}}=8000 \mathrm{mg} / \mathrm{l}, \mathrm{V}_{\text {alim. }}=0,51$ nas condições I $\left(\mathrm{T}_{\text {alim. }}=360 \mathrm{~min}\right), \mathrm{II}\left(\mathrm{T}_{\text {alim. }}=180 \mathrm{~min}\right)$ e III $\left(\mathrm{T}_{\text {alim. }}=10 \mathrm{~min}\right)$.

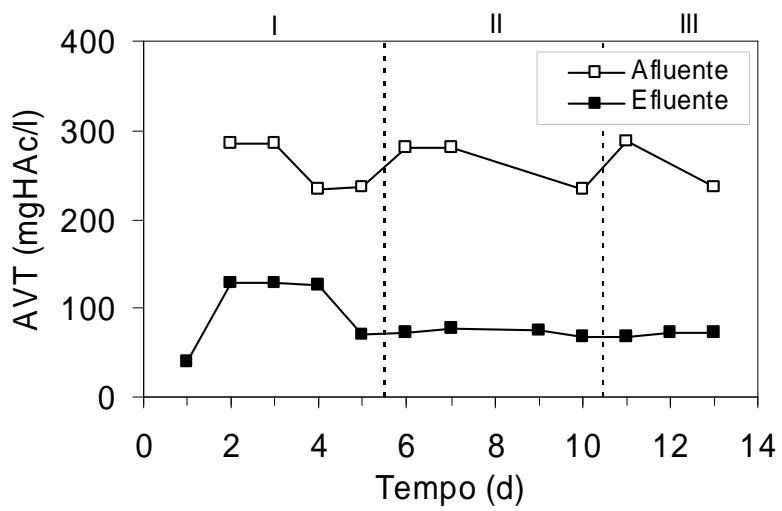

Figura 5.40 - Concentração de Ácidos Voláteis Totais (AVT) de amostras do afluente e do efluente durante a operação em batelada alimentada a $\mathrm{C}_{\mathrm{AF}}=8000 \mathrm{mg} / \mathrm{l}, \mathrm{V}_{\text {alim. }}=0,5 \mathrm{l}$ nas condições I $\left(\mathrm{T}_{\text {alim. }}=360 \mathrm{~min}\right), \mathrm{II}\left(\mathrm{T}_{\text {alim. }}=180 \mathrm{~min}\right)$ e III $\left(\mathrm{T}_{\text {alim. }}=10 \mathrm{~min}\right)$.

\section{Perfil de Conversão ao longo do ciclo}

Os perfis de conversão ao longo do ciclo de $\mathrm{C}_{\mathrm{s}}(\mathrm{mg} / \mathrm{l}), \mathrm{AB}\left(\mathrm{mgCaCO}_{3} / \mathrm{l}\right)$, AVT (mgHAc/l) e AVI (mmol/l) foram realizados no oitavo ciclo de cada condição.

A Figura 5.41 mostra que as operações em batelada alimentada (condições I e II) além de não permitirem a formação de elevados picos de concentração de matéria orgânica durante o ciclo, apresentaram remoção de matéria orgânica solúvel semelhante à operação em batelada (condição III). 


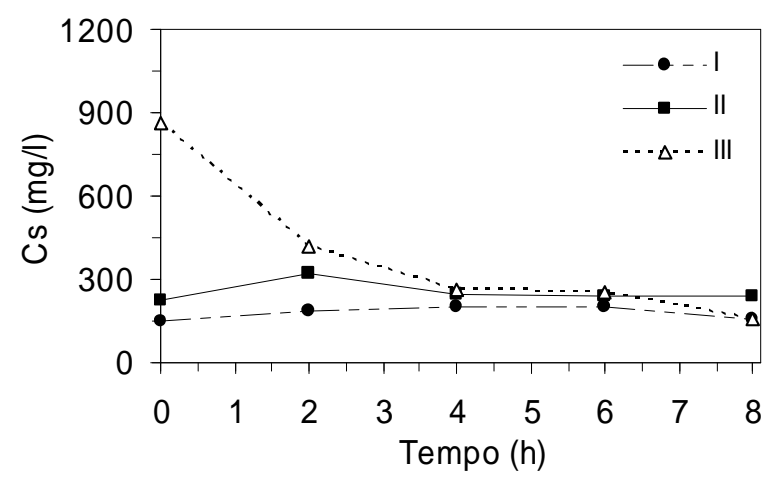

Figura 5.41 - Perfil de concentração de matéria orgânica ao longo do ciclo, em termos de DQO, durante a operação em batelada alimentada a $\mathrm{C}_{\mathrm{AF}}=8000 \mathrm{mg} / \mathrm{l}, \mathrm{V}_{\text {alim. }}=0,5 \mathrm{l}$ nas condições $\mathrm{I}$ $\left(\mathrm{T}_{\text {alim. }}=360 \mathrm{~min}\right), \mathrm{II}\left(\mathrm{T}_{\text {alim. }}=180 \mathrm{~min}\right)$ e III $\left(\mathrm{T}_{\text {alim. }}=10 \mathrm{~min}\right)$.
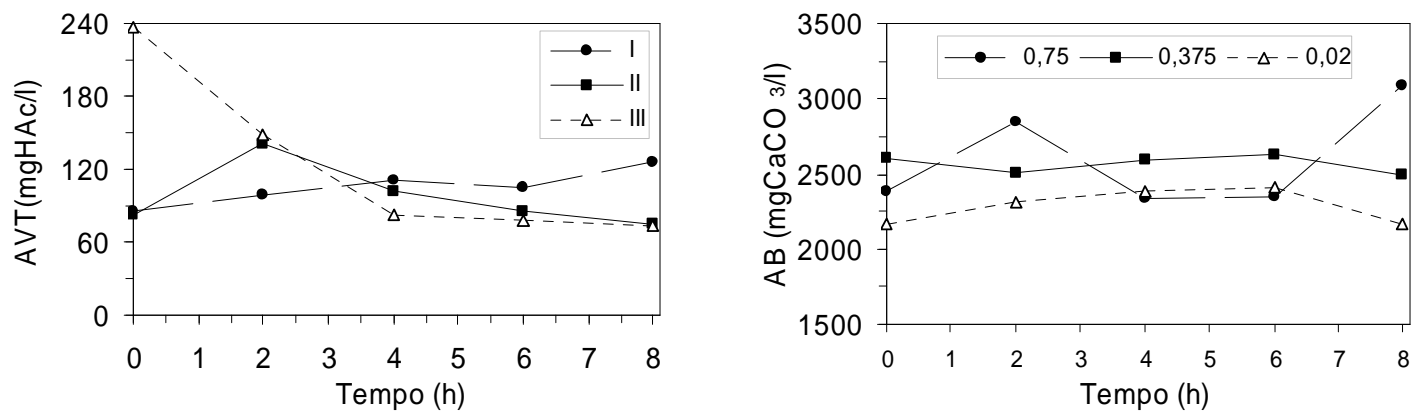

Figura 5.42 - Perfil de Concentração de Ácidos Voláteis Totais (AVT) e de Alcalinidade a Bicarbonato $(\mathrm{AB})$ ao longo do ciclo, durante a operação em batelada alimentada a $\mathrm{C}_{\mathrm{AF}}=8000$ $\mathrm{mg} / \mathrm{l}, \mathrm{V}_{\text {alim. }}=0,51$ nas condições I $\left(\mathrm{T}_{\text {alim. }}=360 \mathrm{~min}\right), \mathrm{II}\left(\mathrm{T}_{\text {alim. }}=180 \mathrm{~min}\right)$ e III $\left(\mathrm{T}_{\text {alim. }}=10 \mathrm{~min}\right)$.

Pode-se observar na Figura 5.42 que a concentração de pico dos ácidos voláteis totais não foi a mesma para as condições I, II e III. As concentrações de pico de AVT e de $\mathrm{AB}$ foram mais acentuadas na operação em batelada (condição I) que nas operações em batelada alimentada(condições I e II). Assim também o perfil de $\mathrm{pH}$ teve poucas variações sendo que as maiores variações ocorreram na operação em batelada (condição III), conforme a Figura 5.43. 


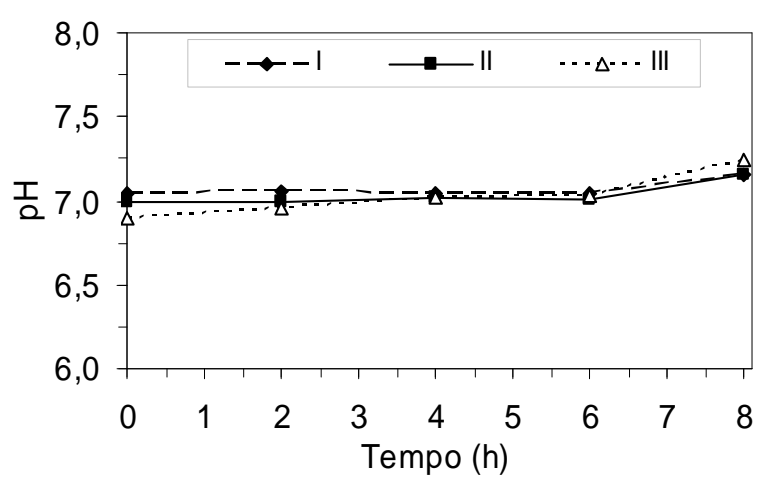

Figura 5.43 - Perfil de $\mathrm{pH}$ ao longo do ciclo durante a operação em batelada alimentada a $\mathrm{C}_{\mathrm{AF}}=$ $8000 \mathrm{mg} / \mathrm{l}, \mathrm{V}_{\text {alim. }}=0,51$ nas condições I $\left(\mathrm{T}_{\text {alim. }}=360 \mathrm{~min}\right), \mathrm{II}\left(\mathrm{T}_{\text {alim. }}=180 \mathrm{~min}\right)$ e III $\left(\mathrm{T}_{\text {alim. }}=10\right.$ $\min )$.

As Tabelas 5.13, 5.14 e 5.15 apresentam os perfis de ácidos voláteis intermediários dos ensaios a $\mathrm{C}_{\mathrm{AF}}$ de $8000 \mathrm{mg} / \mathrm{l}, \mathrm{V}_{\text {alim }}$ de 0,51 para os $\mathrm{T}_{\text {alim }}$ de $360,180 \mathrm{e}$ $10 \mathrm{~min}$, respectivamente. Os perfis foram colocados separadamente, cada um em uma tabela, para facilitar a visualização dos perfis de AVI.

Segundo a Tabela 5.14, os ácidos voláteis intermediários que tiveram maior influência no processo, em termos de concentração durante a condição I ( $\mathrm{T}_{\text {alim }}$ de 360 min), foram os ácidos acético e propiônico.

Tabela 5.14 - Perfil de concentração de Ácidos Voláteis Intermediários (AVI) ao longo do ciclo durante a operação em batelada alimentada a $\mathrm{C}_{\mathrm{AF}}=8000 \mathrm{mg} / \mathrm{l}, \mathrm{V}_{\text {alim. }}=0,51$ e $\mathrm{T}_{\text {alim. }}=360 \mathrm{~min}$.

\begin{tabular}{ccccc}
\hline \multicolumn{5}{c}{ perfil AVI (mmol/l) } \\
\hline tempo (h) & Acético & Propiônico & Iso-Butírico & Butírico \\
\hline 0 & 0,00 & 0,00 & 0,00 & 0,00 \\
2 & 14,86 & 6,34 & 1,66 & 6,57 \\
4 & 16,17 & 8,03 & 1,54 & 6,02 \\
6 & 24,25 & 12,42 & 1,76 & 7,12 \\
8 & 0,00 & 0,00 & 0,00 & 0,00 \\
\hline
\end{tabular}


Tabela 5.15 - Perfil de concentração de Ácidos Voláteis Intermediários (AVI) ao longo do ciclo, durante a operação em batelada alimentada a $\mathrm{C}_{\mathrm{AF}}=8000 \mathrm{mg} / \mathrm{l}, \mathrm{V}_{\text {alim. }}=0,51 \mathrm{e} \mathrm{T}_{\text {alim. }}=180$ $\min$.

\begin{tabular}{ccccc}
\hline \multicolumn{5}{c}{ perfil AVI (mmol/l) } \\
\hline tempo (h) & Acético & Propiônico & Iso-Butírico & Butírico \\
\hline 0 & 0,00 & 0,00 & 0,00 & 0,00 \\
2 & 47,58 & 27,78 & 2,88 & 9,54 \\
4 & 0,00 & 12,29 & 0,00 & 0,00 \\
6 & 0,00 & 0,00 & 0,00 & 0,00 \\
8 & 0,00 & 0,00 & 0,00 & 0,00 \\
\hline
\end{tabular}

Os ácidos voláteis intermediários que tiveram maior influência no processo, em termos de concentração durante a condição II ( $\mathrm{T}_{\text {alim }}$ de $\left.180 \mathrm{~min}\right)$, foram os ácidos acético e propiônico, conforme a Tabela 5.15.

Para a condição III ( $\mathrm{T}_{\text {alim }}$ de $\left.10 \mathrm{~min}\right)$, os ácidos voláteis intermediários que tiveram maior influência no processo, em termos de concentração, foram os ácidos acético e propiônico, como se observa na Tabela 5.16.

Tabela 5.16 - Perfil de concentração de Ácidos Voláteis Intermediários (AVI) ao longo do ciclo durante a operação em batelada a $\mathrm{C}_{\mathrm{AF}}=8000 \mathrm{mg} / \mathrm{l}, \mathrm{V}_{\text {alim. }}=0,5 \mathrm{le} \mathrm{T}_{\text {alim. }}=10$ minutos.

\begin{tabular}{ccccc}
\hline \multicolumn{5}{c}{ Perfil AVI (mmol/l) } \\
\hline tempo (h) & Acético & Propiônico & Iso-Butírico & Butírico \\
\hline 0 & 70,00 & 9,01 & 0,00 & 13,25 \\
2 & 37,12 & 56,56 & 5,75 & 4,59 \\
4 & 0,00 & 0,00 & 0,00 & 0,00 \\
6 & 0,00 & 0,00 & 0,00 & 0,00 \\
8 & 0,00 & 0,00 & 0,00 & 0,00 \\
\hline
\end{tabular}

Pode-se observar a partir da comparação dos perfis de AVI que o aumento do $\mathrm{T}_{\text {alim }}$ resultou em menores picos de concentração dos ácidos acético e propiônico. 


\section{Análise de Sólidos do Lodo}

Após a realização dos perfis de concentração ao longo do ciclo, em cada um dos ensaios retirou-se uma amostra para a análise do lodo presente no reator. Dessa análise foi possível obter a relação mássica SVT/ST que serve de indicação da quantidade de microrganismos presentes na biomassa. Dessa forma obteve-se que fração mássica(SVT/ST) foi de 86,4\% para a condição I ( $\mathrm{T}_{\text {alim }}$ de $360 \mathrm{~min}$ ), 84,5\% para a condição II ( $\mathrm{T}_{\text {alim }}$ de $\left.180 \mathrm{~min}\right)$ e $85,1 \%$ para a condição III ( $\mathrm{T}_{\text {alim }}$ de $\left.10 \mathrm{~min}\right)$.

\subsubsection{3 $\left(C_{A F}=2000 \mathrm{mg} / \mathrm{l} ; V_{\text {alim. }}=2,0 \mathrm{l}\right)$}

Terminado o BA-F6 iniciou-se o ensaio BA-F7 a COV aplicada correspondente a 2,4 g/l.d., com volume de efluente tratado por ciclo igual a 2,0 litro a $\mathrm{C}_{\mathrm{AF}}$ de 2000 $\mathrm{mg} / \mathrm{l} \mathrm{e} \mathrm{T}_{\text {alim. }}$ de 10 minutos. Apesar do nome do ensaio o reator foi operado em batelada.

Os valores experimentais obtidos durante o monitoramento do ensaio BA-F7 estão apresentados no anexo H7.

\section{Monitoramento do reator}

Os valores médios das variáveis monitoradas no afluente e no efluente durante o ensaio BA-F7 estão apresentados na Tabela 5.17, onde $\mathrm{C}_{\mathrm{ST}}$ é a concentração da matéria orgânica para amostras não filtradas, $\mathrm{C}_{\mathrm{SS}}$ é a concentração da matéria orgânica para amostras filtradas, $\varepsilon_{\mathrm{T}}$ é a eficiência de remoção para as amostras não filtradas, $\varepsilon_{\mathrm{S}}$ é a eficiência de remoção para amostras filtradas. Este ensaio foi monitorado durante 5 dias. 
Tabela 5.17 - Valores médios das variáveis monitoradas durante a operação em batelada a $\mathrm{C}_{\mathrm{AF}}=$ $2000 \mathrm{mg} / \mathrm{l}, \mathrm{V}_{\text {alim. }}=2,01 \mathrm{e} \mathrm{T}_{\text {alim. }}=10$ minutos.

\begin{tabular}{ccc}
\hline Parâmetro & Afluente & Efluente \\
\hline $\mathrm{C}_{\mathrm{ST}}(\mathrm{mg} / \mathrm{l})$ & $2338,9 \pm 162,9^{(4)}$ & $190,7 \pm 34,2^{(4)}$ \\
$\varepsilon_{\mathrm{T}}(\%)$ & - & $91,8 \pm 1,5^{(4)}$ \\
$\mathrm{C}_{\mathrm{SS}}(\mathrm{mg} / \mathrm{l})$ & - & $85,7 \pm 16,8^{(4)}$ \\
$\varepsilon_{\mathrm{S}}(\%)$ & - & $96,3 \pm 0,7^{(4)}$ \\
$\mathrm{AVT}(\mathrm{mgHAc} / \mathrm{l})$ & 81,6 e $111,1^{(\mathrm{obs})}$ & $38,1 \pm 15,2^{(4)}$ \\
$\mathrm{AB}(\mathrm{mgCaCO} / \mathrm{l})$ & 660,2 e $778,9^{(\mathrm{obs})}$ & $972,1 \pm 152,2^{(4)}$ \\
$\mathrm{AI} / \mathrm{AP}$ & 0,37 e $0,42^{(\mathrm{obs})}$ & $0,42 \pm 0,04^{(4)}$ \\
$\mathrm{pH}$ & 7,4 e $8,3^{(\mathrm{obs})}$ & $6,78 \pm 0,07^{(4)}$ \\
$\mathrm{ST}(\mathrm{mg} / \mathrm{l})$ & 3130 e $3236^{(\mathrm{obs})}$ & 1638 e $2112^{(\mathrm{obs})}$ \\
$\mathrm{SVT}(\mathrm{mg} / \mathrm{l})$ & 2088 e $2332^{(\mathrm{obs})}$ & 466 e $794^{(\mathrm{obs})}$ \\
$\mathrm{SST}(\mathrm{mg} / \mathrm{l})$ & 80 e $104^{(\mathrm{obs})}$ & 130 e $151^{(\mathrm{obs})}$ \\
$\mathrm{SSV}(\mathrm{mg} / \mathrm{l})$ & 60 e $76^{(\mathrm{obs})}$ & 106 e $122^{(\mathrm{obs})}$ \\
\hline
\end{tabular}

*Entre parênteses o número de amostras consideradas no cálculo da média obs: Valores mínimo e máximo das variáveis monitoradas

Como se pode observar na Tabela 5.16 e nas figuras 5.44 a 5.46 , o reator apresentou elevada eficiência em remoção da matéria orgânica solúvel $(96,3 \pm 0,7)$. A concentração de AVT $(38,1 \pm 15,2)$ abaixo de $60 \mathrm{mgHac} / 1$, a concentração de $\mathrm{AB}(972,1$ $\pm 152,2)$ próxima a $1000 \mathrm{mgCaCO} / \mathrm{l}$ e o $\mathrm{pH}(6,78 \pm 0,04)$ próximo do neutro, no efluente, mostram que a operação foi mantida estável durante todo o ensaio. 


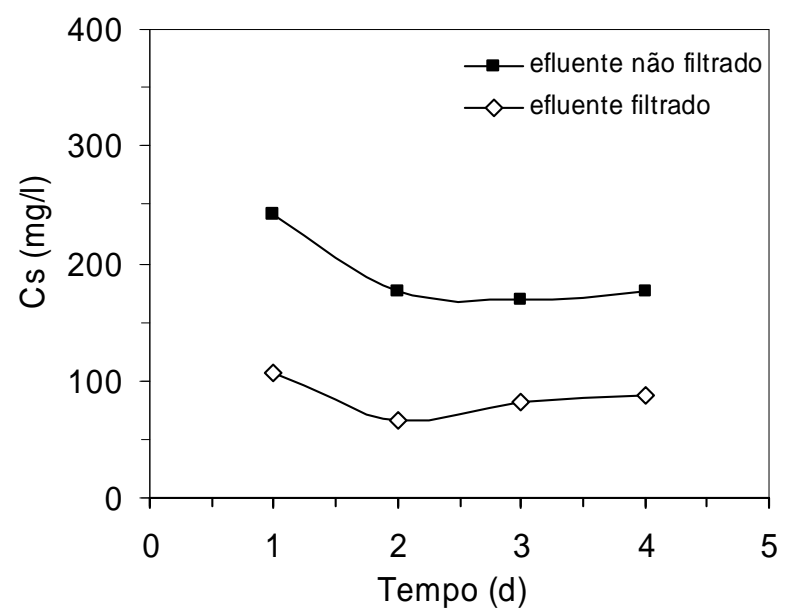

Figura 5.44 - Concentração de matéria orgânica, em termos de DQO, de amostras filtradas e não filtradas no efluente durante a operação em batelada a $C_{\mathrm{AF}}=2000 \mathrm{mg} / \mathrm{l}, \mathrm{V}_{\text {alim. }}=2,01 \mathrm{e} \mathrm{T}_{\text {alim. }}$. $=10$ minutos.

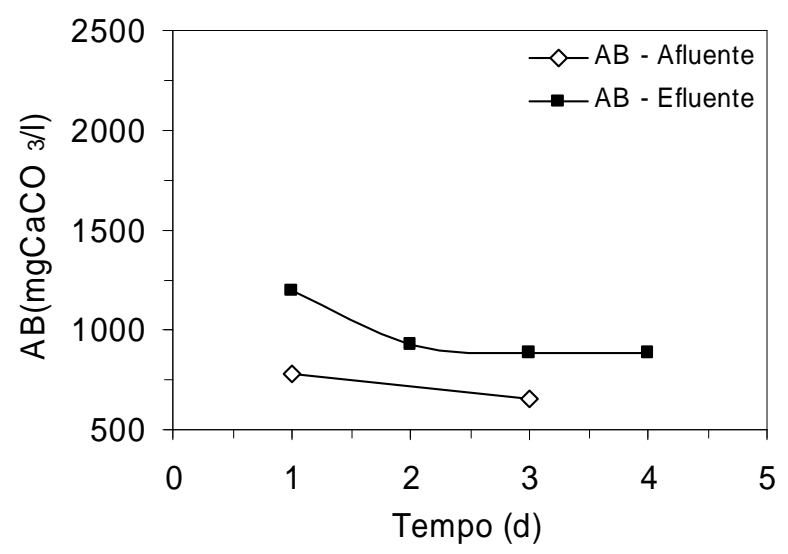

Figura 5.45 - Concentração de Alcalinidade a Bicarbonato (AB), de amostras do afluente e do efluente durante a operação em batelada a $\mathrm{C}_{\mathrm{AF}}=2000 \mathrm{mg} / \mathrm{l}, \mathrm{V}_{\text {alim. }}=2,01 \mathrm{e} \mathrm{T}_{\text {alim. }}=10$ minutos. 


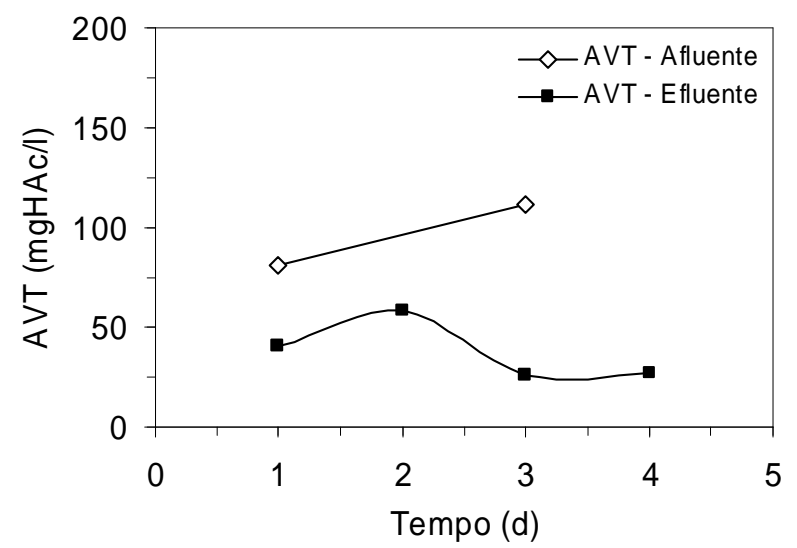

Figura 5.46 - Concentração de Ácidos Voláteis Totais (AVT), de amostras filtradas e não filtradas no efluente durante a operação em batelada a $\mathrm{C}_{\mathrm{AF}}=2000 \mathrm{mg} / \mathrm{l}, \mathrm{V}_{\text {alim. }}=2,01 \mathrm{e} \mathrm{T}_{\text {alim. }}=$ 10 minutos.

\section{Perfil de Conversão ao longo do ciclo}

Os perfis de conversão ao longo do ciclo de $\mathrm{C}_{\mathrm{s}}(\mathrm{mg} / \mathrm{l}), \mathrm{AB}\left(\mathrm{mgCaCO}_{3} / \mathrm{l}\right)$, AVT (mgHAc/l) e AVI (mmol/l) foram realizados no oitavo ciclo.

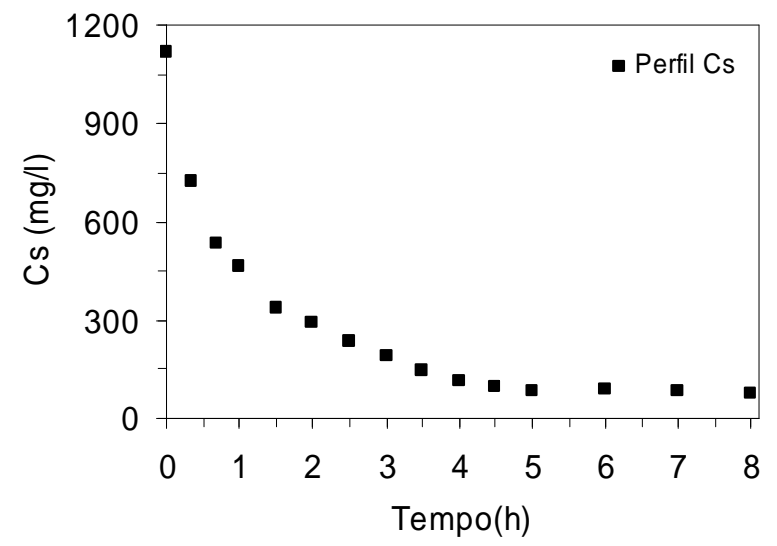

Figura 5.47 - Perfil de concentração da matéria orgânica ao longo do ciclo, em termos de DQO, durante a operação em batelada a $\mathrm{C}_{\mathrm{AF}}=2000 \mathrm{mg} / \mathrm{l}, \mathrm{V}_{\text {alim. }}=2,0 \mathrm{le} \mathrm{T}_{\text {alim. }}=10$ minutos. 
A Figura 5.47 mostra que a degradação da matéria orgânica ao longo do ciclo foi rápida atingindo a estabilidade após 4 horas de ciclo. Os valores da matéria orgânica solúvel ao final do ciclo estabilizaram em valores próximos a $100 \mathrm{mg} / \mathrm{l}$, em termo de DQO.
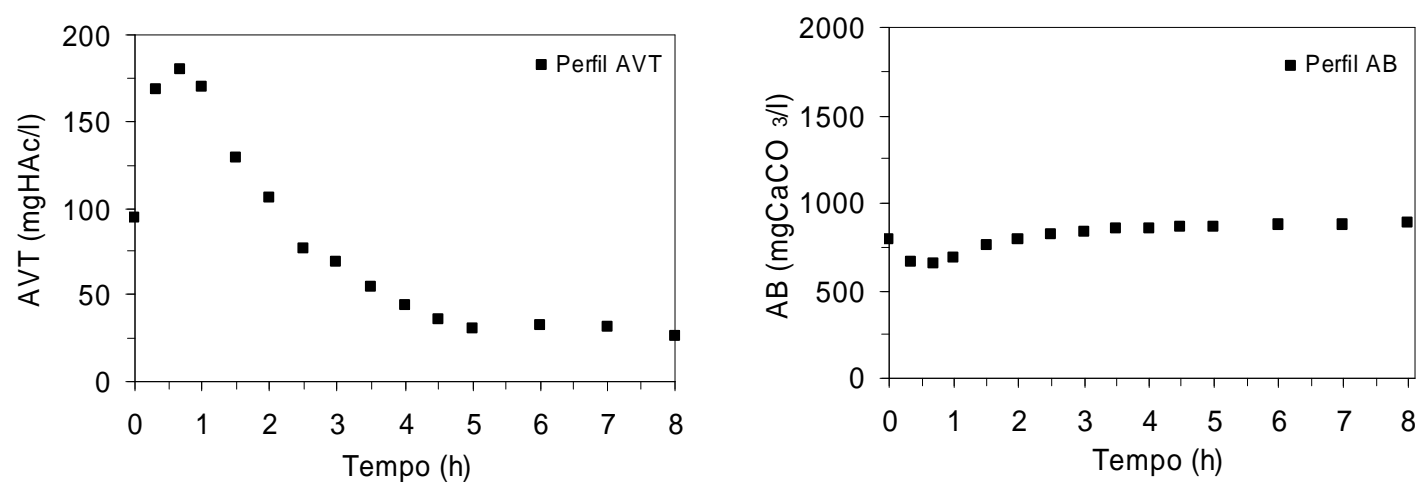

Figura 5.48 - Perfil de concentração de Ácidos Voláteis Totais (AVT) e de Alcalinidade a Bicarbonato $(\mathrm{AB})$ ao longo do ciclo durante a operação em batelada a $\mathrm{C}_{\mathrm{AF}}=2000 \mathrm{mg} / \mathrm{l}, \mathrm{V}_{\text {alim. }}=$ $2,01 \mathrm{e} \mathrm{T}_{\text {alim. }}=10$ minutos.

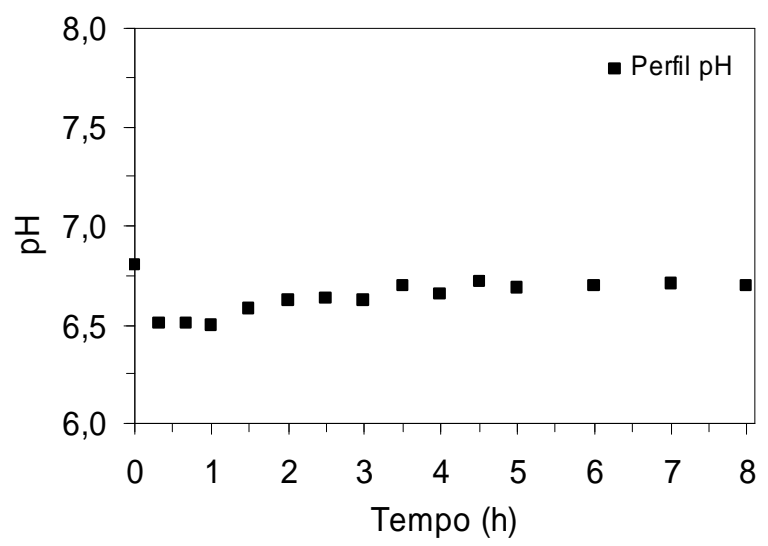

Figura 5.49 - Perfil de pH ao longo do ciclo durante a operação em batelada a $\mathrm{C}_{\mathrm{AF}}=2000 \mathrm{mg} / \mathrm{l}$, $\mathrm{V}_{\text {alim. }}=2,01 \mathrm{e} \mathrm{T}_{\text {alim. }}=10$ minutos. 
Observando-se a Figura 5.48 nota-se que a concentração de AVT teve um pico levemente acentuado ao início do ciclo, o qual foi reduzido até estabilizar após 4 horas de ciclo. O pico de AVT pouco acentuado causou leve alteração na concentração de $A B$ no início do ciclo, contudo a concentração de $\mathrm{AB}$ permaneceu praticamente constante durante todo o ciclo. As poucas alterações detectadas nas concentrações de AVT e de $\mathrm{AB}$ foram confirmadas com o perfil de $\mathrm{pH}$ já que este teve uma pequena queda no início do ciclo, que foi sendo lentamente recuperada ao longo do ciclo, conforme a Figura 5.49 .

Os ácidos voláteis intermediários que tiveram maior influência no processo, em termos de concentração, foram os ácidos acético e propiônico, conforme a Tabela 5.18.

Tabela 5.18 - Perfil de concentração de Ácidos Voláteis Intermediários (AVI) ao longo do ciclo durante a operação em batelada a $\mathrm{C}_{\mathrm{AF}}=2000 \mathrm{mg} / \mathrm{l}, \mathrm{V}_{\text {alim. }}=2,01 \mathrm{e} \mathrm{T}_{\text {alim. }}=10$ minutos.

\begin{tabular}{ccccccc}
\hline \multicolumn{7}{c}{ Perfil AVI $(\mathrm{mmol} / \mathrm{l})$} \\
\hline tempo (h) & Acético & Propiônico Iso-Butírico & Butírico & Iso-Valérico & Valérico \\
\hline 0 & 16,87 & 8,88 & 0,00 & 1,59 & 0,00 & 0,00 \\
0,33 & 49,15 & 38,31 & 0,00 & 5,38 & 1,88 & 0,00 \\
0,67 & 64,88 & 73,91 & 2,16 & 5,16 & 3,94 & 1,57 \\
1 & 29,27 & 49,57 & 1,51 & 2,39 & 3,12 & 1,25 \\
1,5 & 36,60 & 107,87 & 3,51 & 2,82 & 7,43 & 2,61 \\
2 & 0,00 & 84,87 & 3,24 & 0,00 & 6,28 & 1,99 \\
2,5 & 0,00 & 76,67 & 3,20 & 0,00 & 4,98 & 0,00 \\
3 & 0,00 & 60,48 & 2,53 & 0,00 & 2,95 & 0,00 \\
3,5 & 0,00 & 32,95 & 0,00 & 0,00 & 0,00 & 0,00 \\
4 & 0,00 & 17,33 & 0,00 & 0,00 & 0,00 & 0,00 \\
4,5 & 0,00 & 6,51 & 0,00 & 0,00 & 0,00 & 0,00 \\
5 & 0,00 & 0,00 & 0,00 & 0,00 & 0,00 & 0,00 \\
\hline
\end{tabular}

\section{Análise de Sólidos do Lodo}

Após a realização dos perfis de concentração ao longo do ciclo, para o ensaio BA-F7, retirou-se uma amostra para a análise do lodo presente no reator. Dessa análise foi possível obter a relação mássica SVT/ST que serve de indicação da quantidade de microrganismos presentes na biomassa. Dessa forma obteve-se que fração mássica (SVT/ST) foi de $85,3 \%$ para este ensaio. 


\section{Análises Microbiológicas}

Durante a realização dos ensaios observou-se que parte da biomassa flotava, enquanto outra parte continuava apresentando boas características de sedimentação. Surgiu então a hipótese de haver dentro do reator uma separação natural das fases acidogênicas e metanogênicas. Dessa forma haveria uma maior concentração de acidogênicas no lodo flotado, enquanto no lodo sedimentado haveria uma maior concentração de metanogênicas.

Assim, o exame microbiológico de amostras de grânulos flotados e de grânulos sedimentados separadamente poderia esclarecer um pouco o assunto, com resultados favoráveis ou contrários à hipótese levantada. Contudo, os exames microbiológicos não puderam provar a hipótese levantada. Observou-se portanto, a necessidade de uma investigação mais profunda neste assunto a fim de se analisar os diversos parâmetros que podem influenciar a biomassa, resultando na flotação da mesma.

Observou-se também que durante a primeira etapa, na qual não se suplementou nutrientes, a coloração dos grânulos foi mudando para uma tonalidade mais acinzentada. Com a suplementação de nutrientes, durante a segunda etapa, não houve alteração na cor dos grânulos, o que indica que a biomassa sentiu os efeitos do desequilíbrio da razão C: N: P.

Os exames microbiológicos foram realizados utilizando microscopia ótica comum, por contraste de fase. As Figuras 5.50 e 5.51 apresentam as fotografias originais e as imagens tratadas para obter melhor visualização. Pode-se observar nessas figuras as duas principais estruturas encontradas, agrupamentos de cocos (Figura 5.50) e cocos em cadeia (Figura 5.51).

As estruturas são apenas uma indicação de algumas arqueas que podem ter sido detectadas. O agrupamento de cocos é uma estrutura típica de bactérias como a Methanosarcina, por exemplo. Um exemplo de bactéria que possui estrutura de cocos enfileirados é a Methanobacterium. Assim, essas análises não são conclusivas necessitando de técnicas mais avançadas para identificar os grupos de microrganismos presentes no reator. 

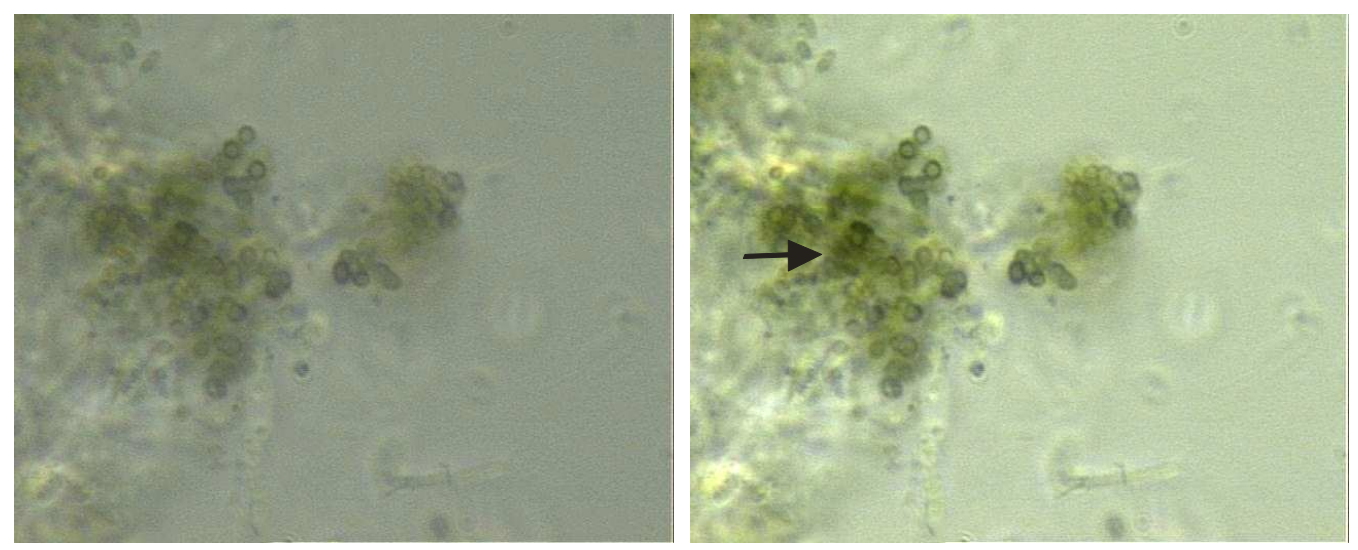

Figura 5.50 - Fotografia obtida por microscopia ótica comum, por contraste de fase e a imagem tratada para melhorar a visualização da estrutura de cocos aglomerados.
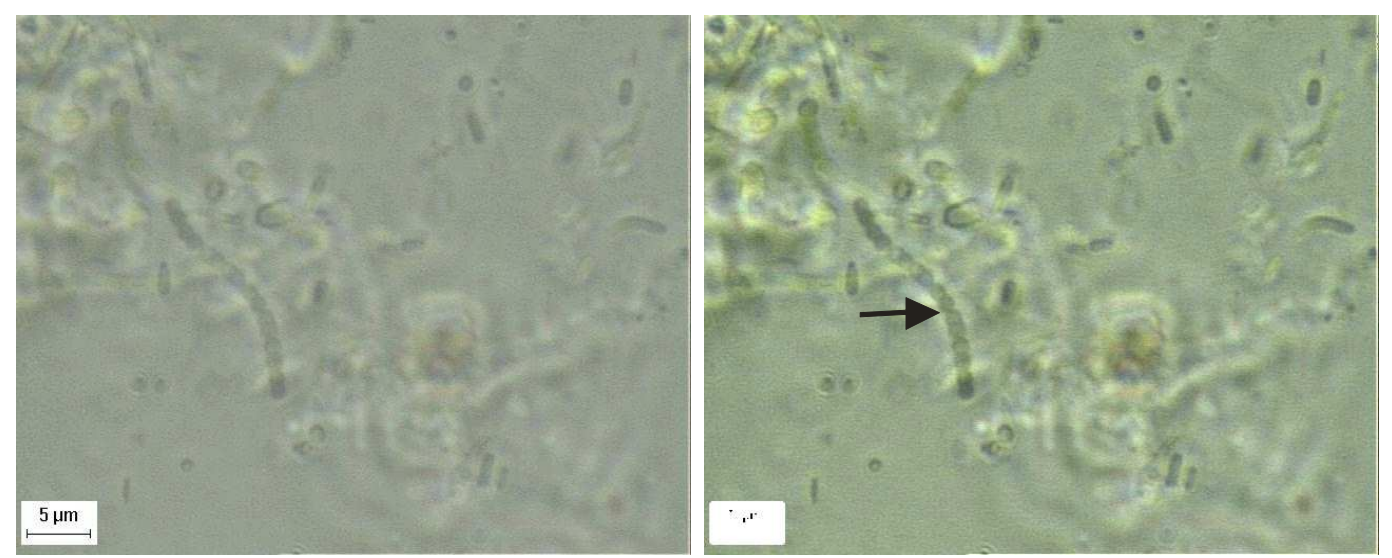

Figura 5.51 - Fotografia obtida por microscopia ótica comum, por contraste de fase e a imagem tratada para melhorar a visualização da estrutura de cocos em cadeia. 


\section{CONCLUSÕES E SUGESTÕES}

A partir da operação do ASBR em batelada e batelada alimentada tratando soro de queijo, as seguintes conclusões foram estabelecidas:

- O estudo da influência da estratégia de alimentação mostrou que maiores tempos de enchimento levam à redução dos picos de concentração, de matéria orgânica, AVT e AB, ao longo do ciclo.

- A avaliação da influência da COV aplicada concluiu-se que foi possível operar o ASBR tratando soro de queijo a COV de 4,8 g/l.d com elevada eficiência, em termos de DQO, e com estabilidade.

- A análise da influência das formas de aplicação da COV de 2,4 g/l.d, variandose $\mathrm{C}_{\mathrm{AF}}$ e $\mathrm{V}_{\text {alim }}$, durante a operação em batelada alimentada, mostrou que o parâmetro $\mathrm{C}_{\mathrm{AF}}$ teve maior influência sobre a eficiência do ASBR que o parâmetro COV aplicada.

- A aplicação do "draft tube" ao ASBR melhorou a agitação dentro do reator e reduziu as resistências à transferência de massa, o que ficou comprovado pelos elevados valores obtidos para as constantes cinéticas $\mathrm{k}_{1 \mathrm{~s}}$.

- Dos dispositivos desenvolvidos para assegurar a retenção da biomassa concluiuse que a configuração ASBR Híbrido com agitação mecânica é muito sensível a perdas de carga, por isso não foi possível obter operação estável. 
Sugere-se a continuidade de pesquisas enfocando o mesmo tema, mas sob os seguintes aspectos:

- Investigação dos parâmetros físicos, químicos e microbiológicos que levam à flotação da biomassa granulada submetida a elevadas COV aplicadas.

- Investigação e desenvolvimento de estratégias de adição de nutrientes sobre o ASBR submetido a altas cargas.

- Avaliação da aplicação do ASBR Híbrido com recirculação da fase líquida. 


\section{REFERÊNCIAS BIBLIOGRÁFICAS}

ANGENENT, L.T.; DAGUE, R.R. (1995). A laboratory- scale comparison of the UASB and ASBR processes. In: PURDUE INDUSTRIAL. WASTEWATER CONFERENCE, 50., 1995, Chelsea. Proceedings... Chelsea, Ann Arbor Press. p.365-77.

AMERICAN PUBLIC HEALTH ASSOCIATION, AMERICAN WATER WORKS ASSOCIATION, WATER ENVIRONMENT FEDERATION (1995). Standard methods for examination of water and wastewater. $19^{\text {th }}$ ed., Washington D. C.

BACKUS, B.D.; CLANTON, C. J.; GOODRICH, P. R.; MORRIS, H. A. (1988). Carbon-to-nitrogen ratio and hydraulic retention time effect on the anaerobic digestion of cheese whey. Transactions of the ASAE, v.31, p.1274-82.

BAGLEY, D.M.; BRODKORB, T.S. (1999). Modeling microbial kinetics in an anaerobic sequencing batch reactor - model development and experimental validation. Water Environmental Research, v.71, p.1320-32.

BORGES, A.C.; SIMAN, R.R.; RODRIGUES, J.A.D.; RATUSZNEI, S.M.; ZAIAT, M.; FORESTI, E.; BORZANI, W. (2003). Stirred anaerobic sequencing batch reactor containing imobibilized biomass: a behavior study when submitted to different fill times. In: INTERNATIONAL CONFERENCE ON BIOFILM SYSTEMS, 5., 2003, CapeTown. Proceedings... CapeTown. 1 CD-ROM.

BRITO, A.G.; RODRIGUES, A.C.; MELO, L.F. (1997). Feasibility of a pulsed sequencing batch reactor with anaerobic aggregated biomass for the treatment of low strength wastewaters. Water Science and Technology, v.35, n.1, p.193-8.

CAMARGO, E.F.M. (2000). Tratamento anaeróbio de águas residuárias, em batelada, com microrganismos imobilizados e circulação da fase aquosa. Dissertação de mestrado. Escola de Engenharia de São Carlos, Universidade de São Paulo. São Carlos, 207p. 
CHAPMAN, D. (1989) Mixing in Anaerobic Digesters: State of the art. In: Cheremisinoff, P. (Ed.), Encyclopedia of Enviromental Control Technology, vol. 3. Gulf Publishing Company, houston, pp. 325-354.

CUBAS, S.A.; PINHO, S.C.; FORESTI, E.; RODRIGUES, J.A.D., RATUSZNEI, S.M., ZAIAT, M. (2002). Effects of solid-phase mass transfer on a stirred anaerobic sequencing batch reactor containing immobilized biomass. In: LATIN-AMERICAN WORKSHOP AND SEMINAR ON ANAEROBIC DIGESTION, 7., 2002, Mérida. Proceedings... Mérida. p.229-36.

DAGUE, R.R.; HABBEN, C.E.; PIDAPARTI, S.R. (1992). Initial studies on the anaerobic sequencing batch reactor. Water Science and Technology, v.26, p.242932.

DAMASCENO, L.H.S.; RODRIGUES, J.A.D.; RATUSZNEI, S.M.; ZAIAT, M.; FORESTI, E. (2006) Effects of feeding time and organic loading in an anaerobic sequencing batch biofilm reactor (ASBBR) treating diluted whey. Journal of Environmental Management. (no prelo)

DE HAAST, J.; BRITZ, T.J.; NOVELLO, J.C.; LATEGAN, P.M. (1983). Anaerobic digestion of cheese whey using a stationary fixed-bed reactor. New Zealand Journal of Dairy Science and Technology, v.18, p.261-71.

DROSTE, R.L.; MASSÉ, D.I. (1995). Anaerobic treatment in sequencing batch reactor. In: INTERNATIONAL SYMPOSIUM ON TECHNOLOGY TRANSFER, 1995, Salvador. Proceedings... Salvador. p.353-363.

DUGBA, P.N.; ZHANG, R. (1999). Treatment of dairy wastewater with two-stage anaerobic sequencing batch reactor systems - thermophilic versus mesophilic operations. Bioresource Technology, v.68, p.225-33.

ERGÜDER, T. H.; TEZEL, U.; GÜVEN, E.; DEMIRER G. N. (2001) Anaerobic Biotransformation and Methane Generation Potential of Cheese Whey in Batch and UASB Reactors. Waste Management, 21: 643-650.

GARCIA, P.A.; RICO, J.L.; POLANCO, F. (1991) Anaerobic Treatment of Cheese Whey in a 2-Phase UASB Reactor. Environmental Technology, 12(4): 355-362. 
KALYUZHNYI, S.V.; MARTINEZ, E.P; MARTINEZ, J.R. (1997). Anaerobic Treatment of High-Strength Cheese-Whey Wastewaters in Laboratory and Pilot UASB-Reactors. Bioresource Technology, v.60, p.59-65.

KATO, M.T.; FIELD, J.A.; KLEEREBEZEM R.; LETTINGA, G. (1994). Treatment of Low Strength Soluble Wastewaters in UASB Reactors. Journal of Fermentation and Bioengineering, v.77, n.6, p.679-86.

KENNEDY, K.J.; SANCHEZ, W.A.; HAMODA, M.F.; DROSTE, R.L. (1991). Performance of anaerobic sludge blanket sequencing batch reactors. Research Journal of Water Pollution Control Federation, v.63, p.75-83.

LO, K.V.; LIAO, P.H. (1986). Digestion of Cheese Whey with Anaerobic Rotating Biological Contact Reactor. Biomass, v.10, p.243-52.

MALASPINA, F.; CELLAMARE, C.M.; STANTE, L.; TILCHE, A. (1996). Anaerobic treatment of cheese whey with a downflow-upflow hybrid reactor. Bioresource Technology, v.55, p.131-9.

MARTINS, S.D.; GUYOMAR, P.P.; RIBEIRO, E.R.; XAVIER, A.M.F. (2000). Tratamento anaeróbio em duas etapas do soro de queijo empregando-se duas configurações de reatores UASB. In: LATIN-AMERICAN WORKSHOP AND SEMINAR ON ANAEROBIC DIGESTION, 6., 2000, Recife. Proceedings... Recife, UFPE. v.2. p. 9-12.

MAWSON, A.J. (1994). Bioconversions for whey utilization and waste abatement. Bioresource Technology, v.47, p.195-203.

MOCKAITIS, G.; RATUSZNEI, S.M.; RODRIGUES, J.A.D.; ZAIAT, M.; FORESTI, E. (2006). Anaerobic whey treatment by a stirred sequencing batch reactor (ASBR): effects of organic loading and supplemented alkalinity. Journal of Environmental Management. (no prelo)

NDON, U.J.; DAGUE, R.R. (1997). Ambient temperature treatment of low strength wastewater using anaerobic sequencing batch reactor. Biotechnology Letters, v.19, p.319-23.

ORRA, A.A.; RATUSZNEI, S.M.; RODRIGUES, J.A.D.; FORESTI, E.; ZAIAT, M. (2003). Effects of Feeding Strategies on the Performance of an Anaerobic Discontinuous Reactor Containing Immobilized Biomass with Circulation System for Liquid-Phase Mixing. In: INTERNATIONAL CONFERENCE ON BIOFILM SYSTEMS, 5., 2003, CapeTown. Proceedings... CapeTown. 1 CD-ROM. 
ÖZTÜRK, I.; EROGLU, V.; UBAY, G; DEMIR, I. (1993). Hybrid Upflow Anaerobic Sludge Blanket Reactor (HUASBR) Treatment of Dairy Effluents. Water Science Technology, v.28, n.2, p.77-85.

PATEL, P.; PATEL, C.; MADAMWAR, D. (1999). Anaerobic upflow fixed-film bioreactor for biomethanation of salty cheese whey. Applied Biochemistry and Biotechnology, v.76, n.3, p.193-201.

PINHO, S.C.; CUBAS, S.A.; RATUSZNEI, S.M.; RODRIGUES, J.A.D.; FORESTI, E.; ZAIAT, M. (2002). Influence of the agitation rate on the treatment of partially soluble wastewater in anaerobic sequencing batch reactor containing immobilized biomass. In: LATIN-AMERICAN WORKSHOP AND SEMINAR ON ANAEROBIC DiGESTION, 7., 2002, Mérida. Proceedings... Mérida. p.103-6.

PODLECH, P.A.S.; LUNA, M.F.; JERKE, P.R.; SOUZA, O.; SOUZA NETO, C.A.C.; PASSOS, R.F.; BORZANI, W. (1991). Fermentação semi-contínua de soro de leite por Lactobacillus bulgaricus em Instalação Piloto. Revista do Instituto Cândido Tostes, v.46, p.26-33.

RATUSZNEI, S.M.; RODRIGUES, J.A.D.; CAMARGO, E.F.M.; ZAIAT, M.; BORZANI, W. (2000). Feasibility of a stirred anaerobic sequencing batch reactor containing immobilized biomass for wastewater treatment. Bioresource Technology, v.75, p;127-32.

RATUSZNEI, S.M.; RODRIGUES, J.A.D.; CAMARGO, E.F.M.; ZAIAT, M.; BORZANI, W. (2001). Influence of agitation rate on the performance of a stirred anaerobic sequencig batch reactor containing immobilized biomass. Water Science and Technology, v.44, p.305-12.

RATUSZNEI, S.M.; RODRIGUES, J.A.D.; CAMARGO, E.F.M.; RIBEIRO, R.; ZAIAT, M. (2003a). Effects of feeding strategy on the stability and efficiency of a stirred anaerobic sequential fed-batch reactor containing immobilized biomass. Bioresource Technology, v.90, p.199-205.

RATUSZNEI, S.M.; RODRIGUES, J.A.D.; ZAIAT, M. (2003b). Operating feasibility of anaerobic whey treatment in a stirred sequencing batch reactor containing immobilized biomass. Water Science and Technolgy, v.48, p.179-186.

REYES III, F.L.; DAGUE, R.R. (1995). Effects of initial seed concentration on the startup of anaerobic sequencing batch reactor. In: PURDUE INDUSTRIAL. WASTEWATER CONFERENCE, 50., 1995, Chelsea. Proceedings... Chelsea, Ann Arbor Press. p. 449-59. 
RIPLEY, L.E.; BOYLE, W.C.; CONVERSE, J.C. (1986). Improved alkalimetric monitoring anaerobic digestion of high-strenght wastes. Journal of Water Pollution Control Federation, v.58, p.406-11.

RODRIGUES, J.A.D., RATUSZNEI, S.M., ZAIAT, M. (2003). Fed-batch and batch operating mode analysis of a stirred anaerobic sequencing reactor with selfimmobilized biomass treating low-strength wastewater. Journal of Environmental Management, v.69, p.193-200.

RUIZ, C.; TORRIJOS, M.; SOUSBIE, P.; LEBRATO MARTINES, J.; MOLETTA, R.; DELGENÈS, J.P. (2001). Treatment of winery wastewater by an anaerobic sequencing batch reactor (ASBR). In: WORLD CONGRESS ON ANAEROBIC DIGESTION, 9., 2001, Antuérpia. Proceedings... Antuérpia. p.347-53.

SHIZAS, I.; BAGLEY, D.M. (2002). Improving anaerobic sequencing batch reactor performance by modifying operational parameters. Water Research, v.36, p.363-7.

SPEECE, R.E. (1996). Anaerobic biotechnology for industrial wastewater treatment. Ed. Archae Press, Nashville, 394p.

SUNG, S.; DAGUE, R.R. (1995). Laboratory studies on the anaerobic sequencing batch reactor. Water Environmental Research, v.67, p.294-301.

SUTHAKER, S; POLPRASERT, C; DROSTE, R.L (1991). Sequencing batch anaerobic reactors for treatment of a highstrength organic wastewater. Water Science and Technology, v.23, p.1249-57.

SWITZENBAUM, M. S. (1982) Anaerobic Expanded Bed Treatment of Whey. Agricultural Wastes 4: 411-426.

TIMUR, H.; ÖSTURK, I. (1999). Anaerobic sequencing batch reactor treatment of landfill leachate. Water Research, v.33, p.3225-30.

VARESCHE, M.B.; ZAIAT, M.; VIEIRA, L.G.T.; VAZOLLER, R.F.; FORESTI, E. (1997). Microbial colonization of polyurethane foam matrices in horizontal-flow anaerobic immobilized-sludge reactor. Applied Microbiology and Biotechnology, v.48, p.534-8.

WILDENAUER, F.X.; WINTER, J. (1985). Anaerobic digestion of High Strength Acidic Whey in a pH-Controlled Up-Flow Fixed-Film Loop Reactor. Applied Biochemistry and Biotechnology, v.22, p.367-72.

YAN, J. Q.; LIAO, P.H.; LO, K.V. (1988). Methane production from cheese whey. Biomass, v.17, p.185-202. 
YILMAZER, G.; YENIGÜN, O. (1999). Two-Phase Anaerobic Treatment of Cheese Whey. Water Science Technology, v.40, n.1, p.289-95.

ZAIAT, M.; RODRIGUES, J.A.D.; RATUSZNEI, S.M.; CAMARGO, E.F.M.; BORZANI, W. (2001). Anaerobic sequencing batch reactors for wastewater treatment: A developing technology. Applied Microbiology and Biotechnology, v.55, p.29-35.

ZHANG, R.; YIN, Y.; SUNG, S.; DAGUE, R.R. (1996). Anaerobic treatment of swine waste by the anaerobic sequecing batch reactor. In: PURDUE INDUSTRIAL. WASTEWATER CONFERENCE, 51., 1996, Chelsea. Proceedings... Chelsea, Ann Arbor Press. p.315-20. 
SEÇÃO DE ANEXOS 



\section{ANEXO A - ENSAIOS PRELIMINARES - VALORES EXPERIMENTAIS}

Tabela A.1 - Valores da concentração de substrato $\left(\mathrm{C}_{\mathrm{AF}}\right), \mathrm{pH}$, alcalinidade parcial (AP), alcalinidade intermediária (AI), alcalinidade total (AT), alcalinidade a bicarbonato (AB) e ácidos voláteis totais (AVT) em amostras do afluente nos ensaios preliminares.

\begin{tabular}{ccccccccc}
\hline Meio & $\mathrm{C}_{\mathrm{AF}}$ & $\mathrm{pH}$ & $\mathrm{AP}$ & $\mathrm{AI}$ & $\mathrm{AT}$ & $\mathrm{AI} / \mathrm{AP}$ & $\mathrm{AB}$ & $\mathrm{AVT}$ \\
\hline 1 & 504,5 & - & - & - & - & - & - & - \\
4 & 545,5 & - & - & - & - & - & - & - \\
5 & 502,5 & 8,57 & 50,15 & 19,10 & 69,25 & 0,38 & 27,43 & 58,91 \\
6 & 503,3 & - & - & - & - & - & - & - \\
7 & 498,7 & - & - & - & - & - & - & - \\
8 & 512,8 & 8,16 & 130,02 & 54,18 & 184,20 & 0,42 & 133,20 & 71,82 \\
9 & 509,9 & - & - & - & - & - & - & - \\
11 & 514,9 & 8,55 & 114,85 & 41,17 & 156,02 & 0,36 & 139,92 & 22,68 \\
12 & 543,0 & - & - & - & - & - & - & - \\
15 & 503,0 & 7,62 & 253,54 & 73,68 & 327,22 & 0,29 & 295,46 & 44,73 \\
\hline
\end{tabular}

Unidades:

$\mathrm{C}_{\mathrm{AF}}=\mathrm{mg} / \mathrm{l}$, em termos de DQO

AP; AI; $\mathrm{AT} ; \mathrm{AB}=\mathrm{mgCaCO}_{3} / 1$

$\mathrm{AVT}=\operatorname{mgHAc} / 1$ 
Tabela A.2 - Valores da concentração de substrato ( $\mathrm{C}_{\mathrm{ST}}$ e $\mathrm{C}_{\mathrm{SS}}$ ), $\mathrm{pH}$, alcalinidade parcial (AP), alcalinidade intermediária (AI), alcalinidade total (AT), alcalinidade a bicarbonato (AB) e ácidos voláteis totais (AVT) em amostras do efluente nos ensaios preliminares.

\begin{tabular}{cccccccccccc}
\hline Tempo & $\mathrm{C}_{\mathrm{ST}}$ & $\varepsilon_{\mathrm{T}}$ & $\mathrm{C}_{\mathrm{SS}}$ & $\varepsilon_{\mathrm{S}}$ & $\mathrm{pH}$ & $\mathrm{AP}$ & $\mathrm{AI}$ & $\mathrm{AT}$ & $\mathrm{AI} / \mathrm{P}$ & $\mathrm{AB}$ & $\mathrm{AVT}$ \\
\hline 2 & 137,6 & 73,22 & 89,1 & 82,66 & 7,46 & 398,0 & 94,2 & 492,2 & 0,24 & 450,8 & 58,3 \\
4 & 165,6 & 67,77 & 47,5 & 90,76 & 7,46 & 325,3 & 77,0 & 402,3 & 0,24 & 380,6 & 30,7 \\
5 & 216,1 & 57,94 & 33,7 & 93,44 & 6,99 & 295,3 & 72,8 & 368,1 & 0,25 & 347,9 & 28,4 \\
6 & 47,5 & 90,76 & 25,8 & 94,98 & 7,00 & 278,2 & 85,6 & 363,8 & 0,31 & 347,9 & 22,4 \\
7 & 95,0 & 81,51 & 21,0 & 95,91 & 7,24 & 256,8 & 77,0 & 333,8 & 0,30 & 320,6 & 18,7 \\
8 & 65,3 & 87,29 & 12,9 & 97,49 & 7,54 & 269,6 & 72,8 & 342,4 & 0,27 & 316,9 & 35,9 \\
11 & 95,1 & 81,49 & 32,8 & 93,62 & 7,53 & 235,4 & 98,4 & 333,8 & 0,42 & 321,6 & 17,2 \\
12 & 51,5 & 89,98 & 0,0 & 100,00 & 7,52 & 231,1 & 94,2 & 325,3 & 0,41 & 310,4 & 20,9 \\
13 & 21,7 & 95,78 & 0,0 & 100,00 & 7,02 & 160,0 & 49,6 & 209,6 & 0,31 & 191,2 & 25,9 \\
18 & 65,5 & 87,25 & 29,4 & 94,28 & 7,09 & 290,4 & 78,0 & 368,4 & 0,27 & 351,8 & 23,3 \\
19 & 33,8 & 93,42 & 4,1 & 99,20 & 7,10 & 290,4 & 78,0 & 368,4 & 0,27 & 350,1 & 25,8 \\
\hline
\end{tabular}

Unidades:

Tempo $=$ dia

$\mathrm{C}_{\mathrm{ST}} ; \mathrm{C}_{\mathrm{SS}}=\mathrm{mg} / \mathrm{l}$, em termos de DQO

$\varepsilon_{\mathrm{T}} ; \varepsilon_{\mathrm{S}}=\%$

$\mathrm{AP} ; \mathrm{AI} ; \mathrm{AT} ; \mathrm{AB}=\mathrm{mgCaCO}_{3} / 1$

$\mathrm{AVT}=\mathrm{mgHAc} / \mathrm{l}$ 


\section{ANEXO $B-\left(C O V=1,2\right.$ g/l.d $\left.; C_{A F}=1000 \mathrm{mg} / \mathrm{l}\right)-$ VALORES EXPERIMENTAIS}

Tabela B.1 - Valores da concentração de substrato $\left(\mathrm{C}_{\mathrm{AF}}\right), \mathrm{pH}$, alcalinidade parcial (AP), alcalinidade intermediária (AI), alcalinidade total (AT), alcalinidade a bicarbonato (AB) e ácidos voláteis totais (AVT) em amostras do afluente no ensaio de COV = 1,2 g/l.d, durante a operação do reator em batelada nas condições I $\left(\mathrm{NaHCO}_{3} / \mathrm{DQO}=1,0\right)$ e II $\left(\mathrm{NaHCO}_{3} / \mathrm{DQO}=0,5\right)$.

\begin{tabular}{ccccccccc}
\hline Meio & $\mathrm{C}_{\mathrm{AF}}$ & $\mathrm{pH}$ & $\mathrm{AP}$ & $\mathrm{AI}$ & $\mathrm{AT}$ & $\mathrm{AI} / \mathrm{AP}$ & $\mathrm{AB}$ & $\mathrm{AVT}$ \\
\hline 21 e 22 & 1004,2 & 7,54 & 414,8 & 175,9 & 590,7 & 0,424 & 540,28 & 70,98 \\
23 & 1009,7 & 8,30 & 324,6 & 103,7 & 428,4 & 0,319 & 396,95 & 44,23 \\
24 & 1032,6 & 8,43 & 252,5 & 72,1 & 324,6 & 0,286 & 295,57 & 40,95 \\
25 & 1001,8 & - & - & - & - & - & - & - \\
28 & 1010,4 & 8,26 & 92,7 & 31,2 & 124,0 & 0,337 & 70,48 & 75,33 \\
29 & 1120,1 & 8,20 & 95,1 & 28,3 & 123,5 & 0,298 & 87,80 & 50,22 \\
30 & 918,3 & 8,47 & 105,0 & 23,1 & 128,1 & 0,220 & 86,34 & 58,76 \\
31 & 1004,6 & 8,54 & 105,5 & 21,9 & 127,4 & 0,208 & 95,53 & 44,86 \\
32 & 1004,0 & 8,12 & 199,9 & 33,3 & 233,2 & 0,167 & 203,84 & 41,39 \\
35 & 994,8 & 8,05 & 181,4 & 44,4 & 225,8 & 0,245 & 177,66 & 67,84 \\
36 & 1009,2 & 8,34 & 199,9 & 37,0 & 236,9 & 0,185 & 207,95 & 40,82 \\
38 & 983,6 & 7,87 & 263,1 & 64,8 & 327,9 & 0,246 & 295,45 & 45,69 \\
39 & 971,7 & 7,62 & 255,0 & 76,9 & 331,9 & 0,302 & 303,97 & 39,38 \\
40 & 964,2 & 7,86 & 263,1 & 68,8 & 331,9 & 0,262 & 305,09 & 37,81 \\
\hline
\end{tabular}

Unidades:

$\mathrm{C}_{\mathrm{AF}}=\mathrm{mg} / \mathrm{l}$, em termos de DQO

$\mathrm{AP} ; \mathrm{AI} ; \mathrm{AT} ; \mathrm{AB}=\mathrm{mgCaCO}_{3} / 1$

$\mathrm{AVT}=\operatorname{mgHAc} / 1$ 
Tabela B.2 - Valores da concentração de substrato ( $\mathrm{C}_{\mathrm{ST}}$ e $\left.\mathrm{C}_{\mathrm{SS}}\right), \mathrm{pH}$, alcalinidade parcial (AP), alcalinidade intermediária (AI), alcalinidade total (AT), alcalinidade a bicarbonato (AB) e ácidos voláteis totais (AVT) em amostras do efluente no ensaio de COV = 1,2 g/l.d durante a operação do reator em batelada nas condições $\mathrm{I}\left(\mathrm{NaHCO}_{3} / \mathrm{DQO}=1,0\right)$ e II $\left(\mathrm{NaHCO}_{3} / \mathrm{DQO}=0,5\right)$.

\begin{tabular}{cccccccccccc}
\hline $\begin{array}{c}\text { Tempo } \\
\text { (dia) }\end{array}$ & $\mathrm{C}_{\mathrm{ST}}$ & $\varepsilon_{\mathrm{T}}$ & $\mathrm{C}_{\mathrm{SS}}$ & $\varepsilon_{\mathrm{S}}$ & $\mathrm{pH}$ & $\mathrm{AP}$ & $\mathrm{AI}$ & $\mathrm{AT}$ & $\mathrm{AI} / \mathrm{P}$ & $\mathrm{AB}$ & $\mathrm{AVT}$ \\
\hline 1 & 307,1 & 69,37 & 20,2 & 97,99 & 7,46 & 398,0 & 94,2 & 492,2 & 0,237 & 450,8 & 58,3 \\
2 & 66,4 & 93,38 & 42,7 & 95,74 & 7,46 & 325,3 & 77,0 & 402,3 & 0,237 & 380,6 & 30,7 \\
5 & 144,3 & 85,61 & 54,0 & 94,61 & 6,99 & 295,3 & 72,8 & 368,1 & 0,246 & 347,9 & 28,4 \\
6 & 296,8 & 70,40 & 104,0 & 89,63 & 7,00 & 278,2 & 85,6 & 363,8 & 0,308 & 347,9 & 22,4 \\
7 & 147,3 & 85,31 & 47,1 & 95,30 & 7,24 & 256,8 & 77,0 & 333,8 & 0,300 & 320,6 & 18,7 \\
8 & 125,9 & 87,44 & 69,6 & 93,06 & 7,54 & 269,6 & 72,8 & 342,4 & 0,270 & 316,9 & 35,9 \\
9 & 52,3 & 94,78 & 27,9 & 97,22 & 7,53 & 235,4 & 98,4 & 333,8 & 0,418 & 321,6 & 17,2 \\
12 & 43,1 & 95,70 & 27,5 & 97,26 & 7,52 & 231,1 & 94,2 & 325,3 & 0,407 & 310,4 & 20,9 \\
13 & 113,8 & 88,65 & 73,0 & 92,72 & 7,02 & 160,0 & 49,6 & 209,6 & 0,310 & 191,2 & 25,9 \\
14 & 70,2 & 93,00 & 46,1 & 95,40 & 7,09 & 290,4 & 78,0 & 368,4 & 0,269 & 351,8 & 23,3 \\
15 & 50,5 & 94,96 & 48,6 & 95,15 & - & - & - & - & - & - & - \\
16 & 43,7 & 95,64 & 19,0 & 98,11 & 7,10 & 290,4 & 78,0 & 368,4 & 0,269 & 350,1 & 25,8 \\
19 & 35,6 & 96,45 & 19,8 & 98,03 & - & - & - & - & - & - & - \\
20 & 57,2 & 94,30 & 50,6 & 94,95 & 7,30 & 325,78 & 55,53 & 381,31 & 0,170 & 363,35 & 25,30 \\
21 & 44,3 & 95,58 & 12,6 & 98,74 & 6,72 & 267,17 & 89,06 & 356,22 & 0,333 & 344,67 & 16,28 \\
22 & 42,3 & 95,78 & 21,4 & 97,87 & 6,64 & 242,88 & 105,25 & 348,13 & 0,433 & 339,55 & 12,08 \\
23 & 30,8 & 96,93 & 21,1 & 97,90 & 6,77 & 263,12 & 97,15 & 360,27 & 0,369 & 352,82 & 10,50 \\
\hline
\end{tabular}

Unidades:
Tempo $=$ dia
AP; AI; AT; $\mathrm{AB}=\mathrm{mgCaCO}_{3} / 1$
$\mathrm{C}_{\mathrm{ST}} ; \mathrm{C}_{\mathrm{SS}}=\mathrm{mg} / \mathrm{l}$, em termos de DQO
$\mathrm{AVT}=\operatorname{mgHAc} / 1$
$\varepsilon_{\mathrm{T}} ; \varepsilon_{\mathrm{S}}=\%$ 
Tabela B.3 - Concentração de sólidos : totais (ST), voláteis totais (SVT), em suspensão totais (SST), em suspensão voláteis (SSV) em amostras do afluente e do efluente no ensaio de $\mathrm{COV}=1,2 \mathrm{~g} / \mathrm{l} \cdot \mathrm{d}$ durante a operação do reator em batelada nas condições $\mathrm{I}$ $\left(\mathrm{NaHCO}_{3} / \mathrm{DQO}=1,0\right)$ e II $\left(\mathrm{NaHCO}_{3} / \mathrm{DQO}=0,5\right)$.

\begin{tabular}{c|cccc|cccc}
\hline & \multicolumn{4}{|c|}{ Efluente } & \multicolumn{4}{c}{ Afluente } \\
\hline $\begin{array}{c}\text { Tempo } \\
\text { (dia) }\end{array}$ & ST & SVT & SST & SSV & ST & SVT & SST & SSV \\
\hline 1 & 712 & 252 & 20 & 20 & 1762 & 1126 & 0 & 0 \\
6 & 840 & 352 & 46 & 38 & 1692 & 1236 & 24 & 18 \\
8 & 630 & 224 & 2 & 2 & 1312 & 956 & 12 & 10 \\
14 & 590 & 248 & 18 & 16 & 1380 & 1048 & 30 & 26 \\
20 & 602 & 258 & 4 & 4 & 1494 & 1164 & 18 & 18 \\
\hline
\end{tabular}

Unidades:

ST; SVT; SST; SSV = mg/l 


\section{ANEXO C - $\left(\mathrm{COV}=2,4\right.$ g./l.d $\left.; \mathrm{C}_{\mathrm{AF}}=2000 \mathrm{mg} / \mathrm{l}\right)-$ VALORES EXPERIMENTAIS}

Tabela C.1 - Valores da concentração de substrato $\left(\mathrm{C}_{\mathrm{AF}}\right)$, pH, alcalinidade parcial (AP), alcalinidade intermediária (AI), alcalinidade total (AT), alcalinidade a bicarbonato (AB) e ácidos voláteis totais (AVT) em amostras do afluente no ensaio de $\mathrm{COV}=2,4 \mathrm{~g} / \mathrm{l}$.d durante a operação do reator em batelada nas condições $\mathrm{I}\left(\mathrm{NaHCO}_{3} / \mathrm{DQO}=1,0\right)$, II $\left(\mathrm{NaHCO}_{3} / \mathrm{DQO}=0,5\right)$ e III. $\left(\mathrm{NaHCO}_{3} / \mathrm{DQO}=0,25\right)$.

\begin{tabular}{ccccccccc}
\hline Meio & $\mathrm{C}_{\mathrm{AF}}$ & $\mathrm{pH}$ & $\mathrm{AP}$ & $\mathrm{AI}$ & $\mathrm{AT}$ & $\mathrm{AI} / \mathrm{AP}$ & $\mathrm{AB}$ & $\mathrm{AVT}$ \\
\hline 43 & 1990,6 & 8,41 & 1007,95 & 271,22 & 1279,17 & 0,269 & 1221,61 & 81,06 \\
44 & 1941,7 & 8,40 & 975,57 & 246,93 & 1222,50 & 0,253 & 1168,00 & 76,75 \\
45 & 2186,9 & 8,36 & 979,62 & 259,07 & 1238,69 & 0,264 & 1185,01 & 75,60 \\
49 & 1948,5 & 8,37 & 539,30 & 150,30 & 689,60 & 0,279 & 641,51 & 67,73 \\
50 & 1968,7 & 8,35 & 530,46 & 141,46 & 671,92 & 0,267 & 622,74 & 69,26 \\
51 & 2009,0 & 8,12 & 274,07 & 97,25 & 371,32 & 0,355 & 324,32 & 66,21 \\
52 & 2040,7 & 8,34 & 282,91 & 88,41 & 371,32 & 0,313 & 323,59 & 67,22 \\
55 & 2045,7 & 8,45 & 286,00 & 91,49 & 377,48 & 0,320 & 335,74 & 58,80 \\
56 & 2071,8 & 8,40 & 260,78 & 85,50 & 346,28 & 0,328 & 303,43 & 60,35 \\
57 & 2010,9 & 8,33 & 260,78 & 85,50 & 346,28 & 0,328 & 301,54 & 63,01 \\
58 & 2004,6 & - & - & - & - & - & - & - \\
61 & 1992,0 & 8,21 & 269,33 & 89,78 & 359,10 & 0,333 & 311,05 & 67,67 \\
62 & 1939,8 & 8,23 & 265,05 & 81,23 & 346,28 & 0,306 & 301,85 & 62,57 \\
63 & 2009,5 & - & - & - & - & - & - & - \\
64 & 1954,2 & - & - & - & - & - & - & - \\
65 & 2038,0 & 8,08 & 250,09 & 87,64 & 337,73 & 0,350 & 299,92 & 53,25 \\
\hline
\end{tabular}

Unidades:

$\mathrm{C}_{\mathrm{AF}}=\mathrm{mg} / \mathrm{l}$, em termos de DQO

$\mathrm{AP} ; \mathrm{AI} ; \mathrm{AT} ; \mathrm{AB}=\mathrm{mgCaCO} 3 / 1$

$\mathrm{AVT}=\operatorname{mgHAc} / 1$ 
Tabela C.2 - Valores da concentração de substrato ( $\mathrm{C}_{\mathrm{ST}}$ e $\mathrm{C}_{\mathrm{SS}}$ ), pH, alcalinidade parcial (AP), alcalinidade intermediária (AI), alcalinidade total (AT), alcalinidade a bicarbonato (AB) e ácidos voláteis totais (AVT) em amostras do efluente no ensaio de COV = 2,4 g/l.d durante a operação do reator em batelada nas condições I $\left(\mathrm{NaHCO}_{3} / \mathrm{DQO}=1,0\right)$, II $\left(\mathrm{NaHCO}_{3} / \mathrm{DQO}=0,5\right)$ e III $\left(\mathrm{NaHCO}_{3} / \mathrm{DQO}=0,25\right)$.

\begin{tabular}{cccccccccccc}
\hline \multirow{2}{*}{ Tempo } & $\mathrm{C}_{\mathrm{ST}}$ & $\varepsilon_{\mathrm{T}}$ & $\mathrm{C}_{\mathrm{SS}}$ & $\varepsilon_{\mathrm{S}}$ & $\mathrm{pH}$ & $\mathrm{AP}$ & $\mathrm{AI}$ & $\mathrm{AT}$ & $\mathrm{AI} / \mathrm{P}$ & $\mathrm{AB}$ & $\mathrm{AVT}$ \\
\hline 1 & 197,2 & 90,19 & 30,4 & 98,49 & 6,93 & 821,7 & 206,4 & 1028,2 & 0,25 & 1006,1 & 31,0 \\
2 & 56,3 & 97,20 & 18,4 & 99,08 & 6,89 & 874,4 & 283,4 & 1157,7 & 0,32 & 1137,3 & 28,7 \\
3 & 107,0 & 94,68 & 21,1 & 98,95 & 6,84 & 935,1 & 315,7 & 1250,8 & 0,34 & 1233,3 & 24,7 \\
8 & 82,3 & 95,90 & 24,2 & 98,80 & 6,68 & 507,3 & 175,8 & 683,1 & 0,35 & 666,0 & 24,1 \\
9 & 181,8 & 90,95 & 16,0 & 99,20 & 6,66 & 526,0 & 225,4 & 751,5 & 0,43 & 737,3 & 20,0 \\
10 & 64,4 & 96,80 & 19,6 & 99,02 & 6,58 & 397,8 & 194,5 & 592,3 & 0,49 & 581,0 & 16,0 \\
11 & 81,3 & 95,95 & 33,0 & 98,36 & 6,43 & 300,6 & 150,3 & 450,9 & 0,50 & 438,7 & 17,2 \\
15 & 41,8 & 97,92 & 20,9 & 98,96 & 6,36 & 233,0 & 134,7 & 367,7 & 0,58 & 354,4 & 18,7 \\
16 & 61,2 & 96,95 & 42,5 & 97,89 & 6,37 & 235,1 & 132,5 & 367,7 & 0,56 & 356,4 & 15,9 \\
17 & 72,1 & 96,41 & 21,1 & 98,95 & 6,42 & 243,7 & 128,3 & 371,9 & 0,53 & 356,0 & 22,5 \\
18 & 81,3 & 95,95 & 7,4 & 99,63 & - & - & - & - & - & - & - \\
21 & 101,3 & 95,0 & 31,5 & 98,4 & 6,55 & 295,0 & 136,8 & 431,8 & 0,46 & 416,3 & 21,8 \\
22 & 90,6 & 97,5 & 22,5 & 99,1 & - & - & - & - & - & - & - \\
23 & 89,7 & 95,5 & 12,2 & 99,4 & 6,39 & 237,3 & 141,1 & 378,3 & 0,59 & 365,4 & 18,2 \\
24 & 75,4 & 96,2 & 22,5 & 98,9 & - & - & - & - & - & - \\
25 & 50,8 & 97,5 & 17,3 & 99,1 & 6,53 & 254,4 & 117,6 & 371,9 & 0,46 & 361,6 & 14,5 \\
\hline
\end{tabular}

Unidades:

$$
\begin{array}{ll}
\text { Tempo }=\text { dia } & \mathrm{AP} ; \mathrm{AI} ; \mathrm{AT} ; \mathrm{AB}=\mathrm{mgCaCO}_{3} / 1 \\
\mathrm{C}_{\mathrm{ST}} ; \mathrm{C}_{\mathrm{SS}}=\mathrm{mg} / \mathrm{l}, \text { em termos de DQO } & \mathrm{AVT}=\mathrm{mgHAc} / \mathrm{l} \\
\varepsilon_{\mathrm{T}} ; \varepsilon_{\mathrm{S}}=\% &
\end{array}
$$


Tabela C.3 - Concentração de sólidos : totais (ST), voláteis totais (SVT), em suspensão totais (SST), em suspensão voláteis (SSV) em amostras do afluente e do efluente no ensaio de $\mathrm{COV}=2,4 \mathrm{~g} / \mathrm{l}$.d durante a operação do reator em batelada nas condições I $\left(\mathrm{NaHCO}_{3} / \mathrm{DQO}=1,0\right), \mathrm{II}\left(\mathrm{NaHCO}_{3} / \mathrm{DQO}=0,5\right)$ e III $\left(\mathrm{NaHCO}_{3} / \mathrm{DQO}=0,25\right)$.

\begin{tabular}{c|cccc|cccc}
\hline & \multicolumn{4}{|c|}{ Efluente } & \multicolumn{4}{c}{ Afluente } \\
\hline $\begin{array}{c}\text { Tempo } \\
\text { (dia) }\end{array}$ & ST & SVT & SST & SSV & ST & SVT & SST & SSV \\
\hline 3 & 1538 & 742 & 70 & 66 & 3372 & 2400 & 12 & 12 \\
8 & 1330 & 624 & 76 & 72 & 2976 & 2234 & 30 & 30 \\
10 & 898 & 244 & 72 & 52 & 2336 & 1846 & 54 & 32 \\
15 & 2334 & 1910 & 44 & 34 & 750 & 294 & 50 & 46 \\
17 & 760 & 314 & 36 & 22 & 2378 & 1854 & 44 & 28 \\
22 & 734 & 322 & 60 & 44 & - & - & - & - \\
24 & 628 & 310 & 30 & 26 & 1956 & 1590 & 22 & 30 \\
\hline
\end{tabular}

Unidades:

$\mathrm{ST} ; \mathrm{SVT} ; \mathrm{SST} ; \mathrm{SSV}=\mathrm{mg} / \mathrm{l}$ 


\section{ANEXO D $-\left(\mathrm{COV}=4,8 \mathrm{~g} / \mathrm{l} . \mathrm{d} ; \mathrm{C}_{\mathrm{AF}}=4000 \mathrm{mg} / \mathrm{l}\right)-$ VALORES EXPERIMENTAIS}

Tabela D.1 - Valores da concentração de substrato $\left(\mathrm{C}_{\mathrm{AF}}\right), \mathrm{pH}$, alcalinidade parcial (AP), alcalinidade intermediária (AI), alcalinidade total (AT), alcalinidade a bicarbonato (AB) e ácidos voláteis totais (AVT) em amostras do afluente no ensaio de $\mathrm{COV}=4,8 \mathrm{~g} / \mathrm{l}$.d durante a operação do reator em batelada nas condições I $\left(\mathrm{NaHCO}_{3} / \mathrm{DQO}=1,0\right)$, II $\left(\mathrm{NaHCO}_{3} / \mathrm{DQO}=0,5\right)$ e III. $\left(\mathrm{NaHCO}_{3} / \mathrm{DQO}=0,25\right)$.

\begin{tabular}{ccccccccc}
\hline Meio & $\mathrm{C}_{\mathrm{AF}}$ & $\mathrm{pH}$ & $\mathrm{AP}$ & $\mathrm{AI}$ & $\mathrm{AT}$ & $\mathrm{AI} / \mathrm{AP}$ & $\mathrm{AB}$ & $\mathrm{AVT}$ \\
\hline 70 & 3897,1 & 8,30 & 1634,76 & 793,44 & 2428,20 & 0,485 & 2348,57 & 112,16 \\
71 & 3762,4 & 7,69 & 1696,32 & 560,88 & 2257,20 & 0,331 & 2129,27 & 180,19 \\
72 & 4300,9 & 8,22 & 916,56 & 342,00 & 1258,56 & 0,373 & 1172,40 & 121,35 \\
73 & 3943,9 & 8,14 & 902,88 & 369,36 & 1272,24 & 0,409 & 1189,31 & 116,80 \\
77 & 4062,4 & 8,41 & 982,51 & 293,39 & 1275,90 & 0,299 & 1186,70 & 125,63 \\
78 & 3985,2 & 8,35 & 1043,92 & 238,81 & 1282,72 & 0,229 & 1187,01 & 134,80 \\
79 & 4028,1 & 8,11 & 539,02 & 143,28 & 682,30 & 0,266 & 591,80 & 127,47 \\
80 & 3980,6 & 8,15 & 552,66 & 143,28 & 695,95 & 0,259 & 603,49 & 130,22 \\
84 & 3980,6 & 8,21 & 539,44 & 134,86 & 674,30 & 0,250 & 586,29 & 123,95 \\
85 & 4025,7 & 8,34 & 532,70 & 148,35 & 681,04 & 0,278 & 597,50 & 117,66 \\
86 & 3997,7 & 8,35 & 525,95 & 161,83 & 687,79 & 0,308 & 604,24 & 117,66 \\
87 & 3955,6 & 8,12 & 519,21 & 161,83 & 681,04 & 0,312 & 596,23 & 119,46 \\
90 & 3901,8 & 8,28 & 525,95 & 175,32 & 701,27 & 0,333 & 617,09 & 118,56 \\
91 & 4023,8 & - & - & - & - & - & - & - \\
92 & 4031,4 & 8,29 & 519,21 & 168,58 & 687,79 & 0,325 & 602,97 & 119,46 \\
93 & 3889,2 & - & - & - & - & - & - & - \\
\hline
\end{tabular}

Unidades:

$\mathrm{C}_{\mathrm{AF}}=\mathrm{mg} / \mathrm{l}$, em termos de DQO

$\mathrm{AP} ; \mathrm{AI} ; \mathrm{AT} ; \mathrm{AB}=\mathrm{mgCaCO}_{3} / 1$

$\mathrm{AVT}=\operatorname{mgHAc} / 1$ 
Tabela D.2 - Valores da concentração de substrato ( $\mathrm{C}_{\mathrm{ST}}$ e $\mathrm{C}_{\mathrm{SS}}$ ), pH, alcalinidade parcial (AP), alcalinidade intermediária (AI), alcalinidade total (AT), alcalinidade a bicarbonato (AB) e ácidos voláteis totais (AVT) em amostras do efluente no ensaio de COV = 4,8 g/l.d durante a operação do reator em batelada nas condições I $\left(\mathrm{NaHCO}_{3} / \mathrm{DQO}=1,0\right)$, II $\left(\mathrm{NaHCO}_{3} / \mathrm{DQO}=0,5\right)$ e III $\left(\mathrm{NaHCO}_{3} / \mathrm{DQO}=0,25\right)$.

\begin{tabular}{cccccccccccc}
\hline \multirow{2}{*}{ Tempo } & $\mathrm{C}_{\mathrm{ST}}$ & $\varepsilon_{\mathrm{T}}$ & $\mathrm{C}_{\mathrm{SS}}$ & $\varepsilon_{\mathrm{S}}$ & $\mathrm{pH}$ & $\mathrm{AP}$ & $\mathrm{AI}$ & $\mathrm{AT}$ & $\mathrm{AI} / \mathrm{P}$ & $\mathrm{AB}$ & $\mathrm{AVT}$ \\
\hline 1 & 97,7 & 97,55 & 33,1 & 99,17 & 6,73 & 1333,8 & 800,3 & 2134,1 & 0,60 & 2116,5 & 24,8 \\
2 & 192,3 & 95,17 & 35,1 & 99,12 & 7,02 & 1757,9 & 601,9 & 2359,8 & 0,34 & 2336,1 & 33,3 \\
3 & 119,5 & 97,00 & 30,2 & 99,24 & 6,77 & 1128,6 & 499,3 & 1627,9 & 0,44 & 1605,2 & 32,0 \\
4 & 102,9 & 97,42 & 34,0 & 99,15 & 6,67 & 930,2 & 458,3 & 1388,5 & 0,49 & 1368,4 & 28,4 \\
8 & 123,5 & 96,90 & 36,0 & 99,10 & 6,83 & 1016,6 & 361,6 & 1378,2 & 0,36 & 1354,6 & 33,3 \\
9 & 111,1 & 97,21 & 39,9 & 99,00 & 6,88 & 1064,4 & 286,6 & 1351,0 & 0,27 & 1325,8 & 35,5 \\
10 & 122,6 & 96,92 & 48,2 & 98,79 & 6,77 & 750,5 & 211,5 & 962,0 & 0,28 & 937,2 & 35,0 \\
11 & 121,3 & 96,96 & 47,0 & 98,82 & 6,74 & 614,1 & 191,0 & 805,1 & 0,31 & 779,3 & 36,4 \\
15 & 158,3 & 96,03 & 62,9 & 98,42 & 6,65 & 552,9 & 209,0 & 762,0 & 0,38 & 733,2 & 40,5 \\
16 & 156,3 & 96,08 & 73,6 & 98,15 & 6,60 & 505,7 & 222,5 & 728,2 & 0,44 & 702,3 & 36,6 \\
17 & 176,9 & 95,56 & 73,9 & 98,15 & - & - & - & - & - & - & - \\
18 & 212,4 & 94,7 & 93,1 & 97,7 & 6,70 & 519,2 & 209,0 & 728,2 & 0,40 & 701,7 & 37,4 \\
21 & 302,2 & 92,4 & 117,7 & 97,0 & - & - & - & - & - & - & - \\
22 & - & - & 94,8 & 97,6 & 6,74 & 526,0 & 209,0 & 735,0 & 0,40 & 706,3 & 40,5 \\
23 & 193,6 & 95,1 & 92,2 & 97,7 & - & - & - & - & - & - \\
25 & - & - & 82,5 & 97,9 & 6,64 & 539,4 & 249,5 & 788,9 & 0,46 & 754,0 & 49,2 \\
\hline
\end{tabular}

Unidades:

$$
\begin{array}{ll}
\text { Tempo }=\text { dia } & \mathrm{AP} ; \mathrm{AI} ; \mathrm{AT} ; \mathrm{AB}=\mathrm{mgCaCO}_{3} / 1 \\
\mathrm{C}_{\mathrm{ST}} ; \mathrm{C}_{\mathrm{SS}}=\mathrm{mg} / \mathrm{l}, \text { em termos de DQO } & \mathrm{AVT}=\mathrm{mgHAc} / \mathrm{l} \\
\varepsilon_{\mathrm{T}} ; \varepsilon_{\mathrm{S}}=\% &
\end{array}
$$


Tabela D.3 - Concentração de sólidos : totais (ST), voláteis totais (SVT), em suspensão totais (SST), em suspensão voláteis (SSV) em amostras do afluente e do efluente no ensaio de $\mathrm{COV}=4,8$ /l.d durante a operação do reator em batelada nas condições $\mathrm{I}$ $\left(\mathrm{NaHCO}_{3} / \mathrm{DQO}=1,0\right), \mathrm{II}\left(\mathrm{NaHCO}_{3} / \mathrm{DQO}=0,5\right)$ e III $\left(\mathrm{NaHCO}_{3} / \mathrm{DQO}=0,25\right)$.

\begin{tabular}{c|cccc|cccc}
\hline & \multicolumn{4}{|c|}{ Efluente } & \multicolumn{4}{c}{ Afluente } \\
\hline $\begin{array}{c}\text { Tempo } \\
\text { (dia) }\end{array}$ & ST & SVT & SST & SSV & ST & SVT & SST & SSV \\
\hline 1 & 2624 & 534 & 64 & 62 & 6504 & 3794 & 52 & 46 \\
8 & 1946 & 568 & 84 & 56 & 5136 & 3702 & 120 & 98 \\
10 & 1656 & 718 & 144 & 130 & 4370 & 3552 & 52 & 42 \\
15 & 1390 & 600 & 160 & 144 & 4346 & 3482 & 88 & 100 \\
17 & 1198 & 372 & 126 & 66 & 4316 & 3424 & 120 & 92 \\
22 & 1302 & 468 & 152 & 118 & 4490 & 3638 & 88 & 72 \\
24 & 1358 & 460 & 124 & 90 & 4416 & 3474 & 82 & 64 \\
\hline
\end{tabular}

Unidades:

ST; SVT; SST; SSV = mg/l 


\section{ANEXO E $-\left(\mathrm{COV}=7,2 \mathrm{~g} / \mathrm{l} . \mathrm{d} ; \mathrm{C}_{\mathrm{AF}}=6000 \mathrm{mg} / \mathrm{l}\right)-$ VALORES EXPERIMENTAIS}

Tabela E.1 - Valores da concentração de substrato $\left(\mathrm{C}_{\mathrm{AF}}\right), \mathrm{pH}$, alcalinidade parcial (AP), alcalinidade intermediária (AI), alcalinidade total (AT), alcalinidade a bicarbonato (AB) e ácidos voláteis totais (AVT) em amostras do afluente no ensaio de $\mathrm{COV}=7,2 \mathrm{~g} / \mathrm{l}$.d durante a operação do reator em batelada nas condições I $\left(\mathrm{NaHCO}_{3} / \mathrm{DQO}=1,0\right)$ e II $\left(\mathrm{NaHCO}_{3} / \mathrm{DQO}=0,5\right)$.

\begin{tabular}{ccccccccc}
\hline Meio & $\mathrm{C}_{\mathrm{AF}}$ & $\mathrm{pH}$ & $\mathrm{AP}$ & $\mathrm{AI}$ & $\mathrm{AT}$ & $\mathrm{AI} / \mathrm{AP}$ & $\mathrm{AB}$ & $\mathrm{AVT}$ \\
\hline 1 & 5852,4 & 8,47 & 2810,10 & 909,15 & 3719,25 & 0,324 & 3623,20 & 135,28 \\
2 & 6253,3 & 0,00 & 0,00 & 0,00 & 0,00 & 0,000 & 0,00 & 0,00 \\
3 & 6176,5 & 8,30 & 1719,12 & 462,84 & 2181,96 & 0,269 & 2056,68 & 176,45 \\
4 & 6153,9 & 8,30 & 1355,46 & 462,84 & 1818,30 & 0,341 & 1694,69 & 174,10 \\
7 & 6100,1 & 8,30 & 1405,05 & 429,78 & 1834,83 & 0,306 & 1780,54 & 76,46 \\
8 & 6043,7 & - & - & - & - & - & - & - \\
\hline
\end{tabular}

Unidades:

$\mathrm{C}_{\mathrm{AF}}=\mathrm{mg} / \mathrm{l}$, em termos de DQO

$\mathrm{AP} ; \mathrm{AI} ; \mathrm{AT} ; \mathrm{AB}=\mathrm{mgCaCO} / 1$

$\mathrm{AVT}=\operatorname{mgHAc} / 1$ 
Tabela E.2 - Valores da concentração de substrato $\left(\mathrm{C}_{\mathrm{ST}}\right.$ e $\left.\mathrm{C}_{\mathrm{SS}}\right), \mathrm{pH}$, alcalinidade parcial (AP), alcalinidade intermediária (AI), alcalinidade total (AT), alcalinidade a bicarbonato (AB) e ácidos voláteis totais (AVT) em amostras do efluente no ensaio de COV = $7,2 \mathrm{~g} / \mathrm{l} . \mathrm{d}$ durante a operação do reator em batelada nas condições $\mathrm{I}\left(\mathrm{NaHCO}_{3} / \mathrm{DQO}=1,0\right)$ e II $\left(\mathrm{NaHCO}_{3} / \mathrm{DQO}=0,5\right)$.

\begin{tabular}{cccccccccccc}
\hline \multirow{2}{*}{ Tempo } & $\mathrm{C}_{\mathrm{ST}}$ & $\varepsilon_{\mathrm{T}}$ & $\mathrm{C}_{\mathrm{SS}}$ & $\varepsilon_{\mathrm{S}}$ & $\mathrm{pH}$ & $\mathrm{AP}$ & $\mathrm{AI}$ & $\mathrm{AT}$ & $\mathrm{AI} / \mathrm{P}$ & $\mathrm{AB}$ & $\mathrm{AVT}$ \\
\hline 1 & 766,2 & 87,43 & 360,2 & 94,09 & 7,05 & 2691,7 & 869,6 & 3561,3 & 0,32 & 3389,2 & 242,3 \\
2 & 854,8 & 85,98 & 568,0 & 90,68 & 7,12 & 2673,8 & 1124,8 & 3798,6 & 0,42 & 3577,1 & 312,1 \\
3 & 1077,4 & 82,33 & 625,4 & 89,74 & 6,87 & 1530,5 & 811,4 & 2341,9 & 0,53 & 2061,9 & 394,4 \\
4 & 1122,0 & 81,60 & 718,8 & 88,21 & 6,80 & 1383,0 & 774,5 & 2157,5 & 0,56 & 1839,7 & 447,6 \\
8 & 1547,1 & 74,62 & 1320,2 & 78,35 & 6,65 & 995,8 & 811,4 & 1807,1 & 0,81 & 1514,9 & 411,6 \\
9 & 1620,0 & 73,43 & 1415,6 & 76,78 & - & - & - & - & - & - & - \\
\hline
\end{tabular}

Unidades:

$$
\begin{aligned}
& \text { Tempo = dia } \\
& \mathrm{C}_{\mathrm{ST}} ; \mathrm{C}_{\mathrm{SS}}=\mathrm{mg} / \mathrm{l}, \text { em termos de DQO } \\
& \varepsilon_{\mathrm{T}} ; \varepsilon_{\mathrm{S}}=\% \\
& \mathrm{AP} ; \mathrm{AI} ; \mathrm{AT} ; \mathrm{AB}=\mathrm{mgCaCO}_{3} / 1 \\
& \mathrm{AVT}=\mathrm{mgHAc} / 1
\end{aligned}
$$




\section{ANEXO F - ENSAIO BA-A - VALORES EXPERIMENTAIS}

Tabela F.1 - Valores da concentração de substrato $\left(\mathrm{C}_{\mathrm{AF}}\right), \mathrm{pH}$, alcalinidade parcial (AP), alcalinidade intermediária (AI), alcalinidade total (AT), alcalinidade a bicarbonato (AB) e ácidos voláteis totais (AVT) em amostras do afluente, durante a operação do reator em batelada alimentada no ensaio BA-A a COV $=4,8 \mathrm{~g} / \mathrm{l} . \mathrm{d}, \mathrm{V}_{\text {alim }}=0,51 \mathrm{e} \mathrm{T}_{\text {alim }}=6$ horas, com $\mathrm{NaHCO}_{3} / \mathrm{DQO}=0,5$.

\begin{tabular}{ccccccccc}
\hline Meio & \multirow{2}{*}{$\mathrm{C}_{\mathrm{AF}}$} & $\mathrm{pH}$ & $\mathrm{AP}$ & $\mathrm{AI}$ & $\mathrm{AT}$ & \multirow{2}{*}{$\mathrm{A} / \mathrm{AP}$} & $\mathrm{AB}$ & \multirow{2}{*}{ AVT } \\
\hline 1 & 16422,0 & 7,95 & 3918,7 & 1288,7 & 5207,4 & 0,33 & 4340,3 & 1221,3 \\
2 & 17301,0 & 7,92 & 3945,0 & 1209,8 & 5154,8 & 0,31 & 4316,6 & 1180,6 \\
6 & 16917,0 & 8,00 & 3839,8 & 1315,0 & 5154,8 & 0,34 & 4698,1 & 643,2 \\
7 & 14787,0 & 7,67 & 3655,7 & 1393,9 & 5049,6 & 0,38 & 4586,2 & 652,7 \\
8 & 16647,5 & 7,70 & 3629,4 & 1367,6 & 4997,0 & 0,38 & 4524,8 & 665,1 \\
\hline
\end{tabular}

Unidades:

$\mathrm{C}_{\mathrm{AF}}=\mathrm{mg} / \mathrm{l}$, em termos de DQO

$\mathrm{AP} ; \mathrm{AI} ; \mathrm{AT} ; \mathrm{AB}=\mathrm{mgCaCO} / 1$

$\mathrm{AVT}=\operatorname{mgHAc} / 1$ 
Tabela F.2 - Valores da concentração de substrato $\left(\mathrm{C}_{\mathrm{ST}}\right.$ e $\mathrm{C}_{\mathrm{SS}}$ ), pH, alcalinidade parcial (AP), alcalinidade intermediária (AI), alcalinidade total (AT), alcalinidade a bicarbonato (AB) e ácidos voláteis totais (AVT) em amostras do efluente, durante a operação do reator em batelada alimentada no ensaio BA-A a COV = 4,8 g/l.d, $\mathrm{V}_{\text {alim }}$ de 0,5 1 e $\mathrm{T}_{\text {alim }}$ de 6 horas, com $\mathrm{NaHCO}_{3} / \mathrm{DQO}=0,5$.

\begin{tabular}{cccccccccccc}
\hline Tempo & $\mathrm{C}_{\mathrm{ST}}$ & $\varepsilon_{\mathrm{T}}$ & $\mathrm{C}_{\mathrm{SS}}$ & $\varepsilon_{\mathrm{S}}$ & $\mathrm{pH}$ & $\mathrm{AP}$ & $\mathrm{AI}$ & $\mathrm{AT}$ & $\mathrm{AI} / \mathrm{P}$ & $\mathrm{AB}$ & $\mathrm{AVT}$ \\
\hline 1 & 315,3 & 98,1 & 109,2 & 99,3 & 7,17 & 1867,3 & 683,8 & 2551,1 & 0,37 & 2336,1 & 302,9 \\
2 & 404,2 & 97,5 & 146,8 & 99,1 & 7,61 & 2182,9 & 604,9 & 2787,8 & 0,28 & 2561,2 & 319,2 \\
6 & 658,5 & 96,0 & 126,2 & 99,2 & - & - & - & - & - & - & - \\
7 & 940,0 & 94,3 & 99,6 & 99,4 & 7,22 & 2566,9 & 894,2 & 3461,1 & 0,35 & 3327,3 & 188,4 \\
8 & 1592,2 & 90,3 & 212,2 & 98,7 & 7,35 & 3208,6 & 957,3 & 4165,9 & 0,30 & 3994,8 & 241,0 \\
\hline
\end{tabular}

Unidades:

Tempo $=$ dia

$\mathrm{C}_{\mathrm{ST}} ; \mathrm{C}_{\mathrm{SS}}=\mathrm{mg} / \mathrm{l}$, em termos de DQO

$\varepsilon_{\mathrm{T}} ; \varepsilon_{\mathrm{S}}=\%$

$\mathrm{AP} ; \mathrm{AI} ; \mathrm{AT} ; \mathrm{AB}=\mathrm{mgCaCO}_{3} / 1$

$\mathrm{AVT}=\mathrm{mgHAc} / 1$ 


\section{ANEXO G - ENSAIO BA-E - VALORES EXPERIMENTAIS}

Tabela G.1 - Valores da concentração de substrato $\left(\mathrm{C}_{\mathrm{AF}}\right)$, $\mathrm{pH}$, alcalinidade parcial (AP), alcalinidade intermediária (AI), alcalinidade total (AT), alcalinidade a bicarbonato (AB) e ácidos voláteis totais (AVT) em amostras do afluente, durante a operação do reator em batelada alimentada no Ensaio BA-E a COV $=4,8 \mathrm{~g} / \mathrm{l} \cdot \mathrm{d}, \mathrm{C}_{\mathrm{AF}}=16000 \mathrm{mg} / \mathrm{l}, \mathrm{V}_{\mathrm{alim}}=1,01 \mathrm{e}$ $\mathrm{T}_{\text {alim }}=6$ horas, $\operatorname{com~} \mathrm{NaHCO}_{3} / \mathrm{DQO}=0,5$.

\begin{tabular}{ccccccccc}
\hline Meio & $\mathrm{C}_{\mathrm{AF}}$ & $\mathrm{pH}$ & $\mathrm{AP}$ & $\mathrm{AI}$ & $\mathrm{AT}$ & $\mathrm{AI} / \mathrm{AP}$ & $\mathrm{AB}$ & $\mathrm{AVT}$ \\
\hline 1 & 8171,1 & - & - & - & - & - & - & - \\
2 & 8250,1 & 7,81 & 1928,7 & 646,5 & 2575,2 & 0,335 & 2325,3 & 352,0 \\
3 & 8037,2 & 7,80 & 1961,1 & 625,0 & 2586,0 & 0,319 & 2344,5 & 340,1 \\
4 & - & - & - & - & - & - & - & - \\
5 & 7862,7 & 7,75 & 2184,0 & 720,0 & 2904,0 & 0,330 & 2816,2 & 123,7 \\
8 & - & - & - & - & - & - & - & - \\
10 & 8450,4 & 7,75 & 2184,0 & 696,0 & 2880,0 & 0,319 & 2763,3 & 164,3 \\
11 & 9875,2 & - & - & - & - & - & - & - \\
12 & 8678,8 & 8,30 & 2280,0 & 696,0 & 2976,0 & 0,305 & 2821,8 & 217,2 \\
13 & 8731,6 & 8,49 & 2304,0 & 648,0 & 2952,0 & 0,281 & 2805,9 & 205,8 \\
14 & 8371,2 & 8,45 & 2256,0 & 648,0 & 2904,0 & 0,287 & 2757,3 & 206,7 \\
\hline
\end{tabular}

Unidades:

$\mathrm{C}_{\mathrm{AF}}=\mathrm{mg} / \mathrm{l}$, em termos de DQO

$\mathrm{AP} ; \mathrm{AI} ; \mathrm{AT} ; \mathrm{AB}=\mathrm{mgCaCO} / 1$

$\mathrm{AVT}=\operatorname{mgHAc} / 1$ 
Tabela G.2 - Valores da concentração de substrato $\left(\mathrm{C}_{\mathrm{ST}}\right.$ e $\mathrm{C}_{\mathrm{SS}}$ ), pH, alcalinidade parcial (AP), alcalinidade intermediária (AI), alcalinidade total (AT), alcalinidade a bicarbonato (AB) e ácidos voláteis totais (AVT) em amostras do efluente, durante a operação do reator em batelada alimentada no Ensaio $\mathrm{BA}-\mathrm{E}$ a COV $=4,8 \mathrm{~g} / \mathrm{l} \cdot \mathrm{d}, \mathrm{C}_{\mathrm{AF}}=16000 \mathrm{mg} / \mathrm{l}, \mathrm{V}_{\text {alim }}=1,01 \mathrm{e} \mathrm{T}_{\text {alim }}=6$ horas, com NaHCO $/ \mathrm{DQO}$ $=0,5$.

\begin{tabular}{cccccccccccc}
\hline \multirow{2}{*}{ Tempo } & \multirow{2}{*}{$\mathrm{C}_{\mathrm{ST}}$} & $\varepsilon_{\mathrm{T}}$ & $\mathrm{C}_{\mathrm{SS}}$ & $\varepsilon_{\mathrm{S}}$ & $\mathrm{pH}$ & $\mathrm{AP}$ & $\mathrm{AI}$ & $\mathrm{AT}$ & $\mathrm{AI} / \mathrm{P}$ & $\mathrm{AB}$ & $\mathrm{AVT}$ \\
\hline 1 & 981,2 & 74,32 & 109,2 & 97,14 & 6,97 & 1508,5 & 603,4 & 2111,9 & 0,4 & 2003,8 & 152,2 \\
2 & 2181,7 & 42,91 & 824,9 & 78,41 & 6,94 & 1853,3 & 711,2 & 2564,5 & 0,4 & 2302,7 & 368,7 \\
3 & 1870,7 & 51,05 & 506,6 & 86,74 & 7,10 & 2155,0 & 754,3 & 2909,3 & 0,4 & 2703,2 & 290,2 \\
4 & 1294,0 & 66,14 & 138,8 & 96,37 & 7,53 & 2227,1 & 546,3 & 2773,3 & 0,2 & 2653,1 & 169,3 \\
5 & 880,1 & 76,97 & 173,1 & 95,47 & 7,37 & 1701,8 & 588,3 & 2290,1 & 0,3 & 2141,9 & 208,8 \\
8 & 973,6 & 74,52 & 253,2 & 93,37 & 7,11 & 1344,6 & 210,1 & 1554,7 & 0,2 & 1168,6 & 543,9 \\
11 & 526,8 & 86,21 & 215,4 & 94,36 & 7,47 & 2069,5 & 619,8 & 2689,3 & 0,3 & 2120,8 & 800,7 \\
12 & 475,4 & 87,56 & 194,6 & 94,91 & 7,34 & 2472,0 & 672,0 & 3144,0 & 0,3 & 3092,0 & 73,2 \\
13 & 738,1 & 80,69 & 267,2 & 93,01 & 7,30 & 2472,0 & 672,0 & 3144,0 & 0,3 & 3099,5 & 62,6 \\
14 & 490,4 & 87,17 & 182,5 & 95,22 & 7,35 & 2448,0 & 696,0 & 3144,0 & 0,3 & 3096,1 & 67,5 \\
15 & 444,6 & 88,37 & 113,2 & 97,04 & 7,27 & 2424,0 & 696,0 & 3120,0 & 0,3 & 3079,6 & 57,0 \\
\hline
\end{tabular}

Unidades:

Tempo $=$ dia

$\mathrm{C}_{\mathrm{ST}} ; \mathrm{C}_{\mathrm{SS}}=\mathrm{mg} / \mathrm{l}$, em termos de DQO

$\varepsilon_{\mathrm{T}} ; \varepsilon_{\mathrm{S}}=\%$

$\mathrm{AP} ; \mathrm{AI} ; \mathrm{AT} ; \mathrm{AB}=\mathrm{mgCaCO}_{3} / 1$

$\mathrm{AVT}=\mathrm{mgHAc} / 1$ 
ANEXO H - ENSAIOS EM BATELADA ALIMENTADA - VALORES EXPERIMENTAIS 


\section{ANEXO H 1 - ENSAIO BA-F 1 - VALORES EXPERIMENTAIS}

Tabela H.1 - Valores da concentração de substrato $\left(\mathrm{C}_{\mathrm{AF}}\right)$, $\mathrm{pH}$, alcalinidade parcial (AP), alcalinidade intermediária (AI), alcalinidade total (AT), alcalinidade a bicarbonato (AB) e ácidos voláteis totais (AVT) em amostras do afluente, durante a operação do reator em batelada alimentada no Ensaio BA-F1 a COV $=2,4 \mathrm{~g} / \mathrm{l} \cdot \mathrm{d}, \mathrm{C}_{\mathrm{AF}}=4000 \mathrm{mg} / \mathrm{l} \mathrm{V}_{\text {alim }}=1,01 \mathrm{e}$ $\mathrm{T}_{\text {alim }}=6$ horas, com $\mathrm{NaHCO}_{3} / \mathrm{DQO}=0,5$.

\begin{tabular}{ccccccccc}
\hline Meio & $\mathrm{C}_{\mathrm{AF}}$ & $\mathrm{pH}$ & $\mathrm{AP}$ & $\mathrm{AI}$ & $\mathrm{AT}$ & $\mathrm{AI} / \mathrm{AP}$ & $\mathrm{AB}$ & \multirow{2}{*}{$\mathrm{AVT}$} \\
\hline 1 & 4362,6 & & - & - & - & - & - & - \\
2 & 4815,3 & 7,97 & 1011,4 & 547,8 & 1559,2 & 0,542 & 1443,3 & 163,1 \\
3 & 4902,8 & 7,70 & 927,1 & 453,0 & 1380,1 & 0,489 & 1221,1 & 224,0 \\
4 & 4879,1 & 7,60 & 916,5 & 379,3 & 1295,8 & 0,414 & 1147,3 & 209,2 \\
\hline
\end{tabular}

Unidades:

$\mathrm{C}_{\mathrm{AF}}=\mathrm{mg} / \mathrm{l}, \mathrm{em}$ termos de DQO

$\mathrm{AP} ; \mathrm{AI} ; \mathrm{AT} ; \mathrm{AB}=\mathrm{mgCaCO}_{3} / 1$

$\mathrm{AVT}=\mathrm{mgHAc} / 1$ 
Tabela H.2 - Valores da concentração de substrato $\left(\mathrm{C}_{\mathrm{ST}}\right.$ e $\left.\mathrm{C}_{\mathrm{SS}}\right), \mathrm{pH}$, alcalinidade parcial (AP), alcalinidade intermediária (AI), alcalinidade total (AT), alcalinidade a bicarbonato (AB) e ácidos voláteis totais (AVT) em amostras do efluente, durante a operação do reator em batelada alimentada no Ensaio BA-F1 a COV $=2,4 \mathrm{~g} / \mathrm{l} \cdot \mathrm{d}, \mathrm{C}_{\mathrm{AF}}=4000 \mathrm{mg} / \mathrm{l} \mathrm{V}_{\text {alim }}=1,01 \mathrm{e} \mathrm{T}_{\text {alim }}=6$ horas, com NaHCO $3 / \mathrm{DQO}$ $=0,5$.

\begin{tabular}{cccccccccccc}
\hline Tempo & $\mathrm{C}_{\mathrm{ST}}$ & $\varepsilon_{\mathrm{T}}$ & $\mathrm{C}_{\mathrm{SS}}$ & $\varepsilon_{\mathrm{S}}$ & $\mathrm{pH}$ & $\mathrm{AP}$ & $\mathrm{AI}$ & $\mathrm{AT}$ & $\mathrm{AI} / \mathrm{P}$ & $\mathrm{AB}$ & $\mathrm{AVT}$ \\
\hline 1 & 673,6 & 85,8 & 274,3 & 94,2 & 7,38 & 1675,1 & 495,1 & 2170,2 & 0,30 & 2125,4 & 63,1 \\
2 & 836,4 & 82,4 & 330,7 & 93,0 & 7,18 & 1369,6 & 505,7 & 1875,2 & 0,37 & 1813,7 & 86,6 \\
3 & 580,4 & 87,8 & 224,1 & 95,3 & 7,24 & 1243,1 & 463,5 & 1706,7 & 0,37 & 1667,4 & 55,3 \\
4 & 656,7 & 86,1 & 209,0 & 95,6 & 7,00 & 1137,8 & 463,5 & 1601,3 & 0,41 & 1556,5 & 63,1 \\
\hline
\end{tabular}

Unidades:

$$
\begin{aligned}
& \text { Tempo }=\text { dia } \\
& \mathrm{C}_{\mathrm{ST}} ; \mathrm{C}_{\mathrm{SS}}=\mathrm{mg} / \mathrm{l}, \text { em termos de DQO } \\
& \varepsilon_{\mathrm{T}} ; \varepsilon_{\mathrm{S}}=\% \\
& \mathrm{AP} ; \mathrm{AI} ; \mathrm{AT} ; \mathrm{AB}=\mathrm{mgCaCO}_{3} / 1 \\
& \mathrm{AVT}=\mathrm{mgHAc} / 1
\end{aligned}
$$




\section{ANEXO H 2 - ENSAIO BA-F 2 - VALORES EXPERIMENTAIS}

Tabela H.3 - Valores da concentração de substrato $\left(\mathrm{C}_{\mathrm{AF}}\right)$, $\mathrm{pH}$, alcalinidade parcial (AP), alcalinidade intermediária (AI), alcalinidade total (AT), alcalinidade a bicarbonato (AB) e ácidos voláteis totais (AVT) em amostras do afluente, durante a operação do reator em batelada alimentada no Ensaio BA-F2 a COV $=2,4 \mathrm{~g} / \mathrm{l} \cdot \mathrm{d}, \mathrm{C}_{\mathrm{AF}}=4000 \mathrm{mg} / \mathrm{l} \mathrm{V}_{\mathrm{alim}}=1,01 \mathrm{e}$ $\mathrm{T}_{\text {alim }}=3$ horas, com $\mathrm{NaHCO}_{3} / \mathrm{DQO}=0,5$.

\begin{tabular}{ccccccccc}
\hline Meio & $\mathrm{C}_{\mathrm{AF}}$ & $\mathrm{pH}$ & $\mathrm{AP}$ & $\mathrm{AI}$ & $\mathrm{AT}$ & $\mathrm{AI} / \mathrm{AP}$ & $\mathrm{AB}$ & \multirow{2}{*}{$\mathrm{AVT}$} \\
\hline 1 & 4668,5 & 8,13 & 946,28 & 356,13 & 1302,40 & 0,376 & 1189,24 & 159,37 \\
2 & 4635,8 & 7,88 & 1028,95 & 334,69 & 1363,64 & 0,325 & 1255,64 & 152,11 \\
3 & 4278,2 & 7,89 & 936,10 & 366,30 & 1302,40 & 0,391 & 1194,40 & 152,11 \\
4 & 4354,4 & - & - & - & - & - & - & - \\
\hline
\end{tabular}

Unidades:

$\mathrm{C}_{\mathrm{AF}}=\mathrm{mg} / \mathrm{l}$, em termos de DQO

$\mathrm{AP} ; \mathrm{AI} ; \mathrm{AT} ; \mathrm{AB}=\mathrm{mgCaCO}_{3} / 1$

$\mathrm{AVT}=\operatorname{mgHAc} / 1$

Tabela H.4 - Concentração de sólidos : totais (ST), voláteis totais (SVT), em suspensão totais (SST), em suspensão voláteis (SSV) em amostras do afluente e do efluente, durante a operação do reator em batelada alimentada no Ensaio BA-F2 a COV $=2,4 \mathrm{~g} / \mathrm{l} \cdot \mathrm{d}, \mathrm{C}_{\mathrm{AF}}=4000$ $\mathrm{mg} / \mathrm{l} \mathrm{V}_{\text {alim }}=1,01$ e $\mathrm{T}_{\text {alim }}=3$ horas, $\operatorname{com~} \mathrm{NaHCO}_{3} / \mathrm{DQO}=0,5$.

\begin{tabular}{c|cccc|cccc}
\hline \multicolumn{5}{c|}{ Efluente } & \multicolumn{4}{c}{ Afluente } \\
\hline $\begin{array}{c}\text { Tempo } \\
\text { (dia) }\end{array}$ & ST & SVT & SST & SSV & ST & SVT & SST & SSV \\
\hline 2 & 1498 & 702 & 393 & 327 & 5558 & 3668 & 76 & 76 \\
3 & 1736 & 558 & 198 & 174 & 5756 & 3898 & 146 & 120 \\
4 & 2364 & 918 & 351 & 297 & 5606 & 3768 & 142 & 110 \\
5 & 2412 & 748 & 444 & 376 & 5520 & 3714 & 164 & 134 \\
\hline
\end{tabular}

Unidades:

ST; SVT; SST; SSV = mg/l 
Tabela H.5 - Valores da concentração de substrato $\left(\mathrm{C}_{\mathrm{ST}}\right.$ e $\left.\mathrm{C}_{\mathrm{SS}}\right)$, pH, alcalinidade parcial (AP), alcalinidade intermediária (AI), alcalinidade total (AT), alcalinidade a bicarbonato (AB) e ácidos voláteis totais (AVT) em amostras do efluente, durante a operação do reator em batelada alimentada no Ensaio BA-F2 a COV $=2,4 \mathrm{~g} / \mathrm{l} \cdot \mathrm{d}, \mathrm{C}_{\mathrm{AF}}=4000 \mathrm{mg} / \mathrm{l} \mathrm{V}_{\text {alim }}=1,01 \mathrm{e} \mathrm{T}_{\text {alim }}=3$ horas, com NaHCO $3 / \mathrm{DQO}$ $=0,5$.

\begin{tabular}{ccccccccccccc}
\hline Tempo & $\mathrm{C}_{\mathrm{ST}}$ & $\varepsilon_{\mathrm{T}}$ & $\mathrm{C}_{\mathrm{SS}}$ & $\varepsilon_{\mathrm{S}}$ & $\mathrm{pH}$ & $\mathrm{AP}$ & $\mathrm{AI}$ & $\mathrm{AT}$ & $\mathrm{AI} / \mathrm{P}$ & $\mathrm{AB}$ & $\mathrm{AVT}$ & \\
\hline 1 & 360,7 & 92,0 & 123,2 & 97,3 & 6,74 & 468,1 & 203,5 & 671,6 & 0,43 & 655,6 & 22,4 \\
2 & 475,5 & 89,4 & 170,5 & 96,2 & 6,84 & 785,5 & 271,1 & 1056,6 & 0,35 & 1018,6 & 53,6 \\
3 & 584,0 & 87,0 & 140,2 & 96,9 & 6,87 & 932,1 & 323,6 & 1255,8 & 0,35 & 1224,0 & 44,8 \\
4 & 636,5 & 85,8 & 160,9 & 96,4 & 6,86 & 934,9 & 387,2 & 1322,1 & 0,41 & 1298,2 & 33,7 \\
\hline
\end{tabular}

Unidades:

$$
\begin{aligned}
& \text { Tempo }=\text { dia } \\
& \mathrm{C}_{\mathrm{ST}} ; \mathrm{C}_{\mathrm{SS}}=\mathrm{mg} / \mathrm{l}, \text { em termos de DQO } \\
& \varepsilon_{\mathrm{T}} ; \varepsilon_{\mathrm{S}}=\% \\
& \mathrm{AP} ; \mathrm{AI} ; \mathrm{AT} ; \mathrm{AB}=\mathrm{mgCaCO}_{3} / 1 \\
& \mathrm{AVT}=\mathrm{mgHAc} / 1
\end{aligned}
$$




\section{ANEXO H 3 - ENSAIO BA-F 3 - VALORES EXPERIMENTAIS}

Tabela H.6 - Valores da concentração de substrato $\left(\mathrm{C}_{\mathrm{AF}}\right)$, pH, alcalinidade parcial (AP), alcalinidade intermediária (AI), alcalinidade total (AT), alcalinidade a bicarbonato $(\mathrm{AB}) \mathrm{e}$ ácidos voláteis totais (AVT) em amostras do afluente, durante a operação do reator em batelada alimentada no Ensaio BA-F3 a COV $=2,4 \mathrm{~g} / \mathrm{l} \cdot \mathrm{d}, \mathrm{C}_{\mathrm{AF}}=4000 \mathrm{mg} / \mathrm{l} \mathrm{V}_{\mathrm{alim}}=1,01 \mathrm{e}$ $\mathrm{T}_{\text {alim }}=10$ minutos, com $\mathrm{NaHCO}_{3} / \mathrm{DQO}=0,5$.

\begin{tabular}{ccccccccc}
\hline Meio & $\mathrm{C}_{\mathrm{AF}}$ & $\mathrm{pH}$ & $\mathrm{AP}$ & $\mathrm{AI}$ & $\mathrm{AT}$ & $\mathrm{AI} / \mathrm{AP}$ & $\mathrm{AB}$ & $\mathrm{AVT}$ \\
\hline 1 & 4521,4 & 8,24 & 1263,2 & 430,2 & 1693,3 & 0,341 & 1603,7 & 126,2 \\
2 & 4429,4 & 8,17 & 1164,7 & 503,9 & 1668,5 & 0,433 & 1580,0 & 124,6 \\
3 & 4457,7 & 8,18 & 1172,9 & 512,1 & 1685,0 & 0,437 & 1594,3 & 127,8 \\
4 & 4628,5 & - & - & - & - & - & - & - \\
\hline
\end{tabular}

Unidades:

$\mathrm{C}_{\mathrm{AF}}=\mathrm{mg} / \mathrm{l}$, em termos de $\mathrm{DQO}$

$\mathrm{AP} ; \mathrm{AI} ; \mathrm{AT} ; \mathrm{AB}=\mathrm{mgCaCO}_{3} / 1$

$\mathrm{AVT}=\operatorname{mgHAc} / 1$

Tabela H.7 - Concentração de sólidos : totais (ST), voláteis totais (SVT), em suspensão totais (SST), em suspensão voláteis (SSV) em amostras do afluente e do efluente, durante a operação do reator em batelada alimentada no Ensaio BA-F3 a COV $=2,4$ g/l.d, $\mathrm{C}_{\mathrm{AF}}=4000$ $\mathrm{mg} / 1 \mathrm{~V}_{\text {alim }}=1,01 \mathrm{e} \mathrm{T}_{\text {alim }}=10$ minutos, com $\mathrm{NaHCO}_{3} / \mathrm{DQO}=0,5$.

\begin{tabular}{ccccc|cccc}
\hline \multicolumn{4}{c|}{ Efluente } & \multicolumn{4}{c}{ Afluente } \\
\hline $\begin{array}{c}\text { Tempo } \\
\text { (dia) }\end{array}$ & ST & SVT & SST & SSV & ST & SVT & SST & SSV \\
\hline 1 & 1324 & 534 & 217 & 189 & 5408 & 3698 & 120 & 106 \\
2 & 1558 & 538 & 130 & 104 & 5418 & 3868 & 162 & 138 \\
3 & 1818 & 526 & 106 & 108 & 5636 & 3860 & 148 & 128 \\
\hline
\end{tabular}

Unidades:

$\mathrm{ST} ; \mathrm{SVT} ; \mathrm{SST} ; \mathrm{SSV}=\mathrm{mg} / \mathrm{l}$ 
Tabela H.8 - Valores da concentração de substrato $\left(\mathrm{C}_{\mathrm{ST}}\right.$ e $\left.\mathrm{C}_{\mathrm{SS}}\right)$, pH, alcalinidade parcial (AP), alcalinidade intermediária (AI), alcalinidade total (AT), alcalinidade a bicarbonato (AB) e ácidos voláteis totais (AVT) em amostras do efluente, durante a operação do reator em batelada alimentada no Ensaio $\mathrm{BA}-\mathrm{F} 3$ a $\mathrm{COV}=2,4 \mathrm{~g} / \mathrm{l} \cdot \mathrm{d}, \mathrm{C}_{\mathrm{AF}}=4000 \mathrm{mg} / \mathrm{l} \mathrm{V}$ alim $=1,01 \mathrm{e} \mathrm{T}_{\text {alim }}=10$ minutos, com $\mathrm{NaHCO}_{3} / \mathrm{DQO}=0,5$.

\begin{tabular}{cccccccccccc}
\hline \multirow{2}{*}{ Tempo } & \multirow{2}{*}{$\mathrm{C}_{\mathrm{ST}}$} & $\varepsilon_{\mathrm{T}}$ & $\mathrm{C}_{\mathrm{SS}}$ & $\varepsilon_{\mathrm{S}}$ & $\mathrm{pH}$ & $\mathrm{AP}$ & $\mathrm{AI}$ & $\mathrm{AT}$ & $\mathrm{AI} / \mathrm{P}$ & $\mathrm{AB}$ & $\mathrm{AVT}$ \\
\hline 1 & 244,5 & 94,6 & 84,6 & 98,1 & 6,82 & 757,9 & 300,4 & 1058,3 & 0,396 & 1041,9 & 23,1 \\
2 & 267,5 & 94,1 & 92,0 & 98,0 & 6,85 & 996,9 & 409,7 & 1406,6 & 0,411 & 1386,8 & 27,8 \\
3 & 283,0 & 93,7 & 96,9 & 97,9 & 6,95 & 1167,6 & 450,6 & 1618,2 & 0,386 & 1597,7 & 28,9 \\
4 & 302,2 & 93,3 & 115,8 & 97,4 & 6,85 & 996,9 & 409,7 & 1406,6 & 0,411 & 1386,8 & 27,8 \\
\hline
\end{tabular}

Unidades:

$$
\begin{aligned}
& \text { Tempo }=\text { dia } \\
& \mathrm{C}_{\mathrm{ST}} ; \mathrm{C}_{\mathrm{SS}}=\mathrm{mg} / \mathrm{l}, \text { em termos de DQO } \\
& \varepsilon_{\mathrm{T}} ; \varepsilon_{\mathrm{S}}=\% \\
& \mathrm{AP} ; \mathrm{AI} ; \mathrm{AT} ; \mathrm{AB}=\mathrm{mgCaCO}_{3} / 1 \\
& \mathrm{AVT}=\mathrm{mgHAc} / 1
\end{aligned}
$$




\section{ANEXO H 4 - ENSAIO BA-F 4 - VALORES EXPERIMENTAIS}

Tabela H.9 - Valores da concentração de substrato $\left(\mathrm{C}_{\mathrm{AF}}\right)$, pH, alcalinidade parcial (AP), alcalinidade intermediária $(\mathrm{AI})$, alcalinidade total $(\mathrm{AT})$, alcalinidade a bicarbonato $(\mathrm{AB}) \mathrm{e}$ ácidos voláteis totais (AVT) em amostras do afluente, durante a operação do reator em batelada alimentada no Ensaio BA-F4 a COV $=2,4 \mathrm{~g} / \mathrm{l} \cdot \mathrm{d}, \mathrm{C}_{\mathrm{AF}}=8000 \mathrm{mg} / \mathrm{l} \mathrm{V}_{\mathrm{alim}}=0,51 \mathrm{e}$ $\mathrm{T}_{\text {alim }}=6$ horas, com $\mathrm{NaHCO}_{3} / \mathrm{DQO}=0,5$.

\begin{tabular}{ccccccccc}
\hline Meio & $\mathrm{C}_{\mathrm{AF}}$ & $\mathrm{pH}$ & $\mathrm{AP}$ & $\mathrm{AI}$ & $\mathrm{AT}$ & $\mathrm{AI} / \mathrm{AP}$ & $\mathrm{AB}$ & AVT \\
\hline 2 & 8952,1 & 8,27 & 2600,78 & 857,40 & 3458,18 & 0,330 & 3256,33 & 284,30 \\
3 & 8234,6 & 7,66 & 2600,78 & 885,98 & 3486,76 & 0,341 & 3284,91 & 284,30 \\
4 & 8690,4 & 8,25 & 2186,37 & 757,37 & 2943,74 & 0,346 & 2778,17 & 233,19 \\
\hline
\end{tabular}

Unidades:

$\mathrm{C}_{\mathrm{AF}}=\mathrm{mg} / \mathrm{l}$, em termos de DQO

$\mathrm{AP} ; \mathrm{AI} ; \mathrm{AT} ; \mathrm{AB}=\mathrm{mgCaCO}_{3} / 1$

$\mathrm{AVT}=\operatorname{mgHAc} / 1$ 
Tabela H.10 - Valores da concentração de substrato $\left(\mathrm{C}_{\mathrm{ST}}\right.$ e $\left.\mathrm{C}_{\mathrm{SS}}\right), \mathrm{pH}$, alcalinidade parcial (AP), alcalinidade intermediária (AI), alcalinidade total (AT), alcalinidade a bicarbonato (AB) e ácidos voláteis totais (AVT) em amostras do efluente, durante a operação do reator em batelada alimentada no Ensaio BA-F4 a COV $=2,4 \mathrm{~g} / \mathrm{l} \cdot \mathrm{d}, \mathrm{C}_{\mathrm{AF}}=8000 \mathrm{mg} / \mathrm{l} \mathrm{V}_{\text {alim }}=0,5 \mathrm{le} \mathrm{T}_{\text {alim }}=6$ horas, com NaHCO $/ \mathrm{DQO}$ $=0,5$.

\begin{tabular}{cccccccccccc}
\hline Tempo & $\mathrm{C}_{\mathrm{ST}}$ & $\varepsilon_{\mathrm{T}}$ & $\mathrm{C}_{\mathrm{SS}}$ & $\varepsilon_{\mathrm{S}}$ & $\mathrm{pH}$ & $\mathrm{AP}$ & $\mathrm{AI}$ & $\mathrm{AT}$ & $\mathrm{AI} / \mathrm{P}$ & $\mathrm{AB}$ & $\mathrm{AVT}$ \\
\hline 1 & 346,1 & 94,7 & 119,6 & 98,2 & 7,15 & 719,2 & 239,7 & 958,9 & 0,33 & 930,8 & 39,5 \\
3 & 405,6 & 93,7 & 54,7 & 99,2 & 7,40 & 2286,4 & 828,8 & 3115,2 & 0,36 & 3024,1 & 128,3 \\
4 & 605,8 & 90,6 & 162,4 & 97,5 & 7,18 & 2286,4 & 828,8 & 3115,2 & 0,36 & 3024,1 & 128,3 \\
5 & 770,2 & 88,1 & 154,1 & 97,6 & 7,32 & 2457,9 & 714,5 & 3172,4 & 0,29 & 3082,7 & 126,3 \\
\hline
\end{tabular}

Unidades:

$$
\begin{aligned}
& \text { Tempo = dia } \\
& \mathrm{C}_{\mathrm{ST}} ; \mathrm{C}_{\mathrm{SS}}=\mathrm{mg} / \mathrm{l}, \text { em termos de DQO } \\
& \varepsilon_{\mathrm{T}} ; \varepsilon_{\mathrm{S}}=\% \\
& \mathrm{AP} ; \mathrm{AI} ; \mathrm{AT} ; \mathrm{AB}=\mathrm{mgCaCO}_{3} / 1 \\
& \mathrm{AVT}=\mathrm{mgHAc} / 1
\end{aligned}
$$




\section{ANEXO H 5 - ENSAIO BA-F 5 - VALORES EXPERIMENTAIS}

Tabela H.11 - Valores da concentração de substrato $\left(\mathrm{C}_{\mathrm{AF}}\right)$, pH, alcalinidade parcial (AP), alcalinidade intermediária (AI), alcalinidade total (AT), alcalinidade a bicarbonato $(\mathrm{AB}) \mathrm{e}$ ácidos voláteis totais (AVT) em amostras do afluente, durante a operação do reator em batelada alimentada no Ensaio BA-F5 a COV $=2,4 \mathrm{~g} / \mathrm{l} \cdot \mathrm{d}, \mathrm{C}_{\mathrm{AF}}=8000 \mathrm{mg} / \mathrm{l} \mathrm{V}_{\mathrm{alim}}=0,51 \mathrm{e}$ $\mathrm{T}_{\text {alim }}=3$ horas, com $\mathrm{NaHCO}_{3} / \mathrm{DQO}=0,5$.

\begin{tabular}{ccccccccc}
\hline Meio & $\mathrm{C}_{\mathrm{AF}}$ & $\mathrm{pH}$ & $\mathrm{AP}$ & $\mathrm{AI}$ & $\mathrm{AT}$ & $\mathrm{AI} / \mathrm{AP}$ & $\mathrm{AB}$ & \multirow{2}{*}{ AVT } \\
\hline \hline 1 & 7701,0 & 6,89 & 1285,20 & 785,40 & 2070,60 & 0,611 & 1903,70 & 235,08 \\
2 & 8959,0 & 8,00 & 1754,40 & 612,00 & 2366,40 & 0,349 & 2166,29 & 281,85 \\
3 & 8840,0 & 7,78 & 1795,20 & 693,60 & 2488,80 & 0,386 & 2288,69 & 281,85 \\
4 & - & - & - & - & - & - & - & - \\
\hline
\end{tabular}

Unidades:

$\mathrm{C}_{\mathrm{AF}}=\mathrm{mg} / \mathrm{l}$, em termos de DQO

$\mathrm{AP} ; \mathrm{AI} ; \mathrm{AT} ; \mathrm{AB}=\mathrm{mgCaCO}_{3} / 1$

$\mathrm{AVT}=\operatorname{mgHAc} / 1$ 
Tabela H.12 - Valores da concentração de substrato $\left(\mathrm{C}_{\mathrm{ST}}\right.$ e $\left.\mathrm{C}_{\mathrm{SS}}\right), \mathrm{pH}$, alcalinidade parcial (AP), alcalinidade intermediária (AI), alcalinidade total (AT), alcalinidade a bicarbonato (AB) e ácidos voláteis totais (AVT) em amostras do efluente, durante a operação do reator em batelada alimentada no Ensaio BA-F5 a COV $=2,4 \mathrm{~g} / \mathrm{l} . \mathrm{d}, \mathrm{C}_{\mathrm{AF}}=8000 \mathrm{mg} / \mathrm{l} \mathrm{V}_{\text {alim }}=0,5 \mathrm{le} \mathrm{T}_{\text {alim }}=3$ horas, com NaHCO $3 / \mathrm{DQO}$ $=0,5$.

\begin{tabular}{cccccccccccc}
\hline \multirow{2}{*}{ Tempo } & \multirow{2}{*}{$\mathrm{C}_{\mathrm{ST}}$} & $\varepsilon_{\mathrm{T}}$ & $\mathrm{C}_{\mathrm{SS}}$ & $\varepsilon_{\mathrm{S}}$ & $\mathrm{pH}$ & $\mathrm{AP}$ & $\mathrm{AI}$ & $\mathrm{AT}$ & $\mathrm{AI} / \mathrm{P}$ & $\mathrm{AB}$ & $\mathrm{AVT}$ \\
\hline 1 & 856,6 & 90,1 & 135,5 & 98,4 & 7,14 & 1489,2 & 581,4 & 2070,6 & 0,390 & 2021,5 & 69,1 \\
2 & 878,0 & 89,8 & 169,6 & 98,0 & 7,12 & 1570,8 & 612,0 & 2182,8 & 0,390 & 2130,9 & 73,0 \\
3 & 783,4 & 90,9 & 208,4 & 97,6 & 7,15 & 1774,8 & 754,8 & 2529,6 & 0,425 & 2474,9 & 77,0 \\
5 & 619,2 & 92,8 & 191,9 & 97,8 & 7,30 & 1795,2 & 754,8 & 2550,0 & 0,420 & 2496,7 & 75,0 \\
\hline
\end{tabular}

Unidades:

$$
\begin{aligned}
& \text { Tempo }=\text { dia } \\
& \mathrm{C}_{\mathrm{ST}} ; \mathrm{C}_{\mathrm{SS}}=\mathrm{mg} / \mathrm{l}, \text { em termos de DQO } \\
& \varepsilon_{\mathrm{T}} ; \varepsilon_{\mathrm{S}}=\% \\
& \mathrm{AP} ; \mathrm{AI} ; \mathrm{AT} ; \mathrm{AB}=\mathrm{mgCaCO}_{3} / 1 \\
& \mathrm{AVT}=\mathrm{mgHAc} / 1
\end{aligned}
$$




\section{ANEXO H 6 - ENSAIO BA-F 6 - VALORES EXPERIMENTAIS}

Tabela H.13 - Valores da concentração de substrato $\left(\mathrm{C}_{\mathrm{AF}}\right)$, pH, alcalinidade parcial (AP), alcalinidade intermediária (AI), alcalinidade total (AT), alcalinidade a bicarbonato $(\mathrm{AB}) \mathrm{e}$ ácidos voláteis totais (AVT) em amostras do afluente, durante a operação do reator em batelada alimentada no Ensaio BA-F6 a COV $=2,4 \mathrm{~g} / \mathrm{l} \cdot \mathrm{d}, \mathrm{C}_{\mathrm{AF}}=8000 \mathrm{mg} / \mathrm{l} \mathrm{V}_{\mathrm{alim}}=0,51 \mathrm{e}$ $\mathrm{T}_{\text {alim }}=10$ minutos, com $\mathrm{NaHCO}_{3} / \mathrm{DQO}=0,5$.

\begin{tabular}{ccccccccc}
\hline Meio & \multirow{2}{*}{$\mathrm{C}_{\mathrm{AF}}$} & $\mathrm{pH}$ & $\mathrm{AP}$ & $\mathrm{AI}$ & $\mathrm{AT}$ & $\mathrm{AI} / \mathrm{AP}$ & $\mathrm{AB}$ & \multirow{2}{*}{$\mathrm{AVT}$} \\
\hline 1 & 9685,7 & 8,20 & 1856,4 & 683,4 & 2539,8 & 0,368 & 2373,4 & 234,3 \\
2 & 9685,7 & 7,72 & 1836,0 & 612,0 & 2448,0 & 0,333 & 2243,4 & 288,2 \\
3 & 8795,8 & 8,25 & 1917,6 & 532,4 & 2450,0 & 0,278 & 2282,2 & 236,4 \\
4 & 8795,8 & - & - & - & - & - & - & - \\
\hline
\end{tabular}

Unidades:

$\mathrm{C}_{\mathrm{AF}}=\mathrm{mg} / \mathrm{l}$, em termos de DQO

$\mathrm{AP} ; \mathrm{AI} ; \mathrm{AT} ; \mathrm{AB}=\mathrm{mgCaCO}_{3} / 1$

$\mathrm{AVT}=\operatorname{mgHAc} / 1$

Tabela H.14 - Concentração de sólidos : totais (ST), voláteis totais (SVT), em suspensão totais (SST), em suspensão voláteis (SSV) em amostras do afluente e do efluente, durante a operação do reator em batelada alimentada no Ensaio BA-F6 a COV $=2,4$ g/l.d, $\mathrm{C}_{\mathrm{AF}}=8000$ $\mathrm{mg} / \mathrm{l} \mathrm{V}_{\text {alim }}=0,51 \mathrm{e} \mathrm{T}_{\text {alim }}=10$ minutos, com $\mathrm{NaHCO}_{3} / \mathrm{DQO}=0,5$.

\begin{tabular}{ccccc|cccc}
\hline \multicolumn{4}{c|}{ Efluente } & \multicolumn{4}{c}{ Afluente } \\
\hline $\begin{array}{c}\text { Tempo } \\
\text { (dia) }\end{array}$ & ST & SVT & SST & SSV & ST & SVT & SST & SSV \\
\hline 1 & 3484 & 940 & 513 & 410 & 9666 & 6260 & 306 & 238 \\
3 & 3830 & 1114 & 327 & 280 & 9336 & 7206 & 198 & 176 \\
4 & 3746 & 1026 & 303 & 283 & 10356 & 6710 & 254 & 184 \\
\hline
\end{tabular}

Unidades:

ST; SVT; SST; SSV = mg/l 
Tabela H.15 - Valores da concentração de substrato $\left(\mathrm{C}_{\mathrm{ST}}\right.$ e $\left.\mathrm{C}_{\mathrm{SS}}\right)$, pH, alcalinidade parcial (AP), alcalinidade intermediária (AI), alcalinidade total (AT), alcalinidade a bicarbonato (AB) e ácidos voláteis totais (AVT) em amostras do efluente, durante a operação do reator em batelada alimentada no Ensaio BA-F6 a COV $=2,4 \mathrm{~g} / \mathrm{l} \cdot \mathrm{d}, \mathrm{C}_{\mathrm{AF}}=8000 \mathrm{mg} / \mathrm{l} \mathrm{V}_{\text {alim }}=0,51 \mathrm{e} \mathrm{T}_{\text {alim }}=10$ minutos, com $\mathrm{NaHCO}_{3} / \mathrm{DQO}=0,5$.

\begin{tabular}{cccccccccccc}
\hline \multirow{2}{*}{ Tempo } & \multirow{2}{*}{$\mathrm{C}_{\mathrm{ST}}$} & $\varepsilon_{\mathrm{T}}$ & $\mathrm{C}_{\mathrm{SS}}$ & $\varepsilon_{\mathrm{S}}$ & $\mathrm{pH}$ & $\mathrm{AP}$ & $\mathrm{AI}$ & $\mathrm{AT}$ & $\mathrm{AI} / \mathrm{P}$ & $\mathrm{AB}$ & $\mathrm{AVT}$ \\
\hline 1 & 710,7 & 92,3 & 152,3 & 98,4 & 7,19 & 1550,4 & 571,2 & 2121,6 & 0,37 & 2073,8 & 67,4 \\
2 & 727,8 & 92,1 & 201,9 & 97,8 & 7,26 & 1713,6 & 550,8 & 2264,4 & 0,32 & 2215,8 & 68,5 \\
3 & 811,1 & 91,2 & 160,6 & 98,3 & 7,24 & 1713,6 & 612,0 & 2325,6 & 0,36 & 2274,6 & 71,8 \\
4 & 741,1 & 92,0 & 173,2 & 98,1 & 7,14 & 1570,8 & 652,8 & 2223,6 & 0,42 & 2171,8 & 72,9 \\
\hline
\end{tabular}

Unidades:

$$
\begin{aligned}
& \text { Tempo = dia } \\
& \mathrm{C}_{\mathrm{ST}} ; \mathrm{C}_{\mathrm{SS}}=\mathrm{mg} / \mathrm{l}, \text { em termos de DQO } \\
& \varepsilon_{\mathrm{T}} ; \varepsilon_{\mathrm{S}}=\% \\
& \mathrm{AP} ; \mathrm{AI} ; \mathrm{AT} ; \mathrm{AB}=\mathrm{mgCaCO}_{3} / 1 \\
& \mathrm{AVT}=\mathrm{mgHAc} / 1
\end{aligned}
$$




\section{ANEXO H 7 - ENSAIO BA-F 7 - VALORES EXPERIMENTAIS}

Tabela H.16 - Valores da concentração de substrato $\left(\mathrm{C}_{\mathrm{AF}}\right)$, pH, alcalinidade parcial (AP), alcalinidade intermediária (AI), alcalinidade total (AT), alcalinidade a bicarbonato $(\mathrm{AB}) \mathrm{e}$ ácidos voláteis totais (AVT) em amostras do afluente, durante a operação do reator em batelada no Ensaio BA-F7 a COV = 2,4 g/l.d, $\mathrm{C}_{\mathrm{AF}}=2000 \mathrm{mg} / \mathrm{l} \mathrm{V}$ alim $=2,01$ e $\mathrm{T}_{\text {alim }}=10$ minutos, com $\mathrm{NaHCO}_{3} / \mathrm{DQO}=0,5$.

\begin{tabular}{ccccccccc}
\hline Meio & $\mathrm{C}_{\mathrm{AF}}$ & $\mathrm{pH}$ & $\mathrm{AP}$ & $\mathrm{AI}$ & $\mathrm{AT}$ & $\mathrm{AI} / \mathrm{AP}$ & $\mathrm{AB}$ & $\mathrm{AVT}$ \\
\hline 1 & 2126,9 & 8,30 & 610,8 & 226,0 & 836,8 & 0,370 & 778,9 & 81,6 \\
2 & 2471,6 & - & - & - & - & - & - & - \\
3 & 2462,0 & - & - & - & - & - & - & - \\
4 & 2295,0 & 7,35 & 519,2 & 219,9 & 739,1 & 0,424 & 660,2 & 111,1 \\
\hline
\end{tabular}

Unidades:

$\mathrm{C}_{\mathrm{AF}}=\mathrm{mg} / \mathrm{l}$, em termos de $\mathrm{DQO}$

$\mathrm{AP} ; \mathrm{AI} ; \mathrm{AT} ; \mathrm{AB}=\mathrm{mgCaCO}_{3} / 1$

$\mathrm{AVT}=\mathrm{mgHAc} / 1$ 
Tabela H.17 - Valores da concentração de substrato $\left(\mathrm{C}_{\mathrm{ST}}\right.$ e $\left.\mathrm{C}_{\mathrm{SS}}\right)$, pH, alcalinidade parcial (AP), alcalinidade intermediária (AI), alcalinidade total (AT), alcalinidade a bicarbonato (AB) e ácidos voláteis totais (AVT) em amostras do efluente, durante a operação do reator em batelada no Ensaio BA-F7 a COV $=2,4 \mathrm{~g} / \mathrm{l} \cdot \mathrm{d}, \mathrm{C}_{\mathrm{AF}}=2000 \mathrm{mg} / \mathrm{l} \mathrm{V}_{\text {alim }}=2,01 \mathrm{e} \mathrm{T}_{\text {alim }}=10$ minutos, com $\mathrm{NaHCO}_{3} / \mathrm{DQO}=0,5$.

\begin{tabular}{cccccccccccc}
\hline \multirow{2}{*}{ Tempo } & $\mathrm{C}_{\mathrm{ST}}$ & $\varepsilon_{\mathrm{T}}$ & $\mathrm{C}_{\mathrm{SS}}$ & $\varepsilon_{\mathrm{S}}$ & $\mathrm{pH}$ & $\mathrm{AP}$ & $\mathrm{AI}$ & $\mathrm{AT}$ & $\mathrm{AI} / \mathrm{P}$ & $\mathrm{AB}$ & $\mathrm{AVT}$ \\
\hline 1 & 241,8 & 89,7 & 106,5 & 95,4 & 6,78 & 867,3 & 360,4 & 1227,7 & 0,415 & 1198,6 & 41,0 \\
2 & 176,3 & 92,5 & 65,8 & 97,2 & 6,79 & 671,9 & 293,2 & 965,1 & 0,436 & 923,5 & 58,5 \\
3 & 169,6 & 92,7 & 82,6 & 96,5 & 6,85 & 659,7 & 244,3 & 904,0 & 0,370 & 885,3 & 26,3 \\
4 & 175,2 & 92,5 & 88,0 & 96,2 & 6,69 & 617,5 & 282,2 & 899,7 & 0,457 & 880,8 & 26,6 \\
\hline
\end{tabular}

Unidades:

Tempo $=$ dia

$\mathrm{C}_{\mathrm{ST}} ; \mathrm{C}_{\mathrm{SS}}=\mathrm{mg} / \mathrm{l}$, em termos de DQO

$\varepsilon_{\mathrm{T}} ; \varepsilon_{\mathrm{S}}=\%$

AP; AI; AT; $\mathrm{AB}=\mathrm{mgCaCO}_{3} / 1$

$\mathrm{AVT}=\operatorname{mgHAc} / 1$ 
